Miriam Ganzfried

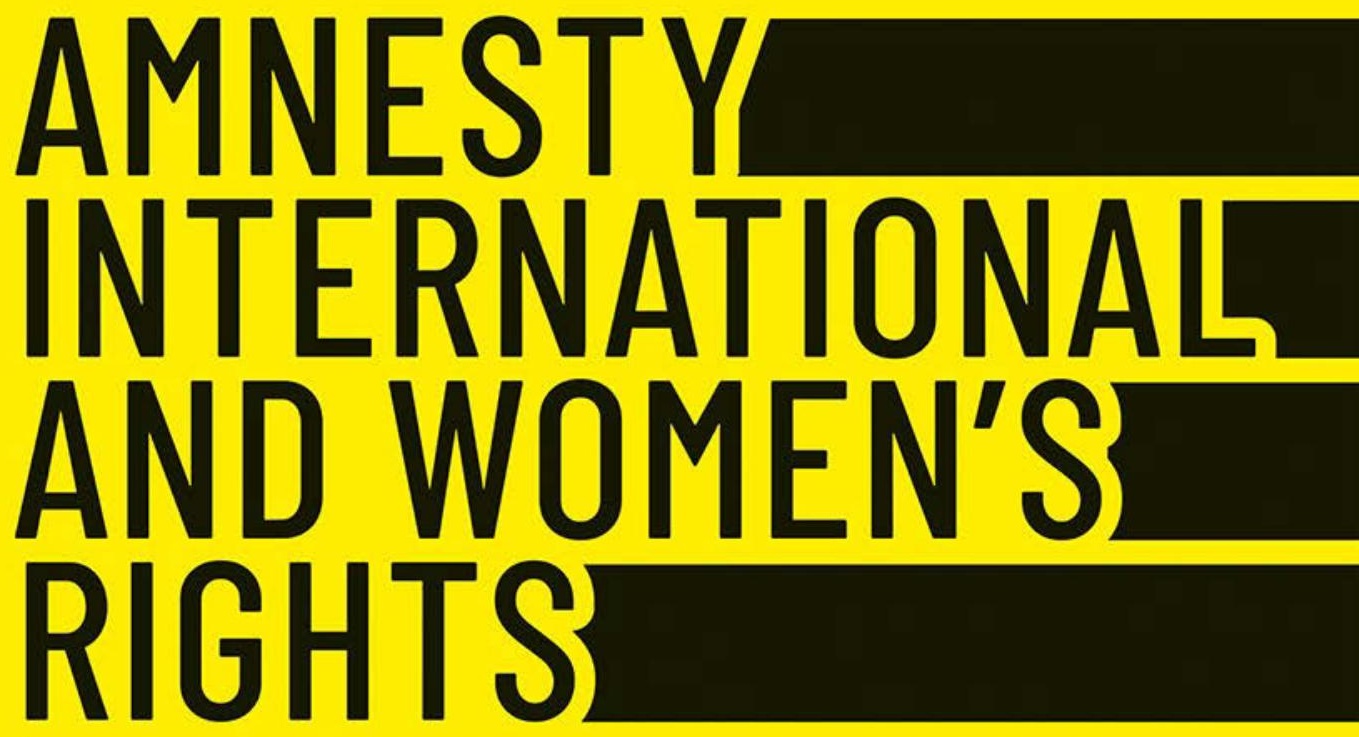

Feminist Strategies, Leadership Commitment and Internal Resistances 
Miriam Ganzfried

Amnesty International and Women's Rights

Political Science | Volume 128 
For my children Ilan and Elena

Miriam Ganzfried (Dr. phil.), born in 1979, is a Political Scientist and works at the Center for Higher Education and Science Studies (CHESS) at the University of Zurich, Switzerland. She studied political science and gender studies at the Universities of Geneva and Zurich. During her dissertation, she worked at the Interdisciplinary Centre for Gender Studies and the Faculty of Business, Economics and Social Sciences of the University of Bern and at the Swiss Agency for Development and Cooperation. Her research interests are change processes and resistances in organizations, equal opportunity policies and higher education management. 
Miriam Ganzfried

\section{Amnesty International and Women's Rights}

Feminist Strategies, Leadership Commitment and Internal Resistances 
Published with the support of the Swiss National Science Foundation

This study was accepted as a dissertation by the Faculty of Arts and Social Sciences at the University of Zurich in the fall semester 2019 on the recommendation of PD Dr. Elham Manea, Prof. Dr. Fabrizio Gilardi and Prof. Dr. Heinzpeter Znoj (University of Bern).

\section{Bibliographic information published by the Deutsche Nationalbibliothek}

The Deutsche Nationalbibliothek lists this publication in the Deutsche Nationalbibliografie; detailed bibliographic data are available in the Internet at http:// dnb.d-nb.de

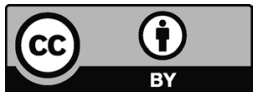

This work is licensed under the Creative Commons Attribution 4.0 (BY) license, which means that the text may be remixed, transformed and built upon and be copied and redistributed in any medium or format even commercially, provided credit is given to the author. For details go to http://creativecommons.org/licenses/by/4.o/

Creative Commons license terms for re-use do not apply to any content (such as graphs, figures, photos, excerpts, etc.) not original to the Open Access publication and further permission may be required from the rights holder. The obligation to research and clear permission lies solely with the party re-using the material.

\section{First published in 2022 by transcript Verlag, Bielefeld () Miriam Ganzfried}

Cover layout: Maria Arndt, Bielefeld

Copy-editing: Ana Petrova

Proofread: Julie Hart and William Keller

Printed by Majuskel Medienproduktion $\mathrm{GmbH}$, Wetzlar

Print-ISBN 978-3-8376-6008-1

PDF-ISBN 978-3-8394-6008-5

https://doi.org/10.14361/9783839460085

ISSN of series: $2702-9050$

eISSN of series: 2702-9069

Printed on permanent acid-free text paper. 


\section{Contents}

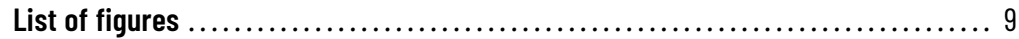

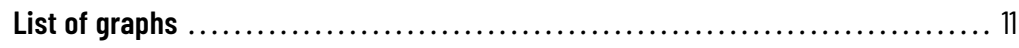

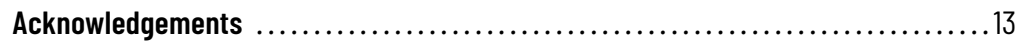

1. Introduction ................................................. 15

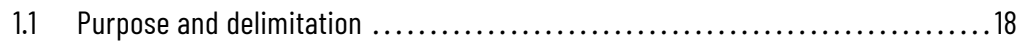

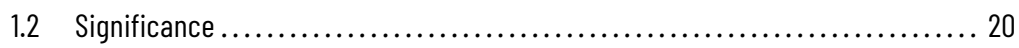

1.3 Theoretical paradigm ....................................... 22

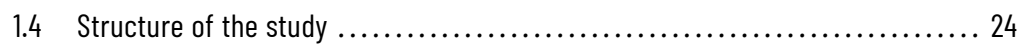

2. Problem and research questions............................. 29

2.1 A gender-biased understanding of human rights ..................... 29

2.2 Contestation of the traditional understanding of human rights ............. 34

2.3 Response of human rights NGOs ............................. 40

2.4 Research questions..................................... 43

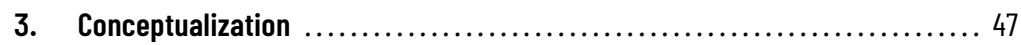

4. Focused literature review ...................................... 51

4.1 Social constructivism in International Relations ...................... 52

4.2 The role of norm entrepreneurs in the emergence of international norms ..... 53

4.3 Comparatively powerless actors' strategies for influencing norm dynamics ................................ 56

4.4 Norm diffusion and norm dynamics .............................. 58

4.5 The study's theoretical contribution ............................. 62 
5. Data and method(s) ........................................ 63

5.1 The origin and characteristics of Grounded Theory .....................6 63

5.2 Reasons for the use of grounded theory techniques .................. 65

5.3 Case selection........................................... 67

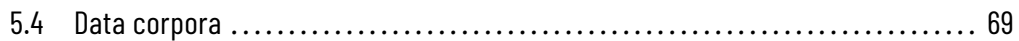

5.4.1 Criteria for data collection and generation ....................69 69

5.4 .2 Written archival documents ................................. 71

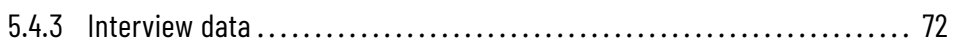

5.5 Data analysis ............................................... 75

6. Al's structure, decision-making, and policy implementation ............ 77

6.1 Brief overview of the development of Al's work in general................. 77

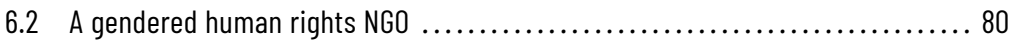

6.3 Internal structure - the international level .......................... 84

6.4 Internal structure - the national levels . ......................... 86

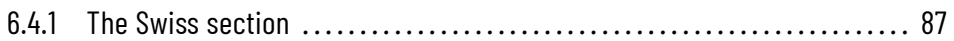

6.4 .2 The German section ...................................91

6.5 Decision-making and implementation ............................ 97

6.5.1 The international level - The IS as a powerfull central node .......... 97

6.5.2 The national level - Al sections ............................. 100

7. The beginnings of Al's interest in VAW ......................... 103

7.1 The international level ...................................... 103

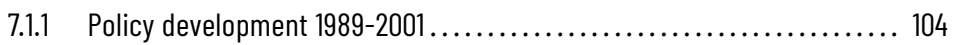

7.1.1.1 ICM decisions indirectly concerning Al's work on VAW........ 106

7.1.1.2 ICM decisions directly concerning Al's work on VAW .......... 110

7.1.2 Policy Implementation

- Al's activities on VAW within the frame of the mandate ............. 116

7.1.2.1 Women in the Front Line ............................ 120

7.1.2.2 Human Rights are Women's Rights ..................... 120

7.1.2.3 Take a Step to Stamp Out Torture ...................... 125

7.1 .3 Feminist strategizing ................................... 127

7.1.4 Al's work on women's rights discussed...................... 146

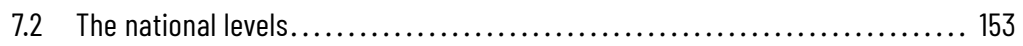

7.2.1 The Swiss section .................................... 154

7.2.1.1 First collective and individual initiatives ................. 154

7.2.1.2 A women's network emerges......................... 159

7.2.1.3 Ignorance rather than opposition $\ldots \ldots \ldots \ldots \ldots \ldots \ldots \ldots \ldots . \ldots \ldots$ 
7.2.2 The German section ...................................... 165

7.2.2.1 Sektionsarbeitskreis Menschenrechtsverletzungen

an Frauen ........................................ 166

7.2.2.2 The MaF's successful attempts to influence decision-making .. 168

7.2.2.3 Disinterest regarding women's rights.................... 171

7.3 Intermediate conclusions ....................................... 174

8. The challenges to make women's rights part of Al's DNA ................ 177

8.1 The international level ........................................ 178

8.1.1 Policy development 2002-2010 ................................ 179

8.1.1.1 ICM Decisions indirectly concerning Al's work on VAW.......... 181

8.1.1.2 Decisions directly concerning Al's work on VAW ............. 183

8.1.2 Policy Implementation

- Focus and content of the SVAW campaign.................... 188

8.1.3 Pushing work on the issue of VAW from the top down .............. 196

8.1.3.1 Policy development initiated by the IEC ................... 197

8.1.3.2 Getting ready for the SVAW campaign .................... 198

8.1.3.3 The SVAW campaign Machinery ....................... 200

8.1.4 Resistance against Al's work on VAW ...........................210

8.1.4.1 Resistance against the SVAW campaign ....................210

8.1.4.2 Resistance against the adoption of a policy on abortion ....... 214

8.2 The national levels ............................................ 220

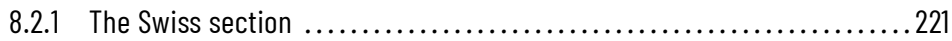

8.2.1.1 Merging the international campaign strategy

with the section's priorities .......................... 222

8.2.1.2 The continuing importance of the women's network ......... 226

8.2.1.3 Women's rights - confined to a story by women acting for women ......................................... 235

8.2.2 The German section ....................................... 243

8.2.2.1 Look \& Act: Preventing Violence against Women ............. 243

8.2.2.2 The MaF - a group of voluntary experts ................... 246

8.2.2.3 Highly controversial issues - domestic violence and abortion .. 249

8.2.3 Comparison between the Swiss and the German Al sections.......... 255

8.3 Intermediate conclusions ..................................... 259

9. Discussion and outlook .......................................... 261

9.1 Summary and new insights ....................................261

9.1.1 New insights into the mandate period ..................... 263 
9.1.2 New insights into the post-mandate period ................... 265

9.2 Implications for other human rights NGOs ........................ 269

9.3 The study's theoretical contribution ..............................271

9.3.1 Ways that comparatively powerless actors can influence

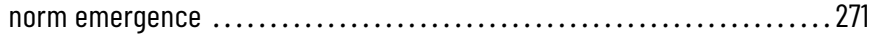

9.3.2 Reasons for limited norm diffusion .......................... 273

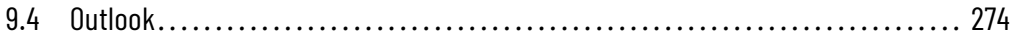

Appendix ........................................................ 281

Appendix 1: Coordinators of the Intersectional Women's Network IWN ........... 281

Appendix 2: Additional graphs and figures ........................... 281

Appendix 3: Al's statute, mandate, and mission........................... 284

Sources and Literature ......................................... 287

Sources........................................................... 287

Amnesty International archive .................................... 287

Archive of the Swiss section of Amnesty International, Bern .............. 288

Archive of the German section of Amnesty International, Berlin ............ 289

Private archives ............................................ 289

Archival Material............................................ 290

Interview Material ............................................ 302

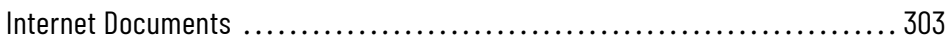

Literature ...................................................... 305

List of abbreviations ................................................ 317 


\section{List of figures}

Figure 1: Overview of the policy development between 1989 and 2001, p.105

Figure 2: Detailed policy development between 1989 and 2001, p.107

Figure 3: Typology of AI activities related to VAW, p.117

Figure 4: The origin of ICM decisions, p.131

Figure 5: Debates on the ICM decisions directly concerning AI's work on VAW, p.147

Figure 6: Overview of policy developments between 2002 and 2010, p.180

Figure 7: Detailed policy developments between 2002 and 2010, p.181

Figure 8: First phase of the SVAW campaign, 2003-2005, p.191

Figure 9: Activities in the second phase of the SVAW campaign, 2007-2010, p.193

Figure 10: ICM decisions and their initiators, 2003-2009, p.197

Figure 11: The SVAW campaign Machinery, p.201

Figure 12: ICM decisions and related debates, 2002-2009, p.215

Figure 13: Origin of the two decisions on sexual and reproductive rights, p.216 Figure 14: Entities involved in the Swiss section's work on VAW in the 2000s, p.229

Figure 15: Comparison between the Swiss and the German AI sections of their success in integrating VAW into their section's work, p.256

Figure 16: Origins of the resolutions preceding an ICM decision directly concerning AI's work on VAW, p.283 



\section{List of graphs}

Graph 1: Representation of women in the IEC 1989-2011 and among Deputy SGs, 1992-2001, p.82

Graph 2: Representation of women in the Swiss section's management positions and Executive Committee, 1990-2008, p.90

Graph 3: Representation of women in the Executive Committee of the German section, 1990-2010, p.93

Graph 4: Decisions per ICM, 1989-2001, p.106

Graph 5: Evolution in the number of activities, 1989-2001, p.119

Graph 6: Evolution of AI sections, 1964-2011, p.281

Graph 7: AICH's evolution in terms of number of groups, 1970-2011, p.282

Graph 8: AI Germany's evolution in terms of number of groups, 1964-2009, p.282 



\section{Acknowledgements}

The present book was submitted as a dissertation to the Department of Political Science at the University of Zurich in March 2019 and revised for publication in 2021. The research behind this book was made possible thanks to a three-year grant from the Swiss National Science Foundation (2011-2014). I owe the idea of this study to Brigitte Schnegg ${ }^{\dagger}$, former director of the Interdisciplinary Centre for Gender Studies at the University of Bern, with whom I developed the initial research project. Her enthusiasm and her support as a mentor were key for the advancement of the research project in its initial years. I am very grateful to her. I would also like to thank Heinzpeter Znoj, who gave me the opportunity to write the thesis as part of the Universities of Bern and Fribourg's interdisciplinary Graduate School Gender: Prescripts and Transcripts. I would also like to thank my supervising professors Elham Manea, Heinzpeter Znoj and Fabrizio Gilardi for their support and valuable feedback on the drafts that I submitted to them. I am very thankful to Julie Hart and William Keller for having thoroughly proofread this book, and to Ana Petrova for her excellent editing work. I would also like to thank Petra Holtrup and Doreen Spörer-Wagner for their support and flexibility with all administrative issues related to the $\mathrm{PhD}$ program at Zurich University, and Basilio Ferrante for his valuable IT support. My thanks also go to Seraina Bohren and Barbara Delahayes for their careful transcription of the interviews in German and French and to Mx Karin Scheidegger for their professional assistance in improving the graphs and figures in the text.

A big thanks goes to all my fellow students at the Graduate Program in Gender Studies at the University of Bern for the numerous, extremely valuable discussions on this book. I would especially like to thank Fabienne Amlinger, Isabelle Schläpfer, and Michèle Amacker for the time they dedicated to giving me feedback on parts of this book and for motivating me again and again. I would also like to thank Ruth Ammann for the many fruitful exchanges on 
our respective research projects. I am grateful to Sarah Kiani for the time we spent together in London and for her hospitality in Berlin.

My research activities would not have been possible without the numerous (former) Amnesty International (AI) officials, activists, and experts who graciously spent some of their valuable time granting me an interview, answering my questions, responding to my requests or helping me find the relevant written data and other suitable interviewees. I would especially like to thank Laurent Mousson, the documentation specialist of the Swiss AI section, and Volkmar Deile, the former Executive Director of AI Germany, both of whom placed great trust in me and gave me access to the archive materials necessary to conduct my research project. Furthermore, I would like to thank Stella Jegher. She facilitated my access to the Swiss section's archive, enabled my visit to the International Secretariat, and gave me the contact details of many potential interviewees. I would also like to express my thanks to all of my interviewees, who took some of their valuable time to talk with me about their engagement within AI and about the organization's work on issues related to women's rights.

Finally, I am infinitely grateful to my family who have always supported me in my research project, believed in me through the difficult times, and motivated me to not give up. I would especially like to thank my husband Christophe Couderc for his patience, the time he spent talking with me about the progress of my dissertation, listening to my concerns when I was stuck, and helping me find answers to my questions. Doing a PhD demands an awful lot of time. I am very thankful to Christophe Couderc for having my back all these years. I would also like to thank my parents Johanna Zawadynska and Ron Ganzfried and their respective partners Walter Friedrich and Megie Oberson for having taken care of our children on many occasions during all these years. At the same time, I would like to thank my two wonderful children Ilan and Elena who had to spend many weekends and holidays without their mom because she had to go to London, Berlin or somewhere else to collect data, or spend her weekends in the office writing her dissertation.

Bern, May 2021 


\section{Introduction}

Amnesty International (AI) was founded as a movement for the liberation of prisoners of conscience in the middle of the Cold War and advocates for the respect of all human rights as defined in the UN Universal Declaration of $\mathrm{Hu}$ man Rights (UDHR). Over the years, it has focused on the defense of people's rights to be free from states' arbitrariness. As one of the most internationally important human rights organizations and an institution with a large grassroots membership, AI has also largely shaped the popular understanding of human rights as those mainly concerning the respect of one's individual civil and political rights. For many years, the organization has promoted awareness of and adherence to the UDHR and embraced "the equal entitlements of women and men to the rights contained in it."1 However, its traditional focus on essentially upholding the International Covenant on Civil and Political rights has marked AI's work with a gender bias. Indeed, the gendered public-private divide means that addressing mainly civil and political rights and largely ignoring economic, social, and cultural rights have entailed a disproportionate focus on human rights violations as typically witnessed by men.

Over the course of many years, women have comprised a small minority of the 'prisoners of conscience' cases that AI has adopted. Around the 1990s, continuing transnational women's activism and networking pressured the UN, national governments, and major human rights organizations, such as $\mathrm{AI}$, to recognize Violence Against Women (VAW) in the private sphere as a human rights violation - a process that transformed the traditional understanding of human rights. As a result, human rights organizations started to reconsider their state-focused work and began taking gender-specific human rights violations into account. Al's first comprehensive report on violations of women's 
rights, Women in the Front Line: Human Rights Violations against Women, was published in 1991 and marked the beginning of AI's work on violations of women's rights. In keeping with the frame of its mandate, the report addressed issues such as VAW in state custody and female human rights defenders and the risks they were facing.

Around the time of the fourth World Conference on Women (WCW) held in Beijing in 1995, AI launched its first major international campaign on women's rights, Human Rights are Women's Rights. The latter focused on torture, state violence, abuses during armed conflicts, and disappearances affecting women. While AI's interest in VAW increased significantly during the first half of the 1990s, civil and political rights remained its main focus. Therefore, the organization did not question the gender bias inherent to its approach. In this context, AI's decision to make cases of VAW in the private sphere $^{2}$ the focus of its first long-term global thematic campaign (the Stop Violence Against Women or SVAW campaign) appears to be rather astonishing. The organization approved this decision in 2001, at the same time it took the decision to adopt a mission including economic, social, and cultural rights.

This book is informed by the theoretical paradigm of feminist constructivism. ${ }^{3}$ It uses a qualitative case-study ${ }^{4}$ approach and applies grounded theory research techniques in an effort to show the reasons behind AI's decision to make VAW in the private sphere the theme of its first global longterm thematic campaign in 2001 , despite its historically determined genderbiased vision of human rights. It also enhances our understanding of why and how AI integrated VAW into its work between the late 1980s and the end of the SVAW campaign in 2010. By exploring AI's work on issues of VAW, this book sheds light on how and why the organization integrated women's rights into its overall work. I focus on AI's inner life and, specifically, on international bodies such as the International Secretariat (IS), the International Executive Committee (IEC), and the International Council (IC), as well as the Swiss and the German sections as two of the most important Western AI sections. Together with an emphasis on female activists and officials, this focus provides previously unknown insights. A broad range of first-hand materials from AI's archives and interviews with the main people involved in AI's work

2 Domestic violence was one of the core issues that Al focused on in this campaign.

$3 \quad$ Locher and Prügl 2001.

$4 \quad$ Lamnek and Krell 2016. 
on women's rights over the two decades of interest allow me to present a detailed picture of a little-known part of the work of one of the most important human rights non-governmental organizations worldwide.

In order to account for the changing global and institutional context the year 2001 marked the end of Al's traditional mandate - the book differentiates between two periods: the 1990s and the 2000s. By focusing on the beginning of AI's interest in women's rights issues in the late 1980 and the beginning of the 1990s, my book describes the evolution of AI's work on VAW from a minor concern held by individual female activists to a prominent human rights concern. It also highlights the key role women within AI played during this transformation. I demonstrate that AI's willingness to make VAW the theme of its first global long-term thematic campaign is not sufficiently accounted for by traditional explanations. The increasing number of women in AI leadership positions, the support of the Secretary General at the time, or external favorable factors like the end of the Cold War and its effect on the nature of human rights violations, which eventually made AI rethink its focus on the state, the fourth WCW in Beijing in 1995, and, relatedly, the women's rights movement's pressure on the international community to work more seriously on women's human rights all fall short of explaining it. Instead, the decision to launch the SVAW campaign must be seen mainly as the result of feminist strategizing. Indeed, by adopting a strategy of intersectional networking and analogous framing, female activists and officials succeeded in making AI significantly increase its work on VAW during the 1990s. While the decision to organize a global campaign on VAW in 2001 and the subsequent launch of the SVAW campaign constituted a great step forward towards more gendersensitive human rights work, a review of this campaign also reveals that $\mathrm{AI}$ did not succeed in making women's rights a part of its DNA. ${ }^{5}$ By focusing on the 2000s, the book highlights AI's attempts to make VAW issues an integral part of its overall work. It shows that, in contrast to the 1990s, the first decade of the $21^{\text {st }}$ century saw AI's leadership as the driving force behind VAW policy development and in charge of the implementation of the SVAW campaign. The book lays out the reasons why despite the commitment of its leadership, AI did not achieve its intended goal of making women's rights part of the organization's DNA. I argue that the factors that best explains this failure are (1) the fact that the female activists and officials who initiated and pushed AI's work on VAW in the 1990s lost their influence on the organization's work on 
VAW issues and (2) activists' and officials' important opposition to this initiative. Furthermore, my analysis of national-level structures shows considerable differences in the extent to which the Swiss and the German sections managed to integrate VAW into their work in the 2000s. While the Swiss section was more successful in making VAW a part of its overall work, similar achievements were limited in the German section. The important opposition to the SVAW campaign and to the adoption of a policy on abortion of the German section's membership help explain this divergence. I argue that the German section members' relative closeness to the Church and their comparatively powerful position further account for the difference between the two sections.

\subsection{Purpose and delimitation}

As a qualitative research endeavor, the present book centers on one particular human rights network. ${ }^{6}$ It thereby relies "primarily on understanding particulars rather than generalization to universals."7 $\mathrm{AI}$ is made up of a large number of country sections and activist groups (besides its headquarters) that comprise an important transnational network. Therefore, answering the research question requires a narrower focus. Based on various criteria (which I explain in detail in chapter 5), I therefore choose the Swiss and the German AI sections as my primary units of analysis, from which I extract information relevant to the functioning of $\mathrm{AI}$ as a whole. The study thus uses case studies as a research approach in the sense that Lamnek and Krell $(2016)^{8}$ highlight, and not as a specific technique of empirical social research. Instead, as the Data and methods chapter explains, I use various data collection methods from grounded theory to answer my research questions. By purposefully selecting two major AI sections as case studies, my book allows for internal generalizability. ${ }^{9}$ The Swiss and the German sections reflect AI's essential characteristics of a Western human rights organization with a longstanding working

Similar to Lake and Wong (2009), the present research considers Al a transnational network (Lake and Wong 2009). This definition best accounts for Al's structure as an organization with a hierarchical center and a large transnational grassroots membership network.

7 Maxwell 2002, p.56.

8 Lamnek and Krell 2016.

9 Maxwell 2002. 
focus on the respect of civil and political rights. This representativeness and the fact that most of its members, groups, and funding are concentrated in its Western sections ${ }^{10}$ make my findings potentially valid for the entire AI network. Thus, while my research's primary aim is to gain new insights into the integration of issues of VAW into AI's work, the study nevertheless provides interesting findings useful for other human rights organizations. ${ }^{11}$ In addition, the application of grounded theory research techniques for data collection and analysis allows me to further develop the theory of norm diffusion and dynamics.

Therefore, the purpose of the study is twofold:

First, by focusing on the 1990s, the study intends to shed light on the reason AI decided to make VAW in the private sphere the theme of its first global long-term thematic campaign in 2001, even though its traditional understanding of human rights did not include this type of violence. My work first shows that AI's growing interest in VAW issues and its subsequent decision must be seen primarily as the result of female AI activists' and offcials' use of two strategies: parallel networking and analogous framing. Further, by narrowing its scope to the 2000s, the book demonstrates that, despite the AI leadership's commitment to the SVAW campaign, the organization was not successful in making women's rights an integral part of its overall work. This happened because the female activists and officials who initiated the AI's work on VAW in the 1990s lost their influence on the organization's work in this realm during the following decade, and part of the organization's activists and officials showed important content-related resistance.

Second, this study seeks to contribute to the developing theory of norm dynamics in International Relations (IR). By defining AI as a transnational network and by concentrating on AI's recognition of VAW in the private sphere as a human rights violation, the study focuses on an international norm and its dissemination within a transnational network. It illustrates how "less politically powerful activists"12 can influence the agenda of a transnational network and shows that the emergence of a new norm does not always depend on so-called norm entrepreneurs, but can also stem from the work of comparatively weak actors in a transnational network. At the same time, the book provides two new insights on why the diffusion of some

$10 \quad$ Hopgood 2006.

11 Cohen and Crabtree 2006.

12 Hertel 2006, p.5. 
norms remains limited within transnational networks. Norm contestation by differently socialized actors can limit norm diffusion, as can the norm contesters' access to decision-making processes.

\subsection{Significance}

Existing studies have so far concentrated on AI's initial work on women's rights and VAW and its development within the frame of the organization's mandate. ${ }^{13}$ More recent publications, such as the Review of the SVAW Campaign $(2010)^{14}$ or Kelleher and Bhattacharjya's 2013 article, ${ }^{15}$ have analyzed AI's approach to the same issues in its post-mandate period. No comprehensive research on this topic has so far covered both periods, encompassed both AI's international and national levels, and delivered a comprehensive picture of the evolution of AI's work on violence against women. In addition to revealing little-known aspects of AI's work by dint of its focus on AI's inner life and internal actors, the book gives a voice to Al's female activists and officials and makes their agency visible. Highlighting women's agency is all the more important, because women have been absent from Al's leadership positions for many decades despite comprising the majority of its membership and staff.

The study also highlights the importance of feminist strategizing for achieving change and the significance of internal opposition in hindering such internal transformations. In addition, even though considerable academic research has focused on AI's formation, the movement's evolving work, ${ }^{16}$ or its role in shaping popular understandings of human rights until today, neither the Swiss nor the German section have been the focus of scholarly interest. ${ }^{17}$ Thus, the present study fills a gap in the literature by providing a detailed account of AI's work on issues of violence against women within the IS and within the Swiss and the German sections.

\footnotetext{
13 Michel 2009; Watson 1997; Bahar 1996; Fried 1994.

14 Wallace and Baños Smith 2010b.

15 Kelleher and Bhattacharjya 2013.

16 Here, it is worth mentioning Hopgood's in-depth study, Keepers of the flames, that focuses on the inner life of Al's headquarters (Hopgood 2006).

17 Bahar 1996; Clifford 2002; Brown Thomson 2002; Clark 2001; Mutua 2001; Scoble and Wiseberg 1974; Steiner 1991; Thakur 1994; Watson 1997; Buchanan 2002; Michel 2009; Pack 1999; Welch 2001; Hopgood 2006; Kelleher and Bhattacharjya 2013; Lake and Wong 2009; Baehr 1994.
} 
Why it is important to know more about AI's recognition of VAW in the private sphere as a human rights violation or, put differently, about the diffusion of norms concerning women's rights within the AI? First, AI has been one of the most influential human rights non-governmental organizations ${ }^{18}$ worldwide since its foundation. ${ }^{19}$ It has played a prominent role in shaping the popular understanding of human rights and in influencing the content of human rights activism internationally over the last fifty-five years. ${ }^{20}$

Because of its agenda-setting power within the international human rights regime, ${ }^{21} \mathrm{AI}$ has been identified as "the seed around which the postwar human rights network crystallized."22 The organization thus greatly contributed to the development of new international human rights standards and to the implementation of existing ones. ${ }^{23}$ It also succeeded in changing states' human rights practices in a number of different countries. ${ }^{24}$ Furthermore, AI's work holds a solid reputation and great credibility among other leading human rights Non-Governmental Organizations (NGOs). ${ }^{25}$ AI can thus be defined as a gatekeeper or "hub organization" 26 as far as the diffusion of norms is concerned, as its "choices have powerful demonstration effects, signaling that certain causes are important." 27

Second, as a democratic movement based on its members' engagement and contributions, AI lets its activists' beliefs about the essence of human rights largely define its work. Thus, because AI has been one of the most influential human rights NGOs worldwide and because its members play a key role in defining its policy, when AI members change their collective beliefs, this normative change can potentially affect the prevailing international discourse and practice on human rights. Therefore, it is important to know more about the recognition of women's rights norms within the AI.

Power 2001.

19 Al was awarded with the International Noble Prize of Peace in 1977, which can be interpreted as a sign of its increasing importance for the definition of human rights internationally.

Thakur 1994; Power 2001; Clark 2001; Reilly 2009; Lake and Wong 2009.

22 Lake and Wong 2009, p.138.

23 Thakur 1994, p.157; Clark 2001.

24 Wapner 1995; Clark 2001.

25 Ron et al. 2005.

26 Carpenter 2011.

27 Clifford 2005, p.6. 


\subsection{Theoretical paradigm}

The present study is informed by the theoretical paradigm of feminist constructivism. ${ }^{28}$ Constructivists think that social reality is constructed and explain political and social change with the interplay between agent and structure. Because of its focus on an international norm and the latter's spread within a transnational non-state actor, this study draws on the work of constructivist International Relations (IR) scholars and further contributes to the theory of norm dynamics. My work draws from the constructivist approach in IR, which sees human individuals as the ultimate constructors of worlds and, therefore, the primary holders of agency. ${ }^{29}$ Agency is thus mainly considered a characteristic of individual actors and not an asset of international organizations, NGOs or states, as is the case in other IR constructivist perspectives. In this sense, I see $\mathrm{AI}$ activists and officials ${ }^{30}$ as the primary actors detaining agency. As Reinharz (1992) accurately states, the goal of feminist research is "making the invisible visible, bringing the women's lives to the center, rendering the trivial important, putting the spotlight on women as competent actors, and understanding women as subjects rather than objects." ${ }^{31}$ In this light, women engaged within AI as activists or staff members are of particular interest to the present research.

The present study is inspired by one of the prominent feminist schools of thought that considers the dichotomy between men and women a fundamental constitutive element of society. As Scott (1994) explains, gender is a constitutive element of social relations and is based on perceived differences between the sexes. ${ }^{32}$ Perceiving the world as something that "is in the process of becoming," ${ }^{33}$ feminist theory sees social reality not as immutable but as constructed, and the subordinated position of women in society cannot be explained by essentialist arguments; rather, it is the result of unequal gendered power relations. Therefore, it is also important to put my research questions

\footnotetext{
28 Locher and Prügl 2001.

29 Adler 2012, p.133; Wight 1999.

30 In the research, I distinguish between activists (voluntary members of one of Al's groups) and officials (people working at the IS or one of the country section's secretariats as employees).

31 Reinharz 1992, p.248.

32 Scott 1994.

33 Locher and Prügl 2001, p.114.
} 
into their historical context. Consequently, chapter 2 discusses the development of the understanding of human rights in the second half of the 2oth century in detail. In this perspective, "feminism contributes to constructivism an understanding of power as an integral element of processes of construction." 34 Even though other categories, such as race, class or sexual orientation, constitute pertinent structuration for the place and the role of individuals in a society, the present research considers gender a central social category. Differences between men and women are thus primarily seen as socially constructed. In this sense, adopting a feminist stance entails using gender as a central category of analysis and adopting a gender perspective in the analysis of AI's work on VAW. Hence, from a feminist point of view, the field of study is itself fundamentally marked by the category gender. Consequently, as I will explain in greater detail later, the post-World War II (WWII) understanding of human rights, which essentially concentrated on civil and political rights, can be seen as gender biased. This stance explains why the study's central question has to do with Al's decision to make cases of VAW in the private sphere the central theme of its first global thematic campaign.

Similar to their perception of social or political reality and change, many constructivists and feminists see knowledge as something socially constructed. ${ }^{35}$ Indeed, in these research traditions knowledge is not seen as something constant and externally observable (unlike the positivistic view prevalent in quantitative social research). Understanding a social phenomenon is intersubjective and a matter of interpretation. Informed by this epistemological stance, the present study sees knowledge as grounded in social contexts. ${ }^{36}$ The researcher is a subjective and reflexive actor closely implicated in the production of knowledge. ${ }^{37}$ As in qualitative research in general, the interaction between researcher and the research subject is an integral part of the research process. ${ }^{38}$ Consequently, as a "real, concrete, historical individual with interests and desires," ${ }^{39}$ I have been closely involved in the research process.

\footnotetext{
34 Locher and Prügl 2001, p.113.

35 Adler 2012, p.113.

36 Locher and Prügl 2001, p.121.

37 Calás and Smircich 2009, p.249.

38 Lamnek and Krell 2016, p.34.

39 Calás and Smircich 2009, p.249.
} 
A feminist constructivist understanding of the world and of the generation of knowledge entails a methodological approach that accounts for my reflexive role as a researcher. The specific qualitative research methodology of Grounded Theory, further detailed in chapter 5 , best meets these requirements. Furthermore, considering the researcher a part of the research process entails making my involvement visible. I therefore write the present study in the first-person voice because bringing the "I" in accounts for the fact that the researcher brings her own subjective "I" to the production of knowledge, as Kathy Davis (2013) highlights. ${ }^{40}$

\subsection{Structure of the study}

The rest of this book is organized in nine chapters. Chapter 2 lays out the central question of this study. It starts with a description of the historically determined gender-biased understanding of human rights that formed in the post-WWII period. The chapter follows up with an account of the ways this understanding was contested, specifically focusing on the second wave of the feminist movement. After long years of transnational mobilizing and lobbying, the latter finally succeeded in making women's rights recognized as human rights by framing VAW in the private sphere as a human rights issue in 1995. Chapter 2.3 shows how human rights organizations, such as AI, responded to transnational feminism's growing critique that mainstream human rights organizations were largely ignoring human rights violations witnessed by women. Finally, chapter 2 presents the research questions motivating this book.

Chapter 3 briefly conceptualizes the notions at the heart of this study. It defines Human Rights and Women's Rights as gendered social and historical constructs, rather than something that has emerged naturally and is unchangeable, once codified. Furthermore, it presents VAW as an issue of women's rights rooted in gendered social structures, ${ }^{41}$ rather than as an individual and random act. Finally, because the book is interested in AI's policy and activities and focuses on the role that activists and officials played in the integration process, but does not directly address the acts that VAW entails,

40 Davis 2013.

41 UN Women. 
I use the expression "violence against women" as an issue area and a social phenomenon.

Chapter 4 provides a short review of the relevant literature on the nature and dynamics of transnational norm diffusion. I primarily concentrate on the first IR scholars who succeeded in anchoring the constructivist approach into the study of world politics in the early 1990s by showing that norms should be taken into account if we were to understand global politics. The chapter then presents the more recent approach to the study of norms in IR, which emphasized the idea of normative contestation and challenged earlier conceptions of a linear diffusion of norms by showcasing norms that failed to be internalized or regressed.

The focus of chapter 5 is on data and method(s). It starts with a review of the origin and the characteristics of grounded theory methods. It goes on to explain why Grounded Theory techniques are used as the main method of the study. The chapter then justifies the selection of the Swiss and the German sections as the two case studies. I describe the process of data collection and provide a detailed account of the data corpora. The chapter then concentrates on data analysis using grounded theory techniques and demonstrates how I arrived at my findings and developed new theoretical insights from the data.

Chapter 6 is the first of three consecutive empirical chapters that, taken together, constitute the principal part of the study. Since my book requires accounting for internal structures and power relations, chapter 6 provides insights into Al's organizational structure and its formal and informal decisionmaking processes. It describes $\mathrm{AI}$ as a networked organization by first focusing on its international structure before concentrating on the structure of the Swiss and the German sections. I demonstrate that gender and religion are two important categories that AI had been built around from its beginnings. I show that AI has traditionally been a highly gendered organization and that Christianity was an integral part of AI's origins. The chapter then provides insights into the decision-making and implementation processes and the power relations among the IS, the AI's headquarters, and the national AI sections by distinguishing between the international and the national levels.

In chapter 7, I explain the beginnings of AI's interest in VAW in the late 1980 and the 1990s. The chapter starts with a short outline of the evolution of AI's work in general before highlighting in detail the changes in AI's human rights policy with regards to VAW and providing an in-depth description of AI's activities related to violence against women in the 1990. The chapter demonstrates that AI's work on VAW mainly focused on violations of women's 
civil and political rights in the 1990s. I highlight that between the late 1980 s and the end of the 1990s, AI women activists and officials successfully pushed AI to increase its work on VAW by employing a strategy of intersectional networking and analogous framing. The chapter identifies these feminist strategies as key to understanding the organization's growing interest in VAW issues and its decision to make VAW in the private sphere the theme of its first global long-term thematic campaign in 2001 . The chapter also highlights that large groups within the movement were indifferent or reluctant to intensifying the organization's work on VAW, despite the important achievements in the integration of women's rights into Al's work.

The focus on the Swiss and the German sections in chapter 7.2 shows the important role that AI female activists at the sectional level played in initiating the organization's work on women's rights in the 1980s and in pushing the issue further, both within their section and in the whole movement during the 1990s. Women in the Swiss section first organized in regional groups and only formed a national network in their section in 2000. Within the German section, the Menschenrechtsverletzungen an Frauen (MaF) women's group, which was composed of women's rights experts scattered throughout the country, was already taking a leading role in the section's activities on women's rights during the 1990s. The chapter shows that while the overall objective of the women's groups in both sections consisted in increasing the organization's work on women's rights, the Swiss section's women's group concentrated its efforts on their section. Meanwhile, as an active member of the Intersectional Women's Network (IWN), the MaF concentrated on actually influencing AI's international decision-making process. In contrast to the German section, where work on VAW largely remained in the hands of MaF activists, the Swiss section began to professionalize its work on violations of women's rights in the late 1990 .

Chapter 8 deals with AI's work on VAW from the adoption of the mission in 2001 until the end of the SVAW campaign. In chapter 8.1, I highlight the elaboration of the AI policy on selected aspects of abortion and show that the organization used gender equality as a means to enhancing internal governance and growth. The chapter demonstrates that, in contrast to the previous period, it was the AI's leadership that pushed policy development in the realm of AI's work on VAW in the 2000s. Nevertheless, AI did not succeed in making women's rights an integral part of its overall work through the SVAW campaign, as it intended. I argue that two reasons are mainly responsible for this failure: first, because the SVAW campaign was implemented from the top 
down, the women activists and officials who had initiated AI's work on VAW in the 1990s lost their influence on the organization's work on VAW issues. Second, activists and officials resisted the SVAW campaign and the adoption of an abortion policy.

Chapter 8.2 describes how the work on VAW trickled down to the Swiss and the German sections in the 2000 s and presents the considerable difference in the extent to which these two sections succeeded in integrating the issues of VAW into their work.

In chapter 9, Discussion and outlook, I recapitulate my main findings and discuss them in light of the existing literature on the integration of women's rights into AI's work. In section 9.1, I briefly recall the study's general objective and summarize the main insights. Section 9.2 draws some broader implications for other human rights NGOs. By relating the empirical findings back to the literature, section 9.3 discusses the book's new theoretical insights. It specifically highlights the study's contribution to the understanding of the ways comparatively powerless actors within a transnational network are able to bring a new norm into existence, and explains the study's contribution to our better understanding of the causes of incomplete norm diffusion. Section 9.4 concludes with an outlook focusing on Al's internal developments in the realm of women's rights in the years since the SVAW campaign. 



\section{Problem and research questions}

\subsection{A gender-biased understanding of human rights}

The public and the private spheres have a history of being defined as highly gendered spaces. Democratic states reserved citizenship exclusively for men until the beginning of the zoth century. ${ }^{1}$ In most countries, women had to wait until the end of the Second World War to be recognized as equal citizens of their states (or until 1971 in Switzerland). As Binion highlights, feminist historians and legal scholars see the dichotomy between the public and the private spheres as a product of "classical Western liberal thought," ${ }^{2}$ which challenged kings' divine rights to govern but did not question "patriarchal family structures." Influential liberal philosophers such as John Locke embraced a vision of the role of individuals in society that entailed that gender roles in the private and the public civic sphere were clearly defined, rendering women invisible in the public sphere. The liberal ideals of the Enlightenment reflected a model of "male hegemony over public life," ${ }^{4}$ entailed a vision of women being subordinated to men, and did not consider women beneficiaries of these basic rights. ${ }^{5}$ For example, in his theory of justice, which profoundly influenced traditional liberal ideas of the $18^{\text {th }}$ century, Kant defined men as active citizens having the rights to freedom of expression, freedom of action, and legal equality vis-à-vis the state. ${ }^{6}$ At the same time, Kant only

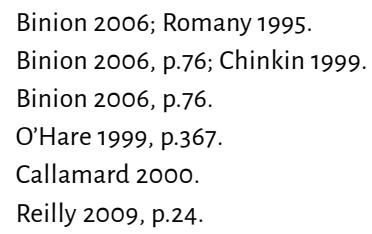


regarded women as passive citizens. ${ }^{7}$ This vision entailed women's "exclusion from the exercise of public power." 8

The human and civil rights declarations of the end of the $18^{\text {th }}$ century, including the 1789 French Declaration of the Rights of Man and of the Citizen and the 1791 United States Bill of Rights, defined a set of universal individual and collective rights for all men vis-à-vis the state. These declarations inspired the 1948 UDHR, which can be considered the foundation of the $20^{\text {th }}$ century understanding of human rights. In contrast to its predecessors, this particular declaration defined human rights broadly, guaranteeing rights and freedoms without distinction of any kind. ${ }^{9}$ As Reilly points out, the UDHR even "pushed the boundaries of traditional liberalism,"10 which prioritized the public over the private, and condoned women's "exclusion from the exercise of public power"11 insofar as it recognized the indivisibility of economic, social, and cultural rights from civil and political rights. Bunch explains that reading the declaration "from the perspective of women's lives, many violations of women's rights such as rape and battering can readily be interpreted as forbidden." ${ }^{12}$ However, the post WWII human rights discourse (dominated by the West) reflected the political dynamics of the Cold War and almost exclusively focused on civil and political rights, while marginalizing economic, social, and cultural rights. As Kelly (2005) highlights, "for much of the twentieth century, human rights discourse has been state centered, reflecting liberal theories of the social contract, and has focused on how to prevent incursions of the state against private actors." ${ }^{13}$

The establishment of two separate legally binding human rights treaties the International Covenant on Civil and Political Rights and the International Covenant on Economic, Social and Cultural Rights - shows the international community's difficulty in finding a common understanding of human rights and considering them as indivisible. While the UDHR overcomes the gender bias inherent to the $18^{\text {th }}$-century classical Western liberal conception of human rights by calling for a holistic approach to human rights, the subsequent

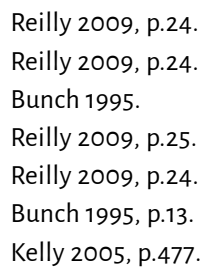


interpretation and legally binding codifications rearticulated the public-private divide. Whereas at first glance, the priority on civil and political rights seems to be unproblematic, a careful analysis from a feminist point of view reveals its inherent gender bias. ${ }^{14}$ For feminist human rights researchers "this binary [between the public and the private sphere] is deeply gendered insofar as it defines human rights priorities according to the criterion of 'what men fear will happen to them' in their relationship with the state, society and other men."15 Thus, feminist legal scholars considered the traditional human rights paradigm as gender biased. ${ }^{16}$ The gender bias becomes especially evident in cases of VAW, such as rape. Bunch explains that considering women's rights uniquely in the civil and political rights paradigm is limited, as "it defines rape as a human rights abuse only when it occurs in state custody but not on the streets or in the home."17

The global political context of the Cold War can be seen as an important element in the making of the mainstream understanding of human rights in the second half of the $20^{\text {th }}$ century and explains the focus on the international Covenant on Civil and Political Rights. Nevertheless, the absence of women from the highest ranks of the UN and other important international and regional organization $\mathrm{s}^{18}$ and the fact that human rights organizations had been dominated and run by men for many years ${ }^{19}$ perpetuated and even enhanced the gender bias of the traditional human rights discourse. Indeed, feminist scholars show that the gender bias is mainly a consequence of the non-existent integration of women's experiences into the practical elaboration of human rights laws, which has focused on human rights violations typically witnessed by men. ${ }^{20}$ Alternatively, "the process by which human rights were conceptualized and defined did not involve significant participation by women."21 Charlesworth and Watson argue that the "long-term male domination"22 of "the Secretariat of the UN and its specialized agencies, for example, the Economic, Social, and Cultural Rights Committee, the Human Rights

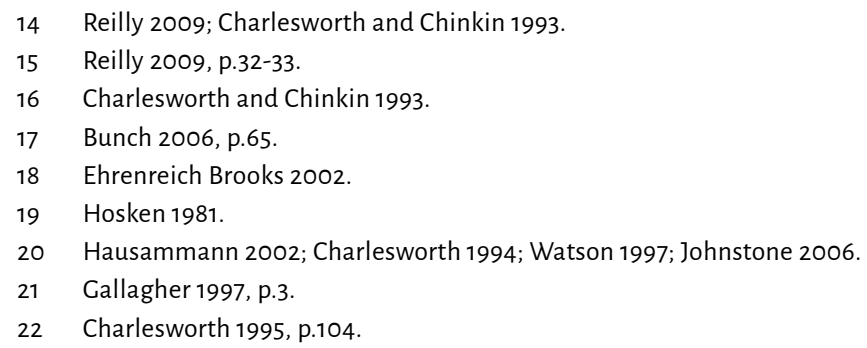


Committee, and the Committee Against Torture [...] means that issues traditionally of concern to men are seen as general human concerns; 'women's concerns', by contrast, are regarded as a distinct and limited category."23 Consequently, by focusing on the state's responsibility to respect the citizens' civil and political rights, the traditional human rights understanding ignored and condoned the gendered public-private divide and has maintained and masked the subordination of women characterizing large parts of human societies. ${ }^{24}$

This gender bias becomes evident in the UN human rights machinery as well as in the work of important international human rights NGOs. In fact, the difference in the allocation of resources and the statute of the Commission of the Status of Women (CSW), established in 1946, compared to that of the United Nation Commission on Human Rights (UNCHR) has reflected the relegation of women's rights in the international human rights regime. As explained by Reilly, "the administration of the CSW was isolated and underfunded in Vienna, while the rest of the human rights machinery developed in the key UN cities of Geneva and New York." ${ }^{25}$ At the same time, the consideration of violations of women rights as separate concerns vis-à-vis human rights is reflected in the prevailing parallel existence of two international human rights regimes: one treating issues on the violations of human rights in general, the UNCHR, and the Committee on the Elimination of Discrimination against Women, which monitors the implementation of the Convention for the Elimination of All Forms of Discrimination Against Women (CEDAW). Furthermore, many international human rights NGOs (most of them were and still are based in the global North) focused their activities on the respect of civil and political rights, and they rarely considered women's rights a priority. Rather, they treated those rights as special interests. ${ }^{26}$

Human rights organizations were not the only institutions that prioritized the Covenant on Civil and Political Rights. Organizations such as $\mathrm{Hu}$ man Rights Watch (HRW) and AI also applied a narrow reading of the broad language of the Covenant. Kenneth Roth, the Executive Director of HRW, emphasized the Covenant's potential ability to combat VAW in the home referring to Article 6 (1) that declares: "Every human being has the inherent right to life. This right shall be protected by law. No one shall be arbitrarily deprived 
of his life," to Article 7, which posits that "No one shall be subjected to torture or to cruel, inhuman or degrading treatment," and to the principle that "Everyone has the rights to...security of person" codified in Article 9 (1). Despite these requirements' potential applicability to the issue of VAW in the private life, these organizations interpreted them, especially in their early years, as if they only concerned the victims of politically motivated abuse. ${ }^{27}$ Thus, Byrne justifiably concludes that, "[m]any human rights NGOs were simply not interested in exploring the gender dimensions of human rights violations." ${ }^{28}$

While its own statute gave AI the mandate "to promote awareness of and adherence to the Universal Declaration of Human Rights and other internationally recognized human rights instruments, the values enshrined in them, and the indivisibility and interdependence of all human rights and freedoms," ${ }^{29}$ the organization declared that it only opposed a limited number of civil and political rights, such as the detention of prisoners of conscience, unfair trials for political prisoners, torture, and the death penalty, as well as "disappearances" and extra-judicial executions. ${ }^{30}$ Like other human rights NGOs founded in the post-WWII period, "activist friends of human rights, such as Amnesty International, slow to view women as victims of denials of human rights, have held firm in their view that government must be seen as the perpetrator of violations in order for their organization to act." ${ }^{31}$ Thus, AI's mandate was gender biased. It promoted awareness of and adherence to the UDHR and, in doing so, proclaimed "the equal entitlements of women and men to the rights contained in it." 32 Nevertheless, it largely ignored the public-private divide and abuses of human rights that overwhelmingly victimized women by representing a narrow understanding of the Covenant on Civil and Political Rights. As I highlight later, AI finally gave its concentration on civil and political rights up in 2001 when it decided to abandon this mandate and adopt a mission engaging with the respect of all human rights, as defined in the UDHR. The focus of Al's mandate was informed by the global political situation of the post-WWII period. The long-lasting

27 Roth 1994, p.327.

28 Byrnes 1988, p.9.

29 Amnesty International: Statute of Amnesty International as amended by the 22nd International Council, meeting in Ljubljana, Slovenia, 12-20 August 1995, 1995.

30 Amnesty International: Statute of Amnesty International as amended by the 22nd International Council, meeting in Ljubljana, Slovenia, 12-20 August 1995, 1995.

31 Binion 2006, p.78.

32 United Nations Human Rights Office of the High Commissioner 2014, p.3. 
male dominance in the organization's management, however, contributed to maintaining this narrow working focus, thereby perpetuating the inherent gender bias in Al's activities.

The rationale developed above has demonstrated that the mainstream understanding of human rights that took root after WWII can be considered gender biased because it focused on the respect of individuals' civil and political rights vis-à-vis the state, thereby prioritizing the public over the private. I have argued that in addition to the prevailing global political context of the Cold War, the absence of women in the UN, in other international and regional organizations, and in key positions of human rights NGOs has contributed to a narrow perception of human rights that mainly protects individuals from state power. The underrepresentation of women in these bodies perpetuated the gender bias. As a typical Western human rights organization dominated by men, AI's working focus, like that of many human rights NGOs, reflected the inherent gender bias of the traditional understanding of human rights. This gender-biased perception of human rights dominated the human rights discourse until the last two decades of the $20^{\text {th }}$ century. As I will illustrate later, women's rights activists' continuous transnational mobilization finally led to the inclusion of women's rights into the mainstream discourse on human rights in the 1990 s.

\subsection{Contestation of the traditional understanding of human rights}

Some feminist historians date the idea of women's human rights back to the publication of Le livre de la Cité des Dames (the book of the City of Ladies) by Christine de Pizan in the early fifteenth century. ${ }^{33}$ Others view women's quest for equal rights as going back to the time of the French Revolution. In her Declaration of the Rights of Women and the Female Citizen, published in 1791 in response to the Declaration of the Rights of Man and of the Citizen, the French playwright and political activist Olympe de Gouge complained about the existing inequalities between women and men and demanded that women be recognized as citizens equal to men. ${ }^{34}$ In England, Mary Wollstonecraft

\footnotetext{
33 Fraser 1999.

34 Olympe de Gouge was shamed and treated as hysterical and irrational. She was guillotined on 3 November 1793 (Callamard 2000).
} 
similarly demanded women's equality in her book Vindication of the Rights of Women, published in $1792 .{ }^{35}$

The battle for equal rights and non-discrimination continued 150 years later. In the first half of the $20^{\text {th }}$ century, women of the so-called "first wave" of the (Western) feminist movement mobilized for equal suffrage. By the end of WWII, most countries had granted suffrage rights to both men and women. As a result of the direct pressure of UN women delegates and the NGOs supporting them, the UN established the CSW in 1946 as the principal global intergovernmental body exclusively dedicated to the promotion of gender equality and the empowerment of women. ${ }^{36}$ In the 1960s/1970s, the "second wave" of the feminist movement (in the West) began to organize around issues, such as equality and gender-based discrimination in academia and other professions. Western feminist groups called for women's equal access to education and women's self-determination on issues related to birth control and abortion. ${ }^{37}$

In contrast, feminists in the "South" deplored imperialism and called underdevelopment out for obstructing women's advancement. ${ }^{38}$ The first signs of change in the mainstream understanding of human rights appeared during the UN women's decade (1975 to 1985), when women's rights activists launched a discussion mainly focused on the issues of education, employment, and health. ${ }^{39}$ The women's decade also saw an explosive growth in the number of women's organizations until the 1995 Beijing conference. ${ }^{40}$ As True and Mintrom point out, "the momentum and organizational buildup to these conferences were the result of efforts by women's advocates worldwide rather than solely the agenda setting of the UN." ${ }^{41}$ The female delegates at the UN and NGOs supported the successful lobbying of the CSW that led to the adoption of CEDAW in 1979. ${ }^{42}$ The Women's Convention contributed to broadening the traditional concept of human rights as it covered both civil and political rights and economic, social, and cultural rights. It also claimed that "not only public institutions and practices needed to be changed to ensure women's

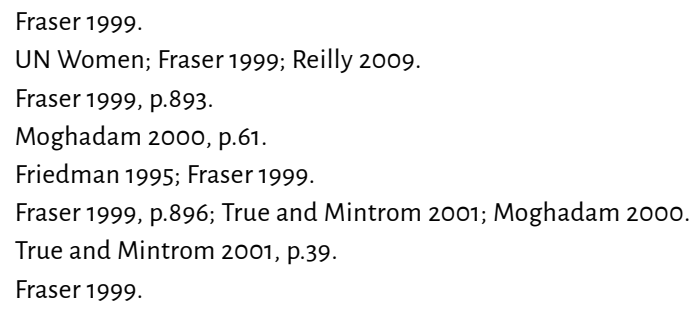


rights; private or family practices also needed to be addressed, and addressed by states." 43

Whereas the traditional human rights discourse neglected economic, social, and cultural rights, these issues were of great concern to the international conferences on women in Mexico in 1975, in Copenhagen in 1980, and in Nairobi in 1985. In fact, education was seen as a priority for development and for the achievement of women's equal statute. The final document of the UN women's conference in Nairobi called education "the basic tool that should be given to women in order to fulfill their role as full members of society." 44

However, none of the human rights norms codified in the International Covenant on Economic, Social and Cultural Rights managed to mobilize women transnationally. Neither did they have the necessary power to reshape the traditional understanding of human rights so as to include the violations of human rights that predominantly concerned women. As Keck and Sikkink point out, the issues of equality and discrimination were important in framing the "second wave" of the women's movement in the North and in the UN system. ${ }^{45}$ At the same time, activists in other regions of the world organized around different issues. In the context of dictatorial regimes in Latin America, the example of the Madres de la Plaza de Mayo showcases women's strong opposition to civil and political rights abuses. The struggle of women's organizations in the South also prioritized the rights to development, food, shelter, and work.

In contrast, the issue of VAW and especially domestic violence concerning women regardless of their socio-economic situation united women across the globe. "The issue transcended race, class and cultures, and united women worldwide in a common cause" ${ }^{46}$ and therefore had the power to clearly illustrate "women's subordinated position as no other issue had." 47 Because of this, VAW in the private sphere reshaped the mainstream conception of human rights and lead to the recognition of women's rights as human rights in the 1990s. In fact, by framing VAW as a human rights issue, the international women's movement managed to put women's rights on the inter-

\footnotetext{
43 Brown Thomson 2002, p.105.

44 United Nations 1986, Paragraph 163.

45 Keck and Sikkink 1998, p.168.

46 Fraser 1999, p.903.

47 Fraser 1999, p.902.
} 
national human rights agenda in the early 1990s. ${ }^{48}$ Even though they were absent from the agenda of the World Conference on Human Rights in Vienna when the UN decided to convene the gathering in 1991, women's rights "became one of the most discussed topics in the international human rights community"49 between 1991 and the end of the World Conference on Human Rights. By framing VAW as a human rights issue, women's rights organizations and the Center for Women's Global Leadership guaranteed the inclusion of VAW in the conference agenda. ${ }^{50}$ Concretely, the Vienna conference can be seen as the moment of convergence of the human rights movement and the women's rights movement. Because of the successful pressuring of women organized in Transnational Feminist Networks, ${ }^{51}$ participants there formulated specific demands for a new human rights paradigm that would engage with women's rights for the first-time. The Women's Rights are Human Rights campaign, launched by women's organizations as part of the World Conference on Human Rights in 1993, was indicative of the re-thinking of human rights at the international and the national levels. ${ }^{52}$

The shift in the human rights paradigm can be observed at a discursive level in the final document of the Conference - the Vienna Declaration and Program of Action. A significant text that formally recognized VAW as a human rights issue, it declared that "[t]he human rights of women and of the girl-child are an inalienable, integral, and indivisible part of universal human rights." 53 Furthermore, the declaration claimed "that women's human rights should form an integral part of the UN human rights activities." 54 The networking, pressuring and lobbying of women's rights activists that culminated in Vienna encouraged the UN to adopt new international human rights standards and mechanisms, such as the Declaration on the Elimination of Violence against Women. The latter was adopted by the UN in December 1993 and, for the first, time provided a definition of VAW. Subsequently, all UN member states agreed to work on eliminating such violence. ${ }^{55}$ The Declaration indicated the human rights community's shift towards recognizing the

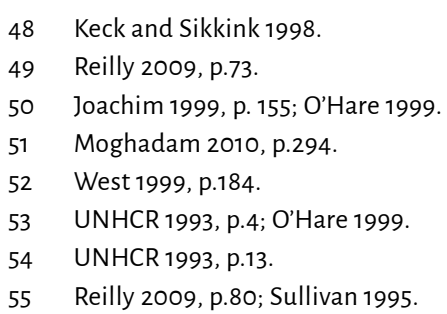


importance of addressing the link between women's subordinated positions in public and private life and the prevalence of VAW. ${ }^{56}$ Focusing on the issue of violence against women, which is mostly committed by men, feminist activists demonstrated the role that male violence played in creating and preserving female subordination. ${ }^{57}$

The women's rights movement's pressure to extend the understanding of human rights to the private sphere finally succeeded at the fourth WCW in 1995. VAW was the "centerpiece of the platform" there and had become a "common advocacy position" of both the women's and the human rights movements. ${ }^{58}$ Feminist scholars explained that Beijing served to make the new global women's rights discourse more concrete and that it embodied the shift of women's rights away from the margin to the center. ${ }^{59}$ With the unprecedented number of participants coming from both the North and the South and the organization of prior preparatory meetings and parallel regional NGO forums, the Beijing conference became an environment especially conducive to the re-conceptualization of women's rights as human rights. ${ }^{60}$ According to Bunch, the Beijing "platform is one that affirms the human rights of women in all areas - the rights of women to education, to health care, to a life without violence, and to fundamental political participation and to first class citizenship in all countries of the world. ${ }^{61}$ In fact, the final document of the WCW was progressive, as it defined VAW as "any act of gender-based violence...whether occurring in public or private life." Furthermore, the document considers VAW "violence perpetrated or condoned by the State, wherever it occurs. ${ }^{62}$ Feminist scholars argue that the success of the Vienna and the Beijing conferences in the realm of women's rights is largely attributable to the continuing pressure of transnationally organized women's rights organizations. ${ }^{63}$

Violence against women, especially forms of it that occurred in the private sphere, had been central to the women's rights movement's demands to see women's rights as human rights. The women's movement successfully

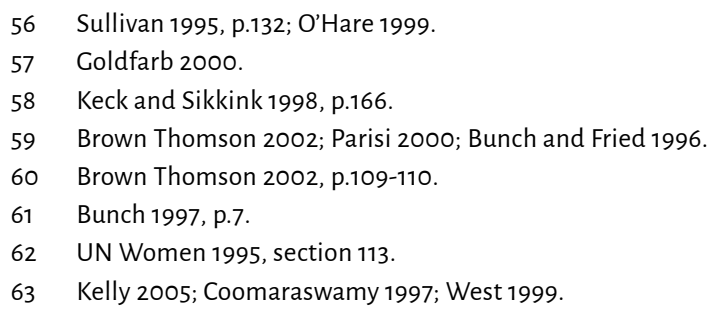


used VAW to illustrate that the traditional human rights paradigm did not protect women's lives due to its inability to cope with violence in the private sphere. ${ }^{64}$ In the process of reconceptualizing human rights around the issue of VAW, the scope of the state's responsibility to prevent and punish abuses of human rights was thus essential. In the traditional human rights discourse, states were uniquely responsible for acts that had been directly imputable to them or to their agents but not for abuses of human rights committed by private individuals. By framing VAW as a human rights issue, the women's rights movement thereby broadened the area of states' accountability for acts perpetuated by individuals and for states' failure to prevent and punish violations of human rights in the private sphere. Thus, "the responsibility of the state for acts committed by individuals [...] is in the center of the integration of women's rights" 65 into the traditional understanding of human rights. At the level of the nation state, this transformation signified that governments had to "transcend the division between what used to be considered public and private life." ${ }^{\prime 66}$

In summary, the shift in the traditional human rights paradigm that led to considering women's rights human rights, which occurred through the recognition of VAW in the private sphere as a violation of human rights, was a long process. The issue was absent from the UN's international political agenda and ignored by human rights groups as well as by the women's movement (in the West) until the mid-1980s. It became a central concern of women's rights groups and a subject of the UN's international political agenda and of the entire human rights movement in the 1990s. The recognition of VAW in the private sphere as a human rights violation was mainly accepted due to continuing international women's activism and networking at the local, the national, and the global levels, which put pressure on the UN and national governments. Women's rights activists entered the global political space opened by the UN in order to make their voices heard. They actively participated in the international UN conferences in the 1990s (World Conference on Human Rights in Vienna 1993, International Conference on Population and Development in Cairo 1994, Fourth World Conference on Women 1995) and successfully used these places to network and exchange strategies to make

\footnotetext{
64 Baer 1994; Bunch 1995; Bunch et al. 2000.

65 Benninger-Budel and Lacroix 1999, p.36.

66 Kaplan 2001, p.303.
} 
their concern visible. ${ }^{67}$ Within a decade, the issue of VAW shifted from being considered "an exclusively domestic and cultural issue" ${ }^{168}$ to being recognized a central human rights issue by the international community.

\subsection{Response of human rights NGOs}

This shift in the discourse on human rights did not only become manifest at international conferences and the declarations issued at their end. As actors of the international human rights regime, human rights NGOs, such as HRW and $\mathrm{AI}$, absorbed these changes and actively contributed to the rearticulation of human rights. In fact, many international human rights organizations established their first important contacts with the women's rights movement at the World Conference on Human Rights in Vienna, were actively involved in the preparation of the fourth WCW, and participated in the related NGO Forum. Not only did women's rights activists strategizing in Transnational Feminist Networks ${ }^{69}$ push the UN to recognize VAW in the private sphere as a human rights violation, they also challenged mainstream human rights organizations to expand their mandate to include women's rights issues. ${ }^{70}$ Ultimately, the shift within the human rights paradigm also affected mainstream human rights NGOs. These groups, which had long essentially focused on governments' abuses of citizens' human rights, "began to accept the fact that violations of rights by citizens against each other were equally valid human rights abrogations. ${ }^{71}$ Internal discussions on the integration of women's rights into their activities started in the 1980s. ${ }^{72}$ Later, in the 1990 and the 2000s, these NGOs recognized VAW in the private sphere as a human rights violation with varying degrees of resistance. ${ }^{73}$ As Fraser accurately points out, finally "the private and public spheres began to merge in human rights theory and practice. ${ }^{74}$

\footnotetext{
67 Friedman 1995, p.19-23; Joachim 1999.

68 Joachim 1999, p.142.

69 Moghadam 2010, p.294.

70 Schmid-Häuer 1998.

71 Fraser 1999, p.903-904.

72 Brown Thomson 2002, p.104; Byrnes 1988.

73 See: Dolgopol 1994; Women in the Law Project 1994; Human Rights Watch 1992, 1994b; Lasco 2002; Human Rights Watch 1994a.

74 Fraser 1999, p.904.
} 
VAW had been largely absent from Al's working focus until the beginning of the 1990s. The organization published its first report on violations of women's rights, Women in the Front Line: Human Rights Violations against Women, in 1991. Even though the publication was significant for its introduction of VAW in state custody and for emphasizing women human rights defenders and the risks that they faced, it clearly respected the mandate's boundary as it essentially focused on the violations of women's civil and political rights committed by state agents. Around the 1995 WCW, AI launched its first major international campaign on women's rights called Human Rights are Women's Rights. The campaign focused on torture, state violence and abuses committed during armed conflicts, and disappearances as they affected women. While AI slowly broadened its working perspective under the mandate - one example of this was its work on abuses committed by non-governmental entities in $1991^{75}$ - the following statement illustrates that the primacy of civil and political rights in the organization's work remained unchanged: "The 1991 formulation did not deny the past evolution. The mandate, before and after 1991, could be summarized as protecting certain basic rights of people against grave abuses of political power (whether by governmental or non-governmental entities)." 76

Reflecting its restricted mandate, the campaign did not address VAW in the private sphere. Moreover, it was criticized for reflecting a traditional vision of gender roles, the relation between the public and private sphere, and between the state and the family. ${ }^{77}$ Only nine years later, in 2004, AI seemed to have completely endorsed VAW in the private sphere as a human rights violation. In fact, with the first global thematic long-term campaign (the SVAW campaign) that took place between 2004 and 2010, AI called for action against human rights violation in the private sphere for the first time in its existence.

In light of the traditional predominance of civil and political rights on AI's agenda and the fact that women had largely been absent from AI's decision-making positions for a long time, it is rather puzzling that AI choose VAW, and especially VAW in the private sphere, as the theme of its first global

The inclusion of non-state actors into Al's mandate can be seen as a consequence of the end of the Cold War and the simultaneous increase of domestic conflicts with unprecedented human rights abuses committed by non-state actors. 
thematic campaign. In fact, the opening of AI's working focus to economic, social, and cultural rights in 2001 was accompanied by major changes in the organization's working methods. From then on, the organization planned to work for the respect of the UDHR in long-term global thematic campaigns, and the first of such campaigns was meant to introduce this new way of working. Given the above-mentioned rationale, AI could have chosen another norm codified in the UN Covenant on Economic, Social, and Cultural Rights as the focus of its first global thematic campaign. In fact, as archive materials reveal, VAW was one of several potential topics that AI discussed. The IEC and different Standing Committees to the International Council Meeting (ICM), AI's decision-making body, generated a list of issues, such as the death penalty, children's rights, holding economic actors accountable for human rights abuses, and the protection of refugee rights. ${ }^{78}$ In addition, the IEC mentioned the right to medication, indigenous people, land rights, and poverty as possible campaign topics within the new mission in meetings prior to the 2001 ICM. Finally, "the IEC decided that VAW should be the topic for the theme campaign"79 and the delegates endorsed the proposition at the 2001 ICM. ${ }^{80}$

Scholars have identified external and internal factors that help account for AI's growing interest in women's rights issues. ${ }^{81}$ As previously mentioned, the changing global political environment (marked by the end of the Cold War) changed the nature of human rights violations and made AI rethink its statefocused mandate. ${ }^{82}$ According to Michel (2009), the extension of Al's mandate to social, cultural, and economic rights in 2001 and the integration of non-state actors into its mandate explain why AI gave its gender blindness up. ${ }^{83}$ The growing international awareness of gender equality stemming from

78 Amnesty International, International Secretariat: 25th International Council Meeting Circular 23 All Human Rights for All: An Integrated Approach to Action, Mandate and Organization, May 2001, p.26.

79 Amnesty International, International Executive Committee: IEC Information Bulletin 37, July 2001, p.13.

80 Amnesty International, International Executive Committee: IEC Information Bulletin 37, July 2001, p.13; Amnesty International, International Secretariat: Action Planning Bulletin November 2001, November 2001.

81 Michel 2009; Kelleher and Bhattacharjya 2013; Friedman 1995; Bahar 1996; Watson 1997; Sidhu and Chatterjee 1995.

82 Thakur 1994; Pack 1999.

83 Michel 2009, p.81. 
the UN Decade for Women 1975-1985 and the related WCWs, which culminated in the fourth WCW in Beijing, did not leave AI unaffected. ${ }^{84}$ At the same time, the women's rights movement also contributed to making AI reexamine its traditional working focus. ${ }^{85}$ Thus, the literature commonly acknowledges that the external political environment and, specifically, the women's rights movement influenced AI's work with respect to women's rights. As Freitas highlights, however, the changes in the international environment "do not fully account for specific policy choices." ${ }^{\prime 86}$ Whereas Kelleher and Bhattacharjya (2013) acknowledge the role of the staff, most especially that of the former SG Pierre Sané, and activists' lobbying the organization to work more seriously on women's rights, ${ }^{87}$ little is known about other factors. First among them is the role that activists and officials at the IS, within sections, and in local groups played in this transformation process. Second, we lack a comprehensive vision of how VAW in the private sphere became integrated into AI's activities and how AI's policy has changed since the beginning of AI's interest in issues of VAW in the late 1980 and until the end of the SVAW campaign.

\subsection{Research questions}

Because Al's work had long been characterized by a gender bias prior to the opening of its mandate to economic, social, and cultural rights, AI could have chosen another right codified in the UN Covenant on Economic, Social, and Cultural Rights to be the focus of its first long-term global thematic campaign. This poses the following research question:

1. Why did AI decide to focus its first global thematic campaign on the issue of violence against women and especially on forms of violence in the private sphere?

The rationale developed in chapter 2.3 traces the evolving understanding of VAW as a human rights violation in theory and practice. While the mainstream notion of human rights mostly ignored VAW in the private sphere,

\footnotetext{
84 Bunch 2001.

85 Watson 1997.

86 Freitas 2004, p.133.

87 Kelleher and Bhattacharjya 2013.
} 
feminist pressuring led to an expansion of the human rights discourse to encompass violations in both the public and the private sphere by the mid-1990s. Al's approach to VAW mirrored this process, albeit with a delay. As the preceding discussion has demonstrated, the organization started to work on issues of VAW in the public sphere in the 1990s. The interest in VAW in the private sphere, which became manifest in the SVAW campaign, was thus preceded by a condemnation of VAW in the public sphere. Because of the connection between the two human rights approaches, it is pivotal to clarify why and how AI dealt with the issue of VAW before and after adopting a comprehensive approach to human rights in 2001. I thus formulate the following research questions:

2. Why has AI integrated VAW into its activities?

3. How has AI integrated VAW into its activities, how has AI's human rights policy changed, and how has this transformation been assimilated and integrated by AI's officials and activists?

Aware of the gendered nature of Al's work and of the role women's rights activists played in the recognition of women's rights at the international level in the 1990s, the study is particularly interested in understanding the role that women activists and officials played within the organization, at the international as well as the national levels. Given the long-lasting gender-biased notion of human rights, the marginalization of women in cases adopted by $\mathrm{AI}$, and the long-lasting underrepresentation of women in AI's leadership positions, I assume that AI's work on VAW in general, and particularly in the private sphere, generated some negative reactions among the members and activists of the organization. It would thus be interesting to examine if this was the case. If such resistance existed, it remains pivotal to explore who articulated it and how they did so. It is therefore key to pose the following subquestions:

- What was the role of female activists and officials in the integration process?

- Has there been any resistance from activists and/or from officials and if so, what kind of resistance?

Given the preceding rationale, AI's approach to VAW can be differentiated into two periods: one starting in the late 1980s, when the organization started to 
discuss the issue of women's rights at the international level, and ending in 2001, and another lasting from 2002 to 2010 , marking the end of the SVAW campaign. Consequently, 2001 is the central point in time from which my study looks back and forth. ${ }^{88}$ This differentiation is also reflected in the structure of the analysis (chapters 7 and 8).

88 In the progress of this research, I became aware of the importance of the 2001 ICM for Al's work on VAW. At the beginning of the research project, I formulated three general research questions on the issue of Al and women's rights. These questions guided the initial stages of the research process and were redefined during the course of the project. CT research strategy indicates that concurrent data collection and analysis helps to narrow down the research questions. Thus, over the course of the research process, based on the concurrent collection and analysis of the data material (written and oral) by means of theoretical sampling, I modified the original research questions and formulated sub questions that are more precise. These more detailed research questions reflect some initial analytical thoughts and, following a CT logic, constitute results in themselves. 



\section{Conceptualization}

This chapter defines three important concepts at the heart of my study: human rights, women's rights, and violence against women.

As chapter 2 has highlighted, the second half of the $20^{\text {th }}$ century witnessed the development of two separate notions of rights: human rights, which formally includes women and men, but can often be interpreted as "men's rights" in its concrete applications, and women's rights, which was framed separately in its interpretation and application. In fact, the mainstream notion of human rights reflected women's subordinate position with respect to men in most societies, which Bunch explains "as a politically constructed reality maintained by patriarchal interests, ideology, and institutions." ${ }^{2}$ The parallel development of separate standards for women's rights and mechanisms like the CSW, the CEDAW, and the UN Declaration on the Elimination of Violence Against Women ${ }^{3}$ are the result of women's subordination to men.

As demonstrated by previous research, the international women's rights movement reshaped the popular understanding of human rights at the end of the $20^{\text {th }}$ century by illustrating that the traditional human rights paradigm did not protect women's lives because of its inability to address violence in the private sphere. ${ }^{4}$ Indeed, as Krook and True (2010) explain, "the meaning of human rights has been [...] challenged to include women's rights, economic rights, and access to drinking water and essential medicines," 5 suggesting a continuing redefinition of the notion of human rights over the course of the last decades of the $20^{\text {th }}$ century. It is thus worth defining human rights "not

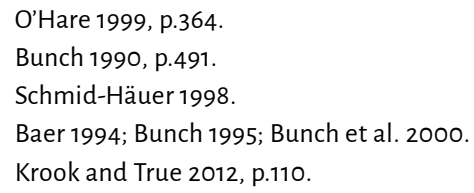


[as] something that somebody gives from on high, [...] It is something that people claim and fight for and struggle for and keep redefining in every era [...]." Therefore, human rights and women's rights cannot be seen as naturally given or static. Instead, they must be considered gendered social and historical constructions. Al's understanding of human rights and women's rights changed over the period of the study's focus (1989 - 2010). Hence, I use the concepts of human rights and women's rights as Amnesty International understood them at the time, which is in turn reflected in the organization's policy and activities.

Violence against women remains primarily an issue of women's rights despite being recognized as a violation of human rights at the beginning of the 1990s, because it "is rooted in gendered social structures rather than individual and random acts." As the discussion above indicates, the UN Declaration on the Elimination of Violence against Women provides the first comprehensive internationally agreed-upon definition of VAW. ${ }^{8}$ It delineates VAW as "any act of gender-based violence that results in, or is likely to result in, physical, sexual or psychological harm or suffering to women, including threats of such acts, coercion or arbitrary deprivation of liberty, whether occurring in public or private life." 9 The definition further includes the "[p]hysical, sexual and psychological violence occurring in the family [...] within the general community [...] perpetrated or condoned by the State, wherever it occurs." ${ }^{10}$ AI's policy delimits the organization's approach and activities concerning VAW. AI's policy and activities, in turn, reflect how AI deals with issues of VAW.

The present research is interested in AI's policy and activities and focuses on the role of activists and officials in the integration process. Consequently, the study does not address acts of violence against women. In the present research, the term 'violence against women' therefore refers to AI's policy that directly or indirectly concerns the way the organization deals with issues of VAW and to the activities concerning acts of gender-based violence, as defined in the UN Declaration on the Elimination of Violence against Women, that the organization engages in. Because AI's work on VAW overlapped with internal efforts and measures seeking to enhance gender equality among staff and

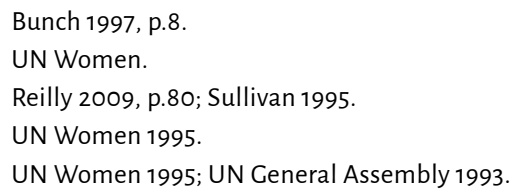


activists (sometimes these efforts were even closely interlinked), the present study applies a broad reading of "AI's work on VAW" that encompasses all policies and activities that directly or indirectly relate to VAW. 



\section{Focused literature review}

This chapter provides a focused review of the literature that my study draws from and to which it seeks to contribute. I discuss my original theoretical insights in detail in chapter 9.3.

My study focuses on the integration of issues of violence against women into Amnesty International's work; that is, the spread of the norm that recognizes VAW as a human rights violation within a transnational network, both in the private and the public sphere and regardless of the agent behind this diffusion. Consequently, the study draws from the work of early and more recent constructivist IR scholars who argued that, in addition to material forces, norms also matter in international relations. They developed our knowledge on the diffusion of norms based on this insight. ${ }^{1}$ The chapter begins with a brief introduction to the theories of social constructivism in IR (4.1). Section 4.2 explains existing theories on the emergence of international norms and shows that the agency of comparatively powerful norm entrepreneurs is commonly considered the primary driver of norm emergence. Section $4.3 \mathrm{ad}-$ dresses what we know about the influence of comparatively weak actors on norm diffusion. Section 4.4 then provides a short overview of the constructivist IR concepts of norm diffusion and norm dynamics. Finally, section 4.5 builds upon this by explaining my study's contribution: enhancing our understanding of how comparatively powerless actors within a transnational network can cause a new norm to emerge why norms decay.

1 Hoffmann 2010. 


\subsection{Social constructivism in International Relations}

In the 1980s and the early 1990s, the so-called first wave of constructivist IR scholarship challenged the dominant neorationalist and neoliberal understandings of world politics. ${ }^{2}$ By highlighting that the international system is not only steered by material forces but by ideas and beliefs as well, they set out to demonstrate that norms matter in international relations. ${ }^{3}$ In doing this, scholars illustrated the important role non-state actors, such as NGOs and Transnational Advocacy Networks (TANs), ${ }^{4}$ play on the international scene. Defining norms as "appropriate behavior for actors with a given identity," early constructivist IR scholars developed their own "conceptual tool for operationalizing process of social construction." 6

These early norm scholars distinguished ideas from norms. Whereas ideas were considered "beliefs held by individuals," norms were conceptualized as "intersubjective beliefs about proper behavior."7 Consequently, empirical studies on norms focused on the reason and the ways "beliefs held by individuals" ${ }^{8}$ were commonly accepted and gained normative status. Scholars like Katzenstein (1996), Finnemore (1996), Price (1997), and Risse et al. (1999) were interested in demonstrating how ideas and norms shape the interests of international actors and how a norm taken for granted by a community of states can spread to states outside of the community. ${ }^{9}$

In contrast to rationalists who are committed to a behavioral logic and who argue that states adopt norms because it "helps them get what they want,"10 constructivists think that states adopt a norm mainly because they

\footnotetext{
2 Hoffmann 2010.

3 Finnemore 1996; Keck and Sikkink 1998.

$4 \quad$ Keck and Sikkink introduced the term 'Transnational Advocacy Network' in their groundbreaking book Activists beyond boarders (1998). These authors explained that in their networked composition, TANs are similar to other transnational networks, but they "can be distinguished from other forms of Transnational Networks by [their] members' shared principled ideas or values in motivating their formation" (Keck and Sikkink 1998, p.1).

$5 \quad$ Finnemore and Sikkink 1998, p.891.

6 Hoffmann 2010, p.5411.

$7 \quad$ Khagram et al. 2002, p.14.

8 Khagram et al. 2002, p.14.

9 Katzenstein 1996; Finnemore 1996; Price 1997; Risse et al. 1999.

10 Finnemore and Sikkink 1998, p.912.
} 
perceive "the behavior to be good, desirable, and appropriate." ${ }^{\text {"1 }}$ This depiction

of the evolution of norms entails a "logic of appropriateness,"12 whereby actors internalize norms because of their desire to conform to the behavior that the vast majority of the members of the social system they evolve in consider appropriate.

Early norm scholars "demonstrated that constructivism consisted of more than a metatheoretical critique of rational/material approaches and could indeed be used to structure rigorous empirical investigations across the spectrum of issues in international relations. ${ }^{13}$ The first constructivist IR scholars succeeded in anchoring the constructivist approach in the study of world politics. However, they failed to recognize the possibility of a norm regression and had difficulties explaining normative change because of three factors. First, they conceived norms as static, meaning that the content of a norm remains the same during the process of diffusion. Second, they mainly treated norms as independent variables in explaining differing behavior or reaction. Finally, they defined diffusion as a linear process. In the 2000 , new constructivist scholars argued that norms are dynamic and their meaning experiences modifications over the course of diffusion. ${ }^{14}$ As I detail later in this chapter, this conception allowed them to explain normative change and grasp the possibility of norm degeneration.

\subsection{The role of norm entrepreneurs in the emergence of international norms}

While the first and the second wave of constructivist IR Scholars disagreed on the nature of norms, both emphasized the role of norm entrepreneurs in the emergence of a new norm. For both, norm entrepreneurs' behavior plays a major part in norm creation. Most studies acknowledged that external factors, such as major crisis situations, could contribute to the emergence of new norms or to normative change by offering "windows of opportunities"15

\footnotetext{
$11 \quad$ Finnemore and Sikkink 1998, p.912.

12 March and Olsen 1989.

13 Hoffmann 2010, p.5412.

14 Sandholtz 2007; Wiener 2007; Hoffmann 2010; Krook and True 2012; Müller and Wunderlich 2013; Hughes et al. 2015.

15 Wunderlich 2013, p.27.
} 
for actors' agency. However, they still stressed the pivotal role of norm entrepreneurs as powerful actors behind new norm genesis.

Constructivist IR scholars generally argued that the emergence of a new norm occurred because norm entrepreneurs succeeded in convincing a critical mass of actors to embrace the new norm. ${ }^{16}$ Finnemore and Sikkink (1998) define norm entrepreneurs as "agents having strong notions about appropriate or desirable behavior in their community." They explain that "new norms never enter a normative vacuum but instead emerge in a highly contested normative space where they must compete with other norms."18 Except in the cases of ideas that are "intrinsically attractive and the social complexity is low enough such that all the agents can appreciate the attractiveness of the idea, the idea cannot become a norm without any entrepreneurial effort." ${ }^{19}$ In contrast to the eradication of murder or cannibalism, which became internationally accepted as norms without any entrepreneurial effort, the recognition of VAW in the private sphere as a violation of human rights had a hard time finding international acceptance and cannot be considered intrinsically attractive, so as to emerge on its own without any actor's contribution. Indeed, as I have previously highlighted, the transnational networking and lobbying of the women's rights movement was key in recognizing VAW as a violation of human rights.

Scholars demonstrated that both individuals and collective actors can initiate norms. Finnemore and Sikkink (1998) identified two cases of individual norm entrepreneurship: Henry Dunan who introduced the international norm of the neutrality of medical personnel, persons wounded in war, and noncombatants; and individual figures in the suffragette movement who led the international campaign for women's suffrage. ${ }^{20}$ Johnstone (2007) demonstrated that the UN Secretary-Generals are very important in the generation of new international norms. ${ }^{21}$ He explained that the Secretary-General can play the role of a successful norm entrepreneur "when he or she joins emerging normative trends - usually first promoted by a group of states or powerful non-state actors - rather than trying to generate new norms out of

\footnotetext{
16 Finnemore and Sikkink 1998, p.895.

17 Finnemore and Sikkink 1998, p.896.

18 Finnemore and Sikkink 1998, p.897.

19 Hoffmann 2003, p.15.

20 Finnemore and Sikkink 1998.

21 Johnstone 2007.
} 
whole cloth." ${ }^{22}$ Citing the example of the US presidents who, following WWII, created the "normative and institutional architecture"23 of the UN, the Bretton Woods Institutions, and the North Atlantic Treaty Organization (NATO), Johnstone (2007) explained that leaders of powerful states can also become norm entrepreneurs.

Other authors concentrated on NGOs and TANs and emphasized how these collective actors can cause a new norm to emerge. Focusing on environmental and human rights politics in the 1990s, Keck and Sikkink (1998) showed that transnational networks of activists could use a so-called "boomerang pattern" by putting pressure on both states and international organizations. ${ }^{24}$ Some authors explained the success of norm entrepreneurship with entrepreneurs' use of organizational platforms to promote norms. ${ }^{25}$ In these cases, platforms are either constructed for the purpose of promoting a specific norm (the NGO Red Cross in Henry Dunand's case) or a specific NGOs member of a broader TAN uses the latter as a platform to promote their ideas (such as the TAN on VAW).

Other authors have identified AI, and especially its headquarters, as a norm entrepreneur. Using a political approach to network theory, Lake and Wong $(2009)^{26}$ argued that AI's international network structure with a powerful central node, the International Secretariat, and a large grass-roots movement organized in national sections explained AI's prominent role in making individual claims to political and civil rights the dominant norm of the postwar human rights movement. ${ }^{27}$ By concentrating on the early days of AI, they explained that AI's success "in setting the norms of human rights" 28 is a result of the IS's (as the central node of the network) ability "to control the content of the AI human rights agenda and [...] to attract new adherents. ${ }^{29}$ The authors further argued that "this staff-based office continues to possess broad authority to set the agenda for the network as a whole." ${ }^{\prime 30}$ In this approach, the IS

\footnotetext{
22 Johnstone 2007, p.138.

23 Johnstone 2007, p.126.

24 Keck and Sikkink 1998.

25 Finnemore and Sikkink 1998, p.896.

26 Lake and Wong 2009.

27 Lake and Wong 2009, p.136-141.

28 Lake and Wong 2009, p.149.

29 Lake and Wong 2009, p.149.

30 Lake and Wong 2009, p.138.
} 
represents the powerful node of the network and acts as a norm entrepreneur within the AI network.

Many constructivists use the concept of framing developed by social movement theorists, such as Snow et al. (1986) ${ }^{31}$ and Tarrow (1999), ${ }^{32}$ in an attempt to comprehend the successful promotion of norms. Framing refers to "the fact that the substantive content of particular issues in world politics is not simply inherent in the issue but is constructed by the participants involved." ${ }^{33}$ Keck and Sikkink (1998) show that an issue's successful appearance on the international agenda depends on how it is framed, or on how the idea is packed and presented to make it persuasive for a larger public. ${ }^{34}$ These authors emphasize the importance of framing when they demonstrate that women's rights TANs made women's rights part of the definition of human rights in the $1990 \mathrm{~s}$ by using frames associated with the prevention of bodily harm. According to Payne (2001), norm entrepreneurs "frame an issue so that target audiences can see how well newly proposed ideas coincide with already accepted ideas and practices." 35 Framing is thus an important approach that norm entrepreneurs use to transform their ideas into commonly accepted norms.

\subsection{Comparatively powerless actors' strategies for influencing norm dynamics}

Even though they acknowledged that external factors can contribute to the emergence of new norms by offering windows of opportunities, most firstand second-wave constructivist norm scholars highlighted the pivotal role norm entrepreneurs (individual or collective actors) played in the appearance of a new norm. Only few researchers questioned this role. Hertel's (2006) study on two transnational advocacy campaigns in the 1990s is the most prominent example of such cases. The campaigns for child rights in the Bangladeshi garment industry and for the prevention of gender discrimination in Mexican border textile manufacturing pointed to two different ways through which comparatively powerless activists can alter

$\begin{array}{ll}31 & \text { Snow et al. } 1986 . \\ 32 & \text { Tarrow 1999. } \\ 33 & \text { Clark et al. 1998, p.25. } \\ 34 & \text { Keck and Sikkink } 1998 . \\ 35 & \text { Payne 2001, p.43. }\end{array}$


the content of a transnational campaign: blocking and backdoor moves. ${ }^{36}$ Hertel differentiated the senders framing the campaign from the North from the receivers of the campaign in the South. The US Harkin bill ${ }^{37}$ called for the boycott of the Bangladeshi garment export industry because these manufacturers employed child workers. Local activists were alarmed by the boycott and the related exclusion of children from the labor market, since the latter's participation was essential for the survival of numerous families in Bangladesh. They started to block the transnational campaign by "organizing their own press conferences and openly calling for the establishment of a local 'movement against the Harkin bill" 38 Thus, local activists at the receiving end significantly hampered the campaign that harmed their specific interests by adopting the mechanism of blocking. As a result, the content of the campaign was significantly altered as "the central normative reference point of the Child Labor Coalition campaign moved from International Labor Organization (ILO) Convention 138 to the UN Convention on the Rights of the Child, a standard both Bangladeshi and American activists could embrace." 39

In contrast to blocking, Backdoor-moves can change the content of a campaign without stopping or altering its substance. Two campaigns against pregnancy screening on women in Mexico illustrate how local actors at the receiving end can deploy backdoor moves. One of the campaigns was launched by Human Rights Watch and focused on women "employed in the export manufacturing plants along Mexico's northern border with the United States." 40 The second was a national-level campaign launched by feminist groups in Mexico City and concentrated on the situation of women in different economic sectors. Mexican activists on the US/Mexican border taking part in the HRW campaign used backdoor-moves to add economic and social rights issues to the overall campaign frame. In doing so, the local activists did not challenge the official frame of the campaign; rather, they brought topics that "resonated with their own priorities" in through the back doors. ${ }^{41}$ While border activists framed their local campaign participation by

36 Hertel 2006.

37 The Harkin bill is a Child Labor Deterrence Act first proposed by Senator Harkin to the United States Congress in 1992, which called for the prohibition of importing products produced by Child labor. Wikipedia.

38 Hertel 2006, p.40.

39 Hertel 2006, p.50.

40 Hertel 2006, p.55.

41 Hertel 2006, p.83. 
introducing their own human rights issues, the overall HRW campaign "did keep the focus on civil and political rights issues." ${ }^{42}$ Thus, backdoor-moves did influence the Bangladeshi campaign's content but did not change it completely. In contrast, activists using the blocking mechanism significantly altered the content of the Mexican campaign.

Hertel (2006) thus shows that comparatively powerless actors participating in a transnational campaign can influence and alter the content of the campaign, ${ }^{43}$ thus changing the content of a norm and influencing its dissemination. At the same time, the study demonstrates that comparatively weak actors might also significantly affect the emergence of a new norm. Similar to Hertel, my research challenges previous constructivist arguments of the importance of norm entrepreneurs as the unique actor responsible for giving ideas a normative status. It also contributes to enhancing our knowledge about the ways in which comparatively powerless actors within a transnational network are able to cause a new norm to emerge. At the same time, my findings allow a relativization of the headquarters' essential role as the principal norm entrepreneur within AI (as emphasized by Lake and Wong [2009]). ${ }^{44}$

\subsection{Norm diffusion and norm dynamics}

Constructivist IR scholars have not only explained the emergence of an international norm, they have also shed light on the process of diffusion. Early constructivist norm scholars, who perceived norms as static, singled out two models of norm diffusion. Finnemore and Sikkink's (1998) 'norm life cycle' stipulated that norms evolve in a linear, three-stage process of norm emergence, norm cascade and norm internalization. ${ }^{45}$ Shortly after, building on Keck and Sikkink's (1998) ${ }^{46}$ "boomerang pattern," Risse, Ropp, and Sikkink

\footnotetext{
42 Hertel 2006, p.85.

43 Hertel 2006.

44 Lake and Wong 2009.

45 Finnemore and Sikkink 1998.

46 Keck and Sikkink showed that citizens are able to pressure their governments indirectly by appealing to citizens in other countries through TANs. TANs have commonly been referred to as networked actors composed of numerous smaller actors sharing the same values and discourse, exchanging information and services on a regular basis, and striving to influence political outcomes in principled issues. By documenting the
} 
(1999) conceptualized norm diffusion as a five-step process and highlighted the interplay between the national and the transnational/international levels. ${ }^{47}$ They explained compliance with human rights norms with the action of TANs that pressured states violating specific norms by using strategies of naming and shaming. ${ }^{48}$ Based on a logic of appropriateness, both models follow a similar mechanisms of international norms diffusion. These mechanisms include coercion, persuasion, learning, and emulation. ${ }^{49}$ Seeing norms as static, employing them mainly as independent variables in causal models of behavior or reaction, and defining diffusion as a linear process have meant that these two paradigms have neglected the possibility of norm-regression and have faced difficulties in explaining normative change. More recent constructivist scholars have criticized this progress-based explanation of norm diffusion for ignoring "the interactive aspect of norm dynamics."

More recently developed research has argued for a more dynamic conception of norm diffusion. and the latest approach to the topic emphasizes that norms' meanings are modified over the course of diffusion. ${ }^{51}$ Cases of norms that failed to be internalized or that have regressed have introduced the idea of normative contestation and challenged the aforementioned assumption of linearity. By inquiring when and where norms matter, and searching for the reasons and the ways through which norms change, these more recent studies have reconceptualized the relationship between actors and structure. They have thus placed the interaction between actors and their normative context in their very hearts.

These latest norm scholars have argued that states do not necessarily adopt norms because of transnational teaching that follows a logic of appropriateness. Instead, they comply with norms because of a dynamic process of socialization in which different normative systems are opposed to each other. Acharya (2004) explained that international norms are adapted to

existence and the functioning of transnational networks on violence against women, these authors have showed the pivotal role of activists in different countries working together on specific issues for the acceptance of women's rights as human rights (Keck and Sikkink 1998).

47 Risse et al. 1999.

48 Risse et al. 1999.

49 Wunderlich 2013.

50 Müller and Wunderlich 2013, p.24-25.

51 Sandholtz 2007; Wiener 2007; Hoffmann 2010; Krook and True 2012; Müller and Wunderlich 2013; Hughes et al. 2015. 
local contexts by actors who manipulate and modify the content of norms so as to conform to the local context. ${ }^{52}$ Similarly, $\mathrm{Ba}$ (2006) argued that norm takers are not passive; they take an active role during the socialization process and are therefore able to influence norms' meaning. ${ }^{53}$ Wiener (2007) showed that norms and the meaning of norms develop through "interaction in a context." ${ }^{54}$ Interested in the reasons behind "contestation of normative meanings beyond the state," 55 Wiener (2007) saw norms as social constructs and argued that, in light of this, norms are also contested by default. Focusing on the contestation of constitutional norms within a community of norm adopters, she demonstrated that actors do not adopt a norm as a result of external influence. Instead, they interpret international norms, which allows the latter's transposition into concrete action at the domestic level. She explained: "It is through this transfer between contexts that the meaning of norms becomes contested as differently socialized actors, for example, politicians, civil servants, parliamentarians, or lawyers trained in different legal traditions seek to interpret them. ${ }^{.56}$ The social environment thus influences how actors interpret and implement norms and is pivotal for comprehending norm contestation and norm diffusion.

Similarly, using a discursive approach to the study of international norm diffusion, Krook and True (2012) conceptualized norms as processes, rather than things, noting: "norms do not necessarily remain stable once they have been constructed. ${ }^{57}$ Focusing on two international norms - gender-balanced decision-making and gender mainstreaming - the authors argued that norms emerge and spread mainly because of two sources of dynamism. Internal sources had to do with the continuing discussions about the exact definitions of the norms among transnational activists and UN gender experts. More external sources come from "changes in broader normative environments. 58 The interaction of these sources of dynamism influence norm dynamics.

Even more recently, in their comprehensive study on the transnational dynamics of multilateral arms control norms, Müller and Wunderlich (2013) re-

$\begin{array}{ll}52 & \text { Acharya 2004. } \\ 53 & \text { Ba 2006. } \\ 54 & \text { Wiener 2007, p.6. } \\ 55 & \text { Wiener 2007, p.2. } \\ 56 & \text { Wiener 2007, p.12. } \\ 57 & \text { Krook and True 2012, p.117. } \\ 58 & \text { Krook and True 2012, p.123. }\end{array}$


jected the norm scholars' general belief in progress and criticized that "norm studies neglected the developments that occur after a norm has been established." ${ }^{59}$ Also adopting a dynamic approach to the study of transnational norm diffusion, the authors investigated what happens once a norm has been established. They argued that contestation is pivotal to understand compliance and non-compliance. ${ }^{60}$ Even internalized norms may "lose their takenfor-granted status, or eventually decay." ${ }^{\prime 61}$ Norm dynamics are characterized by three phases: establishment, further development, and an eventual norm degeneration or decay. At each stage, structural and actor-oriented forces influence norm change. Therefore, like in Wiener's (2007) account, norm diffusion had better be conceived as a permanent process of negotiation, throughout which norm entrepreneurs have to continually work to further consolidate the norms and defend them against norm challengers. This process entails conflicts that influence how a norm evolves.

Using several case studies of international regimes governing arms control, Müller and Wunderlich (2013) demonstrated the pivotal role norm entrepreneurs play in a norm's change from its emergence to its regression. They argued that norm entrepreneurs, such as states, NGOs, and IOs, are "transmission belts for transforming structural challenges and changes into political action that results in norm development." ${ }^{\prime 62}$ Norm change is thus primarily driven by norm entrepreneurs who can "initiate new norms, confirm, maintain, or strengthen a given norm, or alternatively change, amend, or replace it." ${ }^{\text {63 }}$

By pointing to norms' dynamic character, this recent approach to the study of norms has highlighted the interplay of structures and actors in explaining normative change. According to these second-wave constructivist norm scholars, the reasons behind incomplete norm diffusion have to do with a norm's contestation by differently socialized actors, which occurs when the norm is transposed to another context, or with the norm entrepreneurs' incapacity to defend the norm against norm challengers. ${ }^{64}$ While these studies acknowledge that the context and the norm interpreters' socialization

\footnotetext{
59 Wunderlich 2013, p.27.

60 Müller and Wunderlich 2013.

61 Wunderlich 2013, p.28.

62 Müller and Wunderlich 2013, p.351.

63 Wunderlich 2013, p.38.

64 Wiener 2007; Müller and Wunderlich 2013.
} 
explain norm contestation and, therefore, norm decay, they come short of accounting for norm interpreters' power in terms of their access to decisionmaking processes. My study departs from this point and demonstrates that when norm contesters have a relatively good access to decision-making processes, norm contestation is more effective and the likelihood of norm diffusion decreases.

\subsection{The study's theoretical contribution}

My book offers two main theoretical contributions: first, by concentrating on the beginning of AI's interest in violence against women, I show that comparatively powerless actors within a transnational network are able to cause a new norm to emerge. My findings shed light on how this happens by illustrating the strategies of parallel networking and analogous framing. ${ }^{65}$ Second, by emphasizing the preparation and the implementation of AI's first global thematic campaign (the SVAW campaign), I identify three main reasons for norm decay in the case of a transnational network: norms are contested by differently socialized actors; norm entrepreneurs cannot defend the norm from norm challengers; and the norm contesters' power in terms of access to the decision-making processes.

65 I refer to the concept of framing developed by social movement theorists such as Snow et al. (1986) and Tarrow (1999). Snow et al. 1986; Tarrow 1999. 


\section{Data and method(s)}

The present research borrows techniques of data collection, generation, and analysis from Grounded Theory. Therefore, this chapter starts by briefly explaining the origin and characteristics of Grounded Theory (5.1). Section 5.2 justifies my choice to use grounded theory techniques and provides details on the use of a limited set of grounded theory techniques as proposed by Birks and Mills (section 5.2.1). A detailed report on the used data and methods and a meticulous description of the research trail are pivotal for ensuring the trustworthiness and the quality of a qualitative research project. Consequently, sections 5.3 through 5.5 offer a detailed account of the research process and the applied grounded theory techniques. I start with the case selection (5.3), follow up with the data corpora (5.4), which details data collection and generation, before arriving at data analysis (5.5).

\subsection{The origin and characteristics of Grounded Theory}

The origin of grounded theory dates back to the work of Glaser and Strauss, who demonstrated the usefulness of "generating new theory from data, as opposed to testing existing theory"1 in their groundbreaking 1967 book The Discovery of Grounded Theory: Strategies for Qualitative Research. ${ }^{2}$ Throughout Glaser and Strauss' intellectual accomplishments, which the literature commonly refers to as the first generation of grounded theorists, scholars conceived of grounded theory as a single qualitative research method principally aimed at inductively generating a theory out of existing data. Scholars subsequently 
developed an initial paradigm, and today one cannot speak about grounded theory in the singular.

Besides Glaser and Strauss, other authors such as Corbin, Charmaz, and Clarke contributed to the further refinement of developing an inductively anchored social research method. ${ }^{3}$ While the initial inductive paradigm remained unchanged, grounded theory specialists differed in the proposed procedure of developing a new theory out of the data. Indeed, since the 1960s, grounded theory has become one of the most popular methods in qualitative research in social sciences, leading to numerous and sometimes contrasting techniques. Second-generation grounded theorists such as Corbin contributed to filling in the procedural gaps left behind by the texts written by first-generation grounded theorists such as Glaser. They did so by developing methodological frameworks. Glaser focused his writings on "what constitutes a grounded theory itself," while Corbin and Strauss offered a clear set of techniques describing how to actually proceed when developing a grounded theory. In their publications, they proposed a coding paradigm with several concrete steps to best analyze a large amount of data. ${ }^{5}$

In 2007, Bryant and Charmaz identified the relevant characteristics of a grounded theory research design. ${ }^{6}$ In their practical guide, Birks and Mills consider "the following to constitute a set of essential grounded theory methods" 7 for the production of an integrated grounded theory from empirical data: initial coding and categorization of data, concurrent data generation or collection and analysis, writing memos, theoretical sampling, constant comparative analysis, theoretical sensitivity, intermediate coding, selecting a core category, theoretical saturation, and theoretical integration. This process provides a systematic, inductive approach-from data collection and generation to data analysis by means of categorization, to the final generation of theory-that explains the phenomenon being studied. Thoroughly applying this entire set of techniques allows the researcher to study a new or little-known phenomenon by collecting and generating data and developing a theory from those data. Over the years, grounded theory methods have increasingly been used in other research designs. As explained by Birks and Mills, because of

\footnotetext{
3 Strauss and Corbin 1990; Charmaz 1995; Clarke 2005.

$4 \quad$ Birks and Mills 2011, p.5.

5 Strauss and Corbin 1990, 1998.

6 Bryant and Charmaz 2007.

$7 \quad$ Birks and Mills 2011, p.9.
} 
the value of these techniques in the analytical process, a researcher employs grounded theory methods "but does not aim to generate theory." ${ }^{\prime 8}$ Among these so-called mixed-method studies, concurrent data generation or collection and analysis, and theoretical sampling are the most widely adopted. ${ }^{9}$

\subsection{Reasons for the use of grounded theory techniques}

In contrast to other qualitative research methods, grounded theory techniques focus on theory development. ${ }^{10}$ This unique characteristic makes grounded theory methods appropriate for the present research, as one of my goals is to enhance theoretical knowledge on the phenomenon of norm diffusion. Specifically, concurrent data generation (or collection) and analysis are fundamental to any research using grounded theory methods and is a distinctive feature of the latter. As little is known about the phenomenon under investigation (the reasons and the ways AI integrated issues of VAW into its work), answering the research questions requires the collection of a large amount of data and analyzing them to make sense of them. Grounded theory techniques provide the guidelines necessary to proceed with the handling of a large amount of qualitative data. Grounded theory research's focus on theory development facilitates a flexible, iterative approach to the study of phenomena, providing a framework whereby initially broad research questions are incrementally narrowed down. In contrast to most studies where "the research question directs how the study proceeds, in grounded theory, it is the research process that generates the question."

I was initially interested in knowing why and how AI integrated women's rights into its activities in general. Concurrent data collection and analysis revealed the significance of VAW in AI's work on women's rights and allowed me to subsequently concretize the research questions. As I show later, while I initially planned to include three AI sections in order to understand the national level of the organization, I ended up only analyzing two cases.

As I strive to enhance knowledge about norm diffusion, rather than to generate a new theory about this particular issue, it is most appropriate to

\footnotetext{
Birks and Mills 2011, p.29.

Birks and Mills 2011, p.166.

10 Butler and O'Reilly 2010.

11 Birks and Mills 2011, p.20.
} 
use a limited set of grounded theory techniques. The study results are based on the following set of grounded theory methods recommended by Birks and Mills (2011): ${ }^{12}$ initial coding and categorization of data, concurrent data generation and collection and analysis, constant comparative analysis, theoretical sampling, intermediate coding, and memo writing. Together, these techniques constitute a detailed and comprehensive procedure of analyzing a huge amount of different types of qualitative data in a systematic manner, and provide new theoretical insights. I did not follow the final steps proposed by Birks and Mills - identifying a core category, advanced coding a theoretical integration, and generating theory - because I did not intend to develop a new theory. The following paragraphs briefly describe the six grounded theory techniques (based on Birks and Mills's selection) used in the present dissertation. While in reality the researcher applies (part of) these techniques simultaneously, I explain them one by one to facilitate comprehension.

Initial coding and categorization of data is the first step of data analysis and involves the identification, coding, and categorization of words or sentences in the data. During this initial analytical step, the corpora are fragmented and assigned codes and categories that allow a systematic comparison of the data.

The method of concurrent data generation and collection and analysis means generating and collecting data with an initial purposive sample, which is subsequently coded and categorized before additional data is collected or generated. Consequently, a category is called saturated when no new codes belonging to the category emerge from the data analysis. At this point, grounded theorists speak of theoretical saturation. Subsequently, constant comparative analysis compares new codes and categories to already existing ones, allowing for new insights to emerge from the data.

Theoretical sampling is defined as an iterative process for constant comparative analysis, allowing the researcher to assess the saturation of the previously developed categories and the need for additional information. ${ }^{13}$

Whereas grounded theory specialists refer to initial coding as the first step of data analysis and as a process by which the data are fractured, during intermediate coding the data are reconnected in a more abstract manner. ${ }^{14}$ Intermediate coding is thus the second major step of data analysis after initial coding. The interplay of these grounded theory methods means that the researcher moves

\footnotetext{
12 Birks and Mills 2011.

13 Birks and Mills 2011, p.166.

14 Birks and Mills 2011, p.12.
} 
between initial and intermediate coding throughout the process of concurrent data generation or collection and analysis, and the constant comparative analysis. ${ }^{15}$

Lastly, memo writing is an essential analytical process, ${ }^{16}$ during which the reflexive researcher records his or her considerations analytical insights, choices and ideas in relation to a research project. ${ }^{17}$ This activity trails the research journey from the very beginning to the end, and it allows the researcher to record initial thoughts and develop them in a reflexive manner as the analysis progresses.

\subsection{Case selection}

Because of AI's overall structure as a transnational network with an international headquarters and representations in numerous countries, scrutinizing the organization's interest in women's rights must occur at both the international and national levels. I chose the IS and the ICM as representative of the international level. My case sampling purposefully followed four criteria. First, the origin of AI as a Western human rights organization founded in the middle of the Cold War limited the range of potential sections to those in Western countries. Second, the countries' official language(s) served as another criterion. I had to select potential cases according to my language skills, which are limited to German, French, and English. Third, I strove to include sections that differed in their work on women's rights. The fourth criterion concerned the study's feasibility in terms of accessing archival materials and contacting potential interviewees.

Based on the first three criteria, I sought to include three European AI sections in my research: the Swiss, the German, and the Irish or the French sections. The impossibility of accessing the necessary data at the Irish and the French sections finally led me to only consider the Swiss and the German sections. Because it was a Western section, used the languages I am competent in, and faithfully followed the International Secretariat's guidelines about incorporating women's rights into its regular work, the Swiss section was a natural choice from the beginning. First, the Swiss section of AI (AICH) is one

\footnotetext{
15 Birks and Mills 2011, p.11-12.

16 Birks and Mills 2011, p.175.

17 Birks and Mills 2011, p.175.
} 
of the oldest ${ }^{18}$ and largest ${ }^{19} \mathrm{AI}$ sections in terms of its members and funding. Its relatively early foundation meant that the integration of women's rights into the organization's activities could be documented from its very beginning. Second, the necessary data could be collected and generated in German or French. Third, as a first explorative interview with the former SVAW campaign coordinator revealed, the Swiss section's attitude towards the integration of VAW into its activities was comparatively mild. AICH seemed to have been neither a precursor, nor very reluctant to consider this question. The last criterion concerns the feasibility of the research project. Due to previous professional exchanges with the Swiss section's SVAW campaign coordinator, I was certain I could collect and generate sufficient data.

The data generated at the Swiss section allowed me to simultaneously collect the necessary information on how other European sections integrated VAW into their activities and on the feasibility of data collection and generation in them. Finally, it helped me to purposefully select the German section as another case study. In fact, as the fifth largest AI section in terms of its financial contribution to the IS, only behind the US, the UK, the Netherlands, and France, the German section is representative of other Western AI sections. ${ }^{20}$ It has remained one of the most powerful sections from the time of its founding. As I mentioned before, applying the technique of concurrent data collection, generation and analysis allowed me to identify differences in how the work on women's rights was organized in the German section compared to the Swiss section. This made the comparison between the German section and the Swiss section potentially interesting.

18 AlCH was founded in Zurich in 1970, nine years after the foundation of Amnesty International as a global movement. The first so-called prisoner adoption groups already existed in the 1960s (Clark 2001).

19 As of 2004, the Swiss section was the sixth largest Al section behind those in the USA, the UK, the Netherlands, France, and Germany (Hopgood 2006, p.197).

20 Hopgood 2006, p.197. 


\subsection{Data corpora}

\subsubsection{Criteria for data collection and generation}

I chose the data at the core of the analysis according to specific criteria relating to the research topic and the research questions. I strove to triangulate data and methods to enhance my study's validity and cross-check and corroborate my findings. ${ }^{21}$ I used various types of data: written archival materials (both physical and stored and accessible electronically), interviews, and secondary literature. ${ }^{22}$ I treated published literature on AI as data and not only as a theoretical framework, as other forms of research do. ${ }^{23}$ As I describe in greater detail later, these types of data required different data gathering methods.

I applied two specific criteria to my data selection, which are both related to the research topic. First, my research's emphasis on women's rights limited the selection of the data to the period over which AI engaged in work on women's rights issues. In the case of written data, documents had to be published between the mid-1980s and 2010. Potential interviewees were chosen according to their engagement with AI during the same time period.

Second, data were selected according to their main content. Since the study requires accounting for the institutional context in which AI's work on issues of VAW evolved, I chose data containing information on the structure and functioning of AI, as well as data primarily concerning the organization's work on women's rights. The same criteria led me to conduct interviews with two sorts of people: so-called experts, who had worked on the issue of women's rights at the international or the national level within $\mathrm{AI}$ - either officials or activists or external people with specific knowledge related to the research subject - and ordinary AI officials and activists, who witnessed the integration of women's rights into the organization's activities because of their longterm engagement within AI.

$21 \quad$ Lamnek and Krell 2016.

22 Maggs-Rapport 2000.

23 Birks and Mills 2011, p.80. 
In addition to purposive sampling, I used snowball sampling ${ }^{24}$ to identify appropriate interviewees. ${ }^{25}$ With the information collected from interviews and written archival documents, I identified suitable interviewees and could determine the number of interviews required to gain adequate information for my research. Thus, it was the grounded theory methods of concurrent data collection, generation and analysis, and theoretical sampling that enabled me to select suitable interviewees. Cross-checking the lists of potential interviewees provided by interviewed persons and taking into account information found in the archival material helped me make sure that I had an adequate number of interviews.

Data collection and generation took place over a period of nearly four years. While typical for grounded theory research, data analysis started with an initial sample and was subsequently completed with additional data using the technique of theoretical sampling. The following section provides details on the data corpora containing all the data collected and generated over the duration of the study. As mentioned above, the data corpora consisted of three types of data, which were assembled concurrently: written first-hand archival materials, ${ }^{26}$ interviews, and secondary literature. Including data from both the international and national levels, the corpora consisted of nearly 800 archive documents, 49 interviews, and 20 secondary publications. ${ }^{27}$

\section{Noy 2008.}

25 In this situation, I relied on the contact information provided by previously interviewed persons or the assistance of persons external to my research. Most of the potential interviewees I approached agreed to give me an interview. Some did not respond to my request and others refused to be interviewed explaining that they did not have time to participate. However, contacting them was not useless, as they repeatedly served as informants.

26 They include personal notes and letters from staff and activists as well as (confidential) documents, such as meetings minutes and letters from Al bodies at the Swiss, the German, the US, the Canadian, and the Austrian sections.

27 I included the following secondary literature in the data corpora: Scoble and Wiseberg 1974; Ennals 1982; Steiner 1991; Clark and McCann 1991; Besset 1991; Thakur 1994; Fried 1994; Baehr 1994; Sidhu and Chatterjee 1995; Bahar 1996; Watson 1997; Pack 1999; Welch 2001; Mutua 2001; Clark 2001; Buchanan 2002; Hopgood 2006; Michel 2009; Lake and Wong 2009; Kelleher and Bhattacharjya 2013. 


\subsubsection{Written archival documents}

The written first-hand documents (primary sources) were found in the following three archives. First, since important portions of the IS archives housed at the International Institute of Social History in Amsterdam have been closed to the public, I used the intranet-based AI document library called AIDAN Search. The latter is an online tool for accessing documents related to the international level of the organization. It is comprised of AI-indexed documents, which have been published by the IS since 1961. Second, I used catalogued electronic and physical documents from the Swiss section archives. Lastly, I used uncatalogued electronic and physical documents from the German section archives.

I analyzed about 400 documents focusing on the international level. These first-hand documents consisted of IEC Information bulletins and IEC policy papers regarding mandate development; resolutions; reports and decisions of different ICMs; Integrated Strategic Plans (ISP) (detailed long-term plans of AI activities for a period of six years); campaign agendas; reports and strategy papers; meetings agendas and minutes; and consultation papers on mandate development.

The same types of first-hand archive documents were included for the two case studies on AI's national level: meeting minutes, communication papers, and campaign materials. However, there was a sizable difference in the amount of data collected on each section. The corpora for the Swiss section were larger than that for the German section. For the Swiss section, I analyzed approximately 300 documents. These documents consisted of: 1) minutes of different meetings; ${ }^{28}$ 2) communication papers, such as letters, emails and faxes; 3) campaign documents related to planning and evaluation. For the German section, I analyzed about 110 first-hand documents. ${ }^{29}$ These documents

28 Minutes of the Internationale Kommission, the Groupe de travail Gender Action Plan (the working group Gender Action Plan), the Groupe Action Urgente Femmes Chêne-bourg, the Croupe Nord-Vaudois, Frauengruppe Bern, the Frauenrechtskommission, the Groupe de Coordination Femmes, the Frauennetzwerk, the Delegiertenversammlung/Jahresversammlung.

29 The analyzed archival material included the documents consulted at the Cerman secretariat in Berlin, which contained documents about the section's specific work on women's rights from 1993-1995, minutes of the Annual general assemblies 19791993, ai-info 1981-1995. I could not access the minutes of meetings of the AKMenschenrechtsverletzungen an Frauen because these documents are not archived at the secretariat but are distributed among the respective spokespersons. 
consisted of: 1) minutes from annual meetings ${ }^{30}$; 2) communication papers, such as letters, emails, faxes and articles from the section's magazine, ai-intern; 3) campaign documents related to planning and evaluation. For ethical reasons, archive material such as letters, emails or personal statements from individual AI members or staff are anonymized by using a cross-referencing system for pseudonyms.

\subsubsection{Interview data}

I conducted 49 interviews in three languages (German, French, and English) between September 2011 and November 2015. The interviews were conducted face to face (32), by phone (9) or via Skype (7). ${ }^{31}$ The majority of the interviewees agreed to being identified by name. ${ }^{32}$ Nevertheless, I decided to anonymize the interview data for ethical reasons. I removed direct identifiers, such as the interviewees' names, and replaced them with pseudonyms. That is why I dispensed with attaching a list that contains the names of my interviewees.

For the international level component of my analysis, I conducted expert interviews with four (former) IS officials and two external individuals. The former IS staff members I interviewed were specifically chosen among a small group of officials who had worked on women's rights issues between 1989 and 2010. Additionally, I retained four interviews originally conducted for a third case study, as they also provided relevant information for the international level.

For the Swiss section, I conducted 7 expert interviews and 24 interviews with ordinary activists or officials. For the German section, I conducted 7 expert interviews. I was not able to conduct interviews with ordinary officials and activists from the German section. While all potential interviewees were identified according to the two criteria mentioned above, I applied two additional criteria when looking for potential interviewees among ordinary activists at the Swiss section. These criteria were the size and location of the AI

30 Jahresversammlung.

31 Even though I didn't include the Irish or French sections as case studies, I kept the interviews with officials and activists from these sections in the data corpora because they contained relevant information. In fact, many of their statements related to Al's women's rights work in general and were not only about their section's activities.

32 Generally speaking, people from the Swiss section agreed to be identified, whereas officials at IS or Germany and activists from the German section preferred anonymity. 
group $^{33}$ to which the activists belonged. I interviewed members of AI groups in both the German and French parts of Switzerland. ${ }^{34}$ Furthermore, I selected groups located in cities as well as groups working in the countryside.

Given the size of AI, the number of interviews may appear meager at first glance. Nevertheless, the number of interviews is sufficient for two reasons. First, because only few people within AI worked as officials or activists on issues of women's rights both internationally and within national sections over the two decades covered in the study, the number of potential expert interviewees able to provide relevant information on why and how AI integrated VAW into its activities is relatively small, compared to the overall number of officials and activists. Theoretical sampling allowed me to purposefully select interviewees, and it ensured that I included those officials and activists who were involved in AI's work on women's rights between 1989 and 2010. I therefore reached the people having institutional knowledge on the issue. Second, interview data was only one of three types of data included in the analysis. As previously explained, I applied data and methods triangulation to collect a significant amount of first-hand archival material and about a dozen secondary literature sources that allow to corroborate and cross-check the findings. ${ }^{35}$

As I mentioned before, I conducted two forms of interviews: expert interviews and interviews with ordinary AI officials and activists. For both interview types, I created questionnaires that combined main questions, follow-up questions, and probes to structure the conversations. ${ }^{36}$ Because of the study's focus, people had to be asked about things that happened in the past. Since people tend to forget or only partially remember events that they experienced years ago, there was an implicit potential for information loss. By resorting to oral history, a common method in the historical sciences, I tried to account for this bias.

In oral history, researchers explore people's experiences of historical events. ${ }^{37}$ Accordingly, follow-up questions were formulated so as to

A group must consist of at least seven active members. A group of this size implies that the group is implementing the campaigns proposed by the national secretariat.

34 Because of the language barrier, groups located in the canton of Tessin were not considered.

35 Lamnek and Krell 2016.

36 Rubin and Rubin 2005.

37 Ritchie 2003; Ritchie, Donald A. (Ed.) 2011; Kurkowska-Budzan and Zamorski 2009. 
chronologically trace past events and how interviewees experienced them. ${ }^{38}$ Whereas the order of the questions was similar for both types of interviews, the questions diverged and were adapted to the interviewees. One was used in expert interviews at the international level, another one in expert interviews at the Swiss section, one for the ordinary activists and officials at the Swiss section, and one in the expert interviews at the German section.

A good interview is determined not only by the questionnaire and the wording of its questions, but also by the interviewer's skills. In fact, achieving openness, confidence, and a small power imbalance between me as an interviewer and the informants is paramount to ensure the validity of the interview situation and the associated data quality. ${ }^{39}$ For privacy reasons, I suggested not mentioning the interviewees' real names when quoting their statements, opting instead to use pseudonyms. This procedure enhances openness and trust during the interview.

As I already briefly mentioned before, it was relatively easy to collect and generate data for the Swiss case study. Being a member of AICH and having previously collaborated with the section's SVAW campaign coordinator proved to be helpful in accessing the archive and identifying potential interviewees. In fact, throughout the research project the former SVAW campaign coordinator was a very important informant. She introduced me to the section's information and documentation officer who later became fundamental to my research project. In fact, he facilitated the consultation of catalogued documents at the archive, helped me find documents that were not yet catalogued, and provided me with internal address lists containing details on staff members and groups. Because I was a member of one of the Bernese AI groups, I was also given access to normally confidential information, such as minutes from the meetings of the section's executive committee.

Accessing the German section archives and finding potential interviewees in Germany turned out to be a rather difficult endeavour, at least at the onset of my field work. AI Germany's former Secretary-General eventually helped me gather the necessary data for the German case study. He provided me with names of (former) activists and officials involved in women's rights activities in the German section. Furthermore, showing personal interest in my research, he invited me to Berlin and arranged a visit to the archive where he himself was conducting research at the time. 


\subsection{Data analysis}

The data corpora consisted of many written first-hand archival materials, 49 interviews, and a small amount of secondary literature. I used the qualitative data analysis software AtlasTi to organize/code/cross-reference the interview transcripts.

As the first coding step, initial coding, needs a line-by-line analysis of the text of interest. Applying this procedure to my first interviews and to a couple of archival documents on Al's first activities related to women's rights resulted in approximately 100 codes. Concurrent data collection and generation and analysis required me to constantly compare new codes and categories to pre-existing ones. Constant comparative analysis was thus part of the process of concurrent data collection, generation and analysis.

At the same time, theoretical sampling allowed me to assess the saturation of the previously developed categories and evaluate the need for additional information. ${ }^{40}$ I identified the data to be integrated into the data corpora employing the theoretical sampling technique according to the data's ability to contribute to the research topic. ${ }^{41}$ Additional data were collected and generated over a period of approximately four years. While my initial codes were very close to the data, codes became more and more abstract as my research progressed. Later, through intermediate coding, I reduced the number of codes by merging similar codes or redefining them as more abstract concepts. When a code was applied frequently, I developed sub-categories based on the content coded within them. ${ }^{42}$ I also developed higher-level categories as needed. At the end of intermediate coding, when no new codes emerged and the collection and generation of data came to an end, I established a coherent and concise coding system with roughly 200 codes subdivided into 10 overarching categories, 75 categories and 115 subcategories.

The final analysis and the interpretation of the data are thus based on the use of initial and intermediate coding by means of concurrent data analysis, constant comparative analysis and theoretical sampling. The structure of the following three empirical chapters $(6,7$, and 8$)$, which provide the findings of my research, reflects the coding system developed throughout the application of the aforementioned grounded theory methods.

\footnotetext{
40 Birks and Mills 2011, p.166.

41 Birks and Mills 2011, p.25.

42 Friese 2011, p.6.
} 



\section{Al's structure, decision-making, and policy implementation}

Because AI's organizational context is pivotal for the comprehension of AI's growing interest in issues of violence against women, this chapter details the development of AI's work and highlights some essential organizational characteristics, decision-making processes, and policy implementation practices. Chapters 7 and 8, which analyze in detail AI's work on issues related to violence against women, build on these foundations. Because the focus of my study concerns the period 1989-2010, chapter 6 concentrates first and foremost on AI's functioning during these years. The present chapter starts with a brief overview of the development of AI's work in general (section 6.1). Section 6.2 concentrates on three essential organizational characteristics. Section 6.3 describes AI's internal structure at the international level. I describe the International Secretariat, the International Executive Committee, and the International Council as the main components of the AI network at the international level. Section 6.4 details the structure of the Swiss and the German sections. Finally, section 6.5 offers details on the processes of decision-making and implementation at the international and the national levels.

\subsection{Brief overview of the development of Al's work in general}

Conceived as an international movement for the release of prisoners of conscience and mainly composed of volunteers in the 1960s, Amnesty International has, over the course of the following decades, changed tremendously to become a complex and highly professional international human rights NGO. Its membership has grown continually, despite some periods of stagnation, 
and many new sections have emerged. ${ }^{1}$ AI's overall work was defined by its mandate limited to civil and political rights and distinguishing between promotional and oppositional work until 2001. ${ }^{2}$ AI only defended a limited set of civil and political rights; by promoting all human rights, it emphasized the indivisibility, the universality, and the equal importance of all human rights. ${ }^{3}$

During the 1990s, the changing pattern of human rights violations around the world increasingly challenged this specific focus. During this period, AI started working on abuses committed by non-governmental entities and decided to hold governments responsible for their inaction in the face of abuses by non-state actors. In addition to its work against the violation of a limited number of civil and political rights, AI also enlarged the scope of its promotional work during this decade. It began to oppose not only specific practices but also "grave violations" against certain sets of rights. ${ }^{4}$ Consequently, while keeping its traditional individual case work for the release of prisoners of conscience, AI increasingly focused on specific groups of people subjected to mass human rights violations. ${ }^{5}$

In light of these changes in its mandate, AI also modified its activities. Starting in the 1980s, AI began to professionalize its lobbying work; the latter

1 For the growth of the movement in terms of number of sections, see appendix 2.

2 Al's statute defined promotional work as "promoting awareness of and adherence to the Universal Declaration of Human Rights and other internationally recognized human rights instruments, the values enshrined in them, and the indivisibility and interdependence of all human rights and freedoms" (Amnesty International: Statute of Amnesty International as amended by the 22nd International Council, meeting in Ljubljana, Slovenia, 12-20 August 1995, 1995, p.1). Its promotional work focused on the following three techniques: "human rights awareness, training and advocating the ratification of international human rights instruments" (Amnesty International, International Secretariat: Inside the mandate, December 1995, p.3). At the same time, since 1991, Al has defined its oppositional work as "campaigning to oppose grave violations of a limited number of the rights mentioned in the declaration, namely, the detention of prisoners of conscience, unfair trials for political prisoners, torture and the death penalty, and 'disappearances' and extra-judicial executions" (Amnesty International, International Secretariat: Inside the mandate, December 1995, p.3).

3 Amnesty International, International Secretariat: Inside the mandate, December 1995.

4 Amnesty International, International Secretariat: Report of the Standing Committee on Mandate to the 1995 ICM, 14.07.1995.

5 The thematic campaigns on torture, such as the 1995 campaign Human Rights are Women's Rights, were examples of these advocacy activities opposing mass human rights violations. 
advocated for respect of the United Declaration of Human Rights in the UN and other international and intergovernmental organizations. The organization also started to engage in educational activities seeking to enhance its members' and the broader public's understanding of current human rights standards. Further, AI began to collaborate with other NGOs in the 1990s a practice that had been a taboo for many years. As I explain later, women's rights groups were among the first organizations with which AI started to collaborate.

By abandoning its mandate and adopting the mission including civil and political, as well as economic, social, and cultural rights in 2001, the organization radically changed its objectives and adapted its working methods accordingly. From then on, beside its traditional focus on the International Covenant on Civil and Political Rights, AI also engaged in activities promoting the respect of economic, social, and cultural rights. Further, the delegates agreed to address non-state actors' responsibility for abuses committed in the private sphere at the 2001 ICM. The following extract of Irene Khan's opening speech to the 2003 ICM illustrates the significance of the 2001 policy changes for AI:

"Obtaining the release of a prisoner is like a shot of tequila for Al members - an exhilarating experience, directly linking our own compassion with the fate of the individual. But as we expand our work on discrimination and [economic, social and cultural rights], our exhilaration must be with the release of the prisoners of poverty, of the prisoners of prejudice, of the prisoners of powerlessness. This is a qualitatively different business!"6

Conscious of the need to adapt its working methods to the important overall policy change, the organization did so concurrently. At the 2001 ICM, AI abandoned the Work on Own Country policy (WOOC policy), which prohibited national sections from undertaking their own research on human rights violations in their country, giving each section the ability to do research on and oppose violations of human rights in their own country. ${ }^{7}$ national Council of Amnesty International, 2003, p.12.

7 With this principle, Al aimed to protect its own members from being "held responsible for the passing of information by their government" (Ennals 1982, p.67). At the same time, this rule reflected one of the main features of Al's ethical culture - its commitment to international solidarity (Winston 2001, p.31). 
The adoption of the mission also entailed a shift from campaigning that focused on countries and individuals to thematic campaigning. Further, AI ceased distinguishing between promotional and oppositional work after the adoption of the mission. As I detail in chapter 8, these fundamental changes also influenced AI's work on issues of VAW. However, the central principles of the organization, such as impartiality of research, financial independence, independence from governmental influences, nonviolence, and international solidarity remained unchanged. ${ }^{8}$

\subsection{A gendered human rights NGO}

Evidence shows that gender and religion ${ }^{9}$ are important social categories that have structured AI from its beginnings. AI had traditionally been a highly gendered organization, with a majority of female activists and men dominating the organization's leadership positions. As the introduction highlights, the long-lasting male dominance of AI's leadership helps explain the gender bias inherent to AI's traditional work. Like many other Western human rights NGOs, AI had white male founding fathers. ${ }^{10}$ In fact, AI basically attracted two distinct groups of persons in its early years. First, a number of white British men grouped around the lawyer Peter Benenson, ${ }^{11}$ founder of AI. Benenson's peers "constitut[ed] AI's informal senior advisory groups known as the 'Godfathers."." The second was a group of predominantly female volunteers who ran the organization and had little prior experience with human rights issues. Benenson only appointed men to serve as Secretary Generals and to other leadership positions in the organization's first years. The early foreign missions were carried out by men. ${ }^{13}$

\footnotetext{
8 Ennals 1982; Winston 2001.

9 Here, I use the term 'religion' to refer to the prevailing religious communities in a specific geographical region.

10 Mutua 2001, p.151-153.

11 The group of like-minded friends was composed of Louis Blom-Cooper, a well-known attorney; Eric Baker, a Quaker academic who was, at the time, working for the secretary of the National Peace Council in Britain; and David Astor, editor of The Observer (Ennals 1982).

12 Buchanan 2002, p.589.

13 Buchanan 2002, p.590.
} 
At the same time, women played an important but subsidiary role in AI's first years. While men predominated in the organization's leadership positions at least until the end of the 1990s, women constituted the majority of its membership and of lower-level staff within the IS and in many Western sections. ${ }^{14}$ Most of the leading positions at the IS were held by men for many years. ${ }^{15}$ Internal figures presented by Hopgood show that $63 \%$ of the IS staff in 2002 were women, with a disproportionate number of women in lower positions. ${ }^{16}$ The representation of women within sections followed similar patterns. In fact, women constituted the majority of members in most of the sections in the 1980s: "AI France (but that is also the case for the majority of the sections) had an important female majority among their ranges. In total, two of three members are women!" ${ }^{17}$ Nevertheless, they were a minority of higher-level staff within the secretariats. ${ }^{18}$

In addition, AI's Secretary Generals (SG) had always been male until the nomination of the first female SG and deputy SG in 2001. ${ }^{19}$ In fact, the IEC appointed Irene Khan as SG and Kate Gilmore as deputy SG, which was related to the decision to launch a first thematic long-term global campaign on VAW. Even though reliable data on the share of women in AI's management position are lacking, internal information indicates that men's predominance began to shrink within the headquarters in the 1990s. As the following graph illustrates, there was a growing number of women at least among the IS deputy SGs from 1992 to 2001.

Graph 1 sheds light on the share of women in the members of the IEC and among the Deputy SGs ${ }^{20}$ at the IS between 1989 and 2011 . Because of the twofold structure of the study, I first focus on the period from 1989 to

14 There exist no comprehensive data on the representation of women and men within Al as a whole. Thus, the findings are based on secondary literature and archival materials.

15 Besset 1991, p.156.

16 Hopgood 2006, p.149.

17 Besset 1991, p.155: "Amnesty-France (mais il en va de même dans la majorité des sections) comporte une majorité écrasante de femmes dans ses rangs. Au total, sur trois adhérents, deux sont des femmes !".

18 Besset 1991; Frey: Cender Audit bei ai Deutschland-die Ergebnisse, August 2002.

19 The male SGs were: Peter Benenson (1961-1966), Eric Baker (1966-1968), Martin Ennals (1968-1980), Thomas Hammarberg (1980-1986), Ian Martin (1986-1992), Pierre Sané (1992-2000).

20 Calculated in comparison to the total number of Deputy Secretary Cenerals and Finance Directors fluctuating between two and six. 
Graph 1: Representation of women in the IEC 1989-2011 and among Deputy SGs, 1992-2001

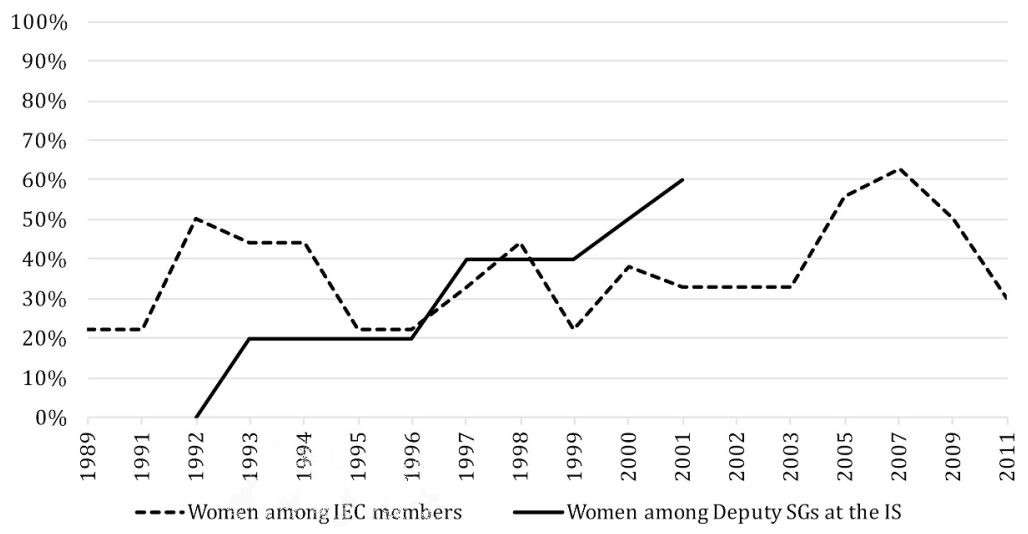

Source IEC members: Minutes of IEC meetings (1992-2003), reports from the International Council Meetings (ICM) (2005, 2007, and 2009), Annual Reports (1989 and 1991). Source Deputy SGs: minutes of meetings of the IEC (December 1992-March 2001)

2001 and then on the period between 2002 and 2010 . Women represented between $22 \%$ and $50 \%$ of the members of the ICMs in the 1990 . No general tendency is apparent for them during this time period. At the same time, the proportion of women in leading positions at the $\mathrm{IS}^{21}$ increased steadily from 0\% in 1992 to $60 \%$ in 2001 . Given that AI's work on issues of VAW began in the late 1980 and increased during the 1990s, the increase in the proportion of women in IS management positions during this period may have contributed to the increase in AI's work on issues of VAW. However, these quantitative data do not suffice to explain AI's growing interest in issues of VAW because of their limited reliability and because such a tendency could only be observed within the IS but not among the members of the IEC. As I show later, an indepth analysis of the transformation process focusing on officials and activists demonstrates the importance of feminist strategizing.

The proportion female IEC members in the 2000 s increased and, for the first time, women represented an average of $50 \%$ of the IEC members between

21 SG, senior directors, deputy SGs, and Finance Director. 
2003 and 2009. The lack of data makes it impossible to track the share of female Deputy SGs at the IS after 2001. Aware of the limited reliability of these data, the generally higher share female IEC members in the 2000 s suggests that AI would have been successful in making issues of VAW part of its overall work. As I show later, even though the SVAW campaign signified a tremendous step towards a more gender-sensitive human rights work, AI did not succeed in making women's rights part of its DNA.

During many years, women were largely absent from the organization's management positions at the IS and within sections. In contrast to their status in the large Western sections, they have always constituted a minority in the membership of African and Middle Eastern sections. ${ }^{22}$ Evidence indicates that even though the share of women in AI's leadership positions increased during the period under scrutiny, and even though women reached the organization's highest positions - SG and Deputy SG, - the masculine working culture within AI's headquarters persisted. In fact, a female IS staff member described the IS culture as a masculine culture of "heroism and self-denial and nothing touches me, and I will break at nothing. [...] I shall be right. I shall produce. [...] And I will never show vulnerability either intellectually or emotionally." ${ }^{23}$ In their assessment of AI's women's rights work, Kelleher and Bhattacharjya point to female IS staff's perception of the internal decisionmaking processes as "deeply patriarchal in how they run the organization." ${ }^{24}$ Referring to the under-representation of women and to Al's cultural origin in Western Europe, Hopgood (2006) described "a white and masculine working culture." 25

The Christian religious and cultural background of European societies has shaped AI from the moment of its founding: "Christianity, culturally and spir-

According to an $\mathrm{Al}$ internal document from 2004 "the most female members are to be found in Europe and the Americas" whereas only $30 \%$ of the members in Africa are women. Only $10 \%$ of the members in the Benin and the Chana sections were women, and in the Senegal and the Gambian sections women represented $30 \%$ and $36 \%$, respectively, of the membership by the year 2000 (Amnesty International, International Secretariat: Women and their role in the Amnesty International movement, 19.02.2004, p.3. Hopgood 2006; Amnesty International, International Secretariat: Female Genital Mutilation: An evaluation of the work of Al in four West African countries, July 2001).

23 Hopgood 2006, p.148.

24 Kelleher and Bhattacharjya 2013, p.10.

25 Hopgood 2006, p.147. 
itually, was an integral part of Amnesty's origins." ${ }^{26}$ Hopgood (2006) located the cultural and social background of AI in the "tradition of ecumenical European Christianity" 27 and saw Al's origin as a response to the decreasing importance of the churches ${ }^{28}$ in defining the moral values of modern Europe in the early 1960s. While AI's statute did not mention God, and many officials and activists were neither religious, nor Christian, AI's initial symbols (such as the candle), its organizational principles of nonviolence, and the operational mechanism behind AI's case work on prisoners of conscience, among others, made Hopgood define AI as a "secular Free Church." 29

While AI's members diversified over the years as AI's work developed, the organization professionalized, and the movement grew (adding new sections and structures in the South), evidence indicates that religion and, more specifically, Christianity have continued to shape parts of the movement. In fact, this cultural specificity manifests in AI's daily work at the sectional level, as the example of AI activist groups cooperating with local parishes in the latter's activities shows. As I highlight later, the organization's closeness to the $\operatorname{church}^{30}$ is more or less pronounced depending on the section.

\subsection{Internal structure - the international level}

The IS, the IEC, and the IC are the main components of the AI network at the international level. The IS, AI's headquarters and central node of the network, is based in London. ${ }^{31}$ Led by the Secretary General and a team of Senior Directors, it is responsible for the daily business of the organization and carries out the majority of the research and campaigning work (concentrated in the IS's Research and Campaigning departments). Since the 1990s, research, campaigning, lobbying, and outreach work have been the core activities of

\footnotetext{
26 Hopgood 2006, p.18.

27 Hopgood 2006, p.8.

28 Hopgood does not distinguish between different churches.

29 Hopgood 2006.

30 I use the term 'Church' to designate the predominant religious communities or Landeskirchen in Switzerland and Germany, which are the catholic and the protestant churches.

31 At the beginning of the 2010s, Al started a restructuration process throughout which many regional programs at the headquarters were delocalized to regional hubs on other continents.
} 
the several hundred human rights professionals working at the IS. They collect and verify information and facts about human rights violations, develop reports, and plan and prepare urgent actions and campaigns that sections subsequently implement. The WOOC rule, which prohibited national sections from undertaking their own research on human rights violations in their country, gave the IS exclusive responsibility over research for many years, until it was abandoned in 2001.

As AI's executive body, the IEC - composed of nine people, all AI members from sections, except for one IS representative and a treasurer - is in charge of the leadership of the AI network worldwide and appoints the Secretary General. ${ }^{32}$ According to AI's statute, the IEC is "responsible for the conduct of the affairs of AI and for the implementation of the decisions of the International Council (IC)." 33 Besides its pivotal role in supervising the activities of the IS, AI's statute gives the IEC the ability to submit resolutions to the ICM, AI's decision-making body where representatives of sections make decisions concerning Al's mandate/mission or its statute in the biannual meeting, organized in a different country section each semester. As I detail below, only the ICM is allowed to make decisions on AI's mission or statute.

32 Four so-called standing committees advised the IEC in specific thematic domains, such as finance, mandate development, or the organization of the movement until 2001. The four standing committees were: The Standing Committee on the Mandate (SCM), The Standing Committee on Research and Action (SCRA), The Standing Committee on Organization and Development (SCOD), and the Standing Committee on Human Resources, Information and Financial Management (SCHIFM) (Amnesty International, International Executive Committee: IEC Information Bulletin No. 23, April 1998a). Later, the so-called Chairs Forum led by the Steering Committee and composed of section chairs and other delegates was appointed by sections as an intermediate structure of governance between ICMs. The Chairs Forum contributes to the development of the ISP, supervises the implementation of Al's policies and priorities, and meets annually (Amnesty International: Report and decisions of the 25th International Council of Amnesty International, 2001, p.141-142). In addition, a so-called Directors Forum composed of senior and other IS managers functioned as a management forum and also met annually (Amnesty International: Report and decisions of the 25 th International Council of Amnesty International, 2001).

33 Amnesty International: Statute of Amnesty International as amended by the 22nd International Council, meeting in Ljubljana, Slovenia, 12-20 August 1995, 1995, p.2. 


\subsection{Internal structure - the national levels}

At the national level, AI's network is composed of country sections or socalled "structures." 34 Whereas the IS is responsible for the preparation of the case work and campaigns, sections concentrate on campaign implementation, fundraising, and membership development. ${ }^{35}$ According to AI's statute, national sections are autonomous in the organization of their work. Most of the sections are organized as associations with a General Assembly supervising the section's activities and electing the board of directors that appoints the section's secretary generals. ${ }^{36}$ Most AI sections are made of one Secretariat $^{37}$ and of a network of various activists groups. ${ }^{38}$ AI groups have been key for the functioning of their respective sections for many years, as they are largely responsible for fundraising. Through their activities, groups raise funds and give them to their respective secretariat. The secretariats in turn always transfer a large amount of resources to the IS according to a defined ratio. For example, in 2010, the Swiss section gave 30\% of its income to the IS. ${ }^{39}$

AI's human rights work has historically been based on the groups' activities fighting for the release of prisoners of conscience. Thus, activists have been key to Al's human rights work. Until the beginnings of the 1990s, groups were each assigned three verified prisoner of conscience cases: one from the West, one from a communist state, and one from the South. Although the adoption of prisoners has no longer been bound to a state's political position since the end of the Cold War, case work has continued to be key for the engagement of many activists. Evidence shows that case work on a particular prisoner has often entailed that activists develop a personal relation

34 In contrast to sections, structures are smaller and are therefore often not economically auto-sufficient and do not financially contribute to the IS. But their work depends on the IS's and other wealthier sections' support. In contrast to Al's representations in the Northern hemisphere, most of Al's branches in the South are so-called structures. Sections had been essential to fundraising as voluntary donations by section members (groups or individuals) have constituted the organization's main income.

36 Typically, the members of the board of directors are long-term Al activists exercising their functions on an honorary basis. In contrast, people working at Al's national secretariats are awarded a salary.

37 Some larger sections, such as the German section, have additional regional offices.

38 Such as local groups, thematic groups, country groups, youth groups, etc.

39 Jegher 2011, p.30. 
to their prisoner of conscience. The fact that activists feel like working "for somebody, for an individual" ${ }^{\circ 0}$ has motivated their engagement at AI. As I highlight later, many long-term activists have complained of losing this personal relation with the opening of the organization's working spectrum to economic, social, and cultural rights in the 2000 s.

\subsubsection{The Swiss section}

This section begins with a short overview of the Swiss section's development from its origins in the 1960 s to 2010 , before it illustrates the section's structure and its functioning. I then briefly highlight the gendered composition of the section's membership and staff and the section's closeness to the church, and identify the section's distinctive particularities: its constructive culture of interactive debate and its general openness to policy changes.

As I have briefly mentioned before, the Swiss AI section is one of the oldest and largest AI sections member-and funding-wise. In Switzerland, the first AI groups had already formed by the 1960s, with ten local groups finally establishing the Swiss section in Zurich on 15 October 1970, nine years after AI's foundation as a global movement. ${ }^{41}$ Group-wise, the section grew until 1993 when it comprised 93 groups. ${ }^{42}$ That number decreased to about 80 in 2011. In the same period, the Secretariat developed a professional structure: one employee started working there part-time in $1976^{43}$ and personnel had increased to 47 employees and 11 trainees by $2010 .{ }^{44}$

Since its formation, the section has been organized as an association with an Executive Committee (EC), ${ }^{45}$ an Annual Delegates Assembly (the section's decision-making body), ${ }^{46}$ a Secretariat headed by a Secretary General and a

40 Ganzfried: Interview by phone with B.V., 07.06.2013: "Pour quelqu'un, pour une personne.".

41 Chevalier: Mémo chronologique de la création de la section suisse 1964-1975, 26.04.2001.

42 See Appendix 2 for details.

43 From 1970 to1976, a single volunteer was in charge of the work.

44 Amnesty International: Stellenentwicklung im Sekretariat, 2010.

45 In 1978, the EC was reorganized and divided into two bodies: the EC and a Management board composed of senior-level staff from the Swiss secretariat.

46 At the 2007 General Assembly, the delegates voted on a new concept of membership introducing the principle of "one person / one vote" (Motion 3a) and transforming the Delegates Assembly into a General Assembly (Amnesty International: Delegiertenversammlung 2007, 06.05.2007). 
Management Board. ${ }^{47}$ The Secretariat's responsibilities first included campaigning, human rights education, and lobbying, and later also incorporated fundraising. ${ }^{48}$ The secretariat prepared and coordinated the campaigns and actions coming from the IS. The groups implemented the campaigns on the ground. ${ }^{49}$

In the early years, AI activists mainly organized in local groups. Later, activists formed topic-, profession-, and country-specific groups called Berufsund Zielgruppen. ${ }^{50}$ An interviewee's testimony provides an insightful picture of the qualitative transformation of the groups over the years: "before there were completely generalist groups with young, elderly, men and women [...] with different professional backgrounds. It was a real representation of society. And later it became more fragmented. We started to found groups only for the young and the same thing for women." ${ }^{51}$ Another informant highlighted the importance the personal identification with the victims of human rights violations held for the groups' diversification and for the activists' engagement: "Previously, the idea behind these professional groups was that they would primarily engage in single cases of victims of human rights violations in their domain, meaning students for students, lawyers for lawyers." 52

47 The supervision and control of the section were incumbent upon the EC elected for two years by the Annual Assembly and composed of a minimum of five and a maximum of nine members (mostly seven) from 1994 to 2000 . Following a reorganization, the number of EC members was reduced to five or six by 2000 (Ganzfried: Conversation with C.D., 12.08.2011; Ganzfried: Interview with A.U., 10.10.2012).

48 Until the beginning of the 2000 s, a group had to collect at least $3000 \mathrm{CHF}$ per year for the Swiss Secretariat. Later, the fundraising was professionalized and carried out by the Secretariat.

49 The groups' main work methods consisted in urgent action letter writing, signature collections, stand actions, photo or art exhibitions, and concerts. Groups often organized their activities in collaboration with other organizations or institutions on occasion of, for example, the International Refugee Day, the International Human Rights Day, or the International Women's Day.

50 Such as women's groups or the group of lawyers, youth groups, university groups, and, later, groups like "Queeramnesty" or the "Groupe LCBT".

51 Ganzfried: Interview with B.I., 07.06.2013: "Avant c'était les groupes complètement généralistes avec des jeunes, des vieux, des hommes, des femmes. [...] toutes sortes de professions différentes. C'était vraiment une représentation de la société. Et on a morcelé. On a commencé à faire des groupes uniquement jeunes. [...] Et la même chose avec les femmes."

52 Ganzfried: Interview mit B.F., 04.04.2012: "Die Idee ist früher gewesen, dass die sich vor Allem für einzelne Fälle einsetzen sollen, für Opfer von Menschenrechtsverletzungen, die in ihrem Cebiet sind, also Studenten für Studenten, Juristen für Juristen." 
Evidence shows that the growth of the secretariat was accompanied by a professionalization of the section's work and the groups' decreasing importance in the section's work on human rights in the 2000s. An interviewee explained the effects of the growing professionalization of the section's work: "the secretariat had been serving the groups. They [the secretariat] provided [the groups] the necessary material, they gave the petitions [to the groups], I think, for a long time, [the groups] had been giving impulse to the work." 53 In contrast, referring to the actual situation, the same interviewee explains that "today, I sometimes have the impression that the groups serve the secretariat." $" 54$

Similar to most other sections, women formed a majority of the Swiss Section's members and lower-level staff. However, as graph 2 highlights, women also occupied a majority of the section's management positions from 1992 until 1998. They became a minority of management staff in the following years. In the same period, the representation of women in the EC increased from $30 \%$ to $67 \%$ between 1990 and 2008, despite some setbacks and boosts (Graph 2).

Evidence suggests that the section or at least some of its members were close to the Church. ${ }^{55}$ As I show later, this closeness is less pronounced in the Swiss section than in the German section. In fact, out of the 24 interviewed activists, all women over 60 referred to their proximity to the Church. One woman reported that she found something similar to the Church at AI, explaining that "I always declared: human rights are my religion." 56 Others mentioned their personal affiliation to the local parish or described outreach activities that their group had co-organized with the local parish. ${ }^{57}$

53 Ganzfried: Interview with A.L., 06.06.2013: "Le Secrétariat, qui pour moi pendant des années étaient un peu au service des groupes, c'est eux qui nous fournissaient le matériel, c'est eux qui nous donnaient les pétitions, [...] je trouvais pendant très longtemps que c'était nous qui donnions un peu l'impulse aux choses, à la pratique."

54 Ganzfried: Interview with A.L., 06.06.2013: "Maintenant [...] j'ai des fois l'impression que les groupes sont au service du Secrétariat."

55 The interview material does not allow me to determine which church (catholic or protestant) the activists were linked to in each case. Therefore, by the expression 'close to the church,' I mean the catholic or the protestant church.

56 Ganzfried: Interview with A.E., 14.06.2013: "J'ai essayé de retrouver parce que je suis dans la paroisse aussi, [...] moi je dis toujours ma religion c'est les droits de l'homme."

57 Ganzfried: Interview by phone with B.G., 05.06.2013; Ganzfried: Interview by phone with B.V., 07.06.2013 Ganzfried: Interview with A.D., 06.06.2013; Ganzfried: Interview with A.L., 06.06.2013; Ganzfried: Interview with A.N., 03.06.2013; Ganzfried: Interview with A.S., 15.05 .2013 
Graph 2: Representation of women in the Swiss section's management positions and Executive Committee, 1990-2008

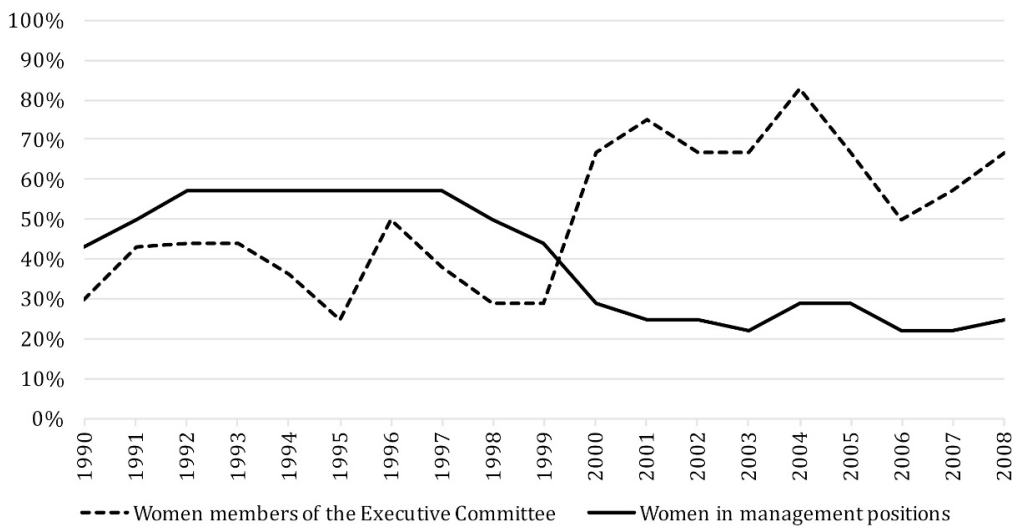

Source: My own, based on an internal list provided by the document specialist of the Swiss section's Secretariat in 2011.

Evidence indicates that the Swiss section was rather open to mandate changes. Comparing the Swiss section to its German counterpart, an interviewee described the Swiss section as "much more flexible. It is just so lovely and open and always considering everything coming from the IS marvelous. [...] It has somehow been such a lovely section." ${ }^{58}$ Further, evidence shows that a culture of constructive discussion among the membership was another particularity of the Swiss section. In fact, according to a long-term official, attendants to the Swiss Annual Assembly from other sections often expressed their astonishment with the section members' unanimous approval of budgets or reports of the EC. ${ }^{59}$

58 Ganzfried: Interview by Skype with A.T., 12.09.2012: "Die Schweizer Sektion, die war ja viel geschmeidiger. Die ist einfach so lieb und offen und findet immer alles toll was vom IS kommt. [...] Das war irgendwie so eine süsse Sektion."

59 Ganzfried: Interview with A.A., 31.05.2013: "IIs sont tous complètement surpris de voir que quand on vote le budget ou le rapport du Comité il n'y a quasiment aucune question qui est posée et puis le budget il passe avec...cette année il a été voté à l'unanimité moins une voix." 


\subsubsection{The German section}

This section begins by briefly presenting the German section's development since its foundation in parallel with the evolution of the international movement, from the 1960s until 2010. It then expounds on the structure and functioning of the section before explaining the division of labor between the Secretariat and the groups and its evolution over time. Later, I highlight the gendered composition of the section's membership and staff, and I demonstrate that in general the German section's membership can be considered rather church $^{60}$ oriented. Finally, I stress the German section's nature of a powerful, autonomous, immovable, and sometimes obstinate associate of the AI network.

The German section grew rapidly from its very beginnings and became the biggest $\mathrm{AI}$ section in the 1970s. It has been contributing half of the IS budget for many years and continues to be one of the most powerful sections today. The German AI section formed two months after the foundation of AI's international movement in 1961 and became the first section outside the UK. ${ }^{61}$ The section registered an enormous growth in terms of the number of its groups, which multiplied from 7 in 1963 to 500 in 1974 and 650 in 1982. Between the 1980 s and the end of the 2000 s, the number of groups remained the same at $650 .^{62} \mathrm{~A}$ first secretariat was inaugurated in 1963/1964 in Bonn. The German section's secretariat grew from about 6 people in 1974 to 65 staff members, called Hauptamtliche (officials), in 2012. ${ }^{63} \mathrm{AI}$ Germany's secretariat had one office in Bonn and another one in Berlin for several years before they centralized in Berlin in the early 2010s. ${ }^{64}$

The German section is organized as an association with an EC, a General Assembly (GA) serving as the section's decision-making body, a Secretariat

\footnotetext{
60 Again, I refer to the catholic or the protestant church, as the data do not allow me to distinguish between these religious communities.

61 Whereas the Al section of the Federal Republic of Cermany formed as early as 1961, a new section in Eastern Cermany was only founded in 1990. Both associations united in 1992.

62 See appendix 2 for details.

63 In full-time positions. The Secretariat counted 28 officials in 1990 and 43 in 1999 (Amnesty International Sektion Bundesrepublik Deutschland).

64 Other smaller regional offices existed; for example, one of them was in Munich.
} 
headed by a Secretary General, and an Executive Secretary. ${ }^{65}$ The Secretariat is responsible for the coordination of the section's daily business and for the implementation of the GA's decisions under the direction of the Secretary General. The supervision and control of the section's management are incumbent upon the EC, which was elected for two years and was comprised of 6 to 7 members between 1990 and $2010 .{ }^{66}$

Activists in the German section are organized in local, country or thematic groups. The so-called Länder-Kogruppen or Fachgruppen (approximately 60 Kogruppen existed in the 1990s) are composed of activists with a specific thematic or country expertise, assisting the work of local groups and serving as experts for the section's thematic work. ${ }^{67}$ In light of their increasing number, local groups organized in so-called Bezirke, which "are associations of AI members and groups in one region." ${ }^{68}$ The Bezirke have their own assemblies called Bezirksversammlungen where group members decide upon their common tasks and where they elect the Bezirk spokesperson (BezirkssprecherIn) and other thematic consultant (FachreferentInnen). ${ }^{69}$

The regional subdivision of the groups and the importance of the Fachgruppen for the section's topical work distinguish the German section from the Swiss section and from many other sections. As I highlight later, this specificity entails a particularly powerful membership. Given Fachgruppen's importance for the section's thematic and country-specific work, the Secretariat has mainly concentrated on campaigning, communication, and country-specific work over the course of many years. As an interviewee explained, the section's work was mainly country specific, and asylum was the only thematic humanrights issue the secretariat worked on until the end of the 1990s. The section started to integrate a broader range of topics into its thematic work only at the beginning of the 2000 s. Despite its gradual professionalization, evidence

65 The position of the Secretary General was created by the Executive Committee for the purpose of giving the section's human rights interventions an appearance of greater importance in politics and among the public in the 1970s (Ganzfried: Interview by phone with B.U., 13.02.2015).

66 Deile et al. 2015.

67 As experts, these groups often were the first contact for media requests in their domain of expertise. They kept lobbying appointments independently from the secretariat (Ganzfried: Interview with A.C., 14.04.2015). Amnesty International Sektion Bundesrepublik Deutschland: "Bezirke sind der Zusammenschluss von Mitgliedern und Gruppen eines Gebiets.".

69 Amnesty International Sektion Bundesrepublik Deutschland. 
indicates that the Fachgruppen and the Länder-Kogruppen continued to play a pivotal role in the section's work.

As in many other sections, women have represented a majority of all members and have been underrepresented in the EC and in the high-level positions at the German section's secretariat. Data from an internal gender audit show that in 2002, 40\% of the members of 169 groups were men and $60 \%$ women. In the same year, women and men were equally represented in the BezirkssprecherInnen. ${ }^{70}$ At the same time, as graph 3 illustrates, the proportion of women among the EC lay between $\mathrm{o}$ and about 30\%, except for a short period of approximate parity between 2001 and 2003. The gender audit indicates that with 56-44 men-to-women ratio, women were also a minority in the section's management board in the beginning of the 2000 s. $^{71}$ Female secretary generals headed the section from 1986 to 1990 and from 1999 to $2009 .^{72}$

Graph 3: Representation of women in the Executive Committee of the German section, 1990-2010

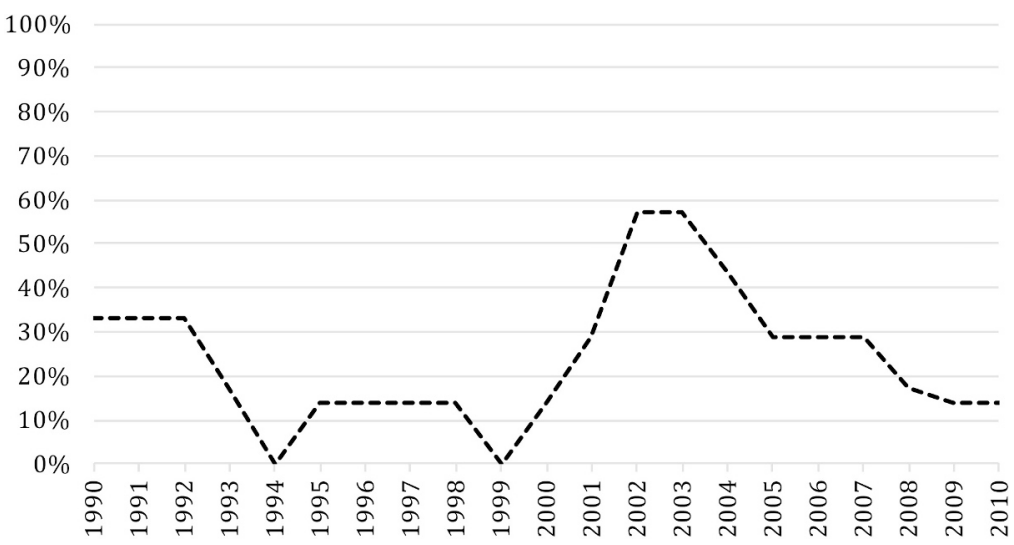

Source: Chronik der Deutschen Sektion von Amnesty International, Deile et al. 2015.

Evidence indicates that members' closeness to the Church was more pronounced in the German section than in the Swiss section. An informant called

70 Frey: Gender Audit bei ai Deutschland-die Ergebnisse, August 2002, p.17.

71 Frey: Gender Audit bei ai Deutschland - die Ergebnisse, August 2002.

72 Brigitte Erler, 1990-1999: Volkmar Deile; 1999-2009: Barbara Lochbihler. 
my attention to the religious tendencies among the membership, saying: "You are surely aware that many German AI members are Church oriented."73 Another interviewee further explained: "The membership is rather conservative. Conservative because AI Germany had always been closely connected to the Churches here in Germany." 74 The importance of the Christian faith for many of the German section's members becomes evident in an extract of an internal document that indicates that many members of the German section believe that human beings' life starts at the moment of conception and not at birth. ${ }^{75}$ The connection to the Church also becomes evident in the groups' activities. In fact, the document retracing the section's history and the internal AI journal mention group activities organized with Christian institutions, such as sermons or Al's participation in the Evangelischer Kirchentag. ${ }^{76}$ Further, in contrast to the Swiss section, a transregional group called Kirchen Arbeitskreis, whose aim has been to convince more and more Christians and members of other religious communities to stand for the respect of human rights globally through the organization of church services on AI's matters of concern, has existed since 1980. ${ }^{77}$

The German section had always been a rather uncomfortable member of the AI network. Together with an early formation and a dominant grassroots membership, the interviews present the section as a powerful, autonomous, immovable, and sometimes obstinate associate of the AI network. An interviewee explained that "the German section had always been different from other sections." ${ }^{78}$ As another informant accurately explains, because of its relatively early creation, the German section had to develop on its own, without having a model on how to deal with the growing number of members, or on how to

73 Ganzfried: Interview by phone with A.Y., 09.01.2015: "Sie wissen ja auch, dass viele AmnestyMitglieder kirchenorientiert sind."

74 Ganzfried: Interview with B.T., 15.04.2015: "Die Mitgliedschaft ist eine eher konservative Mitgliedschaft, konservativ weil Amnesty Deutschland ist immer sehr stark mit den Kirchen hier in Deutschland verbunden, [...]."

75 Amnesty International, International Secretariat: 28th International Council Meeting Circular 42 Resolution and Statute Amendment Pack, July 2007, p.12.

76 Amnesty International Sektion Bundesrepublik Deutschland: ai-intern, November 2006; Deile et al. 2015.

77 Deile et al. 2015; Kirchen Arbeitskreis (AK) München und Oberbayern.

78 Ganzfried: Interview with B.T., 15.04.2015: "Die deutsche Sektion ist zu anderen komplett unterschiedlich.". 
organize its work..$^{79}$ The resulting specific group structure, which I have already described, made the German section immobile and, at the same time, lead to "a very solid basis." ${ }^{\text {" }}$ According to the same interviewee, this particularity has influenced the section throughout the years, shaping a self-feeding structure, which can only be influenced from the outside with difficulty. ${ }^{81}$

Related to this, AI Germany has, for many years, used a logo that is different from the one used internationally. ${ }^{82}$ These specific characteristics are also reflected in the section's position on the development of AI's mandate and in the implementation of activities coming from the IS. Evidence indicates that the German section has often been reluctant to open the mandate. ${ }^{83}$ An interviewee stated: "The German section is that balky. At each mandate modification, they thought 'The mandate is already this huge, we cannot possibly change it anymore." ${ }^{\prime 4}$ At the same time, as another interviewee highlights, the section has also sometimes been at the vanguard, proposing things to the IS which the latter did not want. ${ }^{85}$ For instance, the German section was the first AI section where members started to work on the right to food in 1982, almost two decades before the movement decided to abandon the mandate. In contrast to others, the German section also ignored the WOOC rule by working on prisoners' cases in Germany, ${ }^{86}$ and engaged for the release of any imprisoned asylum seeker, regardless of his or her political convictions. ${ }^{87}$

79 Ganzfried: Interview by phone with B.U., 13.02.2015.

80 Ganzfried: Interview by phone with B.U., 13.02.2015: "Die deutsche Sektion ist durch die Cruppenstruktur in gewisser Hinsicht unbeweglich gewesen, aber sie hat ein sehr solides Fundament gehabt.".

81 Ganzfried: Interview by phone with B.U., 13.02.2015: "Meine Erklärung ist bis heute, dass daraus eine Struktur gewachsen ist, die selbst tragend war, und auf die es schwieriger ist von aussen Einfluss zu nehmen".

82 Ganzfried: Interview with A.C., 14.04.2015.

83 Ganzfried: Interview with A.N., 03.06.2013; Ganzfried: Interview by phone with A.Q., 27.02.2015; Ganzfried: Interview by Skype with A.T., 12.09.2012.

84 Ganzfried: Interview by Skype with A.T., 12.09.2012: "Die [Die Deutsche Sektion] ist so bockig. Die fand immer bei jeder Mandatsänderung: [...] das [Mandat] ist doch so gross schon, wir können das unmöglich noch ändern.".

85 Ganzfried: Interview by phone with B.U., 13.02.2015: "Also die deutsche Sektion ist auch manchmal vorwärts stürmend gewesen und wollte was von der Internationalen Organisation was diese nicht wollte.".

86 Deile et al. 2015.

87 Deile et al. 2015. 
Consequently, the relationship between the German section and the IS has been rather conflicting.

In fact, several debates about the groups' autonomy vis-à-vis the international organization's centralism occurred between 1981 and $1986 .{ }^{88}$ In one of the EC meetings in 1985, the minutes keeper stated: "The German section perceives the IS as a very distant instance." ${ }^{89}$ Further, an interviewee reported that in the German section, "London" was a term filled with fear. ${ }^{90}$ In light of the section's sometimes critical and antagonistic positions vis-à-vis the international movement, it is not astonishing that activists describe their Annual Assembly like this: "discussions are very tough, it is not at all some 'cuddle'Amnesty." 1 The same interviewee reported guests from other sections' astonishment upon visiting the AI Germany's GA and being confronted with this manner of discussion and debate. ${ }^{92}$

Summing up, while the Swiss section and the German section are both among the most important AI sections members- and funding-wise, evidence points to some central differences between these two sections in several domains, other than size. First among them is the power structure between the secretariat (professional structure) and the groups (activists). In the German section, the groups play a pivotal role in the section's work, whereas in the Swiss section, the professional structure seems to be more important, as thematic work is mainly centralized in the Secretariat. In fact, whereas both sections were marked by a tendency to professionalize over the period under scrutiny, in the German section, thematic work remained in the hands of the Länder-Kogruppen or Fachgruppen. Further, as I show in section 6.5.2, the German section's membership has a particularly powerful position within the section due to its ability to participate in decision-making at both the national and the local levels.

Second is the share of women in the EC. In fact, in general terms, the proportion of female EC members was more important in the Swiss than in the German section during both periods. Third, whereas evidence shows a

\footnotetext{
88 Deile et al. 2015.

89 Deile et al. 2015: "Das internationale Sekretariat wird aus der Sicht der Sektion als eine sehr entfernte Instanz wahrgenommen.".

90 Deile et al. 2015: "Reinhard Marx schreibt zum gleichen Thema: 'London' ist ein angstbesetzter Begriffinnerhalb der deutschen Sektion.".

91 Ganzfried: Interview by Skype with A.G., 26.04.2015: "Da wird sehr hart diskutieren, das ist gar nicht so Kuschel-Amnesty.".

92 Ganzfried: Interview by Skype with A.G., 26.04.2015.
} 
certain closeness to the Church in both sections, this proximity seems to be more pronounced in the German section. Fourth is the relationship between the section and the headquarters. The Swiss section seems to have been open to mandate changes and can be described as a rather assimilated member of the overall AI network. In contrast, AI Germany has been rather critical of mandate changes and can be characterized as a powerful, autonomous, immovable, and sometimes obstinate associate of the AI network. As I explain later, these differences help us understand how both sections integrated issues of VAW into their work from the start. They also help explain the difference in the extents to which the Swiss and the German sections managed to integrate the issue of VAW into their work in the 2000 s.

\subsection{Decision-making and implementation}

As an organization build on democratic principles, the process of policy-making, which delineates the organization's working focus, and the implementation of its policy are key to properly understanding AI. By distinguishing between the international and the national levels, this chapter provides insights into the mechanism of decision-making and its implementation as well as the underlining power relations.

\subsubsection{The international level - The IS as a powerfull central node}

At the international level, only the ICM can make decisions amending the mandate/the mission or the statute defining Al's working focus. ${ }^{93} \mathrm{AI}$ describes the ICM as "AI's highest decision-making body and a significant element of its democracy in action." ${ }^{94}$ Every two years, delegations from all sections and "structures" meet at the ICM to discuss AI's future direction and work. Section delegates there debate various topics in working groups and vote on resolutions submitted either by the IEC (enabling resolutions) or by sections (resolutions) in plenary sessions. Each of the sections sends a delegation to the ICM. The latter is composed of activists and officials and is proportional to its size, calculated as a function of the number of its members. In contrast, the IEC does not have the right to vote at the ICMs. As I show

93 Amnesty International: Statute of Amnesty International, August 1991.

94 Amnesty International. 
hereafter, even though the IS is formally excluded from decision-making at the ICM, it nevertheless influences the process indirectly. In fact, despite not having the right to vote IS members participate in the ICM.

Decisions at the ICMs require "a simple majority of the votes cast." 95 However, decisions are often taken by consensus, often involving long and intensive discussions among section representatives during the two weeks of the ICMs. Evidence shows that reaching a consensus on particular issues usually starts months or even years before a definitive decision is made. Welch (2001) has noted that "expansion of the mandate requires years of patient, worldwide lobbying of national sections." ${ }^{96}$ Sections thus prepare their statements and inputs to the ICM in advance and seek alliances with like-minded sections on issues on the meeting's agenda, which the IEC has defined in advance.

Generally, before sections submit their resolution to the ICMs, their members decide on the submission at the section's GA. Thus, to a certain extent, the content of the resolution and, consequently, the following ICM decisions reflect the activists' opinions. The sections' role in AI's decision-making process is important, as Al's statute gives sections the exclusive right to participate in the process in two ways. Whereas sections can submit resolutions to the ICMs and have the exclusive right to vote on resolutions, as well as adopt subsequent decisions, the IEC is only given the right to submit resolutions and is excluded from voting on them. The sections and, consequently, AI's membership are thus assigned a pivotal role in the policy-making process.

Nevertheless, evidence shows that the headquarters significantly influence decision-making and policy implementation. In fact, the composition of the IS, its exclusive task of doing research for the whole movement over a long period, and its involvement in the executive affairs and in the organization of the ICMs make the IS comparatively powerful. Even though it is formally excluded from participating in the ICM, evidence indicates the ability of the IS "to control the content of the AI human rights agenda." ${ }^{.97}$ IS staff are professional human rights workers and therefore generally possess greater, specific knowledge of human rights than ordinary AI section activists do. Relatedly, as explained by an interviewee, the exclusive task of conducting research for the whole movement "gives [the IS] enormous power on the movement."

\footnotetext{
95 Amnesty International: Statute of Amnesty International, August 1991.

96 Welch 2001, p.92.

97 Lake and Wong 2009, p.149.

98 Ganzfried: Interview with A.I., 26.09.2012: "ça donne un pouvoir enorme sur le mouvement.".
} 
Further, as stressed by Welch (2001), even though the ICM "examines broad policy matters, including the mandate, and although the IEC supervises national sections, the overwhelming majority of operational decisions are made within the IS." 99 The decisions about the adoption of prisoners of conscience are based on confidential information and sources, which precludes the IS from consulting with the whole movement. As the professional expertise remains in IS staff, decisions concerning individual country work are also made within the IS.

The IS is also closely involved in the organization's executive work. In fact, as the minutes of the IEC meetings show, in addition to the regular IS representative, the SG and its deputies regularly participate in the committee's meetings. IS staff members also represent the IS within various Standing Committees, such as the Standing Committee on the Mandate (SCM), formerly called the Mandate Review Committee, ${ }^{100}$ established to examine possible ways to modify the mandate. The resignation of the chairman of this specific committee in 1990 shows that because of the professional staff's knowledge advantage, the Secretariat's influence on executive affairs was judged highly problematic by AI members themselves. In fact, the chairman declared: "I am not opposed to the I.S. influencing the Committee. However, I am of the view that, given the number of I.S. staff at the meetings and the fact that they have more knowledge than most of us regarding the issues, their influence has been undue."101

Furthermore, evidence shows the close involvement of IS staff both in the organization of the ICMs and in lobbying for or against particular decisions. In fact, as Hopgood highlights, while "IS staff members undertake the organization of the ICM, [...] particular IS senior directors can be heavily involved, for example, in behind-the-scene lobbying, resolution drafting, and coalition building for IEC positions." ${ }^{102}$ At the same time, according to Hopgood, "a

99 Welch 2001, p.109.

100 Generally, at least one staff member and the SC as well as the deputy SCs represented the IS at the IEC. The 2003 ICM eliminated the IS representative on the IEC following an Al Israel resolution (Hopgood 2006, p.194.). According to different minutes of meetings of the SCM, the IS represented half of the SCM members from 1992 to 1996. The IS was present in the three other standing committees, as well.

101 Deile et al. 2015.

102 Hopgood 2006, p.194. 
ritualistic pretense is maintained that the IS is not involved at every stage in giving serious and detailed strategic and policy advice to the IEC." ${ }^{103}$

Thus, while the sections and, consequently, the members officially determine AI's human rights work through their right to submit resolutions and their exclusive voting right at the ICM, "de facto the professional structure [the IS] had much more power compared to the governing structure [the ICM]." ${ }^{104}$ As explained by an interviewee, this is because the IS cumulates the task of preparing the decisions for the ICM and the task of subsequently implementing these decisions. Hence, even though the statutes mainly limit the headquarters' role to conducting daily business, the IS has remained "the heart - and the brain - of AI." ${ }^{105}$ As Lake and Wong (2009) and Welch (2001) highlight, we can even assume that over the years "the power of the central node increased,"106 as "the longer an organization survives, the greater the likelihood that its permanent employees rather than its members determine the goals."107

\subsubsection{The national level - Al sections}

As I have previously highlighted, the sections participate in the decision-making process by submitting resolutions and deciding upon them at the ICMs. Sections play a key role in decision implementation. Organized as independent associations, "sections [took] no action on matters that [did] not fall within the stated object and mandate of AMNESTY INTERNATIONAL"108 until 2001. Sections are autonomous in the implementation of the campaigns and in the individual cases of prisoners developed and proposed by the IS. This has been even more so since the adoption of the mission, which changed the scope of AI "from being constrained by its statute in what it could do, to being free to do pretty much what its staff and volunteers wanted to do."109 Member involvement happens in each section's groups, which implement the

\footnotetext{
103 Hopgood 2006, p.194.

104 Ganzfried: Interview with A.I., 26.09.2012: "De facto la structure professionnelle a nettement plus de power que la structure de gouvernance.".

105 Welch 2001, p.90.

106 Lake and Wong, 2009: 152.

107 Welch 2001, p.109.

108 Amnesty International: Statute of Amnesty International as amended by the 22nd International Council, meeting in Ljubljana, Slovenia, 12-20 August 1995, 1995, p.5.

109 Deile et al. 2015.
} 
campaigns and actions prepared by the IS on the ground. Thus, activists are assigned a pivotal role in the achievements of the organization's objectives.

As independent associations, sections autonomously decide upon their annual budget, their members' financial contributions, their long-term strategic and financial planning, and the election of their secretary generals. In the case of the Swiss section, activists can influence policymaking by submitting a motion or a postulate to the GA on behalf of their respective group. These instruments enable activists to demand the submission of a resolution to the ICM. Further, activists can vote on these motions or postulates at the AG and, in doing so, influence AI's decision-making process. ${ }^{110}$

In contrast to the Swiss section and to the majority of the other sections, the German section has given its members additional opportunities to influence decision-making at the section level. According to an interviewee, the German AI activists have more opportunities to participate in the decisionmaking compared to their counterparts in other sections. ${ }^{111}$ The fact that activists can participate in decision-making at the national as well as the local levels gives the membership a particularly powerful position within the section. At the GA, delegates decide on long-term strategic planning, elect the $\mathrm{EC}$, and vote on motions coming either from individual members, group(s), from a Bezirk or from the EC. ${ }^{112}$ At the regional assemblies (Bezirksversammlungen), group members of the respective Bezirk decide on their common tasks and elect the regional spokesperson. ${ }^{113}$ The latter is closely involved in EC's affairs through her or his participation in the Bezirkssprecherinnenkonferenz, a conference bringing all regional spokespersons together twice a year. ${ }^{114}$

110 Until 2007, internal collectives, such as groups, commissions or working groups, had a collective voting right (groups voting rights were fivefold). At the $2007 \mathrm{CA}$, the delegates decided to introduce the principle of "one person / one vote." From then on, each member of the Swiss section had the right to vote, transforming the delegates' assembly into a Ceneral Assembly (Amnesty International: Delegiertenversammlung 1997, 27.04.1997; Amnesty International: Delegiertenversammlung 2007, 06.05.2007).

111 Ganzfried: Interview with A.C., 14.04.2015: "Unsere Mitglieder haben sehr viel Mitspracheund Partizipationsrecht, wahrscheinlich mit am meisten bei Amnesty".

112 Each group sends a delegate with the rights to vote. Since 1991, each group has had one delegate with ten votes, while individual members (who were not affiliated to one group) had the right to participate in the AG with one vote. The decisions are taken through a simple majority of the votes.

113 Amnesty International Sektion Bundesrepublik Deutschland.

114 As explained in the statutes, the EC is committed to taking the decisions of the Bezirkssprecherinnenkonferenz into account in their decision-making. Important section 
The preceding paragraph illustrates the sections' and therefore the members' pivotal role in the process of decision-making and the subsequent implementation of the decisions. At the same time, the IS has a very powerful de facto position with regards to the definition of AI's agenda. In fact, even though it is excluded from voting at the ICMs, the IS, with its composition of human rights professionals, its exclusive role in conducting research, its involvement in the organization's executive affairs through its participation in the IEC and in the related Standings Committees, and its role as the organizer of the ICMs, has exerted consistent influence on the organization's human rights agenda. Al's democratic principle is safeguarded within the sections thanks to the general assemblies, where the members decide on their section's work. Even though activists are assigned a pivotal role in the decisionmaking process within sections, as the example of the Swiss and the German sections shows, the activists' importance in defining the section's work varies. Because of their importance in the section's thematic work and their involvement in decision-making at the national and the local levels, the German section's membership has a particularly powerful stance compared to that of its Swiss counterpart.

tasks, such as long-term planning and the coordination and implementation of the section's actions, are incumbent upon both the EC and the Bezirkssprecherinnenkonferenz Amnesty International Sektion Bundesrepublik Deutschland. 


\section{The beginnings of Al's interest in VAW}

The present chapter examines the beginnings of Al's interest in issues of violence against women, focusing on the period between 1989 and 2001 . I first explore the international level (section 7.1) and then the Swiss and the German sections in section 7.2. This chapter thus highlights the changes concerning VAW in AI's human rights policy and emphasizes the ways in which AI integrated the issue into its activities, while respecting the boundaries of its mandate. In so doing, the chapter stresses the importance of women strategizing at the international and the national levels for understanding AI's growing interest in VAW. Further, it shows the disinterest with which parts of the movement approached the intensification of AI's work on issues of VAW in the 1990s.

\subsection{The international level}

Section 7.1.1 begins by descriptively charting the gradual development of AI's policy from its essential focus on civil and political rights to the adoption of a mission recognizing the indivisibility of all human rights, including economic, social, and cultural rights. It does so by examining ICM decisions. Section 7.1.2 then highlights how the organization integrated VAW into its activities while respecting the frame of the mandate. In section 7.1.3, I emphasize the relevant internal actors. I also demonstrate that female activists' strategizing in an intersectional network initiated AI's work on women's rights and successfully influenced decision-making and implementation by lobbying sections, the IEC, and the IS. Later, section 7.1.4 shows that the integration of issues of VAW into AI's work met with officials' and activists' disinterest and reluctance, rather than with their resistance. 


\subsubsection{Policy development 1989-2001}

By focusing on the decisions made at the ICMs between 1989 and 2001, this section provides a detailed account of AI's policy development regarding $\mathrm{VAW}^{1}$ and concludes with a brief description of how the policy changes were reflected in AI's strategic plans. Between 1989 and 2001, the International Council met seven times (in 1989, 1991, 1993, 1995, 1997, 1999, and 2001). The delegates made many decisions at each ICM. ${ }^{2}$ Some of them concerned AI's work on VAW either directly or indirectly. As I show later, distinguishing between these two types allows me to accurately explain the origins of the respective ICM decision and the debates heralding its adoption. I also differentiate between these two categories because, as I have mentioned before, policy developments regarding VAW cannot be analyzed in isolation from the modification of the essential principles of Al's mandate.

By distinguishing between the two categories, figure 1 provides a graphical overview of the policy developments between 1989 and 2001 . The mandate modifications highlighted in the left rectangles of the figure indirectly concerned AI's work on VAW, as their principal target was not VAW, but AI's broader mandate. In fact, as I have already revealed, the integration of nonstate actors into Al's mandate (illustrated in the upper gray box in the right rectangle of figure 1) and the subsequent end of the mandate, with the concomitant extension to social, cultural, and economic rights (illustrated in the lower gray box in the right rectangle of figure 1) are important general policy changes that also influenced how AI dealt with issues of VAW in its activities.

At the same time, the organization directly adopted various decisions concerning its work on VAW (illustrated in the right rectangle of figure 1). ${ }^{3}$ For instance, the delegates adopted several decisions demanding an increase in AI's work on women's rights. I have labeled these decisions "Al's work on women's rights" (illustrated on the left in the right rectangle of figure 1 ). At the same

Because only the ICM can make decisions amending the mandate/the mission or the statute, analyzing ICM decisions allows us to understand policy development in general and regarding VAW in particular.

2 As an example: The 1989 ICM released 55 decisions, the 1991 ICM issued 86 decisions, the 1993 ICM and the 1995 ICM each resulted in 50 decisions, the 1997 ICM resulted in 51 decisions, the 1999 ICM resulted in 49 decisions, and the 2001 ICM resulted in 36 decisions.

3 I label these three sub-types as decisions directly concerning Al's work on VAW because their focus was only and explicitly on how Al should handle VAW in its work. 
time, the ICM explicitly decided to integrate Female Genital Mutilation (FGM) in its promotional and, later, in its oppositional work. The related decisions are labeled "a specific women's right/a specific women's rights violation" in the middle of the right rectangle in figure 1 . Further, the organization decided to broaden its approach concerning governmental inaction in cases of VAW committed by private actors and enlarged the criteria for the adoption of prisoners of conscience (labeled "women's rights in general" on the right side of the right rectangle of figure 1 ).

Figure 1: Overview of the policy development between 1989 and 2001

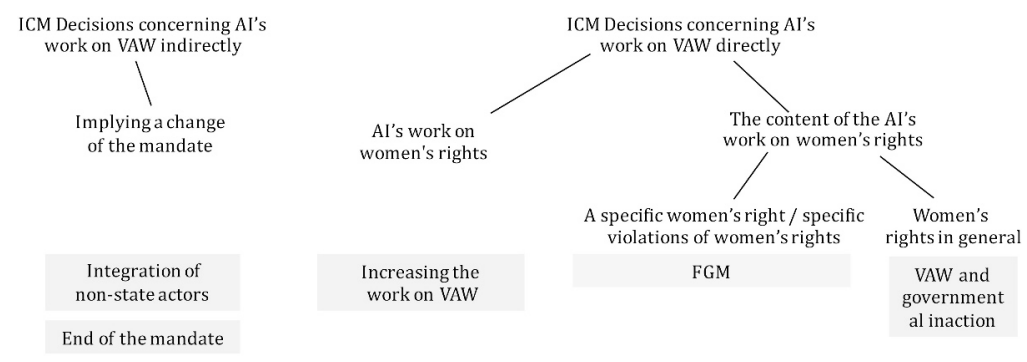

Source: my own

If we classify the summarized decisions according to the ICM during which they were adopted, it becomes evident that AI adopted most of the decisions directly concerning its work on VAW at the 1995 ICM (graph 4 and figure 2). This convergence points to the importance that the momentum gained at the fourth WCW held for the organization's growing interest in women's rights issues. As I explain in more detail later, the WCW can be considered a window of opportunity as far as the advancement of the organization's work on VAW is concerned. 
Graph 4: Decisions per ICM, 1989-2001

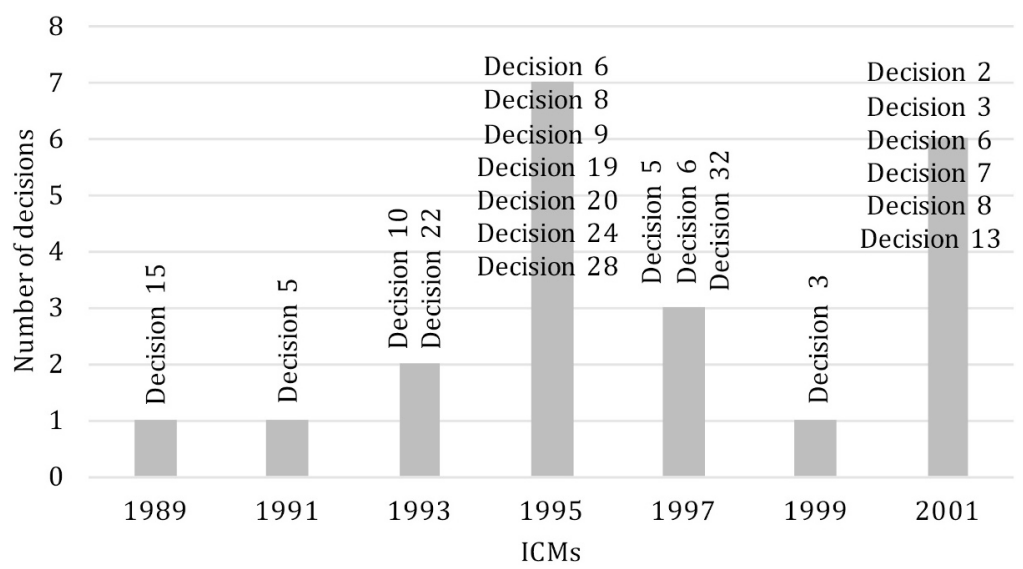

Source: my own, based on ICM reports for the years 1989, 1991, 1993, 1995, 1997, 1999, and 2001.

By distinguishing between ICM decisions directly and indirectly concerning AI's work on VAW, this paragraph provides a general overview of the development of AI's policy in this issue area between 1989 and 2001. The following sections highlight the policy developments focusing on the content of the ICM decisions adopted between 1989 and 2001. It starts with the description of the decisions indirectly concerning AI's work on VAW before describing the ICM decisions directly concerning the latter. Figure 2 shows all ICM decisions directly or indirectly concerning AI's work on VAW.

\subsubsection{ICM decisions indirectly concerning Al's work on VAW}

The following section illustrates the implications of AI's gradual mandate opening for the work on violence against women by focusing on the ICM decisions indirectly concerning this work (illustrated in the left rectangle of figure 2). In this period, the delegates to the ICM made several decisions challenging the essence of the mandate, which finally led to the adoption of a new mission in 2001. I distinguish between decisions implying a reconceptualization of the civil and political rights approach (upper gray box in the left rectangle of figure 2 ) and decisions that demand abandoning this old way of working (lower gray box in the left rectangle of figure 2). 
Figure 2: Detailed policy development between 1989 and 2001

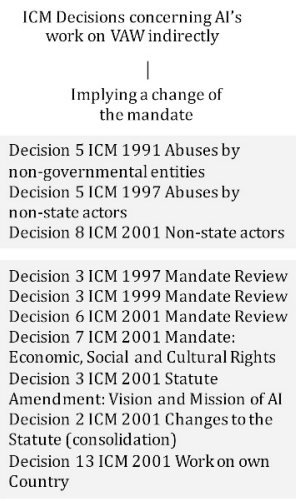

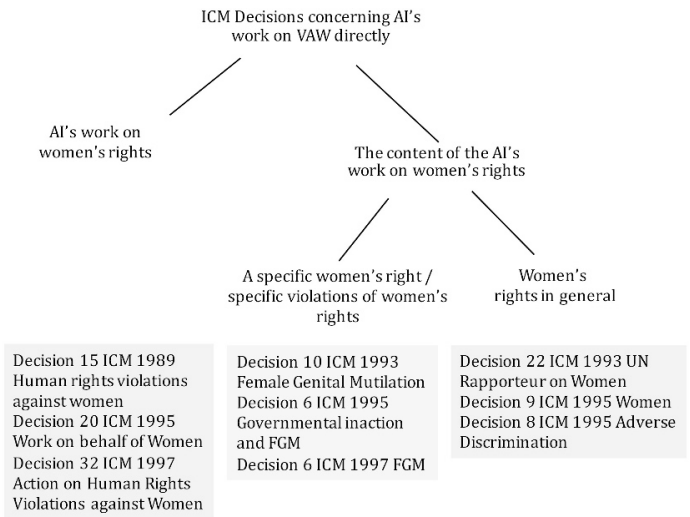

Source: my own, based on ICM reports for the years 1989, 1991, 1993, 1995, 1997, 1999, and 2001.

Until 1991, AI considered the state to be the primary violator of human rights and the organization's activities mostly targeted governments. Because of the topicality of interstate conflicts and the emergence of new patterns of human rights violations, AI included abuses committed by "political nongovernmental entities," such as arbitrary killings and hostage taking, into its mandate in 1991 (Decision 5 of the 1991 ICM). ${ }^{4}$ Hopgood states that "the implications of this [decision] were profound - it opened the way for social and economic rights, allowing AI to move its attention away from the state exclusively to take in corporations or the relations between individuals (e.g., men and women)." Nevertheless, the same decision reaffirmed "that AI should continue to regard human rights as the individual's rights in relation to governmental authority." 6

Subsequent ICM decisions continued to challenge AI's focus on civil and political rights and on the state as the primary perpetrator of human rights abuses in the following years. For example, by adopting decision 5 at the 1997 ICM, the delegates decided that: "AI will act when governments breach their

\footnotetext{
$4 \quad$ Kelleher and Bhattacharjya 2013.

5 Hopgood 2006, p.120.

6 Amnesty International: 1991 ICM Decisions.
} 
duty to ensure respect for human rights by failing to take action against abuse of human rights by private actors where that abuse would constitute a grave violation of human rights [...]." Working on cases of human rights violations where the state failed to meet its obligation to prevent the abuse was a new field of activity for AI. Conscious of the need to acquire first experiences in this particular domain, the ICM decided to do pilot projects in order to develop its future oppositional work on abuses by non-state entities. Decision 5 of the 1997 ICM called for an inclusion of the issues of women's rights into these pilot projects. ${ }^{8}$ As I detail in the next section, three out of four pilot projects finally concerned issues of women's rights, such as honor killings in Pakistan, abuses affecting women trafficked from Russia into Israel's sex industry, private security actors in Brazil, and female genital mutilation in West Africa. ${ }^{9}$ At the same time, by prohibiting the use of oppositional techniques towards non-state actors, AI dispensed with holding these actors accountable. Four years later, the delegates finally decided to use oppositional and promotional techniques towards non-state actors (Decision 8 of the 2001 ICM). This amendment was decisive for AI's effective work on VAW, as it enabled the organization to hold the perpetrators accountable.

During the same period, AI started a general discussion about its mandate. Several ICM decisions reflected this debate and preceded the ultimate decision to abandon the mandate, which was taken at the 2001 ICM (see the gray box on the lower left side in the left rectangle of figure 2). As a concrete manifestation of this final amendment, delegates expressed the concern that "the mandate is sometimes perceived as unwieldy and unfocused"10 and called for a comprehensive review of AI's mandate until the 2001 meeting at the 1997 ICM (Decision 3 of the 1997 ICM). ${ }^{11}$ Two years later, the 1999 ICM (Decision 3) stressed the importance of a mandate review again, suggesting that the IC

7 Amnesty International, International Secretariat: The Decision of the 1997 ICM, 05.01.1998, p.8-9.

Amnesty International, International Secretariat: The Decision of the 1997 ICM, 05.01.1998, p.9.

9 Amnesty International, International Secretariat: Mandate Review 1997-2001: NonState Actors, August 2000, p.6.

10 Amnesty International, International Secretariat: Inside the mandate - issue 9, November 2000 .

11 Amnesty International, International Secretariat: Inside the mandate - issue 9, November 2000 . 
should "explore whether and to what extent AI could address more effectively violations of economic, social and cultural rights."12

After a movement-wide consultation, the IEC submitted three different approaches for a first discussion: first, the "status quo" approach, which would continue to restrict AI's work to civil and political rights; second, the "new core concept" approach, which would gradually broaden the scope of AI's work to integrate some economic, social, and cultural rights; and third, the "full spectrum" approach, which would change the mandate into a mission and would enable AI to use oppositional techniques against violations of economic, social, and cultural rights. ${ }^{13}$ At the 2001 ICM, after an intensive discussion, the delegates finally agreed to go for the "full spectrum" approach and to replace the mandate with a mission. The organization thus scratched the list of specific violations of civil and political rights off its statutes and claimed to "undertake research and action focused on preventing and ending grave abuses of the rights to physical and mental integrity, freedom of conscience and expression, and freedom from discrimination, within the context of its work to promote all human rights" (Decision 2 and Decision 3 of the 2001 ICM). ${ }^{14}$ In decision 6, the IC further affirmed "the need to break down the perception that civil and political rights are more important than economic, social, and cultural rights;",15 and recognized "the consensus in the movement that AI needs to engage further with economic, social and cultural rights. ${ }^{16}$ With Decision 6, the IC further decided to increase its cooperation with other NGOs: "[...] engaging in strategic alliances with other NGOs whose expertise, information or action possibilities can usefully and effectively combine with those of AI [.... ${ }^{n 17}$ Meanwhile, decision 7 of the 2001 ICM emphasized the indi-

Amnesty International, International Secretariat: 24th International Council 1999, September 1999, p.7-8.

13 Amnesty International, International Secretariat: Inside the mandate - issue 9, November 2000 .

Decision 2 specifies that the IC decided to adopt the new Statute of Al detailed in Decision 3 (Amnesty International, International Secretariat: Report and Decisions of the 25th International Council of Amnesty International, 2001).

Amnesty International, International Secretariat: Report and Decisions of the 25 th International Council of Amnesty International, 2001, p.116.

Amnesty International, International Secretariat: Report and Decisions of the 25 th International Council of Amnesty International, 2001, p.116.

17 Amnesty International, International Secretariat: Report and Decisions of the 25th International Council of Amnesty International, 2001, p.117. 
visibility of all human rights stating that "AI may use any appropriate technique to oppose grave abuses of economic, social and cultural rights where these abuses arise from a policy of discrimination, or are abuses of the rights to freedom of conscience and expression, freedom from discrimination, or physical and mental integrity." 18

The adoption of the mission was significant for AI's work on VAW, as it allowed for the interpretation of VAW as a structural and social problem whose root causes lay in the social and economic subordination of women, and not merely as individual acts. Yet equally important for AI's concrete and effective work for the elimination of VAW was the 2001 ICM decision abandoning the WOOC rule, which prohibited sections from intervening in favor of victims of human rights abuses in their own country. This limitation had been debated repeatedly. Yet, only in 2001 did a majority of the sections' delegates finally vote for the abolition of this rule (Decision 13 of the 2001 ICM). ${ }^{19}$ This decision facilitated AI's engagement against VAW, as it enabled sections to campaign against specific women's rights violations in their own countries. It therefore enhanced the cooperation with local women's rights organization on this specific issue, which in turn was crucial for effective action.

\subsubsection{ICM decisions directly concerning Al's work on VAW}

This section demonstrates that by adopting three ICM decisions calling for an increase in AI's work on women's rights, the organization intended to strengthen its work on VAW, which falls within the mandate during the 1990 s (gray box on the bottom left in the right rectangle of figure 2). The section then emphasizes that FGM was the first women-specific human rights violation with which AI expanded its mandate (gray box in the middle of the right rectangle in figure 2 ). The section concludes by describing several ICM decisions that illustrate the organization's growing awareness of the importance of gender-specific human rights violations (gray box on the right side in the right rectangle of figure 2 ).

\footnotetext{
18 Amnesty International, International Secretariat: Report and Decisions of the 25th International Council of Amnesty International, 2001, p.119.

19 The WOOC policy was first adopted in Decision 29 of the 1979 ICM, revised in Decision 35 of the 1987 ICM, and simplified in Decision 48 of the 1995 ICM.
} 
ICM decisions calling for an increase in the work on women's rights

As mentioned before, until 1989, AI's work on violence against women was rather ephemeral and essentially limited to individual cases of female prisoners of conscience. At the 1989 ICM, the IC adopted its first decision calling for increased attention and resources for the work on human rights violations against women. In decision 15, the IC "resolved that human rights violations against women which fall within AI's mandate deserve more attention in the research of the IS and the publication activities of the IS and sections and that adequate resources be provided for that." ${ }^{20}$ In decision 15 , the IC further requested $\mathrm{AI}$ to cooperate with other NGOs and Intergovernmental Organizations (IGOs) in its actions "to seek protection and safeguards for women which give due consideration to the aspects of human rights violations that are specific to their sex." ${ }^{21}$

As I show later, because parts of the movement considered the resulting activities related to violations of women's rights insufficient, decision 20 of the 1995 ICM recalled decision 15 of the 1989 ICM and requested a clarification of AI's work on women. Further, decision 20 sought to ensure that the work for the promotion and protection of women's human rights be carried out at all levels of the organization. It also stipulated that the work on women's human rights become an integral part of AI's overall work, especially in research and publications, so that adequate personal and financial resources be provided in its support. In contrast to decision 15 (1989 ICM), decision 20 of the 1995 ICM further recommended strengthening the financial and human resources available to initiate and effectively monitor the work to end human rights violations against women, which falls within the mandate. ${ }^{22}$

Again in 1997, the IC declared itself "concerned that [...] the full potential for AI's work on women's human rights has yet to be realized,"23 and worried about providing "continued provision of support for the implementation of organizational mechanisms that will lead to the full integration of women's human rights in all areas of Amnesty International's work." ${ }^{24}$ In order to re-

\footnotetext{
20 Amnesty International, International Secretariat: Decision No. 15 ICM 1989, 1989.

21 Amnesty International, International Secretariat: Decision No. 15 ICM 1989, 1989.

22 Amnesty International, International Secretariat: 22nd International Council Meeting, 1995.

23 Amnesty International, International Secretariat: The Decision of the 1997 ICM, 05.01.1998, p.47.

24 Amnesty International, International Secretariat: The Decision of the 1997 ICM, 05.01.1998, p.47.
} 
alize the integration of women's rights into all areas of AI's work, the IC recommended conducting a comprehensive gender audit at all levels of the organization and including a focus on gender into the sections' mandate training and development sessions as well as in their strategic planning processes. ${ }^{25}$ As I highlight later, the ICM delegates refused to undergo a gender audit at the 1995 ICM, but accepted the request at the 1997 ICM.

These three ICM decisions sought to make the organization increase its work on violations of women's rights that fell within the mandate without demanding a change in the state-focused mandate. They called for sufficient personal and financial resources, and they formulated concrete recommendations on how to make women's rights an integral part of AI's overall work. As I highlight later, these decisions go back to female AI activists' and officials' movement-wide strategizing to make AI increase its work on violations of women's rights. Even though none of these decisions explicitly mentioned the issue of VAW, they directly enabled and promoted AI's activities on this front, as they demanded a sustained integration of the work on women's rights violations into AI's overall work within the frame of the mandate.

ICM decisions concerning the work on FGM

Female genital mutilation was the first women-specific human rights violation with which AI expanded its mandate. Concretely, the issue entered the decision-making process at the 1993 ICM. There, in decision 10, the IC expressed its concern about the practice of FGM, considering it as "[...] causing permanent health risks and in many cases death or major damage to [the] health [of women]." ${ }^{26}$ Decision 10 urged the IEC to include the issue in a study on governmental inaction, in order to clarify if and to what extent AI should include FGM in its promotional work and get involved in cases "where human rights abuses are inflicted by individual citizens on each other." ${ }^{27}$ Further, the decision "instructs the IEC to present recommendation on this matter to the next ICM."28

25 Amnesty International, International Secretariat: The Decision of the 1997 ICM, 05.01.1998.

26 Amnesty International, International Secretariat: The Decisions of the 1993 ICM, 30.09.1993, p.13

27 Amnesty International, International Secretariat: The Decisions of the 1993 ICM, 30.09.1993, p.14.

28 Amnesty International, International Secretariat: The Decisions of the 1993 ICM, 30.09.1993, p.14. 
After intensive debates, AI recognized the practice as "[affecting] the full enjoyment of human rights by millions of women and girls" and acknowledged that governmental inaction in cases of FGM constitutes a violation of international human rights standards. It then integrated FGM into its promotional mandate (Decision 61995 ICM). Two years later, by integrating FGM into the pilot projects on the future of Al's oppositional work against nonstate actors, AI also allowed oppositional work against the practice (Decision 61997 ICM). It did so by recognizing "that FGM constitutes an abuse by nonstate actors and is therefore covered by Decision 5 of the 1997 ICM."29

Because oppositional work on FGM required cooperation with local NGOs and the involvement of $\mathrm{AI}$ activists in the countries where it was a widespread phenomenon, the IC specified that, in accordance with the ongoing loosening of the WOOC rule, ${ }^{30}$ sections might be allowed to work on FGM in their own countries. With this final decision on FGM, AI broadened its mandate with an issue of violence against women. It confronted the issue of governmental responsibility for inaction and tested the ways AI might hold private actors accountable. Thus, the decisions on FGM must be considered a "significant expansion into the private sphere." 31

ICM decisions concerning women's rights in general

The gradual mandate opening illustrated, among other things, the importance of the issue of FGM for future work on non-state actors. In addition to the decisions calling for an increase in AI's work on women's rights, AI also deliberated on other subjects related to violence against women in the same period. I will only mention the most important among them, which are decision 22 of the 1993 ICM and decisions 9 and 8 of the 1995 ICM. Decision 22 called for support for the UN initiative to establish a Special Rapporteur on violence against women. AI stressed that every effort should be made to use campaign opportunities to work against human rights violations against women. ${ }^{32}$ This decision echoed decision 15 of the 1989 ICM and recognized "that women suf-

29 Amnesty International, International Secretariat: The Decision of the 1997 ICM, 05.01.1998, p.12.

30 As described in Decision 48 of the 1995 ICM Work on Own Country.

$31 \quad$ Watson 1997, p.8.

32 Amnesty International, International Secretariat: 21th International Council Meeting Report and Decisions, Resolutions referred to the IEC, 1993, p.63. 
fer grave human rights violations, including rape and sexual ill-treatment and other forms of persecution directed against their sex." ${ }^{33}$

Then, in decision 9 of the 1995 ICM, the IC explicitly called to:

"examine situations where the government systematically fails to prevent, investigate and punish acts of violence against women [...], including but not limited to honor killings, bride burning and the systematic non-persecution of domestic violence."34

Similar to the decision on FGM, this decision signaled an opening of AI's working spectrum to human rights violations occurring in the private sphere. At the same time, AI extended the criteria for the adoption of prisoners of conscience, enabling the organization to also include persons imprisoned because of existing laws that make their identity "a defined element of the offense." 35 In fact, decision 8 of the 1995 ICM allowed the organization to help women detained because of their sex and to engage in promotional work against such discriminatory rules.

Whereas the ICM decisions reflect the policy frame of Al's activities, the Integrated Strategic Plans (ISPs) fix the movement's strategic direction for four to six years. ${ }^{36}$ The analysis of AI's first ISP, the Ljubljana Action Plan (LAP) 1996 - 1999, indicates where the organization put its emphasis when it comes to the implementation of the respective ICM decisions. While decisions related to AI's work on VAW ranked among the top priority issues of mandate development for the first time, ${ }^{37}$ other decisions concerning AI's work

33 Amnesty International, International Secretariat: The Decisions of the 1993 ICM, 30.09.1993, p.30.

34 Amnesty International, International Secretariat: The Decisions of the 1995 ICM, 01.09.1995, p.21.

35 Amnesty International, International Secretariat: The Decisions of the 1995 ICM, 01.09.1995, p.20.

36 Prior to 1996, Al had broadly formulated medium-term objectives (five to six years) formulated as ICM decisions (Decision 1 of the 1993 and the 1995 ICM). These objectives were criticized for not allowing adequate priority setting and demand regulation. In contrast to the medium-term objectives, the new planning instrument in the face of the ISP allowed for a rolling long-term strategic planning, integrated with financial planning (Amnesty International, International Secretariat: Strategic directions: 19951998 A discussion paper, 30.06.1993, p.16-21).

37 The LAP classified the decisions of the 1995 ICM into four areas (mandate, action, organization and development, and finances). In each of these areas, decisions were categorized either as top-priority, mid-priority, or low-priority. 
on VAW were only given medium priority, meaning that their implementation depended on resource availability. In fact, the organization stressed its intention to integrate its work on the promotion and protection of women's rights into its overall work. It also emphasized its intention to work on FGM in its promotional activities by singling the respective decisions (decision 20 1995 ICM, decision 61995 ICM) out as high-priority issues. At the same time, AI ascribed less importance to a comprehensive gender audit at all levels of the organization and to oppositional work on FGM, considering these decisions (decision 32 of the 1997 ICM, decision 6 of the 1997 ICM) of only medium priority.

Summing up, AI's human rights policy gradually shifted from its essential focus on civil and political rights and on the state as the basic violator of human rights, to adopting a mission that recognized the indivisibility of all human rights including economic, social and cultural rights. The recognition of abuses committed by political non-state actors within the mandate in 1991 was the first step of the subsequent redefinition of Al's policy away from seeing the state as the primary violator of human rights. The issue of FGM was central to AI's redefinition of its position regarding state accountability for inaction in cases of human rights violations committed by nongovernmental entities and the responsibility of private actors for abuses of human rights. In fact, FGM was the first women-specific human rights violation with which AI expanded its mandate. These mandate amendments were significant for effective action against violations of women's rights because they entailed the end of the long-lasting public-private divide inherent to the traditional understanding of human rights. They enabled the AI to take action against VAW whoever the perpetrator. The adoption of the mission, which also considered economic, social, and cultural rights, enabled the organization to campaign against VAW as a structural and social problem whose root causes resided in the social and economic subordination of women. While these policy changes indirectly contributed to making AI increase its work on issues of VAW, AI adopted three subsequent ICM decisions calling on the organization to increase its work on women's rights within the frame of the mandate. As I explain in more detail later, these decisions originated from female activists and officials in the sections, and they directly stimulated AI's activities on issues of VAW. 


\subsubsection{Policy Implementation - Al's activities on VAW within the frame of the mandate}

The present chapter concentrates on the ways AI initially integrated VAW into its activities while respecting the boundaries of the mandate. It shows that AI's work in this regard evolved considerably between 1989 and 2001. I start by providing a broad overview of AI's activities related to VAW before focusing on three major activities that the organization undertook during the same period. Combining a quantitative overview with a detailed description of these activities, I provide a comprehensive picture of the evolution of AI's activities on issues of VAW under the mandate.

The analysis of archive documents from the International Secretariat allows me to capture the approximate number and variety of activities that the organization carried out following the initial decision at the 1989 ICM. It also allows me to draw a typology of activities based on the content and the type of activity (Figure 3). ${ }^{38}$ As a reminder, the ICM decision called for increased attention and resources for the work on human rights violations against women. Based on the data, I establish two categories related to the activities' content (horizontally illustrated in figure 3): AI either addressed women's rights in general or focused on a specific case of VAW. Within this category, I distinguish between cases of VAW committed by the state or by state actors and those cases committed by private actors for which the state can be held accountable for failing to prevent or punish them. Further, I differentiate between four broad types of activities (vertically illustrated in figure 3): "Institutional measures;" "Research and campaigning;" "IGO work;" and "Outreach."

"Institutional measures" includes all activities seeking to increase the staff's and activists' awareness of women's rights issues. The type "Research and Campaigning" is comprised of reports and campaigns with a regional or a thematic focus as well as individual appeal cases and specific activities such as women's day actions. Within this type I further distinguish between activities specifically and uniquely focusing on violations of women's rights and those that added a women's branch to other thematic- or country-specific human rights reports or campaigns. Under the type "IGO work," I classified 
Figure 3: Typology of AI activities related to VAW

\begin{tabular}{|c|c|c|c|c|c|}
\hline & & & \multicolumn{3}{|c|}{ The activitiy's content: Women's rights are addressed } \\
\hline & & & \multirow[b]{2}{*}{ In general } & \multicolumn{2}{|c|}{ By focusing on a specific case of VAW } \\
\hline & & & & $\begin{array}{l}\text { Committed by the } \\
\text { state }\end{array}$ & $\begin{array}{l}\text { Committed by private } \\
\text { actors }\end{array}$ \\
\hline \multirow{6}{*}{ 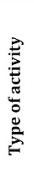 } & & Institutional Measures & & & \\
\hline & \multirow{2}{*}{$\begin{array}{l}\text { Research and } \\
\text { campaigning }\end{array}$} & Unique focus on women's rights or VAW & & & \\
\hline & & Integrated in other reports or campaigns & & & \\
\hline & \multirow{2}{*}{ IGO work } & $\begin{array}{l}\text { With organizations spezialized in women's } \\
\text { rigths or VAW }\end{array}$ & & & \\
\hline & & $\begin{array}{l}\text { With organizations working on human rights in } \\
\text { general }\end{array}$ & & & \\
\hline & & Outreach & & & \\
\hline
\end{tabular}

Source: my own, based on archival material.

AI's activities consisting in lobbying the UN or other IGOs. Again, I differentiate between IGO activities with organizations specialized in women's rights and those activities with organizations working on human rights in general. Further, I classified contact to and collaboration with women's rights groups, associations, and organizations as belonging to the "outreach" type. As I further highlight later, these women's rights NGOs constituted an important knowledge basis for AI. The collaboration with these groups enhanced AI's campaigning capacity with respect to VAW.

Figure 3 illustrates the categories according to which I classified AI's activities on VAW. Concerning the "Institutional Measures" category, AI put various actions in place to increase awareness of women's rights among staff and activists: the pilot project for decentralized work on women, the international consultation meeting in Bonn in preparation of the campaign Human Rights are Women's Rights, member training within the frame of the aforementioned campaign, and the latter's evaluation. Further, in 1996, AI established a Gender Forum ${ }^{39}$ at the IS to provide strategic advice in the implementation of the objectives regarding women's rights fixed in its long-term strategic plan (the LAP). In addition, AI issued Gender-Sensitive Research Methodology Guidelines (as demanded in decision 32 of the 1997 ICM) ${ }^{40}$ and endorsed a harassment pol-

39 The role of the Gender Forum is discussed in chapter 8.

40 Amnesty International, International Secretariat: Gender Sensitive Research Methodology Guidelines, January 1999. 
icy in 1999 (as specified in decision 2 of the 1997 ICM). ${ }^{41}$ Finally, AI organized specific training courses for staff on the issue of rape as a form of torture in preparation for the Take a Step to Stamp Out Torture campaign.

"Research and campaigning" was the most common type of activity. The predominance of research and campaign activities is not surprising, as these activities had always constituted AI's "primary organizational output." 42 As I highlight in more detail later, the 1991 report Women in the Front Line and the 1995 campaign Human Rights are Women's Rights were Al's most important actions organized in the 1990 in terms of how issues of VAW were integrated and of financial and personal resources. Besides, the IS issued several smaller country and thematic reports, and prepared numerous Appeal Cases focusing on cases of VAW committed by state actors and by non-state actors alike. AI also focused on specific cases of VAW by integrating them into other reports and campaigns. The Take a Step to Stamp Out Torture campaign launched in 2000 was the most important, as it was the first time that AI had considered VAW in the private sphere a form of torture.

Further, AI started to lobby several IGOs on women's rights around the mid-1990s. In doing so, AI's either promoted the topic within IGOs in charge of human rights issues in general, such as the $\mathrm{UN}$, or it tried to collaborate with IGOs specialized in women's rights issues, such as the CSW or the Special Rapporteur on Violence Against Women. The occasions on which AI promoted specific cases of VAW were much more rare. Examples of this were the efforts to recognize rape as a war crime in the Rome Statute and the International Criminal Court or the participation in a UN Committee drafting a protocol on trafficking of women and children in 1996. Even though AI had established links to the women's rights organization prior to the WCW, particularly, after the 1993 UN Conference on Human Rights in Vienna, most of its outreach work to women's NGOs occurred during and after the $1995 \mathrm{cam}$ paign.

The preceding paragraphs have elucidated the variety of activities AI implemented following decision 15 of the 1989 ICM. The classification of these activities according to the year of their launch allows us to see that most of them were launched in 1996 (graph 5). The significant increase in activities in 1996

41 Amnesty International, International Secretariat: Strengthening Research and Action on Human Rights Violations against Women Formulating an Implementation Strategy for the LAP (1996-2000), 06.07.1999 
is linked to the fourth WCW in Beijing 1995 and to the related campaign $\mathrm{Hu}$ man Rights are Women's Rights as well as to decision 20 of the 1995 ICM, which called for an increase in AI's work on violations of women's rights. Graph 5 also illustrates that AI's activities on the issue regressed in quantitative terms after 1996 but that they remained higher than before 1995.

Graph 5: Evolution in the number of activities, 1989-2001

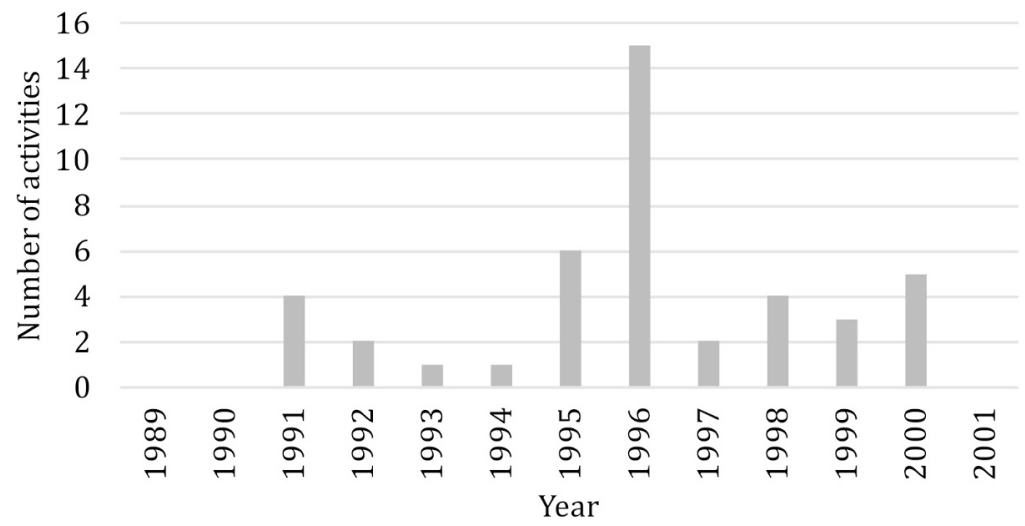

Source: my own, based on archive materials from the IS.

By classifying these activities according to their content and type, these paragraphs have provided an overview of AI's work on VAW in the 1990s. While I have commented on its variety and numeric progression, the classification does not account for the qualitative evolution of AI's work on VAW during this period. By providing a detailed account of three key activities, I chose according to information from my interviews or archival materials, the following three sections shed more light on how AI effectively integrated VAW into its activities and how this work evolved. First, I offer details on AI's first comprehensive report, Women in the Front Line, published in 1991 and the related pilot project for decentralized work on women. Then, I concentrate on the 1995 campaign Human Rights are Women's Rights, AI's first comprehensive international campaign on the rights of women. Finally, the campaign Take a Step to Stamp Out Torture illustrates how the organization included a case of VAW in a long-term thematic campaign. 


\subsubsection{Women in the Front Line}

As a result of the first ICM decision that demanded an increase in the work on women's rights (decision 15 of the 1989 ICM), the AI section in the US (AIUSA) and the IS worked out a pilot project seeking to decentralize AI's work on women from the IS to AIUSA. Within this pilot project, AIUSA was accountable to the IS for the development of AI's so-called "target sector work" for women for a period of two years, from January 1991 to December $1992 .{ }^{43}$ One of the outcomes of the pilot project was AI's first report on violations of women's rights, Women in the Front Line: Human Rights Violations Against Women. The latter introduced the issue of gender-based violence in state custody into AI's language. ${ }^{44}$ For the first time, women were not only portrayed as victims of state violence but also as political actors challenging state repression. According to AI, "the report was the first AI report ever to compile a worldwide survey of human rights violations against women" ${ }^{25}$ falling within the mandate. Eight appeal cases of women prisoners reflecting "the different kinds of human rights abuses within AI's mandate that women suffer" accompanied the release of the report. ${ }^{46}$

\subsubsection{Human Rights are Women's Rights}

AI organized its first international campaign on women's rights, Human Rights are Women's Rights, in parallel with its preparation for and participation in the fourth WCW. Therefore, this section also includes AI's involvement in the Beijing conference. In terms of employed resources, the 1995 campaign was by far the most important action on issues of VAW that AI had realized under the mandate. The campaign had two broad objectives: "define and raise the profile of AI's work on human rights abuses against women" and "pressure governments to place the indivisibility of human rights and women's rights at the heart of the WCW." 47 Benefiting from the momentum of the fourth

43 Amnesty International: Report of the Intersectional Meeting on Women and Human Rights, August 1991, p.17.

44 Roach 1994.

45 Amnesty International, International Secretariat: Women's action 1991, 1990, p.3.

46 Amnesty International, International Secretariat: Women's action 1991, 1990, p.1.

47 Amnesty International, International Secretariat: Evaluation of Theme Campaign Women and Human Rights, October 1996, p.5; Amnesty International, International Secretariat: Evaluation of Theme Campaign - Women and Human Rights, October 1996. 
WCW, AI intended the campaign to place the issue of women's rights at the top of public and the governmental concerns. ${ }^{48}$

The campaign sought to make women's civil and political rights appear in the fourth WCW's final document, mobilizing global public opinion and contributing to the ratification of all international treaties regarding women's rights by as many states as possible. ${ }^{49} \mathrm{AI}$ pushed to integrate a clear reference to states' responsibility for VAW and a number of concrete steps governments should take to end VAW into the Platform for Action, the conference's final document. ${ }^{50}$ Thus, at the Beijing conference, AI mainly concentrated on the issues of recognizing states' responsibility to end and prevent VAW, the vulnerability of women in armed conflicts, including states' responsibility to respect international human rights and humanitarian law, and states' responsibility to ensure the respect for female activists' human rights. ${ }^{51}$

AI qualified the 1995 campaign as the beginning of increased activities on women's rights: "the campaign was seen not simply as another short-term exercise but as an opportunity to 'kick-start' a comprehensive and ongoing program of activities. ${ }^{52}$ The importance of the campaign becomes evident in the number of officials and activists involved in its preparation and in the composition of AI's official delegation to the conference in Beijing, which was composed of the SG, 12 IS staff members, and 16 selected AI section participants.

The idea to realize a campaign against the violations of women's rights to accompany the movement's participation in the fourth WCW goes back to the UN Human Rights Conference in Vienna 1993. ${ }^{53}$ It became evident at the 1993 ICM two months later, where Pierre Sané stated: "We need to start planning

48 Amnesty International: Formation continue Campagne Femmes engagée - femmes en danger, 25.02.1995

49 Amnesty International: Formation continue Campagne Femmes engagée - femmes en danger, 25.02.1995

Amnesty International, International Secretariat: Report of the Fourth UN World Conference on Women Beijing, China 4-15 September, October 1995, p.13.

51 Amnesty International, International Secretariat: Report of the Fourth UN World Conference on Women Beijing, China 4-15 September, October 1995, p.24-26.

52 Amnesty International, International Secretariat: Strengthening Research and Action on Human Rights Violations against Women Formulating an Implementation Strategy for the LAP (1996-2000), 06.07.1999, p.2.

53 Amnesty International: ICM 1993: Resolutionen B, 1993. 
for Beijing now." ${ }^{4}$ Effective planning and organizing began in March 1994, when the IEC finally decided to bring this idea to fruition. ${ }^{55}$ At the movement-wide consultation meeting in Bonn in September 1994, AI clarified the content of the campaign and the strategy for its participation in the fourth WCW. Outreach activities had already started during the preparation of the campaign and AI's participation in the WCW. Participating in all of the UN regional and CSW "prepcom" meetings charged with drafting the Beijing Platform for Action, AI began to establish strong links to women's NGOs around the world. ${ }^{56}$ In addition, an Outreach Coordinator at the IS was responsible for AI networking with other NGOs at the various NGO Forum preparatory meetings. As the campaign's evaluation documents: "Sections were encouraged to explore the possibilities of developing long-term relations with NGOs, especially the major women's NGOs [...]." ${ }^{\text {57 }}$ Many sections were involved in lobbying their governments with the objective "to persuade them to adopt the position advocated by AI for the WCW." 58

Further, AI supported an international petition, addressed to the UN and asking it to fulfill its commitment to eliminate VAW. The latter was launched by a large number of organizations affiliated under the title Global Campaign for Women's Human Rights, within which AI sections contributed to the collection of "several hundred thousand signatures," 59 making it "the most successful and popular part of the [Human Rights are Women's Rights] campaign." ${ }^{60}$ At the parallel NGO Forum, where numerous IS staff and section activists repre-

\footnotetext{
54 Amnesty International: Fax from the IWN to the IEC and SC, 18.11.1993, p.1.

55 Amnesty International, International Secretariat: Evaluation of Theme Campaign Women and Human Rights, October 1996.

56 Amnesty International, International Secretariat: Key milestones of Al's work on women's human rights, 02.04.2002, p.2; Amnesty International, International Secretariat: Evaluation of Theme Campaign - Women and Human Rights, October 1996. Amnesty International, International Secretariat: Evaluation of Theme Campaign Women and Human Rights, October 1996, p.10.

58 Amnesty International, International Secretariat: Evaluation of Theme Campaign Women and Human Rights, October 1996, p.7-8.

59 Amnesty International, International Secretariat: Evaluation of Theme Campaign Women and Human Rights, October 1996, p.8.

60 Amnesty International, International Secretariat: Evaluation of Theme Campaign Women and Human Rights, October 1996, p.8.
} 
sented $\mathrm{AI},{ }^{61} \mathrm{AI}$ concentrated its outreach activities on publicity for its work, especially for its Human Rights are Women's Rights campaign, and on networking with NGOs working on women's rights. ${ }^{62}$ After the conference, the outreach to women's NGOs was one of AI's main follow-up activities. In parallel, the IS encouraged sections to continue and intensify their work with women's NGOs in their respective countries in order to ensure the government's fulfillment of the Platform of Action. ${ }^{63}$

After intensive preparations, the Human Rights are Women's Rights campaign was finally launched on the $8^{\text {th }}$ of March 1995 . The campaign's thematic focus fell on violations of women's civil and political rights. Respecting the boundaries of the mandate, it primarily highlighted the issues of VAW in situations of war and affecting female human rights defenders and women in custody. AI pointed to the particular vulnerability of female refugees, defined rape committed by state actors as an act of torture, and stressed the right of women not to be tortured, killed, arbitrarily detained or disappeared. The organization called on governments to implement stronger measures to protect women from human rights violations committed by state and non-state actors. Therefore, the state remained the main addressee of these demands. ${ }^{64}$ An important component of the 1995 campaign, which distinguished it from the 1991 action, was its message that even though women's rights were at the center of the campaign, it was not a women's campaign but a campaign for all AI members.

As far as outcomes are concerned, the evaluation of Human Rights Are Women's Rights reveals that AI considered the campaign successful, as it raised Al's profile as an organization fighting to stop and prevent human rights violations against women. Further, the fact that the campaign stimulated a significant expansion of research and action on women's rights issues, as illustrated in graph 4 , was also deemed positive. An interviewee pointed out that

61 Amnesty International, International Secretariat: Al's Presence in Beijing (Internal), 25.11.1994; Amnesty International, International Secretariat: Letter from the Project Coordinator WCW, 01.03.1995.

62 Amnesty International, International Secretariat: Letter from the Project Coordinator WCW, 01.03.1995.

63 Amnesty International, International Secretariat: "Beyond Beijing - the struggle continues" Follow-up activities on the Platform for Action, March 1996.

64 Amnesty International und International Secretariat: Evaluation Campaign 1995, December 1995 
the implication of the whole movement in the Beijing preparation process enhanced the members' awareness of the importance of integrating the work on women's rights into AI's overall work. She explains: "from the moment that all the sections started to work on the Beijing conference there was a sort of awareness building in people's mentality." 65

Moreover, the relationships established with women's NGOs during the women's campaign were judged very effective. An informant explains that AI's participation in Beijing "was a very successful attempt by Amnesty. For the first time Amnesty became accepted, was accepted very well by the key female leaders in the movement." ${ }^{66}$ At the same time, the limitation fixed by the mandate and the WOOC rule hindered some sections' attempts to reach out to women's rights NGOs because AI could not address the issue of domestic violence. ${ }^{67}$ In addition, the evaluation also stated that other factors hampered the success of the campaign, such as the delayed decision to undertake the campaign, the under-staffing affecting campaign work at the IS, inadequate research information on some subjects, and the fact that the preparation of AI's participation in Beijing took time and resources needed for the broader campaign. ${ }^{68}$ In sum, the lack of human and/or financial resources was considered the main obstacle to effective campaigning. ${ }^{69}$

Consequently, Women in the Front Line and Human Rights are Women's Rights were Al's first comprehensive international research and campaign activities addressing cases of VAW as covered by the mandate. The 1995 campaign focused on a range of women-specific human rights violations covered by the mandate and tackled states' responsibility to end VAW committed by private actors, such as trafficking or FGM. Nevertheless, AI still defined itself as a

65 Ganzfried: Interview with A.J., 09.03.2012: "Il n'y avait pas systématiquement tous les rapports qui parlait de ça mais dès le moment ou après toutes les sections se sont mise à travailler par rapport à la conférence de Beijing il y a un espèce de awareness building dans la mentalité des gens.".

66 Ganzfried: Interview with A.O., 23.01.2015.

67 Amnesty International, International Secretariat: Evaluation of Theme Campaign Women and Human Rights, October 1996, p.10; Amnesty International, International Secretariat und Amnesty International, International Secretariat: 1997 Meeting of the Intersectional Women's Network (IWN), May 1997.

68 Amnesty International, International Secretariat: Evaluation of Theme Campaign Women and Human Rights, October 1996, p.11-12.

69 Amnesty International, International Secretariat: Evaluation of Theme Campaign Women and Human Rights, October 1996, p.11. 
movement "that works to prevent some of the gravest violations by governments of people's fundamental human rights." ${ }^{70}$ Even though archive materials do not allow me to define the exact financial and personal resources $\mathrm{AI}$ destined to the activities related to the fourth WCW, compared to the pilot project and the Women in the Front Line report, which was mainly carried out by a team of two officials at the US section and the IS, AI substantially increased the financial and personal resources available for the Human Rights are Women's Rights campaign. More importantly, through the 1995 campaign and its active participation in the fourth WCW, AI enhanced its staff and activists' awareness of women's rights and became a valuable partner of women's rights organizations in their struggle to make the international community consider women's rights as human rights.

The campaign has been criticized for "continue[ing] to reproduce an image of passive, dependent women who need paternal families and states to protect them." As explained by Bahar, "this image ultimately relies on assumptions of a patriarchal family where female child-rearers depend on strong male figures for protection." ${ }^{71}$ In addition to specific women's rights activities, such as the 1991 report and the 1995 campaign, by the late 1990 s the organization had started to consider the issue of VAW in broader thematic campaigns, such as the one on torture, within which AI considered VAW in the private sphere as an act of torture for the first time.

\subsubsection{Take a Step to Stamp Out Torture}

The Take a Step to Stamp Out Torture campaign was launched in October 2000 and can be considered the most important example of the integration of VAW into a thematic campaign. More important, it was the first international thematic campaign where AI defined VAW in the private sphere as an act of torture. According to an interviewee, the campaign signaled the beginning of AI's work on women's rights in the private sphere: "AI started doing women's rights work and LGBT and sexuality work under the torture campaign." ${ }^{72}$ In fact, identity-based abuses such as torture based on gender, sexuality or race constituted core issues of the campaign. In the main campaign document, AI explains that "Many forms of violence against women in the home and in the

70 Amnesty International, International Secretariat: Campaign on women and human rights - theme leaflets, 07.03.1995, p.2.

$71 \quad$ Bahar 1996, p.117.

72 Ganzfried: Interview with A.W., 25.06.2012. 
community may also constitute torture or ill-treatment. The harm inflicted is often the same or comparable to that which is inflicted on women who are tortured in custody."73

The IS published a specific report on torture and ill-treatment of women within the campaign, underlining AI's aim of holding "states accountable for all acts of torture of women, whatever the context in which they are committed and whoever is the perpetrator." ${ }^{74}$ In fact, by defining cases of VAW in the private sphere as acts of torture, AI applied the International Convention on Torture, a "hard" human rights standard, to women. The work on VAW carried out within the torture campaign was significant, as "Under the rubric [of the torture campaign AI] first began to do the sexuality work using one of the hardest standards in international law, hard law, black letter law, it is an absolute standard, there is no excuse to undermine it." 75 However, as I show later, this new approach seems to have been unsustainable in the SVAW campaign. AI "moved from 'black letter standard' to soft law"76 addressing VAW in the private sphere, such as domestic violence, not as a matter of state accountability but foremost under the concept of due diligence entailing a focus "on the state obligation to create conditions to prevent and adequately respond to violence against women perpetrated by non-state actors."77

Summing up, the present section has highlighted the ways in which AI initially integrated VAW into its activities respecting the boundaries of the mandate and shown that AI's work evolved considerably between 1989 and 2001. Whereas the report Women in the Front Line focused on gender-based violence in state custody and highlighted patterns of political persecutions of women, the Human Rights are Women's Rights campaign focused on torture, the death penalty, extra-judicial executions, and disappearances as they affected women. It also tackled states' responsibility to end VAW committed by private actors such as trafficking or FGM. However, similar to its first report, the state remained the primary addressee of the organization's demands to prevent and condemn VAW. By independently considering all forms of VAW as acts

73 Amnesty International, International Secretariat: Take A Step To Stamp Out Torture, 2000, p.28.

74 Amnesty International, International Secretariat: Broken bodies, shattered minds Torture and ill-treatment of women, 2001, p.4.

75 Ganzfried: Interview with A.W., 25.06.2012.

76 Ganzfried: Correction of citations A.W., 22.08.2018.

77 Benninger-Budel 2008. 
of torture, whatever their context and whoever their perpetrator, the Take a Step to Stamp Out Torture campaign can be seen as AI's first effective attempt to campaign against VAW in the private sphere.

Even though AI's activities on the issue of VAW increased tremendously during the 1990s, both in quantitative and qualitative terms, an internal report from 2000 stated: "the sum of all activities undertaken since 1995 does not amount to institutionalization nor does it amount to sustainability."78 Evidence indicates that despite the intensification of its fundraising efforts and the reallocation of resources following the 1995 ICM, a lack of resources continued to plague efforts to make women's rights an integral part of AI's work. ${ }^{79}$ For example, the medium priority given to the execution of a gender audit in the LAP (decision 32 of the 1997 ICM) and financial cuts in the IS impeded the realization of a comprehensive gender-based evaluation of the whole movement as demanded at the 1997 ICM. ${ }^{80}$

The previous two sections have delineated policy developments regarding VAW and emphasized the evolution of AI's body of work. However, they have remained silent on the origins of this progress. The following section fills this knowledge gap and shows that feminist strategizing is key in comprehending why AI started to do work on VAW and in understanding the subsequent increase in the latter.

\subsubsection{Feminist strategizing}

As mentioned in chapter 2.3, external and internal factors are known to have contributed to AI's growing interest in issues of VAW. The changing patterns of human rights violations contributed to making $\mathrm{AI}$ question its statefocused mandate, ${ }^{81}$ thereby facilitating work on violations of women's rights. Further, the growing international awareness of gender equality stemming from the UN Decade for Women 1975-1985 and the related WCWs, especially

Amnesty International, International Secretariat: Final Implementation Report of the Ljubljana Action Plan, 1996-2000, July 2000, p.8.

79 Amnesty International, International Secretariat: Evaluation of Theme Campaign Women and Human Rights, October 1996, p.15.

80 Amnesty International, International Secretariat: Letter from Habiba Hasan (IEC member with brief on Women \& gender) giving an update on the Gender Audit and Intersectional Women's Network, November 1998.

81 Thakur 1994; Pack 1999. 
the conference in Beijing, affected AI's approach to women's rights. ${ }^{82}$ At the same time, the international women's rights movement challenged mainstream human rights organizations, such as $\mathrm{AI}$, to expand their mandate to violations of human rights in the private sphere. ${ }^{83}$ The positive stance of the SG Pierre Sané, who "took a leading role in enunciating Amnesty's support for women's rights [...]," ${ }^{84}$ the growing number of women occupying management positions at the IS, and activists' lobbying the organization to work on women's rights more seriously are all internal factors known to have contributed to AI's increasing interest in issues of VAW.

Aware of these external and internal factors, the present section demonstrates that the feminist strategies of parallel networking and analogous framing were crucial in increasing AI's interest in issues of VAW. They also explain the decision to launch a first global theme campaign on VAW. Even though female activists and officials within AI would not necessarily have perceived their strategies as feminist, I define them as feminist because they were set up by women and ultimately challenged the underlining gender hierarchy inherent to AI's conception of human rights. ${ }^{85}$

I argue that by setting up the IWN, female activists and officials were able to internally lobby to increase AI's work on violations of women's rights in an effective way. Organizing in an intersectional network allowed female activists and officials to reach out to the whole AI movement and find majorities for their demands at the ICMs. Parallel networking was thus one of the strategies used to influence AI's agenda. I call the strategy parallel networking because the IWN was based on AI's overall transnational-network structure. At the same time, female activists and officials called for an increase in AI's work on women's rights within the frame of the mandate. They thus used a strategy of analogous framing because by demanding an intensification of the organization's work on violations of women's civil and political rights, rather than calling for the end of AI's state-focused mandate, they framed their demand in a manner analogous to AI's overall policy. Similar to the strategy of parallel networking, this strategy was crucial in making AI increase its work on VAW because it allowed female activists to garner the majority of the movement's support to engage more seriously with women's rights.

\footnotetext{
82 Bunch 2001.

83 Bahar 1996.

84 Kelleher and Bhattacharjya 2013, p.4.

85 Sperling et al. 2001.
} 
The section begins by providing initial evidence of the IWN as a vector for change in the 1990s. It proceeds to trace the foundation of the network and highlight female activists' role in initiating AI's work on violations of women's rights that falls within AI's mandate in the late 1980s. The section follows up by highlighting the lack of sustainability of the pilot project for decentralized work on women established following decision 15 (1989 ICM). The section on the UN Conference on Human Rights and the fourth WCW demonstrates how IWN members continued to push the implementation of decision 15 of the 1989 ICM and the adoption of the related follow-up decision at the 1995 ICM (decision 20). In particular, the 1995 WCW in Beijing became a window of opportunity for the lobbying efforts of female activists and officials who wanted the organization to increase its work on VAW and facilitate the integration process. Later, the section illustrates that with the appointment of an IWN coordinator at the IS, the network members changed their lobbying efforts and began to target the essence of AI's work, namely research. The section concludes by establishing that continuing pressure from female activists and officials at various levels organized in the IWN finally led the IEC to decide to launch AI's first global thematic campaign on VAW in 2001.

Several archive documents and secondary publications illustrate the importance of the IWN for making AI increase its work on issues of VAW. This significance proves the existence and the effectiveness of a feminist strategy of parallel networking. Internal voices from both the IS and sections emphasized the network's importance "[...] in raising the profile of AI's work on women's rights in their countries as well as globally." 86 They identified the IWN as "responsible for many of the strides made in AI's work on women's rights and in particular on VAW prior to the launch of the SVAW campaign." ${ }^{87}$ According to Kelleher and Bhattacharjya (2013), "The IWN [...] contributed to the pressure on the IS to bring women's rights to their work." ${ }^{88}$ IWN members themselves emphasized their network's substantial contribution to monitoring the insti-

\footnotetext{
86 Amnesty International, International Secretariat: 2002 Intersectional Women's Network (IWN) Meeting, October 2001, p.1.

87 Amnesty International: Al and a new international women's rights network, November 2009, p.6.

88 Kelleher and Bhattacharjya 2013, p.3.
} 
tutionalization of gender within $\mathrm{AI}^{89}$ and qualified it as a vector for change for the sections. ${ }^{90}$

In fact, the IWN was founded by female activists as an intersectional advisory group with expertise on women's rights issues in the early 1990s. While de facto open to all members, the network was mainly composed of female activists and officials. ${ }^{91}$ It developed from "an informal grouping of women's activists" 92 without a formal standing in 1991 into an officially recognized network ${ }^{93}$ of 58 sections by $2001 .{ }^{94}$ According to an IS document:

"the IWN has evolved over the years from a loose and informal structure with most of its members not having a formal status in sections to a network composed of individuals or groups or networks or committees set up by sections to specialize on their work on women's rights." 95

Combining the IWN's significance in causing AI to strengthen its work on issues of VAW with the fact that all previously described ICM decisions directly concerning VAW (underlined in Figure 4) were based on resolutions initiated by sections (Figure 4$)^{96}$ suggests that the members of the IWN must have pushed policy developments in AI's work on issues of VAW. In fact, I show

89 Amnesty International, International Secretariat und Amnesty International, International Secretariat: 1997 Meeting of the Intersectional Women's Network (IWN), May 1997, p.7.

90 C. und C.: IWN meeting, April 2002.

91 Amnesty International: Amnesty International Intersectional Women's Network Member List, 1995; Amnesty International, International Secretariat: 2002 Intersectional Women's Network (IWN) Meeting, October 2001; Amnesty International, International Secretariat: Information pack for Intersectional Women's Network, May 2001

92 Amnesty International, International Secretariat: Letter from Habiba Hasan (IEC member with brief on Women \& gender) giving an update on the Gender Audit and Intersectional Women's Network, November 1998, p.2.

93 The IEC approved the IWN's Terms of References (TORs) in April 1998 (Amnesty International, International Executive Committee: IEC Information Bulletin No. 23, April 1998b).

94 Amnesty International, International Secretariat: Information pack for Intersectional Women's Network, May 2001.

95 Amnesty International, International Secretariat: Information pack for Intersectional Women's Network, May 2001.

96 Decision 6 of the 1995 ICM goes back to an initiative of the Luxembourg section (formulated in decision 10 of the 1993 ICM) instructing the IEC to present recommendations on how Al should deal with FCM at the next ICM (Amnesty International, International Secretariat: The Decisions of the 1993 ICM, 30.09.1993, p.14). 
that the members of the IWN mostly concentrated on the adoption and implementation of those decisions made at the 1989, 1995, and 1997 ICMs that called for an increase in AI's work on women's rights within the mandate (underlined and in italic in Figure 4). I thus present analogous framing as one of the strategies female activists and officials employed to affect AI. Female activists also seemed to have initiated policy development on FGM: "working on the issue of FGM was, at the time, a demand from the women of the South, from African women." 97 However, this concern was not the focus of the IWN's lobbying efforts. ${ }^{98}$

Figure 4: The origin of ICM decisions

\begin{tabular}{|c|c|}
\hline \multicolumn{2}{|c|}{ ICM decisions based on a resolution initiated by } \\
\hline sections & the IEC \\
\hline $\begin{array}{l}\text { Decision } 151989 \text { ICM Human rights violations against } \\
\text { women } \\
\text { Decision } 101993 \text { ICM Female Genital Mutilation } \\
\text { Decision } 221993 \text { ICM UN Rapporteur on Women } \\
\text { Decision } 91995 \text { ICM Women } \\
\text { Decision } 201995 \text { ICM Work on behalf of Women } \\
\text { Decision } 31997 \text { Mandate Review } \\
\text { Decision } 61997 \text { ICM FGM } \\
\text { Decision } 321997 \text { ICM Action on Human Rights } \\
\text { Violations against Women }\end{array}$ & $\begin{array}{l}\text { Decision } 61995 \text { ICM Governmentalinaction and FGM } \\
\text { Decision } 51997 \text { ICM Abuses by Non-state Actors } \\
\text { Decision } 31999 \text { ICM Mandate Review } \\
\text { Decision } 32001 \text { ICM Statute amandment: Vision and } \\
\text { Mission of Amnesty International } \\
\text { Decision } 132001 \text { ICM Work on own country } \\
\text { Decision } 72001 \text { ICM Mandate: Economic, Social and } \\
\text { Cultural Rights } \\
\text { Decision } 62001 \text { ICM Mandate Review }\end{array}$ \\
\hline
\end{tabular}

Source: ICM reports

Months of internal discussions and lobbying from female AI section activists heralded the adoption of decision 15 at the 1989 ICM. In fact, activists' complains about the systematic under-representation of women in the cases investigated by AI dates back to the late 1980 s. ${ }^{99}$ In this period, the lack of cases involving women seemed striking: "In 1987, of the thirty-three prisoner cases carried in Amnesty's International Newsletter, only three were women and, of the eleven cases initially highlighted in 1988 as part of the 'Human

97 Ganzfried: Interview with B.N., 06.06.2013: "De travailler contre les mutilations génitales, c'était une demande à l'époque des femmes du Sud, donc des femmes africaines [...]." Ganzfried: Interview with A.J., 09.03.2012.

98 The composition of the IWN, whose members mostly came from Western sections may be one reason for this focus. In fact, in 1995, only 1 of 30 members came from an African section (namely Tanzania).

99 Roach 1994. 
Rights Now!' tour, only one was a woman."100 The following statement colorfully illustrates the activists' concern about the absence of women among AI cases from AIUSA's perspective:

"In 1988, Amnesty members from around the United States came together in a membership meeting and they said, 'You know, we've got some reports, we've looked at the materials, and women are really just missing. These are great reports and they are really important. But turning the pages, what you have is case of man after man after man after man-on whose behalf we do want to work. But where are the women?'"101

As a result, in 1989, US section members used an Annual General Meeting Resolution to call upon AIUSA to strengthen work on behalf of the protection of women's human rights. ${ }^{102}$ A large majority of AIUSA members accepted the resolution. The section's board of directors sent a letter to the IEC and to the IS notifying them, among other things, that "Work on women needs to be more comprehensive and visible at every level of the movement"103 and offering "to help in any feasible way, including devoting additional resources to the task." 104

Because they "were really sick and tired of the IS becoming very gender blind," ${ }^{105}$ AI members in Germany, Switzerland, Britain, and Ireland pressured their sections to demand a better integration of women's rights into AI's overall work from the SG and the IEC, as well. ${ }^{106}$ These section initiatives heralded the forming of the IWN.

Then, at the 1989 ICM, a group of section delegates gathered together in an informal meeting to talk about the issue of how to start working on women's rights and "brought back a resolution to the full body that called for strengthening Amnesty's work for women at every level of the organization."107 The

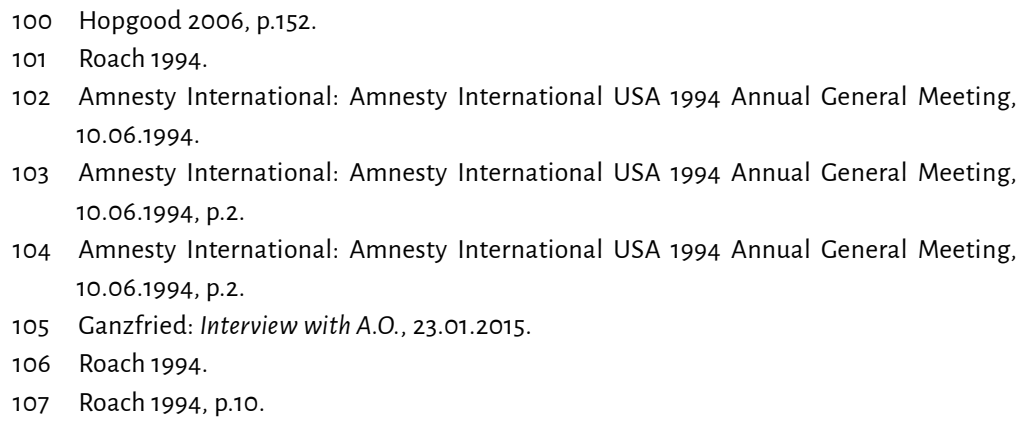

106 Roach 1994.

107 Roach 1994, p.10. 
resolution was subsequently adopted as decision 15 . The adoption of decision 15 can be interpreted as the first success of the feminist strategy of analogous framing, as the decision called on "the movement to strengthen its work on behalf of women" ${ }^{\prime 108}$ as covered by the mandate. During this informal meeting, the participants agreed to develop a "network of representatives from Amnesty sections and groups around the world interested in promoting AI's work for women"109 and decided that AIUSA should coordinate the development of the network. ${ }^{110}$

Consequently, this informal meeting of female delegates at the 1989 ICM can be seen as the origin of the IWN or the beginning of a feminist strategy of parallel networking meant to make AI increase its work on women's rights. The testimony of a participant in the informal meeting at the 1989 ICM reveals the female activists' hope about this first achievement: "We were so happy when we heard [that the resolution passed]. We thought, "This is it! This is the breakthrough. This is what we've been waiting for."'111

The IWN was established (without having recognized Terms of References) at the first intersectional meeting on AI's work on women's rights in Geneva in February 1991. This first intersectional meeting ${ }^{112}$ was meant to push the further development of Al's work for the protection of women's human rights. The Swiss and the US sections co-hosted the gathering ${ }^{113}$ and the engagement of individual female activists seems to have been important for the organization of the event, as the Swiss section initially refused to organize the meeting because of the lack of "logistic possibilities to do it."114 The efforts of some female activists finally made it possible to organize the conference in Geneva. The results of the meeting, attended by representatives from $26 \mathrm{sec}-$ tions, were the forming of the IWN and the adoption of recommendations,

108 Amnesty International: Amnesty International USA 1994 Annual General Meeting, 10.06.1994, p.2.

Amnesty International: Report of the Intersectional Meeting on Women and Human Rights, August 1991.

Amnesty International, International Secretariat: Report of the Intersectional Meeting on Women and Human Rights, August 1991, p.2.

111 Roach 1994, p.10-11.

112 The 1991 meeting was later referred to as the first meeting of the IWN.

113 Amnesty International: Report of the Intersectional Meeting on Women and Human Rights, August 1991.

114 Ganzfried: Interview with A.B., 12.04.2012. 
which "were [subsequently] sent to the IS, IEC, and all sections." ${ }^{\text {"15 }}$ Nevertheless, as I detail hereafter, except for the establishment of the IWN, most of the recommendations have not been implemented because of the lack of financial and personnel resources. ${ }^{116}$

In parallel with the forming of the IWN and as a result of the decision 15 (1989 ICM), the IS and AIUSA worked out the pilot project for decentralized work on women, according to which an AIUSA staff member "worked part time as a member of the IS campaign unit to ensure the integration of work for women in campaigns and actions." 117 Additionally, the IS "target sector coordinator who was also responsible for trade unionists, children, religious groups, journalists, engineers, etc." ${ }^{\text {"18 }}$ was given "women" as an additional target sector. ${ }^{119}$ In a separate arrangement, an AIUSA staff member was given permission to "research IS material on women" 120 and the AIUSA women's task force identified "patterns of abuse that were gender-based." ${ }^{21}$ The outcome of these efforts was the publication of AI's first comprehensive report on the violation of women's rights, Women in the Front Line, in March 1991. However, this first "substantive and effective work"122 on women rights violations was not sustained. By the end of the pilot project in 1993, the work on women's rights issues was handed over to two IS staff persons already responsible for work on the death penalty, political killings, and disappearances. These staff members "made it clear they had no time or resources to devote to women's

115 Amnesty International: Amnesty International USA 1994 Annual Ceneral Meeting, 10.06.1994, p.2.

116 Amnesty International: Amnesty International USA 1994 Annual Ceneral Meeting, 10.06.1994; Amnesty International: Internationale Tagung über die ai-Kampagne für die Menschenrechte von Frauen, Bonn, 16.-18. September 1994, October 1994.

117 Amnesty International: Amnesty International USA 1994 Annual Ceneral Meeting, 10.06.1994, p.2.

118 Amnesty International: Amnesty International USA 1994 Annual Ceneral Meeting, 10.06.1994, p.2.

119 AIUSA, 1994 Annual Ceneral Meeting, June 10-12, Chicago, Illinois, Doc. 052.013, 49.

120 AIUSA, 1994 Annual General Meeting, June 10-12, Chicago, Illinois, Doc. 052.013, 49.

121 Roach 1994, p.11.

122 Amnesty International: Amnesty International USA 1994 Annual Ceneral Meeting, 10.06.1994, p.3. 
human rights issues."123 Further, the funding of the IWN was neither truly clarified nor sufficient in the first years. ${ }^{124}$

Concerned about the decline in work on women's human rights violations, the Canadian and the US sections pushed for an improvement by writing letters to the SG and the IEC. In a letter addressed to Pierre Sané, the Canadians expressed their "anxiety regarding the inadequate level of activity within AI concerning human rights violations against women"125 and asked "that the steps taken by AI towards addressing human rights violations against women be strengthened, as per 1989 ICM Decision 15 [...]."126 At the same time, the Chair of the AIUSA Board of Directors urged the IEC to make a commitment and allocate resources to ensure "that a focus on women is automatically integrated into our ongoing work including research, campaigns, press and publications." ${ }^{127}$ These letters were not signed by IWN members. However, given that the AIUSA member of the IWN had been especially engaged in pushing AI to increase its work on women's rights violations and that she continued to push her section in this regard, it is worth assuming that IWN members must have been behind these initiatives. Further, as I show subsequently, the IWN members of the US and the Canadian sections were particularly engaged in pressuring their section to make the movement strengthen its work on violations of women's rights.

Even though the IWN coordinator described her network at the time of the 1993 ICM as "not organized," 128 IWN members capitalized on the UN Conference on Human Rights in 1993. In fact, IWN members from different AI sections ${ }^{129}$ organized a meeting titled "AI and Women's Human Rights" during the conference and reiterated "their concerns regarding the inadequate level of activity within $\mathrm{AI}$ concerning human rights violations against

123 Amnesty International: Amnesty International USA 1994 Annual General Meeting, 10.06.1994, p.3.

124 Amnesty International: Internationale Tagung über die ai-Kampagne für die Menschenrechte von Frauen, Bonn, 16.-18. September 1994, October 1994.

125 Amnesty International: Letter to the IS concerning Al's work on women's rights, 27.04.1993, p.1.

126 Amnesty International: Letter to the IS concerning Al's work on women's rights, 27.04.1993, p.2.

127 Amnesty International: Letter from the Chair of the Board of Directors of AIUSA to the Chair of the IEC, 10.05.1993, p.1.

128 Roach 1994, p.11.

129 The Austrian, British, Canadian, Dominican, German, and the US sections. 
women." 130 During this meeting the IWN members agreed to urge their respective sections to send letters similar to those previously issued by the US and the Canadian sections. Further, they agreed to ask their delegates to the 1993 ICM to push for a major campaign on women's human rights violations around the $1995 \mathrm{WCW} .^{131}$

As a result, several sections finally complained about the poor implementation of decision 15 (1989 ICM) to the IEC $^{132}$ and others intervened at the 1993 ICM. The German section, for example, submitted a resolution ${ }^{133}$ to the 1993 ICM asking to "capitalize on the event of the UN World Conference on Women to be held in Beijing in 1995 to campaign on human rights violations against women." ${ }^{134}$ The Austrian section actively supported the German resolution in a letter to the ICM delegation and to the German section. ${ }^{135}$ At the 1993 ICM itself, the IWN members "got [their] directors to complain and say that [they] absolutely had to do better work than [what they] had been doing." ${ }^{136}$ Additionally, the AIUSA Women's Human Rights Steering Committee called the SG and the IEC to undertake additional steps to strengthen its work on women's rights in October $1993 .{ }^{137}$

Following these diverse lobbying efforts from IWN members, the IEC organized a movement-wide consultation on a possible theme campaign and decided (based on its outcome) to launch a campaign on human rights violations against women in view of the upcoming fourth WCW. ${ }^{138}$ Additionally, by mid-1994 the IEC assigned a member of the IWN as the first holder of the Spe-

130 Amnesty International: Minutes of the meeting "Al and Women's Human Rights" at the UN World Conference on Human Rights in Vienna, 1993, p.1.

Amnesty International: Minutes of the meeting "Al and Women's Human Rights" at the UN World Conference on Human Rights in Vienna, 1993.

132 Amnesty International, International Secretariat: Report of the meeting of the IEC 1518 April 1994, 26.07.1994, p.39.

133 Resolution B37, see appendix 2.

134 Amnesty International, International Secretariat: 21th International Council Meeting Report and Decisions, Resolutions referred to the IEC, 1993, p.94.

135 Amnesty International: Letter from the Austrian Section to the ICM Delegation 1993 and to the German section, 07.07.1993.

136 Roach 1994, p.11.

137 Amnesty International: Amnesty International USA 1994 Annual General Meeting, 10.06.1994.

138 Roach 1994. 
cial Brief on Women ${ }^{139}$ within the IEC with the objective of increasing the attention to women's rights at all levels, especially within research, ICM resolutions, campaigns, and publications. ${ }^{140}$ Having a representative within the IEC marked an important advance for the IWN members, as their demands were backed from within an AI's governing body from then on. Whereas archive material does not allow me to determine the exact origin of the idea to establish this Special Brief, the following extract from the IEC meeting shows that the IWN clearly backed its creation: "there has been support from sections, namely the inter-sectional network, for the development of the Brief."141

The IWN was closely involved in the planning and organization of the $\mathrm{Hu}$ man Rights are Women's Rights campaign and used the opportunity presented by the fourth WCW to continue pressuring for sustained work on women's rights within the whole movement. At the international consultation meeting for the preparation of the Human Rights are Women's Rights campaign in Bonn in September 1994, ${ }^{142}$ which was initiated by the German section's member of the IWN, the IWN members formulated demands for AI's future work on women's rights. They asked the IEC to make more resources at the IS available for the work on women's rights leading up to Beijing and wanted the IEC-Brief on Women to become a permanent institution. ${ }^{143}$ At the Bonn meeting, which became known as the IWN's second meeting, the IWN additionally agreed to increasingly target sections "to make them collectively push AI's work on persecuted women and to influence the SCM, the ICM and the IEC."144

At the same time, as the following extract from a letter from the IWN coordinator to the members indicates, the network continued pushing for the

139 Amnesty International International, Executive Committee: IEC Information Bulletin No. 12, 17.10.1995, p.30; Ganzfried: Interview with A.O., 23.01.2015.

140 Gruber und Frauenkommission Sektion der Bundesrepublik Deutschland: Letter from the Women's group of Al Cermany to the AI German section, 05.10.1994, p.2.

141 Amnesty International, International Secretariat: Report of the meeting of the IEC 1518 April 1994, 26.07.1994, p.39.

142 Amnesty International: Internationale Tagung über die ai-Kampagne für die Menschenrechte von Frauen, Bonn, 16.-18. September 1994, October 1994.

143 Amnesty International und Stuttard: Bonn Meeting - Summary of minutes, 04.11.1994; Amnesty International und Svorad: Bericht über die Tagung in Bonn, 09.1994.

144 "[l]ndem mehrere Sektionen gemeinsame Vorstösse für verstärkte ai-Arbeit für verfolgte Frauen unternehmen und Einfluss aufs SCM, ICM, IEC usw. ausgeübt wird." (Amnesty International: Internationale Tagung über die ai-Kampagne für die Menschenrechte von Frauen, Bonn, 16.-18. September 1994, October 1994, p.5). 
adoption of another ICM decision that would force AI to allocate the personnel and financial resources necessary for sustained work on violations of women's rights at all levels: "It is very important that as a network we begin now to develop a strategy that will ensure strong support from our section ICM delegates for allocating resources to support substantive work for women in the movement."145

As a result of the IWN members' lobbying, AI appointed a part-time women's rights coordinator at the IS who was responsible for the coordination of the Human Rights are Women's Rights campaign and of the IWN, in addition to other briefs. In fact, following a mutual agreement, AIUSA handed the IWN coordination over to the IS in early $1995 .{ }^{146}$ As I develop later, the centralization of the IWN coordination changed the focus of the IWN members' lobbying. At the same time, the IWN members' pressure on sections also bore fruit. In fact, as a letter from the coordinator to the IWN members highlights, "in about seven sections around the world, [IWN members] have brought forward very specific resolutions"147 to submit to the 1995 ICM. ${ }^{148}$ In light of the upcoming 1995 ICM, the IWN coordinator insisted in a letter to the members: "It is urgent that your delegation a.) Understand and support the resolution, and b.) Be willing to lobby delegates from other sections to support it as well." ${ }^{149}$

Finally, the US, the Canadian, the Austrian, the Irish, the Venezuelan, and the UK sections submitted three resolutions to the 1995 ICM requesting the integration of the work on women's rights into AI's overall work at all levels. ${ }^{150}$ In resolution $\mathrm{B} 4.2$, the US, the Canadian and the Austrian sections called for the creation of a staff position at the IS responsible for the work on women's human rights, among other things. ${ }^{151}$ By submitting resolution B4.3, the Irish section called for a clarification of the mandate in order to work on a broad

145 C.: Letter to the IWN members, 17.06.1994.

146 See the list with the names of the IWN coordinators in appendix 1. (For a short period of time (July to September 1995) Susanne Reichinger from AI Germany held the role of coordinator.).

147 Roach 1994, p.11.

148 Amnesty International: Internationale Tagung über die ai-Kampagne für die Menschenrechte von Frauen, Bonn, 16.-18. September 1994, October 1994, p.6.

149 C.: Letter to the IWN members, 10.03.1995.

150 For details on the resolutions, see appendix 2.

151 Amnesty International, International Secretariat: International Council 1995 Circular XII, 03.03.1995. 
number of violations of women's human rights. The UK section demanded the organization of a movement-wide gender analysis of its structure and work in resolution B4.4. Decision 20 of the 1995 ICM integrated all the demands brought forward in these resolutions except for the request of a comprehensive gender audit.

Thus, the female activists' and officials' strategies of parallel networking and analogous framing reaped its first successes by 1995 . After the adoption of the first ICM decision calling for increased attention and resources for work on human rights violations against women at the 1989 ICM, female activists and officials forced the movement to further increase its work on this issue in decision 20 of the 1995 ICM. Organizing in an intersectional network and formulating their demands in accordance with the mandate were pivotal for the achievements at the policy level as this allowed them to reach out to the whole AI movement and build majorities for their demands at the ICMs. In their quest, the fourth WCW appeared as a window of opportunity to enable female activists and officials to enhance their lobbying efforts and make AI launch its first major theme campaign on women's rights. The creation of the Special Brief on Women at the IEC and the appointment of a women's rights coordinator at the IS, whose responsibilities included coordinating the IWN, can also be considered a consequence of the IWN members' lobbying efforts.

The feminist strategies of parallel networking and analogous framing were also bearing fruit at the national level. In fact, as revealed in the IWN survey, most of the sections developed their work on women's rights around the 1995 campaign: “Although some sections' work on women's rights dates back to the 1980 s, most (92\%) has been established since $1991.75 \%$ of the sections have established their work on women's rights since the 1995 campaign." 152 Many national women's groups or networks formed after 1995, and some sections appointed women's rights coordinators in charge of the coordination of activities on the issues with the IS and other sections. ${ }^{153}$ In many cases, these sectional focal points were members of the IWN at the same time. I detail the development of the work on VAW within sections in the upcoming pages about the Swiss and the German sections.

\footnotetext{
152 Amnesty International, International Secretariat: Al Intersectional Women's Network Survey 2001 - Brief Overview of Results, 2002.

153 Amnesty International, International Secretariat und Amnesty International, International Secretariat: 1997 Meeting of the Intersectional Women's Network (IWN), May 1997, p.6.
} 
As I have highlighted before, until the 1995 campaign, the women organized in the IWN mostly lobbied their sections, the SG, and the IEC in order to make AI increase its work on women's rights, focusing on decision-making and implementation. With the centralization of the IWN coordination at the IS, the IWN also increasingly emphasized the lifeline of the organization - namely, research. Having evaluated the movement's achievements with respect to the IWN goals by the end of the 1995 campaign, an interviewee explained: "we [the IWN] have done very well in our contacts with the women's movement, we have done very well in terms of strengthening our female activists, we have done very well in terms of our presence at the UN but 'What do we do with research?"'154 As the following statement shows, and as I develop further hereafter, the new IWN coordinator at the IS established her own strategy to make AI increase its work on women's rights issues:

"[She] took [her] briefs, [she] developed [her own strategy that [she] will make use of the section's network of women focal points [...]. So together with them [she] strategized, [she] built their capacities, [she] gave them a bigger voice in Amnesty in terms of criticizing Amnesty's reports where there could have been more visibility for women, etc. etc."155

In fact, a group of officials at the IS clustered around the IWN coordinator organized the systemization of gender analysis in AI's research reports. As a consequence of decisions 20 of the 1995 ICM, the SG appointed Agnes Callamard, a women's rights activist and academic, to the position of ResearchPolicy Coordinator to help build the researchers' capacities for gender analysis in $1997 .{ }^{156}$ As an informant explains, whereas the IWN coordinator was more "a campaign and capacity building person,"157 Callamard brought along a "solid background in terms of policy and developing research frameworks"158 and therefore, had the necessary "credibility to provide [the researchers] with tools for gender analysis." 159 Additionally, another colleague "was looking at what is Amnesty's state in terms of IGO at the UN." ${ }^{160}$ According to the same

\footnotetext{
154 Ganzfried: Interview with A.O., 23.01.2015.

155 Ganzfried: Interview with A.O., 23.01.2015.

156 Later Agnes Callamard led Al's policy work and research on women's human rights and served as Chef de Cabinet of the Secretary General from 1998 until 2001.

157 Ganzfried: Interview with A.O., 23.01.2015.

158 Ganzfried: Interview with A.O., 23.01.2015.

159 Ganzfried: Interview with A.O., 23.01.2015.

160 Ganzfried: Interview with A.O., 23.01.2015.
} 
interviewee, they started to build "a family's caucus inside the IS,"161 a "pool of researchers who [were] at least gender sensitive, if not feminist."162 Thus, a "triumvirate"163 had organized within the IS by the year 1997 in order to make AI's research more gender sensitive by producing "some groundbreaking reports so that it would set a precedent, some kind of a template for others to do their thing."164

Similarly, the IWN members lobbied to abandon the WOOC rule because "unless Amnesty's sections could become an important voice in their own country, we will never be able to gain full credibility in the eyes of the women's movement."165 As mentioned before, AI finally cancelled the WOOC rule, opening the way for sections to undertake their own research on violations of women's rights in 2001. What my informant labeled the "caucus of feminists and advocates of gender within the IS ${ }^{\text {"166 }}$ was officially known as the Gender Forum. ${ }^{167}$ This forum aimed at providing strategic advice in the implementation of the objectives fixed in AI's strategic plan (the LAP) regarding women's rights. ${ }^{168}$ Curiously, in contrast to the IWN coordinator, who emphasized the pivotal role of the "caucus of feminists," information about the Gender Forum found in archive documents was scarce. The lack of written data indicates that the triumvirate's strategy of making the research more gender sensitive was not straightforward but obviously hidden and not openly communicated.

Evidence indicates that systematized gender analysis in Al's research was difficult. While "the number of IS staff members who have worked on women's issues or are expressing interest in doing so has increased"169 and "women's human rights violations are integrated in the planning and implementation

161 Ganzfried: Interview with A.O., 23.01.2015.

162 Ganzfried: Interview with A.O., 23.01.2015.

163 Ganzfried: Interview with A.O., 23.01.2015.

164 Ganzfried: Interview with A.O., 23.01.2015.

165 Ganzfried: Interview with A.O., 23.01.2015.

166 Ganzfried: Interview with A.O., 23.01.2015.

167 Mentioned as one of the "Institutional measures" Al put in place in chapter 7.1.2.

168 Amnesty International, International Secretariat: International Secretariat Operational Plan 1996-97, 27.09.1996, p.16.

169 Amnesty International, International Secretariat und Amnesty International, International Secretariat: 1997 Meeting of the Intersectional Women's Network (IWN), May 1997, p.7. 
of all campaigns,"170 the IWN criticized that "the manner by which women's rights are reflected in the overall research and actions produced by the Is are inconsistent and unsustainable"171 and that "contextual information that would highlight the gender-based background of human rights violations against women (e.g. cultural issues) is lacking in IS's research."172 Additionally, between 1996 and 2000, the overwhelming majority of individual AI cases continued to prioritize men. The report on the implementation of the LAP revealed that in this period, 3,013 cases focused on men while 192 focused on women. ${ }^{173}$

Concerned about the inconsistency and un-sustainability of how women's rights are reflected in research and actions carried out by the IS, the IWN members stressed the importance of the IEC taking the leading role in making women's rights an integral part of AI's overall work at its third meeting in January $1997 .{ }^{174}$ In their letter to the IEC, the participants in the IWN meeting stressed:

"the overwhelming sense of the meeting is that the IEC must take the lead in ensuring that the movement takes a hard, clear look at the reality of Al's work on women, and develop clear mechanisms of accountability to ensure that the organization is moving systematically to institutionalize and operationalize ICM commitments to increase Al's effective work to promote women's human rights."175

170 Amnesty International, International Secretariat und Amnesty International, International Secretariat: 1997 Meeting of the Intersectional Women's Network (IWN), May 1997, p.7.

171 Amnesty International, International Secretariat und Amnesty International, International Secretariat: 1997 Meeting of the Intersectional Women's Network (IWN), May 1997, p.7.

172 Amnesty International, International Secretariat und Amnesty International, International Secretariat: 1997 Meeting of the Intersectional Women's Network (IWN), May 1997, p.7.

173 Amnesty International, International Secretariat: Final Implementation Report of the Ljubljana Action Plan, 1996-2000, July 2000, p.8.

174 Amnesty International, International Secretariat und Amnesty International, International Secretariat: 1997 Meeting of the Intersectional Women's Network (IWN), May 1997.

175 Amnesty International, International Secretariat und Amnesty International, International Secretariat: 1997 Meeting of the Intersectional Women's Network (IWN), May 1997, p.12. 
Stressing the IWN's pivotal role for the organization's work on women's rights, the participants in the IWN meeting remarked: "our work can only [be] as powerful as our institutionalized support"176 nodding to the IEC. Beside lobbying the IEC, individual sections continued to pressure AI's decision-making organs leading up to the ICM. Such was the case of the Australian section, headed at the time by Kate Gilmore, ${ }^{177}$ who was known as a "women's rights advocate" 178 and future Deputy Secretary General. In fact, the Australian section submitted resolution C1.3.1 to the 1997 ICM (finally accepted as decision 32), calling for a global gender analysis of AI's work.

By 1998, the remaining pressure from the IWN seemed to have borne fruit. In fact, in response to IWN's demands, the IEC declared that "the work on women should not be marginalized or developed as a 'special project"'179 but should be integrated "into the regular work of the IS." ${ }^{180}$ And, in April 1998, the IEC approved the IWN's TORs, ${ }^{181}$ giving the network a formal standing within AI after years of informal existence. Additionally, the IEC finally allocated the resources necessary for a gender audit between 2000 and $2002 .{ }^{182}$ It thereby responded to an old IWN request formulated in resolution B4.4 to the 1995 ICM, which was reiterated in the Australian resolution C1.3.1 to the 1997 ICM. Declaring that it had "recognized the need to consolidate, sustain and institutionalize work on women's rights violations," 183 the IEC "called for the integration of a movement-wide gender-sensitive perspective to AI work." ${ }^{184}$

176 Amnesty International, International Secretariat und Amnesty International, International Secretariat: 1997 Meeting of the Intersectional Women's Network (IWN), May 1997, p.15.

Appointed as Deputy Secretary General around 2001.

178 Kelleher and Bhattacharjya 2013, p.5.

179 Amnesty International, International Executive Committee: IEC Information Bulletin No. 21, January 1998, p.2.

180 Amnesty International, International Executive Committee: IEC Information Bulletin No. 21, January 1998, p.2.

181 Amnesty International, International Executive Committee: IEC Information Bulletin No. 23, April 1998b.

182 Amnesty International, International Executive Committee: IEC Information Bulletin No. 25, October 1998.

183 Amnesty International, International Executive Committee: IEC Information Bulletin No. 27, April 1999, p.26.

184 Amnesty International, International Executive Committee: IEC Information Bulletin No. 27, April 1999, p.26. 
At the same time, female section secretary generals maintained the same pressure during the following ICM. In fact, at the 1999 ICM, the Australian section's secretary general pledged to develop a strategy to fully integrate women's rights into AI's work. Barbara Lochbihler, ${ }^{185}$ secretary general of the German section, expressed the German section's concern about the decline of AI's work on women's rights. At the same time, AIUSA "suggested to create a gender unit in the IS."186

Parallel to this, IWN members pushed to make the organization appoint its first female SG. One of my interviewees explained:

"by $2000,[. .$.$] this pressure on Amnesty was sustained over time, because you$ have a milestone that helps us. So, every five years...so Beijing plus five, Beijing plus ten, we have those milestones to be able to sustain the momentum also within the organization. So, the year 2000 , the milestone, was to have a woman Secretary Ceneral."187

In fact, the nominations of Irene Khan and Kate Gilmore, who was known as a "relatively high-profile figure in women's rights in Australia," ${ }^{188}$ should underscore the organization's willingness and credibility to engage in human rights work on VAW. An interviewee explained: "it was very clear that the board would appoint a Secretary General who would be a woman, so that the public would see at the highest position, at the highest office of Amnesty, we have a public face who is a woman."189

Finally, in the beginning of 2001, the IEC decided to make violence against women the topic of its first global thematic campaign under the mission from 2003 onwards, picking the issue from a list of themes such as the death penalty, children's rights, economic actors, refugee rights, the rights of indigenous people, and land rights and poverty. ${ }^{190}$ In the same year, the ICM en-

185 Before, she was the director of the Women's International League for Peace and Freedom (WILPF).

186 Amnesty International, International Secretariat: Report and Decisions of the 24th International Council of Amnesty International, 21.08.1999, p.16.

187 Ganzfried: Interview with A.O., 23.01.2015.

188 Ganzfried: Interview with B.R., 25.06.2012.

189 Ganzfried: Interview with A.O., 23.01.2015.

190 Amnesty International, International Executive Committee: IEC Information Bulletin 37, July 2001, p.13; Amnesty International, International Secretariat: 25 th International Council Meeting Circular 23 All Human Rights for All: An Integrated Approach to Action, Mandate and Organization, May 2001. 
dorsed the IEC's proposal of a theme campaign on VAW. ${ }^{191}$ As I demonstrate in chapter 8 , selecting the issue of VAW for AI's first global thematic campaign implied "that it gets very high priority in resources,"192 which needed/called for an unprecedented commitment from AI's management. As such, the decision can be interpreted as the fruit of a continuous strategy of parallel networking and analogous framing by female activists and officials.

Summing up, in setting up the IWN, female activists and officials built a strategy to make AI increase its work on issues of VAW which was well adapted to the overall structure of AI. Linking up with like-minded female activists and officials beyond their own national sections proved useful for effectively putting pressure on the organization's decision-making body, as it allowed them to reach out to the whole AI movement and find majorities for their demands at the ICMs. In fact, the strategy of parallel networking first enabled the women and officials of different sections to convince their section delegates to adopt AI's initial decision demanding an increase in the work on women's rights at the 1989 ICM. It then helped them to push sections to submit resolutions raising the same demands to the 1995 ICM and to lobby their ICM section delegates to vote for these resolutions. The female activists and officials lobbying for the adoption of decision 15 at the 1989 ICM and for decision 20 at the 1995 ICM further indicate that they wanted first and foremost an intensification of the organization's work on violations of women's rights within the frame of the mandate. Their strategy of making AI increase its work on violations of women's rights was thus formulated in compliance with the overall policy of the organization.

The strategy of analogous framing was crucial in making AI increase its work on women's rights because it allowed the same activists to compel the majority of the movement to support their claim. Given the long-lasting significance of the state-focused mandate for AI's human rights work and the important debates occurring around the question of whether and to what extent AI should open its mandate to abuses committed by non-state actors, it is worth assuming that a strategy challenging the essence of Al's work would have been less successful. Further, taking advantage of the 1993 UN Conference on Human Rights and the fourth WCW, female activists and officials

191 Amnesty International, International Executive Committee: IEC Information Bulletin 37, July 2001, p.13; Amnesty International, International Secretariat: Action Planning Bulletin November 2001, November 2001. 
who were organized in the IWN successfully pressured the IEC to mind the effective implementation of the ICM decisions (15 ICM 1989 and 20 ICM 1995). In turn, this finally led to the creation of the Special Brief on Women within the IEC and to the appointment of a women's coordinator at the IS. The creation of the position of a women's rights coordinator at the IS in 1995 changed things and made women organized in the IWN adapt their objectives to this achievement. From then on, a triumvirate of women's rights advocates at the IS engaged in making the core of AI's work, namely research, gender sensitive.

Nevertheless, as the continuing pressure of the IWN on the IEC indicates, the strategy of parallel networking remained crucial for female activists and officials. At the same time, the women organized in the IWN maintained their strategy of analogous framing as decision 32 of the 1997 ICM demonstrates. Finally, both of these strategies were important in making AI decide to launch its first long-term thematic campaign under the mission on the issue of VAW. They enabled the effective lobbying of sections, the IEC, and the SG, which in turn allowed women to convince the organization of the necessity to further strengthen its work on violations of women's' rights.

Consequently, female activists played a central role in initiating AI's work on women's rights at the end of the 1980s, and a subsequent bottom-up process of integrating VAW into AI's activities culminated in the SVAW campaign at the beginning of the 2000s. The feminist strategies of parallel networking and analogous framing are key in understanding AI's growing interest in issues of VAW and the associated decision to make VAW the topic of AI's first long-term thematic campaign under the mission. At the same time, as emphasized in chapter 6.2, it is plausible that the growing number of women in management positions at the IS and the supportive SG Pierre Sané also played a positive role. Further, external factors such as the opening of the mandate, the growing international awareness of gender equality stemming from the UN Decade for Women 1975-1985 and the related WCWs, especially the conference in Beijing, and the international women's rights movement challenging AI to expand their mandate to violations of human rights in the private sphere also contributed to the transformation process.

\subsubsection{Al's work on women's rights discussed}

With the strategies of parallel networking and analogous framing, female activists and officials succeeded in making the organization significantly in- 
crease its work on issues of VAW. However, as the present chapter shows, these achievements met with resistance from sections and from within the headquarters. I focus on the debates on the adoption of the decisions directly concerning AI's work on VAW that took place at the ICMs to demonstrate that sections discussed and sometimes opposed these decisions, which were part of the IWN members' strategy of analogous framing. They sometimes also disagreed with the decisions to integrate the issue of FGM into AI's promotional and oppositional work. Nevertheless, resistance against the latter was more important. Then, the section illustrates that integrating a gender perspective into AI's research was not straightforward. In fact, many IS researchers were reluctant to yield to the IWN demands of integrating a gender perspective into the reports produced at the IS.

Figure 5 illustrates that, of all ICM decisions directly concerning AI's work on VAW, those that followed the IWN member's strategy of analogous framing (namely, decision 15 (1989 ICM), decision 20 (1995 IMC), and decision 32 (1997 ICM)) and the decisions demanding the integration of FGM into AI's promotional and oppositional work (decision 6 of the 1995 and 1997 ICM), caused the most debates (left column in figure 5). In contrast, the first ICM decision on FGM, the decision on the UN rapporteur on Women, and decision 9 of the 1995 ICM were not subject to debates (rights column in figure 5).

Figure 5: Debates on the ICM decisions directly concerning AI's work on VAW

Decisions triggering debates among section delegates at the ICM

\begin{tabular}{|c|c|c|c|}
\hline & & Yes & No \\
\hline 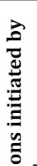 & : & $\begin{array}{l}\text { Decision } 151989 \text { ICM Human rights violations } \\
\text { against women } \\
\text { Decision } 201995 \text { ICM Work on behalf of Women } \\
\text { Decision } 321997 \text { ICM Action on Human Rights } \\
\text { Violations against Women } \\
\text { Decision } 61997 \text { ICM FGM }\end{array}$ & $\begin{array}{l}\text { Decision } 221993 \text { ICM UN Rapporteur on Women } \\
\text { Decision } 91995 \text { ICM Women } \\
\text { Decision } 101993 \text { ICM Female Genital Mutilation }\end{array}$ \\
\hline لֶ. & & $\begin{array}{l}\text { Decision } 61995 \text { ICM Governmental inaction and } \\
\text { FGM }\end{array}$ & \\
\hline
\end{tabular}

Source: my own, based on the reports of the 1989, 1991, 1993, 1995, and 1997 ICMs.

Based on an analysis of the ICM reports, I first highlight the opposition to the IWN members' demand to make AI increase its work on women's rights before illustrating the section's reactions to enlarging AI's mandate with the issue of FGM.

The ICM report reveals that, when discussing decision 15 of the 1989 ICM, "many sections strongly opposed the idea of creating a special category of vic- 
tims of human rights violations, but supported the spirit of the resolution."193 However, given the adoption of decision 15, it is worth assuming that this resistance was limited. Discussions at the 1995 ICM crystallized around the British section's demand for a movement-wide gender analysis of AI's structure and activities (formulated in resolution B4.4). ${ }^{194}$ While the delegates did discuss the usefulness of the other resolutions demanding an increase in AI's work on women's rights, which were finally adopted as decision 20 , they were profoundly divided on resolution B4.4. In fact, a majority of the delegates rejected the resolution, questioning its usefulness and concerned about the costs such a study implied. The Icelandic, Greek, German, and Benin sections, for example, opposed the resolution saying "it was trying to find a problem that did not exist." 195 Referring to the debates around the question of a movement-wide gender analysis, one of the delegates reported that "the quality of the debate [...] was extremely disappointing and showed a lack of understanding of the issues" 196 and a poor understanding of what a gender analysis might imply. ${ }^{197}$

Sections did not only disagree on the content of decision 20. Once it was adopted, sections differed on how the decision should be reflected among AI's strategic priorities over the following years. Various sections questioned the classification of decision 20 as one of LAP's high priority issues. For instance, the Hong Kong section explained that "Amnesty's mandate should be for men, women and children"198 and argued that the disproportional emphasis on women in the LAP "might cause problems in that Amnesty's case-load would not reflect the importance of children."199 Similarly, the Danish and the Swedish sections expressed concern that treating women's rights separately

193 Amnesty International, International Secretariat: Report and Decisions of the 19th International Council of Amnesty International 19-27 August 1989, Dublin, Ireland, 19.08.1989, p.98.

194 See appendix 2 for details on the resolutions.

195 Amnesty International, International Secretariat: 22nd International Council Meeting, 1995, p.132.

196 Watson 1997, p.7.

197 Watson 1997, p.8.

198 Amnesty International, International Secretariat: 22nd International Council Meeting, 1995, p.21.

199 Amnesty International, International Secretariat: 22nd International Council Meeting, 1995, p.21. 
would make them incorrectly appear as "different from men's rights," ${ }^{200}$ or as "different to all people's rights." ${ }^{201}$ In contrast, the Dutch section seemed to have been worried about AI's ability to oppose violations of women's rights: "concentrating too many resources in some situations [of massive human rights violations] might be wasting them; and special emphasis on women could be counterproductive if AI has nothing special to offer." ${ }^{202}$ Further, the Philippines section considered "the women's issues to have been exaggerated" 203 within the LAP.

Sections discussed the demand to increase work on women's' rights with less controversy two years later. While a majority of the section delegates rejected the British resolution for a movement-wide gender policy at the 1995 ICM, they accepted a similar resolution (C1.3.1) from the Australian section that called for "a global assessment for the whole movement of the work accomplished on women's human rights since 1990 "204 at the 1997 ICM. As the report of the 1997 ICM reveals, the formulation of a demand for a gender assessment (rather than a study) of AI's structure and activities rendered the resolution less controversial, finally leading to its acceptance by consensus. This happened despite some sections' initial fears that "expressed concern, given the number of areas covered, that study might be taking precedence over action." 205

Aside from the three subsequent decisions that raised the same demand to the movement, the issue of FGM also caused controversy and triggered some sections' opposition. As section 7.1.1 explained, it took the organization four years to move from the adoption of the first decision (10) at the 1993 ICM to the inclusion of the practice into AI's oppositional work, reflected in decision 6 of the 1997 ICM. This comparatively long process already indicates the

200 Amnesty International, International Secretariat: 22nd International Council Meeting, 1995, p.26.

201 Amnesty International, International Secretariat: 22nd International Council Meeting, 1995, p.26.

202 Amnesty International, International Secretariat: 22nd International Council Meeting, 1995, p.26.

203 Amnesty International, International Secretariat: 22nd International Council Meeting, 1995, p.26.

204 Amnesty International, International Secretariat: 23rd International Council Meeting Report and Decisions, 1997, p.65.

205 Amnesty International, International Secretariat: 23rd International Council Meeting Report and Decisions, 1997, p.65. 
controversial character of the issue. An analysis of the ICM reports shows the content of the debate on the issue among the sections. The delegates approved decision 10 at the 1993 ICM without opposition, urging the IEC to include the issue in a study on governmental inaction and instructing the IEC to present recommendations on how to deal with the issue at the 1995 ICM.

The integration of FGM into AI's promotional work was subject to intensive discussion before and at the 1995 ICM. The contentious nature of the issue becomes evident in the number of different resolutions on it that sections submitted to the 1995 ICM. In addition to an enabling resolution from the IEC, the Netherlands, the Belgium and the Israeli sections submitted resolutions to the 1995 ICM. ${ }^{206}$ While these sections finally withdrew their resolutions in favor of the IEC enabling resolution, the discussions at the ICM concerned three options proposed in the enabling resolution. The first option called for the postponement of the issue to the next ICM. The second one suggested making FGM part of AI's promotional and educational work, and the third, most conservative, option recommended refusing the inclusion of FGM into AI's work. ${ }^{207}$

After long discussions, option two garnered greatest support among the ICM delegates. While some sections suggested amendments to the proposal to make FGM part of AI's promotional work, the final resolution integrating these corrections was finally approved by 33:11 votes to become decision 6. As the ICM report explains, "the debate was divided between those pushing for a major expansion of AI's mandate, and those believing that this whole issue was confusing to the AI mandate." ${ }^{208}$ According to a delegate from the Swiss section, the opposition essentially came from the Northern sections, which claimed that this question would divide the movement between the North and the South. ${ }^{209}$ An interviewee explained the opposition from some of the sections by pointing out that FGM was a taboo that should not be touched upon. $^{210}$

206 See appendix 2 for the details on the resolutions.

207 Amnesty International, International Secretariat: 22nd International Council Meeting, 1995, p.107.

208 Amnesty International, International Secretariat: 22nd International Council Meeting, 1995, p.107.

209 Amnesty International und Internationale Kommission: Procès-verbal de la séance du 28 septembre 1995, 28.09.1995, p.2.

210 Ganzfried: Interview with A.J., 09.03.2012: "Il y a eu des résistances de certaines sections de dire, mais ça c'est un tabou, on ne peut pas toucher à cette problématique.". 
While in 1995 the debate concerned the question of whether AI should or should not integrate FGM into its promotional work, two years later the discussion mainly focused on the way oppositional work on FGM should inform AI's work on non-state actors. Sections presented four different resolutions to the 1997 ICM. This number already indicated the diversity of opinions concerning AI's future work on FGM. In their resolution "Gender Distinction in Genital Mutilation," the Bermuda section, for example, requested not to discriminate between male and female genital mutilation. While the ICM delegates defeated this resolution, they accepted the other three resolutions jointly presented by the Bermuda, the Ivory Coast, and the UK sections. The latter called to test the use of oppositional techniques in the case of FGM and governmental inaction by including the issue in the pilot projects on nonstate actors. ${ }^{211}$ The discussions around the integration of FGM into Al's work that took place between 1993 and 1997 were part of the larger debate AI went through in the 1990s. The latter centered on AI's position concerning cases of human rights violations where the state failed to meet its obligation to prevent the abuse. The debates on how AI should work on the issue of FGM were important because taking action against this practice challenged AI's state-focused mandate, as it also meant taking into account human rights violations perpetrated by individuals.

The analysis of the ICM reports revealed that sections disagreed on the necessity of increasing AI's work on violations of women's rights. Only at the 1997 ICM did a majority of the sections agree upon "the full integration of women's human rights in all areas of Amnesty International's work." 212 The discussions on the adoption of decision 20 at the ICM reveals the existence of internal reticence towards an increase in AI's work on women's rights. However, aside from the resolution calling for a movement-wide Gender Policy at the 1995 ICM, sections did not oppose increasing their work on violations of women's rights. In contrast, the debates on the issue of FGM were more important. They revealed a divide between sections defending Al's work's traditional focus on governments as the primary violator of human rights and others convinced of the necessity to address the problem of state responsibility for inaction in cases of violations of human rights perpetrated in the private sphere.

211 As defined in decision 5 of the 1997 ICM.

212 Amnesty International, International Secretariat: The Decision of the 1997 ICM, 05.01.1998, p.47. 
Evidence from the secondary literature and interviews indicates that resistance to increasing AI's work on women's rights also existed at the IS. Kelleher and Bhattacharjya (2013) point to the negative reactions the Human Rights are Women's Rights campaign received from "conservative members of the IS who were concerned that women's rights activists were trying to highjack Amnesty's voice." ${ }^{213}$ At the same time, the testimony of one of my interviewees reveals the difficulties that plagued the first staff members who integrated a gender perspective into their research:

"Around 1995 [...], I did a report and I had to fight to do a very basic [report]. I used to work on Peru at that time and Ecuador [...]. And I pushed to be able to write a report on women in Peru and the effect on all these women that had been killed by the Shining Path, the Guerrilla group that was in Peru at that time. And it was not easy! They all looked at me oh no I will not do any of that, why? 'You know how many people are disappearing?' I know! It wasn't easy!" 214

Another interviewee mentioned the difficulties the "feminist caucus" at the IS encountered in its efforts to make AI's reports more gender sensitive. She explained that "[The former Research-Policy Coordinator Agnes Callamard] was trying to bring a gender perspective to Amnesty's work and I know she found it very difficult." ${ }^{215}$ For Watson (1997), who used to be a member of AI Australia, the difficulties of integrating a gender perspective into AI had to do with the fact that by this time, the IS research department was dominated by men who "have not been particularly receptive in the past to the criticism that their research strategies have at times been blinkered in ways that mean that women, and the abuses suffered by them, are not readily uncovered."216 For another informant the lack of gender analysis in the researchers' work can be explained with their fear "that once they opened themselves to having a gender analysis in their investigations of what happened to women it would demand a lot of their time, there would be resource implications for them."217

In a nutshell, the analysis of the ICM reports reveals that sections disagreed on the necessity to increase AI's work on issues of VAW. While oppo-

\footnotetext{
213 Kelleher and Bhattacharjya 2013, p.4.

214 Ganzfried: Interview with A.X., 25.06.2012.

215 Ganzfried: Interview by skype with B.H., 18.12.2014.

216 Watson 1997, p.10.

217 Ganzfried: Interview with A.O., 23.01.2015.
} 
sition to the decisions calling for an increase in AI's work on women's rights existed, resistance to AI's position on the issue of FGM was more important as this concern defied AI's mandate. At the same time, the difficulties that female officials at the IS in the 1990s encountered in their efforts to bring a gender perspective into AI's reports indicate that opposition to this new focus existed among the IS staff members. Consequently, AI's work on issues of VAW during the 1990s led to discussions among sections and was criticized from within by the researchers at the IS. However, as I show later, AI's work on VAW encountered much more resistance from sections and from within the IS under the mission.

\subsection{The national levels}

The present chapter illustrates the beginnings of AI's work on issues of violence against women in the Swiss and the German sections. ${ }^{218}$ It highlights that in both sections, female activists initiated this work by forming women's groups focusing on the defense of female prisoners in the early 1980s. Over the years, the women's groups remained the driving force behind the sections' work on issues of VAW. However, women in the two sections organized and proceeded differently. While female activists and officials in the Swiss section seemed to use the strategy of parallel networking, no clear strategy was discernible in the case of the German women's group except for a tendency to focus on influencing decision-making at the international level and maintaining regular exchanges with the IWN. Similar to the section's overall organization of its thematic work, the Swiss section professionalized the work on issues of VAW in the course of the Human Rights are Women's Rights campaign. Meanwhile, in the German section, the women's group continued to be responsible for the majority of the section's work on issues of VAW throughout the 1990s. Further, instead of opposing this initial work, the membership in both sections ignored AI's growing interest in issues of VAW. In contrast, similar to the developments at the international level, the question of state re-

218 In contrast to the Swiss section, where I found many documents on the women's groups themselves, the German section did not grant me access to the documents from the women's group. Therefore, compared to my writing on the Swiss section, the chapter on the German section is less detailed. 
sponsibility for inaction in cases of grave human rights violations committed by non-state actors became an issue of major debate in both sections.

\subsubsection{The Swiss section}

By providing evidence of collective and individual initiatives carried out by female activists concerned about the under-representation of women in the cases AI defended, this section demonstrates that female activists initiated the Swiss section's work on issues of VAW in the early 1980s. Later, I show that the fourth WCW also boosted the section's work on issues of VAW. A demand to the GA to make the section increase its work on women's rights was formulated by a group of female activists and officials during the period leading up to Beijing. In the aftermath of the fourth WCW, the structures involved in issues of VAW developed and female activists and officials finally established a section-wide women's network by 2000 . Thus, in the Swiss case, female activists and officials also used the strategy of parallel networking to make AI increase its work on women's rights at the section level. However, in contrast to the international level, where the IWN had already taken shape in 1989, the formation of a section-wide network was postponed. Then, I highlight that the membership was not generally opposed to work on issues of VAW, as long as the violations did not challenge AI's mandate. In this sense, female activists and officials faced more ignorance than opposition in their efforts to lobby the section.

\subsubsection{First collective and individual initiatives}

The section's work on VAW goes back to the initiatives of female activists in the French and the German parts of Switzerland. ${ }^{219}$ Concerned about the underrepresentation of women in the cases of prisoners of conscience defended by AI, activists formed their own groups and Urgent Action Networks in the beginning of the 1980 s. The latter essentially sought to engage in the release of female prisoners. ${ }^{220}$ The first such group, Réseau d'actions urgentes femmes (Women Urgent Action Network), was comprised of a core group of eight to

\footnotetext{
219 According to one internal document, another urgent action network for women (Frauen-Zielgruppen) existed in Ticino in 1983 (Amnesty International: Frauenkampagne 1991, 1991). However, I could not find further information on this women's urgent action network in the South part of Switzerland.

220 Ganzfried: Interview with B.I., 07.06.2013.
} 
ten women and a pool of about 200 supporters, and was founded in Geneva in $1981 .{ }^{221}$ While the wider network of supporters essentially concentrated on the writing of letters to the relevant authorities, the core group met on a regular basis and organized activities, such as stands for the collection of signatures, or conferences with female victims of political persecution. ${ }^{222}$

The frustration with the invisibility of women in the cases AI defended seems to be the reason for the first collective initiative. In its leaflet, the Geneva Réseau d'actions urgentes femmes explained that "the foundation of such a group was justified by the fact that the public was still ignoring the important number of women prisoners of conscience." ${ }^{223}$ According to them, only $10 \%$ of all Urgent Actions launched within the Swiss section in 1988 concerned women. ${ }^{224}$ According to an interviewee, the group was independent from the rest of the Swiss section finance-wise and activities-wise. ${ }^{225}$

The Réseau d'actions urgentes femmes existed until 1993, when one of the founders of the group left. This withdrawal contributed to the group's difficulties in regrouping and reorganizing its activities. ${ }^{226}$ However, as evidence shows, another women's group formed in Geneva some months later. ${ }^{227} \mathrm{~A}$ second similar collective initiative could be observed in Zurich in the same period. In fact, female activists launched a solidarity women's network called 'Women help politically persecuted women' in $1983 .{ }^{228}$ Like its counterpart in Geneva, the group was composed of a core group of female activists and a wider network of supporters essentially involved in urgent action letter writing.

221 Urgent Actions are one of the methods used by Al. Urgent actions are launched in all cases when a rapid intervention to save a person's life is needed.

Groupe femmes Chêne-bourg: Leaflet on the women's group Chêne-bourg, 14.03.1989. Croupe femmes Chêne-bourg: Leaflet on the women's group Chêne-bourg, 14.03.1989, p.3: "La création d'un tel réseau se justifiait par le fait que le public ignorait et ignore encore trop souvent qu'un grand nombre de prisonniers d'opinion sont en fait des prisonnières.". Croupe femmes Chêne-bourg: Leaflet on the women's group Chêne-bourg, 14.03.1989. Ganzfried: Interview with A.B., 12.04.2012: "Evidemment ça permettait aussi beaucoup de liberté, qui fait que des choses ont pu être faites sans attendre.".

Amnesty International: Schlussbericht zur Reorganisation der Berufs- und Zielgruppen, 09.02.1993.

Amnesty International: Delegiertenversammlung 1994 Postulat F Vorbereitung der Weltfrauenkonferenz in Peking 1995, 30.04.1994. Amnesty International und Frauennetzwerk: Protokoll des Frauennetzwerktreffens vom 21.1.2000, 01.02.2000; Amnesty International: Aufbau eines Solidaritätsnetzes in der Deutschschweiz Frauen helfen politisch verfolgten Frauen, Juni 1983. 
The principle of solidarity seems to have guided the action of these first women's groups. The members' identity as women served as the basis for their engagement for the release of female prisoners. In fact, according to a leaflet, because they faced and continue to be confronted with certain forms of gender-based discrimination and oppression, they felt closer to the women for whom they were writing the urgent actions. ${ }^{229}$ As one of the interviewees explained: "with these women urgent actions, it was about playing with the proximity of women for women." 230 The Women Urgent Action network in Zurich argued for a specific group engaged for the release of women prisoners using the fact that men prisoners of conscience were usually supported by AI professional groups (lawyers, health workers etc.). Meanwhile, female prisoners, often without any professional activity, could not count on a professional solidarity network. ${ }^{231}$

An interviewee explained that women, who were already extremely engaged at the professional level as nurses, social workers, or mothers, initiated these first women's groups. ${ }^{232}$ In contrast to the core group members, the members of the wider network were often just women who wanted to write their letters for other women and "not women who wanted to engage for the UN resolution 1325 or who somehow dealt with a political context." 233 As such, these groups essentially concentrated their public activities at the local level, sometimes collaborating with other local AI groups. At the same time, there was no exchange between the two women's groups until 1988.

229 Croupe femmes Chêne-bourg: Leaflet on the women's group Chêne-bourg, 14.03.1989, p.3: "Notre identité féminine, le fait d'avoir connu et de continuer de connaître certaines formes de discrimination ou d'oppression nous rendent plus proche des femmes pour lesquelles nous écrivons.".

230 Ganzfried: Interview with B.I., 07.06.2013: "avec les actions urgentes socio-professionnelles, c'était de jouer de la proximité des femmes pour des femmes.".

231 Amnesty International: Aufbau eines Solidaritätsnetzes in der Deutschschweiz Frauen helfen politisch verfolgten Frauen, Juni 1983.

232 Ganzfried: Interview with B.I., 07.06.2013: "Par des femmes extrêmement engagées, qui étaient engagées aussi déjà au niveau professionnel, comme infirmière ou comme assistante sociale, ou comme mère de famille aussi.".

233 Ganzfried: Interview mit B.F., 04.04.2012: "Eine Frauengruppe ist früher eine Gruppe gewesen, es sind Frauen gewesen, die zum Beispiel einfach Briefe schreiben wollten zugunsten von Frauen. Das sind nicht Frauen gewesen, die sich für 1325 engagiert haben oder die sich irgendwie mit politischen Kontexten auseinandergesetzt haben. Es sind sehr oft wirklich Frauen gewesen, die wollten einfach ihre Briefe schreiben, aber möglichst für Frauen." 
Then, members of the groups met for the first time at the section's GA. ${ }^{234}$ However, this exchange did not result in other collaborations or activities. Described "as small cells which faced difficulties in expanding,"235 these Women Urgent Action Networks initiated the work on VAW at the Swiss section but their actions had not yet really been recognized by the section. The isolation of the Women Urgent Action Networks began to weaken after the adoption of decision 15 at the 1989 ICM. In fact, the action, launched around the report Women in the Front Line on the $8^{\text {th }}$ of March1991, was the first activity on women's rights organized by the secretariat of the Swiss section in collaboration with the women's group in Zurich. ${ }^{236}$ Women's rights activists affiliated to the Women Urgent Action Network Zurich used the occasion to widen the spectrum of their activities by calling for new members to build up a bigger women's group. ${ }^{237}$ The women's group in Zurich reiterated their call for new members and an action network when launching the women's day action a year later. ${ }^{238}$

Independent of the collective activities of the Women Urgent Action Networks in Geneva and Zurich and the 1991 action, individual AI female activists initiated activities on the issue of VAW on their own. For instance, they focused on violations of women's rights in specific country projects they were in charge of. ${ }^{239}$ Others discussed the issue in their local AI group. An interviewee explained the significance of these individual initiatives:

"At the Swiss section, we also have women who had been engaged since the beginning of Al. Some of them at the Swiss section have always prioritized women's rights even before the movement decided to make it a top priority; they organized fantastic actions and campaigns with effective people mobilization." 240

234 Groupe femmes Chêne-bourg: Procès-verbal du 3 décembre 1987, 03.12.1987; Groupe femmes Chêne-bourg: Procès-verbal du 7 avril 1988, 07.04.1988.

235 Ganzfried: Interview with A.J., 09.03.2012: "C'était comme des petits noyaux qui avait un petit peu de la peine à essaimer.".

236 Amnesty International: Frauenkampagne 1991, 1991.

237 Amnesty International: Frauenkampagne 1991, 1991.

238 Amnesty International: Frauenkampagne 1992 Aktionsanleitung, 08.03.1992.

239 Ganzfried: Interview mit B.F., 04.04.2012: "Ich habe einfach im Rahmen von meiner Arbeit immer geschaut, dass ich irgendwie möglichst viele Frauen auch in diese Projekte hineinnehmen konnte.".

240 Ganzfried: Interview with A.I., 26.09.2012: "On a aussi au niveau d'Al des femmes qui sont engagées depuis quasi les débuts d'Al. [...] p. ex. Alba Viotto [...]; des femmes incroyables qui 
Another interviewee mentioned the exposition of Rwandan artists meant to call attention to the women rights violations that occurred during the genocide as another example of individual initiatives from female activists. ${ }^{241}$ The first collaborations between members of the women's group and staff at the secretariat emerged around the same time, and individual officials started to pay attention to the sex of the prisoners of conscience they were defending. An interviewee explained that she "relied upon these volunteers of the women's [group] to have their know-how about how to sell this question or integrate this women's issue into the campaign ['500 Years of the Discovery of Latin America and Its Impact on Indigenous People']." ${ }^{242}$ She further highlighted that she also attempted "to have a woman when we had our famous illustrative cases and not only have Tibetan monks." 243

Summing up, female activists concerned about the invisibility of women in AI's case work initiated the section's work on VAW in the 1980s. They organized in the so-called Women Urgent Action Networks, which were based on the idea of solidarity among women and took action for the release of women prisoners. In addition to the Women's Urgent Action Networks in Zurich and Geneva, which functioned independently from the secretariat, individual women activists highlighted violations of women's rights with their own specific activities, and individual officials began to consider women's rights within the section's campaign work. A first section-wide action on the issues of VAW was organized in connection with the launch of the report Women in the Front Line. As I show in the next section, the isolation of the work on women's rights began to evolve with the preparation of the 1995 campaign Human Rights are Women's Rights.

ont toujours défendu les droits des femmes avant que le mouvement décide de les mettre en top priorité et qui ont organisé des actions et des campagnes magnifiques capables de mobiliser les gens.".

241 Ganzfried: Interview with A.J., 09.03.2012: "Des femmes comme cette Alba Viotto. Elle a par exemple organisé une exposition d'artiste sur le Rwanda.".

242 Ganzfried: Interview with A.J., 09.03.2012: "Je m’appuyais sur ces bénévoles de ce réseau femme pour avoir un peu leur know-how comment vendre un peu la question, intégrer cette problématique femme dans la campagne [500 ans de découverte de l'Amérique latine sur les peuples indigènes].".

243 Ganzfried: Interview with A.J., 09.03.2012: "On a toujours essayé de voir quand on avait nos fameux cas d'appel illustratifs d'avoir une femme. On n'avait pas que des moines tibétains.". 


\subsubsection{A women's network emerges}

The movement-wide mobilization around AI's participation in Beijing and the 1995 campaign also affected the Swiss section. Female activists and officials actively started to pressure the section to increase its efforts in the area of women's rights in the period preceding the Beijing conference. In fact, concerned about the delayed start of the preparation for the fourth WCW, a group of female activists submitted a postulate to the 1994 Annual Assembly demanding: "instead of waiting for [international] action plans, the section should have already committed to an intensified engagement for women and tried to reinforce the women's groups by now." ${ }^{244}$ In the postulate they further called upon "the Swiss section to stress women's human rights on the occasion of the Beijing conference." 245

Under the name Frauen in Aktion - Frauen in Gefahr, the section participated in the movement-wide Human Rights are Women's Rights campaign in 1995. Many activists and officials were strongly involved in the preparation for and organization of this campaign, which, according to an informant, enhanced the members' awareness of the importance of integrating the work on women's rights into AI's overall work. In view of the 1995 campaign preparation, both designated staff members and the women's groups were responsible for the section's work on women's rights for the first time. Concretely, the people involved in the preparation and coordination of the 1995 campaign Frauen in Aktion - Frauen in Gefahr included a voluntary coordinator (called Frauenkoordinatorin), based at the secretariat and in charge of coordinating activities between the secretariat and the women's groups in Geneva and Wil, ${ }^{246}$ and two female officials responsible for campaigning and action. ${ }^{247}$

244 Amnesty International: Delegiertenversammlung 1994 Postulat F Vorbereitung der Weltfrauenkonferenz in Peking 1995, 30.04.1994, p.1: "Statt Aktionspläne abzuwarten, sollte sich die Sektion schon jetzt zu einem intensiveren Einsatz für Frauen bekennen und bereits jetzt versuchen, die BZ-Gruppen Frauen zu stärken.".

245 Amnesty International: Delegiertenversammlung 1994 Postulat F Vorbereitung der Weltfrauenkonferenz in Peking 1995, 30.04.1994, p.1: "Die Schweizer Sektion [...] setzt anlässlich der Konferenz einen sichtbaren Schwerpunkt für die Menschenrechte von Frauen.".

246 In fact, an analysis of the archival materials sheds light on the formation of a women's group in Wil, which apparently replaced the former Women Urgent Action Network Zurich.

247 Amnesty International: Protokoll der Sitzung vom 3.11.1994 im Al-Sekretariat, Bern Themen: Peking, Frauenkampagne, Stärkung der Frauengruppen, 03.11.1994; Amnesty International: Sitzung in Zürich vom 15. Dezember 1994 zur Vorbereitung der 
Boosted by the movement-wide activities surrounding the 1995 Beijing conference and the campaign, the Swiss section saw the number of women's groups increase in the following years. A new women's group was founded in Lausanne in August 1998. ${ }^{248}$ Initiated by the secretariat, another women's group was established in Bern around the same time. ${ }^{249}$ The Frauen Urgent Action Netz und Frauengruppe Zurich was relaunched as a formal women's group the same year. A new women's group was founded in Geneva in 2000. ${ }^{250}$ Further, a so-called Kogruppe formed in October 1999. ${ }^{251}$ The Kogruppe was an advisory group with the objective of acquiring knowledge on women's rights issues and providing sections with advice on these issues. An interviewee described its role as "similar to other specialist groups that were experts in the export of weapons or death penalty." ${ }^{252}$

As far as the secretariat was concerned, by 2000 , an intern there was given the task of coordinating the activities of the different women's groups, ${ }^{253}$ and a staff member was assigned to work on women's rights. ${ }^{254}$ Thus, by the end of the 1990s, female activists and officials were organized in four local women's groups and a Kogruppe, and two persons were in charge of the work on women's rights issues at the secretariat.

The formation of a section-wide network happened simultaneously and also benefited from the exchange with the IWN. While I could not find any evidence of regular contacts with the IWN, there must have been exchanges at particular points. On a visit to the Swiss section in October 1999, the IWN coordinator met with women activists and stressed the importance of organizing a women's network within the Swiss section: "It is pivotal to know each

Frauenkampagne und Peking, 15.12.1994; Amnesty International: Protokoll der Sitzung vom 15. Dezember 1994 zur Vorbereitung der Frauenkampagne und Peking, 15.12.1994.

248 Amnesty International und Frauennetzwerk: Protokoll des Frauennetzwerktreffens vom 21.1.2000, 01.02.2000.

249 Amnesty International: Reconnaissance d'un groupe Amnesty en formation, 21.09.1999; Frauennetzwerk: Le réseau femmes se présente, ca. 2000.

250 Frauennetzwerk: Le réseau femmes se présente, ca. 2000.

251 Amnesty International und Frauennetzwerk: Protokoll des Frauennetzwerktreffens vom 21.1.2000, 01.02.2000.

252 Ganzfried: Interview by Skype with A.T., 12.09.2012.

253 Amnesty International: Protokoll der Sitzung Aufbauprojekt Kogruppe Frauen, 20.10.1999.

254 Frauennetzwerk: Le réseau femmes se présente, ca. 2000. 
other and to enrich mutually. The women's work does not have to be limited to a small group acting in a corner; the women's issue has to go through the whole section." ${ }^{255}$ The strategy of building a section-wide women's network in order to bring forward the issue of women's rights became evident in the invitation to a first network meeting in January 2000, where the coordinator explained: "It is also important [...] by the establishment of a strong network to build a common ground for leading the battle for the defense of women's rights worldwide but also within AI well and successfully." ${ }^{256}$ At a first meeting in January 2000, the members emphasized their conviction that a women's network was extremely necessary to strengthen, link, and keep the women's rights movement updated. ${ }^{257}$ The network members met again in April and June of the same year. There, they once again stressed the importance of "a continuing presence with regards to the secretariat so that women's rights remain an issue." 258 One of the first actions of the network consisted in an intervention at the section's GA in 2000 , which called the delegates' attention to the activities of the various women's groups. According to the network members, the intervention was successful as it reinforced the participants' impression of the growing significance of the women's network for the section's work. ${ }^{259}$

Summing up, the structures involved in the section's work on issues of VAW evolved from two independently acting urgent action networks in the 1980 into a section-wide women's network composed of activist groups, an

255 Croupe Al femmes - Lausanne: Procès-verbal de la réunion du groupe Amnesty Femmes - Lausanne: 25 Octobre 1999, 30.10.1999.

256 Amnesty International: Einladung zum Frauennetzwerktreffen, 07.12.1999, p.1: "So ist es auch wichtig [...] durch das Bilden eines starken Netzwerkes, eine gemeinsame Basis aufzubauen, damit der Kampf-es ist tatsächlich noch immer ein Kampf-für die Verteidigung der Frauenrechte weltweit aber auch innerhalb von Al, erfolgreich und gut geführt werden kann.".

257 Amnesty International und Frauennetzwerk: Protokoll des Frauennetzwerktreffens vom 21.1.2000, 01.02.2000.

258 Amnesty International und Frauennetzwerk: Protokoll des Frauennetzwerktreffens vom 20. Juni 2000, 20.06.2000, p.3: "eine anhaltende Präsenz gegenüber dem Sekretariat, damit Frauenrechte ein Thema bleiben.".

259 Amnesty International: Einladung zum Frauennetzwerktreffen 19. April 2000, March 2000, p.1: "Die DV Besucher/innen konnten der Erfahrung nicht ausweichen, dass sich innerhalb Al ein ziemlich aktives Frauennetzwerk ausbreitet, das über kurz oder besser lang die Aktivitäten der Sektion beeinflussen wird.". 
advisory group and staff members in the late 1990s. Female activists and officials began to organize collectively with the aim of making their sections increase the work on women's rights issues during the Beijing preparation period. The formation of a section-wide network of women's activists and officials had become a strategy meant to strengthen the section's work on violations of women's rights by 2000 . Thus, parallel networking also was a strategy female activists and officials within the Swiss section employed to make the section increase its work on women's rights. However, compared to the developments at the international level, where female activists had already gathered in the IWN by 1991, this strategy only became evident after the 1995 campaign. Further, in contrast to other sections, such as the US, the Canadian or the British one, where female activists and officials who were organized in the IWN lobbied their sections in order to influence decision-making at the ICM, I could not find any evidence of a female activists' and officials' attempt to influence AI's general agenda. It seems that female activists and officials strategizing in a section-wide women's network focused on the work of their own section.

\subsubsection{Ignorance rather than opposition}

The present section shows that the work on violations of women's rights faced the Swiss section's disinterest, rather than opposition during the 1990s. In contrast to the developments at the international level, no sign of explicit resistance to the work on this issue is detectable at the Swiss section during this decade. Instead, given that almost 20 years passed between the foundation of the first Urgent Action Network in Geneva in 1981 and the establishment of a section-wide women's network by 2000 , the membership must have simply ignored this kind of work for many years. Similar to what I emphasized at the international level, the question of how AI should work on the issue of state responsibility for inaction - and, relatedly, AI's approach to FGM - was much more controversial.

The section's indifference towards women's rights issues became visible in its reaction to the first intersectional meeting of the IWN that was organized in Geneva in 1991. An interviewee, explains that the secretariat was initially unwilling to help the US section to organize the event. She interpreted the refusal as a form of opposition to the initiative stating: "for example, when the Swiss section replied to the US section that it was not able to do it, [...] 
it was a form of resistance, which is important." ${ }^{260}$ In contrast, rather than resistance, the statements of other interviewees demonstrate the disinterest and ignorance of large parts of the membership. An interviewee explained that of "those engaged in the issue of women's rights, a lot had to plough through a layer of boredom and disinterest." ${ }^{261}$ Another informant stated: "I have never felt any resistance to say 'but why are you choosing this women's issue at AI?"'262 Another interviewee agreed that there was no formal opposition forbidding the formation of women's groups. However, she pointed to the section's lack of support and encouragement. ${ }^{263}$ And for another interviewee, the establishment of the women's group and the efforts to raise awareness of women's rights within AICH was quite a battle. ${ }^{264}$

The membership's disinterest also became visible in the women's groups' activities. Throughout the 1990s, the main structures that engaged in activities concerning violations of women's rights were women's groups. As the example of the women's group Bern shows, only a few other activists participated in activities organized by women's groups. In fact, the minutes of the meetings of the women's group Bern reveal that "the AI internal participation was extremely lean and disappointing for us." ${ }^{265}$ The members of the women's group were very disappointed by the officials' lack of enthusiasm and idealism as well as by their general absence from the events organized by the women's group. $^{266}$

260 Ganzfried: Interview with A.B., 12.04.2012: "Quand la section Suisse répond par exemple à la section américaine qu'elle ne peut pas le faire, sans consulter...'est une forme de résistance qui est importante.".

261 Ganzfried: Interview by Skype with A.T., 12.09.2012: "Vermutlich haben sich diejenigen, die sich da sehr engagiert haben dafür, dass Al das aufnimmt, mehr durch so eine Schicht von Langeweile und Desinteresse durchackern müssen, das ist meine Vermutung.".

262 Ganzfried: Interview with A.J., 09.03.2012: "'ai jamais ressenti de résistance de dire 'mais pourquoi vous choisissez cette problématique femme au sein d'Al?".

263 Ganzfried: Interview with A. B., 12.04.2012: "Il n'y avait pas, disons, d'opposition formelle. Moi je n'ai jamais trouvé quelque chose d'écrit qui interdisait la création de groupes femme. Mais il n'y avait pas, en tout cas, de soutien ni d'encouragement, à cette époque-là.."

264 Ganzfried: Interview with B.K., 16.05.2013: "[Die Etablierung der Frauengruppe und die Förderung von Frauenrechten innerhalb Al] ist ein ziemlicher Krampf gewesen.".

265 Frauengruppe Bern: Protokoll der Monatssitzung November der Frauengruppe Bern, 25.11.1999, p.1: "Al-interne Beteiligung war äusserst mager, enttäuschend für uns.".

266 Frauengruppe Bern: Protokoll der Monatssitzung November der Frauengruppe Bern, 25.11.1999, p.1: "Bemerkung zu Al-Sekretariatsleuten: Es wird bemängelt, dass kein En- 
Thus, the membership's reaction to the work on issues of VAW was generally not opposition but disinterest. An interviewee interpreted this as a manifestation of members' fear of the mandate's dissolution or of their lack of knowledge about how to work on violations of women's rights, in the aftermath of long years of engagement against any abuses of political and civil rights, regardless of the victim's identity. ${ }^{267}$ For another interviewee, the lack of interest in the issue was mainly a consequence of the field from which AI developed, which she qualified as "somehow closely related - in a rather problematic way - to the sex-appeal of the political combatant." ${ }^{268}$ The same interviewee qualified some of the very engaged people within $\mathrm{AI}$ as "kind of exciting guys, half Che Guevaras." ${ }^{269}$ According to her, parts of AI's work had always somehow been the search for sex-appeal, thereby making women's rights issues seem much less exciting. ${ }^{270}$ However, she did not interpret the absence of interest as a sign of misogyny. ${ }^{271}$

While there had been no resistance to the work on issues of women's rights in the 1990s, archival material indicates that the opening of the mandate to states' responsibility for inaction and the related issue of FGM caused discussions among the members of the Swiss section. ${ }^{272}$ Members disagreed on the question of whether and to what extent AI should combat violations of human rights in the private sphere. For example, in a comment to the secretariat, the members of the women's group Zurich raised concerns about the inclusion of human rights violations in the private sphere, with which

thusiasmus und Idealismus auf ihrer Seite spürbar ist. Selten kommen Echos von ihnen, da sie sich auch selten an Anlässen zeigen. Finden wir schade.".

267 Ganzfried: Interview mit B.F., 04.04.2012: "Aber mehr zum Teil auch aus Unkenntnis. Oder das Bewusstsein ist einfach von diesen langen Jahren wo man es nicht gemacht hat noch so stark, dass doch eigentlich von Folter, von Verschwinden lassen, von aussergerichtlichen Tötungen. Alle sind betroffen, wieso muss man jetzt das irgendwie fokussieren aufeine Cruppe?".

268 Ganzfried: Interview by Skype with A.T., 12.09.2012: "Also es war eigentlich mehr so, dass das Interesse vielleicht bei einigen nicht so gross war. Wissen Sie, das Feld, aus dem Al gewachsen ist, das ist eine Sache die irgendwie wahnsinnig viel und auch irgendwie auf ein bisschen fragwürdige Art und Weise mit dem Sexappeal des politischen Kämpfers zu tun hat.".

269 Ganzfried: Interview by Skype with A.T., 12.09.2012: "Leute, die sich auch sehr engagiert haben und so aufregende Typen waren so halbe Che Guevaras. Und dann sind Frauen irgendetwas.".

270 Ganzfried: Interview by Skype with A.T., 12.09.2012.

271 Ganzfried: Interview by Skype with A.T., 12.09.2012: "Ich sehe da auch keine grosse Frauenfeindlichkeit dem Thema gegenüber.".

272 Ganzfried: Interview by Skype with A.T., 12.09.2012. 
AI would certainly be overwhelmed. According to the author, an engagement against human rights violations perpetrated by private persons in individual cases was not feasible for practical and technical reasons. ${ }^{273}$ In another statement, a female activist argued that it is important to include state inaction in the mandate in order to effectively protect women from violence. ${ }^{274}$

Relatedly, members disagreed on how to integrate FGM into AI's work. Critical voices argued that working on FGM would mean engaging in an issue that does not concern them ${ }^{275}$ and others reasoned that NGOs, such as UNICEF, that were specialized in the issue were better placed and able to combat this specific women's rights violation than AI. ${ }^{276}$

Consequently, the work on VAW as covered by the mandate - reflected in the report Women in the Front Line and the 1995 campaign Frauen in AktionFrauen in Gefahr as well as the formation of specific women's groups and the creation of a women's network - was not seen as controversial. The disinterest observed at the Swiss section contrasts with the findings about the IS, where the feminist caucus regularly faced with criticism and resistance. Nevertheless, as the discussion around the work on FGM illustrates, cases of VAW became subject to debate when they challenged AI's state-focused mandate.

\subsubsection{The German section}

This section illustrates that by forming the Sektionsarbeitskreis Menschenrechtsverletzungen an Frauen (MaF) female activists initiated the German section's work on women's rights in the 1980s. Similar to the Swiss section, the MaF initially focused on cases of female prisoners. The section continues by highlighting that the MaF carried out the majority of its work on issues of

273 Leiterin Zielgruppe Frauen: Stellungnahme zur Frage der Mandatserweiterung betreffend "Governmental inaction", 05.12.1994.

274 C.: Persönliche Stellungnahme zur Mandatserweiterung "State inaction”, 23.11.1994.

275 Ganzfried: Interview with B.N., 06.06.2013: "Et bien, justement, je me rappelle, justement, sur les mutilations infantiles, les mutilations des jeunes filles. Ça je me rappelle, il y en a qui [disaient] 'oui, mais c'est s'occuper de choses qui ne nous regardent pas'.".

276 Ganzfried: Interview with A.P., 24.06.2013: "Ein ganz typisches Beispiel ist natürlich Frauenbeschneidung gewesen, wo ja UNICEF sich ganz stark macht dafür, wo man irgendwann sagen musste, ja sollen wir auch noch so viele Ressourcen gleichzeitig in diesem Ausmass bringen?'Obwohl wir es thematisiert haben, aber ich denke es ist auch sinnvoll, dass man sagt 'also da gibt es ja eine NCO die das ganz gross bringt, also müssen wir jetzt nicht auch noch nebendran ganz ganz gross sein?'.". 
VAW as a Fachgruppe (expert group) and remained a driving force behind the section's work on violations of women's rights throughout the 1990s. The section further demonstrates that the MaF became involved in policy-making when the movement was about to make its first decision calling for an increase in Al's work on women's rights in the late 1980. The Fachgruppe then demanded the submission of other resolutions about the movement's work on issues of VAW to the ICM in the 1990s. Further, I also show that the MaF was a particularly active part of the IWN at this moment.

However, in contrast to the Swiss section, the German section did not establish a specific position for work on women's rights at the Secretariat. Instead, women's rights violations were included in the work on asylum and refugees, which at this time was the only thematic human rights issue the secretariat worked on. ${ }^{277}$ Then, I briefly describe that the section's reaction towards work on women's rights was mainly disinterest and not resistance. In contrast, just like in the Swiss section, the question of state responsibility for inaction in cases of grave human rights violations committed by non-state actors was an issue of major debate among members.

\subsubsection{Sektionsarbeitskreis Menschenrechtsverletzungen an Frauen}

Female activists initiated the work on women's rights in the German section in the 1980s. The Sektionsarbeitskreis Menschenrechtsverletzungen an Frauen $(\mathrm{MaF})^{278}$ formed in 1984 and was formally recognized by the section in $1987 .^{279}$ An article in the internal magazine ai-info reveals that the foundation of the MaF goes back to "the need of several AI activists to conduct an in-depth analysis of the different situations of women confronted with state measures and to highlight potential analogies." 280 According to an interviewee, "it was very much this working group (MaF) [that pushed the issue of women's rights

\footnotetext{
277 See chapter 6.3.2.2.

278 In English: Working Group Violations of Human Rights of Women.

279 Deile et al. 2015.

280 Amnesty International Sektion Bundesrepublik Deutschland: Artikel im ai info 6/86, Juni 1986, p.10: "Es besteht bei den Mitgliedern das Bedürfnis, die verschiedenen Situationen von Frauen, die staatlichen Massnahmen ausgesetzt sind, inhaltlich tiefergehend zu untersuchen und eventuelle Parallelen aufzuzeigen.".
} 
at the German section] ${ }^{281}$ in the early years. Similar to other Sektionsarbeitskreise, the MaF members were dispersed all over the country and initially only met at the biannual Bezirkssprecherkonferenzen or during seminars. The MaF thus resembled a network linking female activists from all over the section more than it resembled a local AI group.

Like its Swiss counterpart, the group focused on female prisoners and gender-specific forms of violence and persecution in its early years. ${ }^{282}$ In contrast to the Swiss section, where the women's group used the wording "women's rights" to refer to the rights it was engaged with, the MaF explicitly defined its engagement as action against "violations of human rights of women." An interviewee explained the choice of this wording: "In our opinion, there are no women's rights but human rights, and these human rights are particularly often violated in the case of women. [...] These are human rights valid for women. That is why we do not like the phrase 'women's rights'."283

Raising AI members' awareness as well as that of a larger public had been at the core of the group's engagement in the 1980s. Members of the MaF frequently published articles on the issue of politically persecuted women in the ai-info. ${ }^{284}$ Yet, as the following example illustrates, the MaF's activities went beyond promoting the issue within the section. In fact, one of the most important actions the MaF was involved in was the submission of a motion on gender-specific persecution and violence women prisoners were victims of to the Deutsche Bundestag (the German Parliament) in 1988, in cooperation

281 Ganzfried: Interview by phone with B.E., 06.03.2015: "Das war ganz stark diese Arbeitsgruppe [die sich für das Thema Frauenrechte innerhalb der Deutschen Sektion stark gemacht hat].".

282 Amnesty International Sektion Bundesrepublik Deutschland: Artikel im ai info 6/86, Juni 1986.

283 Ganzfried: Interview by phone with A.Y., 09.01.2015: "Wir sind der Ansicht, es gibt keine Frauenrechte, sondern es gibt Menschenrechte und die Menschenrechte werden bei Frauen besonders oft verletzt. [...] Es sind Menschenrechte, die für Frauen gelten, deshalb finden wir das Wort 'Frauenrechte' nicht so gut.".

284 Amnesty International Sektion Bundesrepublik Deutschland: Artikel im ai-info 3/1987, März 1987; Amnesty International Sektion Bundesrepublik Deutschland: Artikel im aiinfo 4/1988, April 1988; Amnesty International Sektion Bundesrepublik Deutschland: Artikel im ai-info 3/1987, März 1987; Amnesty International Sektion Bundesrepublik Deutschland: Mehrere Artikel im ai-intern 3/1989 zum Thema "Frauen und Menschenrechte“, März 1989. 
with 63 women from all congressional parties. ${ }^{285}$ According to an official, "this was one of the first initiatives exclusively introduced by women beyond the congressional parties in the German Parliament."286

\subsubsection{The MaF's successful attempts to influence decision-making}

In addition to internal and public awareness-raising activities on violations of women's civil and political rights, the MaF became involved in policy-making at a relative early stage. In fact, the minutes of the 1988 and the 1989 meetings of the section's GA illustrate the existence of a motion calling on the section to increase its research on human rights violations against women. They also document the section's decision to submit resolution B14 to the 1989 ICM, which was subsequently accepted as decision 15. Even though these documents do not identify the author of the motion, ${ }^{287}$ given the MaF's prominent role in the section's work on women's rights at that time and in the following years, it is worth assuming that female activists organized in the MaF were among the initiators of the demand. The MaF continued to influence decision-making at the international level by submitting a motion to the $1992 \mathrm{GA}$ which the section subsequently submitted to the 1993 ICM as resolution B37, asking the organization to support the establishment of a UN Special Rapporteur on Violence Against Women and to capitalize on the fourth WCW by organizing a campaign on women's rights. ${ }^{288}$

Similar to the IWN, the MaF took advantage of the 1993 UN Human Rights Conference in Vienna "[...] to express again long-standing demands for the protection of women from women-specific persecution at the international level." ${ }^{289}$ In the same document, the MaF spokesperson invited AI "to take

285 Amnesty International Sektion Bundesrepublik Deutschland: Artikel im ai-info 4/1988, April 1988.

286 Ganzfried: Interview by phone with B.U., 13.02.2015: "Das war eine der ersten Initiativen im deutschen Bundestag, die NUR von Frauen angestossen wurde und zwar Fraktionsübergreifend.".

287 Amnesty International Sektion Bundesrepublik Deutschland: Protokoll der 23. Jahresversammlung vom 21.5. bis 23.5.1988 in Wuppertal, 24.05.1988; Amnesty International Sektion Bundesrepublik Deutschland: Protokoll der Jahresversammlung 1989 Oldenburg 13. bis 15. Mai 1989, 15.05.1989.

288 Amnesty International Sektion Bundesrepublik Deutschland: Antrag an die Jahresversammlung 1992 der AK-Menschenrechtsverletzungen an Frauen, 19.03.1992.

289 Reichinger und Sektionsarbeitskreis Menschenrechtsverletzungen an Frauen: Die Weltmenschrechtskonferenz in Wien - eine Bilanz aus frauenspezifischer Sicht, 30.11.1993, p.1: "Auch unser Arbeitskreis nahm diese Konferenz zum Anlass, erneut 
the appeals calling for an increased focus on women's human rights within the human rights work to heart." ${ }^{290}$

In addition to the MaF's attempts to influence decision-making at the international level by submitting motions to the GAs, the group must have also been a particularly active part of the IWN. In fact, the second meeting of the IWN in Bonn goes back to the initiative of the German section's IWN member, who was also the IWN interim coordinator before the appointment of the IWN coordinator at the IS in 1995. Further, the MaF played an important role in the section's activities related to the 1995 campaign. In an outline of the focus of the 1995 campaign sent to the section, the MaF suggested "[...] to call the groups to end the thematic marginalization of violations of human rights on women and to stop always consulting the same public (the Women's movement, church women, union women, women in parliament, etc.)." ${ }^{291}$ In the same document, the MaF further recommended that the country coordination groups work on violations of women's rights in their respective countries. The MaF further argued that international developments were increasingly overtaking AI and "urged that we in our organization handle the new facts regarding the development of human rights in a constructive way, not only to remain modern, but to continue being relevant!"292 It demanded that the section should take the opportunity presented by the campaign to initiate an internal discussion about the section's conception of human rights.

Additionally, the MaF pushed the section to participate in the Germanwide NGO activities in preparation for Beijing by suggesting that the EC

langjährige Forderungen gegenüber internationalen Ebenen zum Schutz von Frauen vor frauenspezifischer Verfolgung vorzubringen."

290 Reichinger und Sektionsarbeitskreis Menschenrechtsverletzungen an Frauen: Die Weltmenschrechtskonferenz in Wien - eine Bilanz aus frauenspezifischer Sicht, 30.11.1993, p.3: "Auch ai sollte sich die Appelle, Frauenmenschenrechte in der Menschenrechtsarbeit mehr Gewicht zu geben, zu Herzen nehmen.".

291 Amnesty International Sektion Bundesrepublik Deutschland: Letter from Frauke Marohn from the MAF-Sektions-AK, 1994, p.3: "[...], wollen wir die Gruppen auffordern, die thematische Marginalisierung von Menschenrechtsverletzungen an Frauen zu beenden und sich nicht immer wieder an immer dieselben Adressaten (Frauenbewegung, Kirchenfrauen, Gewerkschaftsfrauen, Frauen im Bundestag etc.) zu wenden.".

292 Amnesty International Sektion Bundesrepublik Deutschland: Aufriss des MAFSektions-AK's zu einer internationalen ai-Kampagne gegen Menschenrechtsverletzungen an Frauen 1995, 32.3.1994, p.3-4: "Wir halten es darum für dringend geboten, dass wir in unserer Organisation konstruktiv mit den neuen Tatsachen der MR-Entwicklung umgehen, nicht allein, um modern zu sein, sondern um sachgerecht zu bleiben!". 
send a member of their group as the AI representative to the NGO coalition NGO-Frauenforum. ${ }^{293}$ At the same time, various letters to the German delegation illustrate the MaF's involvement in the section's lobbying activities for the integration of women's civil and political rights into the WCW's final document. 294

As far as the section's campaign activities were concerned, while local and thematic groups participated in the campaign, the MaF realized the majority of the thematic work related to the campaign in its capacity as an expert group. In contrast to the Swiss section, the German section had not established any specific position for the work on women's rights issues at the Secretariat by the time of the 1995 campaign. Instead, some officials working in the department on Länder Themen und Asyl (country-related issues and asylum) focused on issues of women's rights because female refugees were considered particularly vulnerable persons, who often fled from gender-based human rights violations. ${ }^{295}$

The lack of archival materials for the period between 1996 and 2000 does not allow me to provide more details about the German section's work on issues of VAW or about the MaF in the post-Beijing period. The only evidence I collected is some information about the dissolution of the MaF during this period. ${ }^{296}$ However, as I show in chapter 8.2.2, the group continued to play a significant role in the implementation of the SVAW campaign within the German section in a new composition.

Summing up, like in the Swiss section, women initiated the German section's work on issues of VAW in the 1980s. By setting up a thematic Sektion-

293 Amnesty International Sektion Bundesrepublik Deutschland: Letter from the Sektions-Arbeitskreis Menschenrechtsverletzungen to the Executive Committee, 24.06.1994.

294 Amnesty International Sektion Bundesrepublik Deutschland: Protokoll Lobbygespräch im Auswärtigen Amt am 22.3.1995, 13.05.1995.

295 Ganzfried: Interview with B.T., 15.04.2015. The section's specific focus on the rights of female refugees also becomes evident in the publication Frauen im Blickpunkt (1991), which included a chapter on female refugees and on the protection of persecuted women in Cermany, and in the report Frauen in Aktion - Frauen in Gefahr (1995), which specifically focused on female asylum seekers in Cermany (Amnesty International Sektion Bundesrepublik Deutschland 1991; Amnesty International, Sektion Bundesrepublik Deutschland 1995).

296 "The preceding group, which had been in place since the 1980s, somehow petered out" (Ganzfried: Interview by phone with A.Y., 09.01.2015). 
sarbeitskreis, with members dispersed all over the country, female activists organized nationally within the German section with the aim of raising the section's awareness of violations of the human rights of women. The MaF got involved in decision-making immediately after its formal recognition by the section in 1987. It initiated several motions to the section's GA demanding the submission of resolutions relevant to AI's work on issues of VAW to the ICM. As an expert group, the MaF carried out most of the section's work on violations of women's rights before and during the 1995 campaign, and it was the driving force behind the section's work in this regard. While I could not clearly identify a specific MaF strategy, it is worth highlighting its focus on influencing decision-making at the international level as well as its exchange with other IWN members, which contrasts with my observations about the Swiss section.

\subsubsection{Disinterest regarding women's rights}

Similar to the Swiss section, the membership of the German section showed no resistance to the initial work on women's rights, except for some critical voices who disapproved of the MaF's initial constitution and questioned the sense of its work. In a June 1986 article in the ai info, a member of the MaF wrote: "Meanwhile, some members expressed their concerns about our [group], which, in sum, question the sense, and the legitimacy of our [group] inside AI and our ability to positively influence and further develop AI's daily work." 297

In general, the issue of women's rights faced ignorance here, as well. However, as the following statement shows, the disinterest seems to have sometimes played an important role. In fact, according to an interviewee, those engaged in the promotion of women's rights issues within AI "sometimes had the impression of being forced to convince their own people of the necessity to work on women's rights much more than the public [...]." ${ }^{298}$ Generally, the critical voices against increasing the work on women's rights argued that

297 Amnesty International Sektion Bundesrepublik Deutschland: Artikel im ai info 6/86, Juni 1986, p.10: “In der Zwischenzeit haben einige Mitglieder Bedenken gegenüber unserem AK geäussert, die zusammengefasst den inhaltlichen Sinn, bzw. Die Existenzberechtigung unseres AK innerhalb ai's und unsere Möglichkeiten einer positiven Einflussnahme und Weiterentwicklung der alltäglichen ai-Arbeit in Frage stellen.". Ganzfried: Interview with B.T., 15.04.2015: "man [hatte teilweise] den Eindruck, man muss die eigenen Leute viel stärker noch von der Notwendigkeit der Arbeit zu Frauenrechten überzeugen als die Öffentlichkeit, [...]". 
"there are women's rights organizations, AI does not have to do this, it should better engage in the release of individual political prisoners." ${ }^{299}$

Instead, just like in the Swiss section, the most controversial discussion of the 1990s concerned the integration of states' responsibility for inaction in cases of grave human rights violations committed by non-state actors. According to an interviewee,

"the German section was almost divided on [the question of non-state actors]. [...] There were votes at the Ceneral Assemblies [...] battle votes and where we barely lost on the question 'Should Al become active in the case of persecutions by non-state actors and therewith in the case of gender-specific persecutions?"'300

While I could not find any evidence of specific opposition to engaging in the issue of FGM, the practice seemed to have been discussed as part of the larger debate about the mandate's enlargement to states' accountability for their inaction as a sort of "case study for the controversy." ${ }^{301}$ According to an interviewee, "the discussions were very theoretical. Theoretical in the sense of 'we want to have a coherent concept of our mandate." ${ }^{302}$ As the following statement shows, as in other sections, AI members feared that the organization would be overtaxed if it had to do research on cases of human rights violations committed by non-governmental entities:

"[...] the related concerns were just questions such as 'Al is not able to do research on all that.' And 'we are already at the limit of our ability to collect really solid information about human rights violations in the classical cases,

299 Ganzfried: Interview with B.T., 15.04.2015: "Es gibt ja Frauenorganisationen oder Frauenrechtsorganisationen und Amnesty soll sich doch lieber für den einzelnen politischen Cefangenen einsetzen, [...]".

300 Ganzfried: Interview by phone with B.E., 06.03.2015: "Also es gab SCHWIERICE Debatten, insbesondere in der deutschen Sektion. Also ich würde sagen, dass Anfang der goer die deutsche Sektion FAST gespalten war in dieser Frage. Also nicht sonst, aber halt in dieser Frage. Da gab es Abstimmungen auf der ] ahresversammlung [...] wo es wirklich KAMPFAbstimmungen gab und wir dann die Frage, SOLL Amnesty auch im Falle nichtstaatlicher Verfolgung UND damit geschlechtsspezifischer Verfolgung tätig werden "knapp verloren haben."

301 Ganzfried: Interview by phone with B.E., 06.03.2015.

302 Ganzfried: Interview by phone with B.E., 06.03.2015: "Die deutsche Sektion hat zum Teil sehr theoretisch diskutiert. Also theoretisch im Sinne von, Wir wollen ein stimmiges Konzept unseres Mandats haben.". 
such as torture, and then you are going to engage in the area of non-state actors where research is even more difficult!" ${ }^{303}$

Let me briefly summarize the main insights provided by the two case studies. Female activists initiated the work on issues of VAW by forming locally anchored Women Urgent Action Networks in the Swiss section and by establishing a section-wide "Arbeitskreis" focusing on the defense of women prisoners in the 1980s. In both sections, these women's groups remained the driving force behind the work on issues of VAW during the 1990s. However, the women at each section organized and proceeded differently. At the Swiss section, women had successfully established a women's network composed of five women's groups and a representative at the secretariat by the end of the 1990s. Thus, parallel networking seemed to have been a strategy female activists and officials used to make the section increase its activities on issues of VAW. Meanwhile, the female activists organized in the MaF focused on influencing decision-making at the international level and were in regular contact with the IWN. However, I could not find evidence for any clear strategy the MaF employed to make its section increase its work on issues of VAW.

Similar to the section's overall organization of its thematic work, the Swiss section professionalized the work on issues of VAW over the course of the Human Rights are Women's Rights campaign. Meanwhile, in the German section, the women's group continued to be responsible for the majority of the section's work on issues of VAW throughout the 1990s. In both sections, the membership's general reaction to AI's activities on issues of VAW and to the women's groups' demands to increase work on violations of women's rights was ignorance, rather than opposition. In contrast, the question of state responsibility for inaction in cases of grave human rights violations committed by non-state actors was an issue of major debate in both sections, just like it was at the international level.

303 Ganzfried: Interview by phone with B.E., 06.03.2015: "Also ja es war wirklich EXTREM umstritten. Und die Sorgen die damit verbunden waren, waren halt so Fragen wie, das kann Amnesty ja alles nicht recherchieren und, wir sind eh schon am Limit unserer Möglichkeiten wirklich SOLIDE Informationen über die Menschenrechtsverletzungen zu liefern in den KLASSISCHEN Fällen wie Folter und dann geht ihr jetzt in den nichtstaatlichen Bereich wo die Recherchen ja ungleich schwieriger sind".". 


\subsection{Intermediate conclusions}

Chapter 7 has illustrated the beginnings of Al's interest in VAW in detail. In the 1990s, AI's human rights policy gradually shifted away from its essential focus on civil and political rights, which saw the state as the primary violator of individuals' human rights. It moved towards adopting a mission that recognized the indivisibility of all human rights including economic, social and cultural rights in 2001 . The 1991 recognition that abuses committed by political non-state actors fell within the mandate was the first step of the subsequent redefinition of Al's policy. Later, AI decided to hold states accountable for inaction in cases of human rights violations committed by non-governmental entities, before it held private actors themselves responsible for abuses of human rights. In 2001, AI adopted the mission and expanded its policy to economic, social and cultural rights. These mandate developments were highly significant for effective action against VAW because they signified the end of the long-lasting public-private divide and allowed the organization to consider VAW as a consequence of structural inequalities rather than as individual acts. This, in turn, enabled AI to take action against VAW whoever the perpetrator. Concurrently with the modification of the mandate, AI adopted three consecutive ICM decisions calling on the movement to strengthen the work on women's rights for the first time.

The evolution of AI's policy on VAW was reflected in its activities. In fact, whereas AI's first comprehensive report on violations of women's rights, Women in the Front Line (1991), focused on gender-based violence in state custody and highlighted patterns of political persecutions of women, the 1995 Human Rights are Women's Rights campaign focused on torture, the death penalty, extra-judicial executions, and disappearances as they affected women. Nevertheless, the state remained the primary addressee of the organization's demands to prevent and condemn VAW. The Take a Step to Stamp Out Torture campaign launched in 2000 was seen as AI's first effective attempt to campaign against VAW in the private sphere because it independently considered all forms of VAW as acts of torture, whatever the context and whoever the perpetrator.

Women organizing and strategizing at the international and national levels are key to our understanding of AI's increasing interest in issues of VAW reflected in the above-mentioned policy developments and activities. Female activists, concerned about the under-representation of women in the cases defended by AI, not only initiated AI's work on issues of VAW by forming 
specific Urgent Action Networks and women's groups in the early 1980s. By forming the IWN and demanding an intensification of work on violations of women's rights within the frame of the mandate, rather than the abolition of the state-focused mandate, female activists and officials also successfully pressured AI to increase its work on VAW and to choose VAW in the private sphere as the theme of its first thematic long-term campaign under the mission. The external factors, such as the changing pattern of human rights violations (contributing to AI's questioning of its state-focused mandate), ${ }^{304}$ the growing international awareness of gender equality (especially in response to the conference in Beijing), ${ }^{305}$ the international women's rights movement (challenging AI to expand its mandate to violations of human rights in the private sphere), ${ }^{306}$ and some internal factors, such as SG Pierre Sanés positive stance and the growing number of women in AI's leadership positions, are therefore insufficient to fully explain the beginning of AI's work on issues of VAW and the movement's growing interest in issues of VAW in the 1990s. Instead, the latter must be seen primarily as the result of the feminist strategy of parallel networking and analogous framing.

In fact, by organizing in the IWN, female activists and officials were able to do effective internal lobbying for an increase in AI's work on violations of women's rights. Organizing in an intersectional network allowed the female activists and officials to reach out to the whole AI movement and build majorities for their demands at the ICMs. Further, female activists and officials called for an increase in AI's work on women's rights within the frame of the mandate. The strategy of analogous framing was crucial in making AI increase its work on VAW because it allowed garnering the majority of the movement's support for more seriously engaging in work on women's rights. In their quest, the fourth WCW in Beijing in 1995 appeared as an important window of opportunity, enabling women organized in the IWN and at the section level to enhance their lobbying efforts and make AI launch its first major theme campaign on women's rights. Finally, both of these strategies were important in making AI decide to launch its first long-term thematic campaign under the mission on the issue of VAW, as they enabled the effective lobbying of sections, the IEC, and the SG. They also convinced the organization of the necessity to further strengthen its work on violations of women's rights. 
AI's increasing interest in issues of VAW in the 1990s was accompanied by controversial internal discussions that crystallized in relevant ICM decisions, yet, above all, in AI's position on states' responsibility for inaction in cases of grave human rights violations. In this regard, the issue of how AI should proceed with the issue of FGM was discussed to much controversy at all levels of the movement during the 1990s. In contrast, the female activists' and officials' lobbying efforts and the multiplying activities on issues of VAW faced members' ignorance. Resistance could primarily be observed among IS staff who criticized the new focus and refused to incorporate a gender perspective into their work.

Thus, AI increasingly integrated VAW into its activities in the 1990s. The feminist strategies of parallel networking and analogous framing proved to be key to policy development and the implementation of activities on issues of VAW. They greatly contributed to making AI choose the issue of VAW in the private sphere as the theme of its first long-term global thematic campaign in 2001. In light of AI's historically grown, long-lasting gender-biased understanding of human rights, this decision was an important achievement. Yet were these achievements truly sustainable? Focusing on the period between 2001 and 2010, the following chapter intends to answer this question. 


\section{The challenges to make women's rights part of Al's DNA}

This chapter emphasizes the development of AI's work on violence against women in the 2000s. Examing first the international and then the national level, it starts by illustrating how policy on VAW developed within the new framework of human rights provided by AI's mission and how AI integrated VAW into its activities. Chapter 8 demonstrates that unlike its passive role in the 1990s, Al's leadership was the driving force behind policy development on the subject in the 2000 s and behind the implementation of the SVAW campaign. Nevertheless, the SVAW campaign did not succeed in making women's rights an integral part of AI's overall work. Two reasons prevented women's rights from becoming part of AI's DNA: first, the top-down implementation of the SVAW campaign caused female activists and officials who had initiated AI's work on VAW in the 1990s to lose their influence on the organization's work on these issues. Second, activists and officials resisted the SVAW campaign and the adoption of a policy on abortion. The focus on the Swiss and the German sections, however, shows considerable differences with respect to the extent to which AI succeeded in integrating the issue of VAW into its work at the national level. While the Swiss section managed to at least partially integrate VAW into its work, the German section reaped little success in this regard.The German section membership's important opposition to the SVAW campaign and to the adoption of a policy on abortion help explain this divergence. I argue that the German section members' relative closeness to the Church and their comparatively powerful position further account for the difference between the two sections. 


\subsection{The international level}

This chapter first describes the development of AI's policy on VAW (section 8.1.1). It especially highlights the development of AI's first common position on the issue of sexual and reproductive rights (particularly abortion). It continues with an account of the thematic focus and the content of the SVAW campaign, the organization's first long-term thematic global campaign (8.1.2). This section spotlights the campaign's successes and shows that one of its core aims, to mainstream gender throughout the organization, ${ }^{1}$ was not achieved. As the review of the campaign indicated, AI did not succeed in making women's rights part of its DNA.

In addition to providing an in-depth picture of how AI prepared and internally organized the SVAW campaign and of the controversial discussions leading to the adoption of AI's position on abortion, sections 8.1.3 and 8.1.4 also explain AI's failure to make women's rights part of its DNA. Section 8.1.3 demonstrates that the organization's leadership initiated the majority of the ICM decisions concerning AI's work on VAW. I highlight how the management pushed the implementation of the SVAW campaign from the top and describe the establishment of the Machinery for the successful running of the SVAW campaign at the IS. Many of the feminist caucus at the IS, who had pushed the organization to increase its work on issues of VAW in the 1990s, were included in the preparation and, particularly, in the implementation of the campaign as members of the SVAW campaign Machinery. However, the Campaign Team's and the Gender Unit's problematic embedding in the IS and their lack of clear responsibilities and power made it difficult for the women's rights advocates at the IS to effectively implement the campaign. I show that the female activists and officials who had initiated AI's work on VAW in the 1990 s lost their influence on the organization's work on issues of VAW. I argue that this loss of influence was one of the reasons AI did not manage to make women's rights part of its DNA through the SVAW campaign.

$1 \quad$ Gender Mainstreaming refers to a "strategy for making women's as well as men's concerns and experiences an integral dimension of the design, implementation, monitoring and evaluation of policies and programs in all political, economic and societal spheres so that women and men benefit equally and inequality is not perpetuated" (Amnesty International, International Secretariat: Stop VAW Campaign internal strategy, September 2003, p.6). For Al's work on VAW during the SVAW campaign this meant that issues of VAW were not confined to the campaign but were meant to become an integral part of Al's overall work. 
Section 8.1.4 then emphasizes the reactions the SVAW campaign received and the participation in it, and focuses on the debates surrounding the adoption of the ICM decisions on sexual and reproductive rights and abortion. I highlight activists' and officials' resistance to the SVAW campaign and to the adoption of a policy on abortion. The opposition to the campaign was motivated by various factors. Some of the members and officials perceived that the SVAW campaign stood for the broader policy change brought about by the adoption of the mission. They resisted the campaign because they were critical of the adoption of the mission. Other critiques related to the structure and the setting of the campaign, rather than to its content. At the same time, at least part of the opposition was primarily motivated by the issue of the campaign itself. In contrast to the resistance to the campaign, the opposition to the adoption of a policy on abortion, which came from the sections, can more clearly be identified as related to the issue of abortion itself and less to AI's overall policy change. Thus, I argue that several sections' resistance to the adoption of a policy on abortion and the opposition to the campaign are important reasons why AI failed to make women's rights part of its DNA.

\subsubsection{Policy development 2002-2010}

Analyzing ICM decisions allows us to understand AI's policy development in general and that on VAW in particular. Between 2003 and 2010, the ICM took place four times (in 2003, 2005, 2007, and 2009). Each ICM issued between 15 and 40 decisions, ${ }^{2}$ some of which either directly or indirectly concerned AI's work on VAW (highlighted in figure 6).

For the period between 1989 and 2001, I classified the ICM decisions demanding a modification of the mandate as indirectly concerning AI's work on VAW. Because of the adoption of the mission, the ICM no longer made similar decisions in the 2000s. As figure 6 highlights, I classify the ICM decisions that sought a more equal representation of women and men in the organization's membership and leadership as indirectly concerning AI's work on VAW (left side of figure 6). I do so because AI considered the equal representation of women and men within the movement and the adoption of a gender sensitive perspective to be important factors in ensuring the credibility of the SVAW campaign. Evidence shows that the leadership wanted to sensitize the and the 2009 ICM - 15 decisions. 
movement to potential gender inequalities among staff and activists, and it considered the internal commitment to gender equality a (pre)condition for a successful campaign on VAW. An internal document issued prior to the SVAW campaign explains: "We need to establish gender equality at the core of AI's mission and organizational culture to ensure a credible and authentic voice for the issues that the campaign will promote." ${ }^{3}$

The analysis of the ICM reports allows me to identify two types of decisions directly concerning AI's work on VAW: those codifying AI's policy on sexual and reproductive rights, and several others related to women's rights in general (highlighted in the right rectangle of figure 6). With the SVAW campaign, female activists' and officials' demand (reflected in decision 15 of the 1989 ICM, decision 20 of the 1995 ICM, and in decision 32 of the 1997 ICM) to increase the organization's work on women's rights came to fruition. That's why there were no ICM decisions that demanded increases in this work during the period between 2002 and 2010.

Figure 6: Overview of policy developments between 2002 and 2010
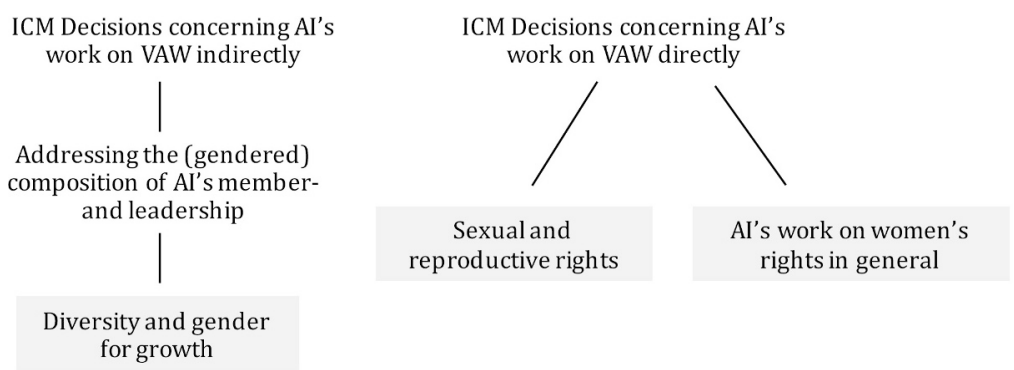

Source: my own, based on the 2003, 2005, 2007, and 2009 ICM reports.

By distinguishing between the ICM decisions directly and indirectly concerning AI's work on VAW, the preceding paragraph has provided a general overview of the development of AI's policy on VAW between 2002 to 2010 . The next section illustrates policy developments by focusing on the content of the ICM decisions adopted between 2002 and 2009. It starts with the description of the decisions indirectly concerning AI's work on VAW before doing the 
same for those directly concerning it. Figure 7 displays all such ICM decisions. I show how gender mainstreaming and the principle of equal representation of men and women became part of Al's policy and demonstrate in detail the internal process leading to the adoption of AI's first position on sexual and reproductive rights, as well as that on abortion.

Figure 7: Detailed policy developments between 2002 and 2010

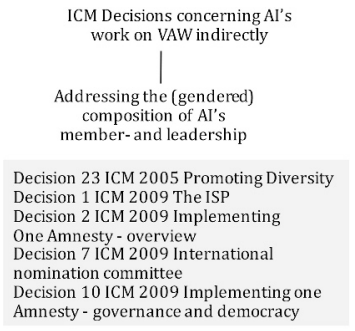

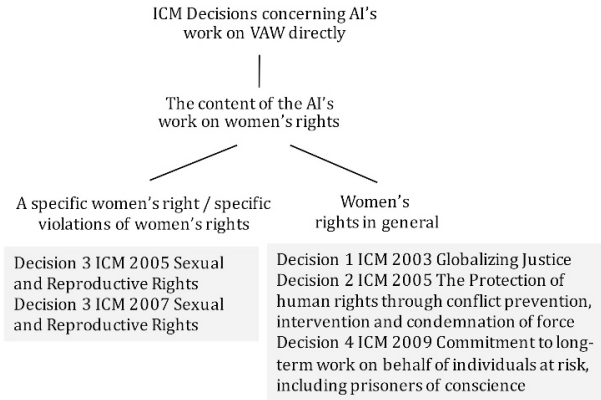

Source: my own, based on the 2003, 2005, 2007, and 2009 ICM reports.

\subsubsection{ICM Decisions indirectly concerning Al's work on VAW}

In the 1990s, AI identified diversity and multiculturalism as issues important for the movement's international growth. ${ }^{4}$ In the 2000 s, AI began to consider gender equality as increasingly relevant to the development of the organization. While equality among its staff and activists had already become an important aspect of the internal SVAW campaign strategy by 2003, AI first integrated the principle of equal representation of women and men into its policy at the 2005 ICM. In decision 5 of the 2005 ICM, the delegates defined "multiculturalism, linguistic plurality, diversity, and equity in both gender and sexual orientation within AI [as] a crucial part of the growth agenda [...]"5 (left side of figure 7). According to this decision, sections were encouraged to

4 Decision 28 of the 1995 ICM that set out the 1996-2001 Integrated Strategic Plan called for a movement-wide implementation of the "standards consistent with Al values, including human resource management strategies covering such issues as multiculturalism and gender equity [...].".

5 Amnesty International, International Secretariat: Report and Decisions of the 27th International Council of Amnesty International, 14th-20th August 2005, p.115. 
develop their own plan for growth and respect gender equality and diversity when deciding on their delegations to international AI meetings.

While AI recognized the importance of a balanced representation of women and men within the organization during the SVAW campaign, the codification of these principles only occurred at the end of the long-term campaign in 2009. At the 2009 ICM, the organization stressed the importance of an equal representation of both genders in all its bodies by making it one of the main objectives of the upcoming Integrated Strategic Plan. At the end of the decade, AI also codified the principle of gender mainstreaming. Figure 7 illustrates that gender equality figured in several decisions of the 2009 ICM as a factor facilitating growth or democracy. The decision thereby codified the principle of diversity and gender equality. Decision 1 of the 2009 ICM stipulated that the 2010 - 2016 strategic plan should enable AI to learn and grow by "[m]aking diversity and gender-mainstreaming a reality," ${ }^{6}$ and defined gender mainstreaming as one of the five pillars of the organization's core work within the ISP "that all AI entities shall undertake."

The International Council also decided to ensure diversity and gender equality in the nominating process for the IEC and other international elected positions (Decision 7). It wanted to make diversity and gender "principles for the movement's democratic governance at all levels" (Decision 10). The IC stated: "AI's governance bodies must be diverse and gender-sensitive." ${ }^{8}$ At the policy level, gender equality thus mostly appeared as a synonym of equal representation of women and men in various hierarchical positions. The analysis of these decisions indicates that gender equality was considered a means to achieving growth and enhancing the movement's democratic governance.

6 Amnesty International, International Secretariat: 29th International Council Meeting Circular 46 ICM Decisions 2009, 16.08.2009, p.3.

7 Amnesty International, International Secretariat: 29th International Council Meeting Circular 46 ICM Decisions 2009, 16.08.2009, p.4.

8 Amnesty International, International Secretariat: 29th International Council Meeting Circular 46 ICM Decisions 2009, 16.08.2009, p.10. 


\subsubsection{Decisions directly concerning Al's work on VAW}

The issue of sexual and reproductive rights first became topical with the launch of the SVAW campaign. While the discussion about AI's work on sexual and reproductive rights had already started around the 2003 ICM, the organization only codified its work at the 2005 and the 2007 ICMs, respectively, and elaborated two respective policies: one on sexual and reproductive rights, and the other on the AI policy on selected aspects of abortion. ${ }^{9}$ As I show in section 8.1.4, finding a common position on sexual and reproductive rights, particularly on abortion, took long, intensive, and controversial discussions. The issue of abortion divided the organization in an unprecedented way and made many long-term activists withdraw from their engagement within AI. The present section highlights the content of the organization's position on sexual and reproductive rights, particularly on the issue of abortion, by focusing on the related ICM decisions. I emphasize the origins of these ICM decisions in section 8.1.3 and describe the related controversial discussions in section 8.1.4.

Following a discussion at the 2003 ICM that did not lead to any decisions, AI organized a movement-wide consultation on sexual and reproductive rights. ${ }^{10}$ Based on it, the International Executive Committee submitted an enabling resolution to the 2005 ICM. The delegates accepted the latter as decision 3 on "Sexual and Reproductive Rights." The content of this decision reveals the sensitivity of the topic. In fact, while it broadly delineates the organization's position on sexual and reproductive rights, it emphasizes the importance of integrating the existing diverging viewpoints on abortion into a policy that should be elaborated in a movement-wide consultation process.

In decision 3, AI affirmed its commitment to defending and promoting sexual and reproductive rights, and averred that the related work should be made in the context of the current ISP. It decided that the IEC would develop a comprehensive statement and a strategy for action on sexual and reproductive rights. A future policy would support the right of access to information about sexual and reproductive health as well as the right of access to sexual and reproductive health services, including contraception. In addition, decision 3 also specified that a "consultation, education, and awareness-raising

Amnesty International, International Secretariat: Amnesty International policy on selected aspects of abortion, 20.04.2007.

10 Amnesty International, International Secretariat: Amnesty International policy on selected aspects of abortion, 20.04.2007, p.15. 
process"11 should be initiated in order to enable the organization to make an informed decision about its position on abortion.

For the first time, AI considered abortion to be closely related to women's subordinated position in society, recognizing "that the need for abortion in a large number of cases is a consequence of violence against women, a lack of empowerment of women as well as of a lack of access to education and health services like contraception." ${ }^{12}$ At the same time, the content of the decision reveals the disagreement on the question of whether AI should defend a woman's right to abortion. It specified that:

"the [consultation, education, and awareness-raising] process should enable Al to take an informed decision as to the organization's position - should it choose to do so - on the question of whether a woman's right to physical and mental integrity includes her right to terminate her pregnancy, subject to reasonable limitations, and of whether abortion should therefore be legal, safe and accessible to all women." ${ }^{13}$

The IEC was given the chance to "fast-track' decision-making"14 on three aspects of abortion, namely the decriminalization of abortion, access "to quality services for the management of complications arising from abortion," and "legal, safe and accessible abortion in cases of rape, sexual assault, incest, and risk to a woman's life." 15 Later, these three aspects formed the core of the AI policy on selected aspects of abortion adopted in $2007 .{ }^{16}$ All other possible AI positions on the issue of abortion were postponed for discussion at the 2007 ICM. $^{17}$

11 Amnesty International, International Secretariat: Report and Decisions of the 27th International Council of Amnesty International, 2006, p.104.

12 Amnesty International, International Secretariat: Report and Decisions of the 27th International Council of Amnesty International, 2006, p.103.

13 Amnesty International, International Secretariat: Report and Decisions of the 27th International Council of Amnesty International, 2006, p.104.

14 Amnesty International, International Secretariat: Amnesty International policy on selected aspects of abortion, 20.04.2007, p.2.

15 Amnesty International, International Secretariat: Report and Decisions of the 27th International Council of Amnesty International, 2006, p.104.

16 Amnesty International, International Secretariat: Amnesty International policy on selected aspects of abortion, 20.04.2007.

17 Amnesty International, International Secretariat: Report and Decisions of the 27th International Council of Amnesty International, 2006, p.104. 
The principles of AI's work on sexual and reproductive rights, which also served as the frame of a future policy on abortion, was subject to a policy paper in October 2006. ${ }^{18}$ In the document, the IEC stated that sexual and reproductive rights were "central to the realization of every individual's human rights" and stressed AI's belief "that all persons must be enabled to enjoy their sexual and reproductive rights free of coercion, discrimination and violence."19 Further, in the "Statement Summarizing Al's Current Policy on Sexual and Reproductive Rights," sexual and reproductive rights were framed as an issue of civil and political rights: "The realization of sexual and reproductive rights requires respect for rights relating to physical and mental integrity, such as the right to life, [...], ${ }^{20}$ as well as an issue of economic, social, and cultural rights: "The realization of sexual and reproductive rights requires also respect for economic, social and cultural rights, such as the right to education and the right to the highest attainable standard of health [...]." ${ }^{21}$ In the same document, AI further affirmed its commitment to defending and promoting these rights in the context of its mission, its core values, and its strategic goal. Finally, AI called upon the responsibility of the state to respect, protect, and fulfill the sexual and reproductive rights of every person, and upon the responsibility of other societal actors, such as corporate actors or health professionals, to do so, as well. ${ }^{22}$

After a movement-wide consultation process, AI adopted its policy on selected aspects of abortion ${ }^{23}$ in April 2007. Based on the three aspects of abortion that were considered capable of drawing a consensus within the movement at the 2005 ICM, the policy called for the decriminalization of abortion but recognized "the right of states to impose reasonable limitations on access to

Amnesty International, International Secretariat: Statement Summarizing Al's current policy on Sexual and Reproductive Rights, 12.10.2006.

19 Amnesty International, International Secretariat: Statement Summarizing Al's current policy on Sexual and Reproductive Rights, 12.10.2006, p.2. Amnesty International, International Secretariat: Statement Summarizing Al's current policy on Sexual and Reproductive Rights, 12.10.2006, p.3.

21 Amnesty International, International Secretariat: Statement Summarizing Al's current policy on Sexual and Reproductive Rights, 12.10.2006, p.3.

Amnesty International, International Secretariat: Statement Summarizing Al's current policy on Sexual and Reproductive Rights, 12.10.2006.

23 Amnesty International, International Secretariat: Amnesty International policy on selected aspects of abortion, 20.04.2007. 
abortion services." 24 It called for access to quality health services in cases of complications arising from abortions, and it requested that states provide access to legal, safe, and accessible abortions "in the case of an unwanted pregnancy as a result of rape, sexual assault or incest, or if the pregnancy poses a risk to the life or grave risk to the health of the woman." 25 It further called for sexual and reproductive health services for women and men, recognizing their importance for the prevention of unwanted pregnancies and abortions. ${ }^{26}$ The policy thus enabled AI to help "those women who wish to end unwanted pregnancies resulting from sexual violence, [...] to support women who seek treatment for complications arising from abortion," and "to oppose imprisonment or other criminal penalties for abortion." 27

That same autumn, the ICM delegates accepted decision 3 at the 2007 ICM. By adopting this decision, the organization codified the previously adopted policy documents on sexual and reproductive rights and abortion. In fact, decision 3 of the 2007 ICM stipulated that:

"the recently adopted policy on: decriminalization of abortion; access to quality services for the management of complications arising from abortion; legal, safe and accessible abortion in cases of rape, sexual assault, incest, risk to the life or grave risk to the health of the woman enables the organization to tackle the grave violations of women's human rights that fall within its mission and its SVAW campaign strategy."28

At the same time, AI confirmed the importance of strengthening preventive work in order to avoid unwanted pregnancies and the recourse to abortions, and it recognized that the work on these issues needed to be "discussed across the movement before AI can make an informed decision about further policy development in relation to other aspects of sexual and reproductive rights not covered by existing policies." 29

24 Amnesty International, International Secretariat: Amnesty International policy on selected aspects of abortion, 20.04.2007, p.3.

25 Amnesty International, International Secretariat: Amnesty International policy on selected aspects of abortion, 20.04.2007, p.3.

26 Amnesty International, International Secretariat: Amnesty International policy on selected aspects of abortion, 20.04.2007.

27 Amnesty International, International Secretariat: Amnesty International policy on selected aspects of abortion, 20.04.2007, p.3.

28 Amnesty International: 28th international Council Meeting, 2007, p.67.

29 Amnesty International: 28th international Council Meeting, 2007, p.87. 
Consequently, after long and intensive movement-wide consultations and debates, the organization finally reached a consensus and codified its policy on sexual and reproductive rights and abortion in 2007. Therein, AI considered sexual and reproductive rights as part of every person's human rights, and it framed these rights as civil and political rights and as economic, social, and cultural rights. The decriminalization of abortion and legal, safe, and accessible abortion, if the unwanted pregnancy is a result of any form of VAW or if the pregnancy endangers the life of the pregnant woman, formed the core principles of AI's position on abortion. AI also agreed on the importance of providing sexual and reproductive health services to women and men, recognizing its importance for the prevention of unwanted pregnancies and abortions. While stressing each individual's right to freely decide on his or her sexuality and reproductive life, AI did not stand for a woman's right to freely choose if she desired to terminate her pregnancy or not. Thus, while AI defended the sexual and reproductive rights of every individual, it adopted a more restrictive position towards abortion, limiting the right to abortion to threatened women, while demanding that the state decriminalize the practice. As I detail later, AI's policy on selected aspects of abortion (widely criticized by women's rights organizations) was a compromise between those within AI who were calling for the right to abort and others who espoused the view that AI should not take a position on the issue.

In addition to the controversial policy-making on sexual and reproductive rights, the organization made three ICM decisions (decision 1 of the 2003 ICM, decision 2 of the 2005 ICM, and decision 4 of the 2009 ICM) concerning other aspects of its work on VAW. The following paragraph briefly presents the content of these decisions.

In decision 1 of the 2003 ICM on "globalizing justice," the delegates decided to make women's rights and VAW an integral part of AI's upcoming 2004 to 2010 ISP. In fact, one of the fifteen goals of the ISP stated that AI should emphasize the strengthening of "the protection of women and girls in international, regional and national law" and that AI should demand "accountability of states regarding respect, protection and fulfillment of rights for women and girls" and "accountability of non-state actors regarding the rights of women and girls." Further, the same goal stipulated that AI should "work in alliance with the women's movement to increase awareness and human rights education towards the eradication of violence against women and 
girls." ${ }^{30}$ Reflecting the objectives of the internal SVAW campaign, the same goal also highlighted the importance of promoting women's rights inside AI and the commitment of its membership and staff to these rights. In accordance to one of the main objectives of the public SVAW campaign, decision 2 of the 2005 ICM resolved to strengthen the movement's work on women in conflicts by emphasizing, among other things, "the ways in which military actions disproportionately affect women,"31 and by searching for solutions to this disparity. Furthermore, at the 2009 ICM, the delegates decided to ameliorate AI's long-term work on behalf of individuals at risk by committing to an equal representation of women and men in its cases of prisoners of conscience (Decision 42009 ICM).

Summing up, AI's policy on VAW mainly developed in two domains in the 2000s. First, at the end of the decade, AI codified gender equality as an important principle of internal governance and growth, and emphasized the importance of integrating women's rights in all areas of its work by codifying the principle of gender mainstreaming. Second, for the first time, AI discussed and decided upon a common position on sexual and reproductive rights and adopted the AI policy on selected aspects of abortion. ${ }^{32}$

\subsubsection{Policy Implementation - Focus and content of the SVAW campaign}

In the 2000s, most of AI's activities on VAW fell within the SVAW campaign. Before describing the content of AI's first global thematic long-term campaign, it is worth it to briefly highlight the institutional context of its implementation. This would allow us to appreciate the challenge that the SVAW campaign represented for the organization and would improve our understanding of the difficulties AI faced in its attempts to integrate VAW into its work. As I have highlighted before, at the turn of the millennium, AI radically changed its approach to human rights by adopting a mission that encompassed all human rights, including economic, social, and cultural rights. As

30 Amnesty International, International Secretariat: Report and Decisions of the 25th International Council of Amnesty International, 2004, p.97.

31 Amnesty International, International Secretariat: Report and Decisions of the 27th International Council of Amnesty International, 2006, p.102.

32 Amnesty International, International Secretariat: Amnesty International policy on selected aspects of abortion, 20.04.2007. 
a consequence, $\mathrm{AI}$ also changed its working methods. For example, it abandoned the WOOC rule and undertook a shift away from campaigning centered around the country and the individual and toward thematic campaigning. Furthermore, collaboration with external actors, such as other human rights or women's rights organizations or experts, became increasingly important during this period, as AI lacked internal expertise in working in the domain of social, economic, and cultural rights and in framing the related work on VAW. As Wallace and Baños (2010) highlight, these modifications signified "a real break with the past"33 and the SVAW campaign was the "flagship" of these changes. ${ }^{34}$ Observing its potential, the IEC explained: "We look forward [...] to the human rights revolution we hope [the SVAW campaign] will inspire!!"35 Relatedly, as an extract of Irene Khan's speech to the delegates at the 2003 ICM illustrates, AI's leadership attached great expectations to the SVAW campaign:

"We stand together, as a movement, at the threshold of an extraordinary opportunity which is the SVAW campaign. I feel, hear and witness the tremendous power of this coming campaign to change inside and outside Al. Through this campaign we will ask you to turn to your own communities and to seek out and act against the violence [...]. We will bring human rights home to every woman. [...]"36

The IS Campaign Team saw the SVAW campaign as a transitional undertaking "in which we are moving from our 'old' style campaigning towards new ways of working, ${ }^{37}$ in which campaigning began to determine research. The increasing importance of thematic campaigning challenged the prominence of AI's researchers at the IS, who had traditionally benefited from a highly valued status. It is therefore not surprising that this group of officials at the IS voiced the most active resistance to the campaign.

AI implemented the campaign in two phases. The first took place between 2003 and 2005 and the second between 2007 and 2010. Initially planned for

33 Wallace and Baños Smith 2010b, p.9.

34 Wallace and Baños Smith 2010b, p.9.

35 Amnesty International, International Executive Committee: IEC Information Bulletin 48, 02.03.2004, p.5. Amnesty International, International Secretariat: Report and Decisions of the 26th International Council of Amnesty International, 2003, p.14.

37 Stop VAW campaign team: STOP VAW Campaign Progress update 4, 12.2003 , p.9. 
two years, the SVAW campaign developed into a global campaign for the duration of the ISP when the IEC approved this change in January $2004 .{ }^{38}$ Without going into detail, the following paragraphs provide an overview of the campaign's thematic content during its two phases. ${ }^{39}$ Then, section 8.1.3 highlights how AI pushed for the implementation of the campaign from the top down.

AI launched the SVAW campaign with an internal campaign at the 2003 ICM because, in the words of the IEC Chair: "We are launching an internal SVAW campaign at this ICM because frankly we need to walk the walk before we can talk the talk on this campaign." ${ }^{40}$ As Irene Khan pointed out, the staff's and activists' commitment to gender equality was pivotal for the public credibility of AI's work on VAW. It also was an important condition for the establishment of an effective partnership with the women's movement a necessity for the SVAW campaign' success. ${ }^{41}$

The so-called Gender Action Plan (GAP) ${ }^{42}$ formed the core of the internal campaign. The plan served as an internal strategy to coherently connecting the public campaign message and the organization's internal functioning. In the GAP, AI emphasized the need to become a "gender equitable organization"43 and stressed the necessity to "ensure that gender is mainstreamed throughout the organization and not confined solely to the VAW Campaign." 44 In fact, "[o]ne of the key aims of the SVAW campaign was to mainstream gender throughout Amnesty International's work - to bring it into the DNA of the organization." 45 The GAP sought to do this with concrete measures, such as gender-awareness training or gender-sensitive tools and guidelines. ${ }^{46}$ Further,

\footnotetext{
38 Amnesty International, International Executive Committee: IEC Information Bulletin 48, 02.03.2004.

39 For more details on the campaign, consult: Wallace and Baños Smith $2010 \mathrm{~b}$.

40 Amnesty International, International Secretariat: Report and Decisions of the 26th International Council of Amnesty International, 2003, p.9.

41 Khan 2003, p.9.

42 Amnesty International, International Secretariat: Stop VAW Campaign internal strategy, September 2003.

43 Amnesty International, International Secretariat: Stop VAW Campaign internal strategy, September 2003, p.7.

44 Amnesty International, International Secretariat: Stop VAW Campaign internal strategy, September 2003, p.7.

45 Wallace and Baños Smith 2010b, p.141.

46 Miller 2006, p.28.
} 
internal gender audits at various level of the organization would ensure that gender was integrated "into AI's way of working internally." ${ }^{27}$ Similarly, staff members were supposed to integrate a gender perspective into their work and to do research on issues of VAW within their specific regional responsibilities. Sections were also asked to subsequently develop and implement their own GAPs based on the overall GAP. ${ }^{48}$

Following the internal launch of the campaign, AI launched its public campaign on the $8^{\text {th }}$ of March 2004. Its first phase essentially concentrated on two topics: "VAW in armed conflicts" and "Domestic violence" (figure 8). In addition, AI continued to implement the GAP.

Figure 8: First phase of the SVAW campaign, 2003-2005

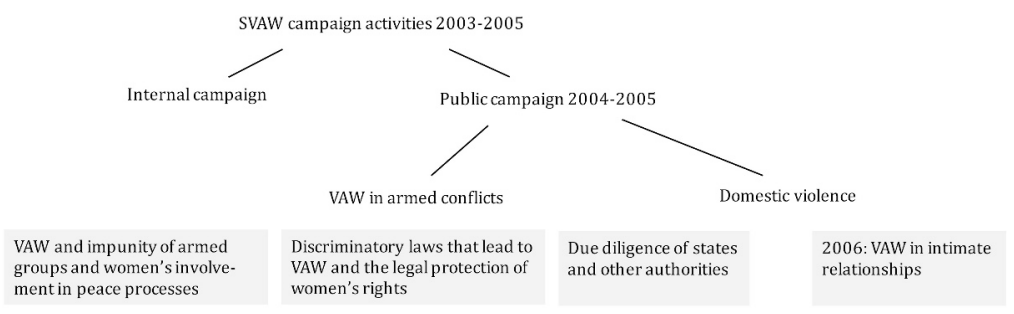

Source: my own

"VAW in armed conflicts" and "Domestic violence" were operationalized in three campaign projects (highlighted in the three gray rectangles of figure 8) which reflected the importance of the concept of "'due diligence' as the main analytical tool of the SVAW campaign." ${ }^{49}$ One project focused on armed groups' impunity for acts of violence against women and on women's involvement in peace processes. Another project concentrated on discriminatory laws that lead to violence against women and the legal protection of women's rights. A third project emphasized the responsibility of "states, national, local and municipal authorities to respect, protect, and fulfill women's rights to be free from violence." 50

\footnotetext{
47 Wallace and Baños Smith 2010b, p.96.

48 The implementation of the GAPs at national level is discussed in chapter 9.2.

49 Ganzfried: Correction of citation A.W., 22.08.2018, p.1.

50 Amnesty International, International Secretariat: Stop Violence Against Women 20042010 Campaign projects for 2004-2006, July 2004, p.7.
} 
In the frame of the public campaign, AI produced many materials defining its approach to issues of VAW. For example, under the campaign, AI defined the persecution of adultery or "zina," considered a crime under sharia law, as a human rights violation. Further, legal officers developed due diligence standards that determined how the movement should deal with the issue of violence in the family and prepared standards on the work on VAW in armed conflicts, both of which were considered important contributions to holding governments and other actors accountable for violence against women. ${ }^{51}$ The IS prepared a huge number of actions for each of the projects, which the sections subsequently implemented. For example, sections worked towards the CEDAW's ratification and implementation by lobbying their respective governments, or they collaborated with other NGOs to pressure governments to abolish laws that discriminated against women. ${ }^{52}$ Lobbying for the implementation of the UN resolution 1325 was one of the activities within the second project. 53

Before launching the second phase of the campaign, AI focused on the issue of violence against women in intimate relationships (highlighted in the white rectangle on the right side of figure 8). Thereby, AI addressed the gap between law and implementation and stressed the importance of women's empowerment for a life without violence. ${ }^{54}$

During the second phase, AI continued with the implementation of the Gender Action Plan (GAP) within the internal campaign (highlighted on the left side of figure 9), stating: "We must be confident that the values we advocate externally are those which we observe within our internal organizational culture." 55 The GAP remained the relevant policy document for the achievement of the internal campaign goal: "change ourselves to change the world." 56 At the same time, even though the campaign strategy of the second phase stated that AI wanted "to build on the achievements and use the knowledge and ex-

\footnotetext{
51 Ganzfried: Correction of citations A.W., 24.08.2018.

52 Amnesty International, International Secretariat: Stop Violence Against Women 20042010 Campaign projects for 2004-2006, July 2004.

53 Amnesty International, International Secretariat: Stop Violence Against Women 20042010 Campaign projects for 2004-2006, July 2004.

54 Amnesty International, International Secretariat: Phase IV - VAW in the family action circular: "VAW in intimate relationships", 02.01.2006.

55 SVAW Team (IS): SVAW campaign strategy: “Make rights real!”, October 2006, p.28.

56 SVAW Team (IS): SVAW campaign strategy: "Make rights real!", October 2006, p.28.
} 
perience gained in the first phase of the campaign, ${ }^{, 57}$ issues of VAW were only integrated into one of three main campaign goals of the second phase. In fact, AI continued its work on VAW in the frame of the newly defined goal of "Human rights concerns." However, it used the second campaign phase to address and resolve the general problem of member stagnation, which it had been facing since the 2000s. Thus, AI defined "Human rights concerns," "Growth of activism globally on VAW," and "Growth of AI through the SVAW Campaign" as the three objectives of the second phase (highlighted in figure 9)..$^{58}$

Figure 9: Activities in the second phase of the SVAW campaign, 2007-2010

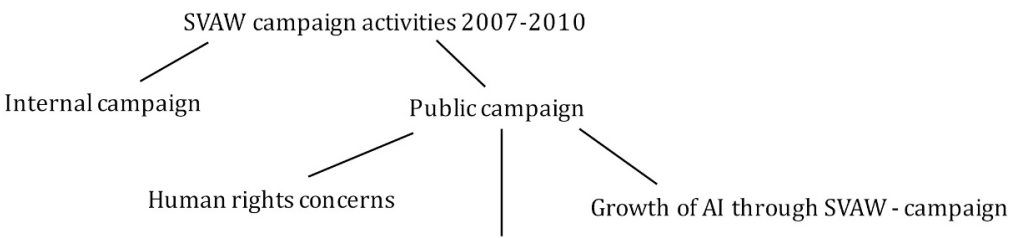

Growth of activism globally on VAW

Source: my own

In the frame of the objective "Human rights concerns," AI campaigned for several initiatives, such as "Safe schools for girls," "Safe work places for women," 59 and services for women survivors of sexual violence, as defined in its newly adopted policy on abortion. ${ }^{60}$ At the same time, under the campaign goals "Growth of activism globally on VAW" and "Growth of AI through the SVAW Campaign," AI called for increasing activism in regions where it traditionally had few members (such as the Middle East or Africa) and specifically sought to reach out to young people and women. Not only did AI modify the focus of the campaign; it also lessened the campaign's intensity during the second phase of the campaign. Wallace and Baños (2010) explain that, compared to the first phase: "much less work was undertaken under the second strategy by researchers and [sections]. ${ }^{61}$ As an example, the first phase

\footnotetext{
57 SVAW Team (IS): SVAW campaign strategy: “Make rights real!”, October 2006, p.4.

58 These areas were developed in consultations with all sections and structures.

59 SVAW Team (IS): SVAW campaign strategy: "Make rights real!", October 2006.

60 SVAW Team (IS): SVAW campaign strategy: “Make rights real!", October 2006, p.9.

61 Wallace and Baños Smith 2010b, p.139.
} 
saw the publication of an average of 60 documents per year; this number decreased to 14.2 publications per year during the second phase of the campaign. ${ }^{62}$

Lacking a clear exit strategy, the SVAW campaign ended with a final communication advisory in March 2010, which indicated how to take various aspects of the SVAW campaign work forward. Yet, it did not specify how existing activities and relationships with women's rights NGOs should be concluded or continued. ${ }^{63}$ As I highlight later, considerable uncertainty surrounded the question of how work on issues of VAW should continue after the SVAW campaign, and the professional future of those working for the campaign within the IS (in the Campaign Team) and within sections remained unclear.

In a nutshell, the internal campaign sought to mainstream gender throughout the organization. VAW in the private sphere - namely "Domestic violence" and "Violence in intimate relationships" - became the main topics of the first phase of the public campaign. Meanwhile, growing the movement through the campaign became the central topic in the latter's second phase.

Since the majority of AI's activities on issues of VAW in the 2000 s were organized under the umbrella of the SVAW campaign, the success of the latter can inform us about the extent to which AI succeeded in integrating VAW into its work. The campaign's 2006 mid-term evaluation and its final review provide an in-depth picture of its successes and failures. ${ }^{64}$ Because the present research project does not seek to assess the campaign and is instead interested in understanding the causes behind the identified failures, I only briefly recapitulate the evaluation's conclusions. The SVAW campaign allowed the movement to embrace economic, social, and cultural rights, and helped women's rights become better recognized as a part of the organization's work. ${ }^{65}$ The production of wide-ranging research on diverse topics re-

62 Whereas the IS published 38 campaign reports in two years (between 2004 and 2005), it produced 26 reports during the four years of the second phase of the campaign (between 2006 and 2010) (Wallace and Baños Smith 2010b, p.149). Also counting the internal documents, 120 documents (public and internal) concerning the SVAW - campaign were produced by the IS in the first phase, and 71 papers were released in the four years of the second phase. Based on information from the AIDAN Search base on Al Intranet. Using the following keywords: AI Class: ACT; Sub-Class: 77; Year: 2004-2010 (Last consultation 17.10.2014).

63 Wallace and Baños Smith 2010b, p.179.

64 Miller 2006; Wallace and Baños Smith 2010b.

65 Wallace and Baños Smith 2010b, p.176. 
lated to women's rights was an important achievement. Specifically, the research and campaigning realized within the Northern sections had a real impact as a consequence of the cancellation of the WOOC rule. ${ }^{66}$ Further, the recognition of collaborating in the domain of VAW led to many fruitful partnerships with local NGO's working on women's rights, which in turn helped AI to act locally against violence against women. ${ }^{67}$

The mid-term review of the campaign also revealed that "the SVAW campaign ha[d] given greater legitimacy to research on VAW" realized by country researchers "and that the Campaign Team (and the Gender Unit) ha[d] facilitated this kind of work through providing resources and research backstopping. ${ }^{68}$ According to Miller (2006), a positive outcome of the first two years of the campaign was its contribution to a greater awareness of the relevance of gender equality and women's rights to the work of AI among the staff at the IS. ${ }^{69}$ Additionally, AI also developed some important policy positions, such as the policy on the restricted aspects of abortion that called on governments to decriminalize abortion, or its position on states' responsibility for the prevention of violence by non-state actors (due diligence). ${ }^{70}$ While the SVAW campaign led to a rise in the active memberships of some sections, others developed new partnerships with local organizations or introduced innovative campaign methods. ${ }^{71}$ On a broader scale, the campaign contributed to VAW becoming universally perceived as a human rights issue. ${ }^{72}$ Even though it is difficult to assess the global impact of the campaign, good AI lobbying and campaigning led i.a.

"to changes in attitudes (for example, around rape in the Nordic countries), policy (for example, the provision of shelters for women in municipalities in Sweden), awareness (lobbying work in several countries and strong membership engagement), partnerships (for example, through the GBV

\footnotetext{
66 Wallace and Baños Smith 2010b, p.176.

67 Amnesty International, International Secretariat: SVAW Campaign 2006-2010 Draft Strategy for Consultation, 21.12.2005, p.8.

68 Miller 2006, p.28.

69 Miller 2006, p.28.

70 Wallace and Baños Smith 2010b.

71 Wallace and Baños Smith 2010b, p.177.

72 Amnesty International, International Secretariat: SVAW Campaign 2006-2010 Draft Strategy for Consultation, 21.12.2005, p.3.
} 
and EVAW networks in Ireland and the UK...), and improved legal rights for women experiencing violence." ${ }^{73}$

In addition to these important achievements, the final review concluded that the campaign had failed in one important aspect. Namely, it did not succeed in making women's rights part of the organization's DNA. ${ }^{74}$ The most important evidence of this failure manifests in the GAP's faltering and in the Demand Dignity campaign's nonexistent "gender analysis or aims around women's rights." 75 It is thus worth asking why AI did not succeed in sustainably integrating women's rights into its work through the SVAW campaign? I first focus on AI's policy-making style and on the campaign's implementation (section 8.1.3). I then examine the reaction the SVAW campaign elicited, the participation in it, and the debates accompanying the adoption of the ICM decisions on sexual and reproductive rights (section 8.1.4). I do so to show that the main reasons for this failure had to do with the fact that the female activists and officials who had initiated AI's work on VAW in the 1990s lost their influence on the organization's VAW work during the SVAW campaign and with the resistance that the campaign and the adoption of a policy on abortion faced from activists and officials alike.

\subsubsection{Pushing work on the issue of VAW from the top down}

This section demonstrates that, in contrast to the 1990s, AI pushed the work on VAW from the top down. The section starts by illustrating the IEC's pivotal role in the adoption of the ICM decisions directly and indirectly concerning AI's work on VAW. Then, the section focuses on the SVAW campaign preparation period and examines the management's leading role in it. I later provide details on the SVAW campaign Machinery and highlight the role the different components of the machinery played in the implementation of the campaign. I specifically focus on the Campaign Team and the Gender Unit and highlight how their problematic embeddedness into the IS and their lack of clear responsibilities and power hampered this implementation. In doing so, I show that the top-down implementation of the SVAW campaign meant that the female activists and officials who had initiated AI's work on VAW in the 1990s lost their influence on the organization's work in this domain.

\footnotetext{
73 Wallace and Baños Smith 2010b, p.177.

74 Wallace and Baños Smith 2010a, p.16.

75 Wallace and Baños Smith 2010a, p.16.
} 


\subsubsection{Policy development initiated by the IEC}

This paragraph highlights the important role that the IEC and the SG played in pushing policy development on VAW further. The classification of the ICM decisions into two groups based on their origin from a resolution submitted by either a section or several sections (illustrated on the left in figure 10) or by the IEC (illustrated on the right in figure 10) shows that the IEC initiated all but one ICM decision, whether directly (underlined in figure 10) or indirectly concerning the work on violence against women.

Figure 10: ICM decisions and their initiators, 2003-2009

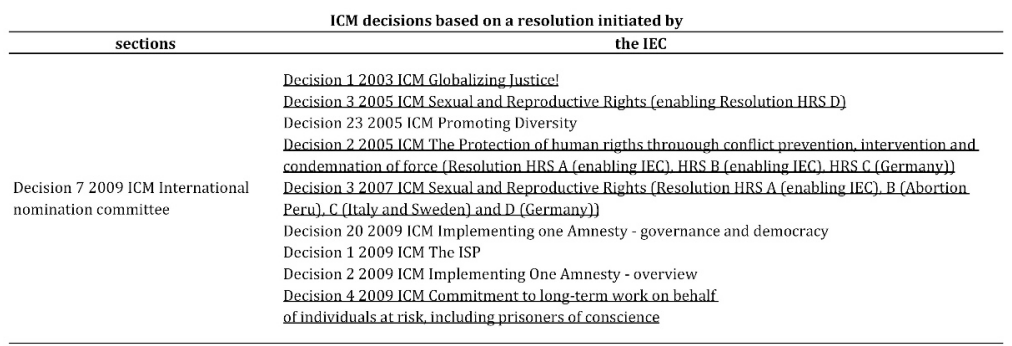

Source: my own, based on the 2003, 2005, 2007, and 2009 ICM reports*

"Decision 2 (2005 ICM) is classified as coming from the IEC because two of the original resolutions were enabling resolutions. Decision 3 (2007 ICM) is classified as coming from the IEC because it followed decision 3 of the 2005 ICM, which originated from an enabling resolution.

The classification in figure 10 highlights the important role the IEC played in shaping AI's policy development concerning the organization's work on VAW in the 2000s. Given the overlap between the IEC and the SG highlighted in chapter 6 , and in light of the fact that a huge majority of the ICM decisions originated from enabling resolutions, the classification also indicates the existence of a top-down process of policy development. Thus, while the decisions calling for an increase in AI's work on women's rights in the 1990 s had been initiated by female activists and officials organized in the IWN, evidence indicates that female activists were no longer the driving forces behind the development of AI's policy on VAW in the 2000 s. 


\subsubsection{Getting ready for the SVAW campaign}

The following paragraphs demonstrate the management's leading role in preparing the SVAW campaign and the IWN activists' and officials' shrinking importance in the planning of the top-down endeavor.

As a "flag-ship" for the changes in focus and working methods brought about by the adoption of the mission, the SVAW campaign was conceived as a top-down endeavor from its beginning. This meant that its preparation and implementation were steered from within the IS. Consequently, the SG and her deputy played a leading role in the campaign's preparation. Evidence further shows that, in addition to this, the SG deputy also pushed AI's work on issues of VAW in this period. According to one interviewee: "[Irene Khan] pushed it quite hard and the second person, who was Kate Gilmore, extraordinary, I mean she was a proper feminist. ${ }^{.76}$ Another considered Kate Gilmore the key figure stating: "the arrival of somebody like Kate Gilmore to the Secretariat. [...] So, she came in and she just, you know, 'we must do gender. Again, we just look like a dinosaur; we need to get some serious gender analysis." 77 Similarly, another interviewee qualified Kate Gilmore as "a very powerful figure pushing for women's rights. ${ }^{78}$

The importance of the IS, the SG and her deputy for AI's work on issues of VAW was reinforced by the dissolution of the IWN in $2002 .{ }^{79}$ The fact that the IWN's fourth and last meeting held in London in April 2002 was organized by the IS (unlike previous gatherings) already indicates that the issue of VAW was pushed increasingly from the top down. This top-down approach and the leading roles that SG Irene Khan and her Deputy Kate Gilmore played in preparing the SVAW campaign were reflected in, among other things, three campaign preparation meetings in May 2002, October 2002, and July 2003. Organized prior to the launch of the internal campaign, these gatherings sought to create a broad commitment to the campaign among activists and officials. They were informed by the need to include the women's rights movement, deemed essential for the success of the campaign. By inviting Charlotte Bunch of the Center for Women's Global Leadership and Roxanna Carillo from

76 Ganzfried: Interview with A.X., 25.06.2012.

77 Ganzfried: Interview with B.R., 25.06.2012.

78 Ganzfried: Interview with B.R., 25.06.2012.

79 Despite the fact that no archive material puts the dissolution of the IWN in black and white, the fact that I could not find any minutes of IWN meetings after 2002 indicates that the network ceased to exist. 
the UN Development Fund For Women (UNIFEM), two important figures in the women's rights movement, the first meeting, organized exclusively for the IS staff, sought to inform "the IS thinking and planning to deliver the forthcoming campaign on VAW." 80 There, Roxanna Carillo emphasized the necessity to work with the women's movement by stating that AI "had to overcome the 'general perception from the women's movement about AI ... Always going solo ... which could hamper AI's credibility as a voice for women's human rights." 81

After a movement-wide consultation, Irene Khan convened a second campaign-preparation meeting with sections and IS representatives and again invited several high-profile figures of the women's rights movement ${ }^{82}$ with the goal of discussing and deciding upon the campaign's focus. There, the participants chose "domestic violence" and "VAW in armed conflicts" as the primary themes of the campaign, and approved the twofold campaign strategy (an internal launch followed by a public campaign starting around 8 March 2004). Therefore, the campaign's focus can be considered the fruit of a movementwide consultation and of the inclusion of voices from the women's rights movement. Indeed, it was the latter who suggested making "domestic violence" the principal theme of the campaign. ${ }^{83}$

At the third consultation meeting in Oxford in July 2003, the SG invited IS staff, officials and activists from sections with the aim of building a movement-wide engagement in the preparation of the VAW campaign and of initiating the internal transformative processes necessary for ensuring the effectiveness of the campaign. Once again, an important number of prominent international women's rights and "gender and organizational change" experts ${ }^{84}$

80 Amnesty International, International Secretariat: IS Staff Forum on Violence Aganist Women Campaign 9 May 2002, 12.05.2002, p.1.

81 Hopgood 2006, p.153.

82 Roxanna Carrillo (Unifem), Doo Aphane (Women and Law in Southern Africa), Shamima Ali, Fiji (Women's Crisis Centre), Indai Sajor (International Criminal Justice Institute), Asma Khadeer (Sisterhood is Clobal Institute in Jordan) (Amnesty International, International Secretariat: Report of the Violence Aganist Women Campaign Consultation Forum, 14.11.2002).

83 Amnesty International, International Secretariat: Courrier électronique hebdomadaire 40/02 à l'attention des coordonnatuers Campagnes, 23.10.2002

84 Among the invited experts were: Radhika Coomaraswamy (former UN Special Rapporteur on VAW), Zaitun Mohammed Kassim (independent consultant and member of Sisters in Islam Malaysis), Agnes Callamard (Executive Director of the Geneva-based 
were invited to help AI in assessing its organizational culture and identifying the key internal challenges that AI needed to address, if it was to carry out a credible and effective campaign on VAW. ${ }^{85}$ At the Oxford meeting, the SG stressed the importance of the internal campaign by emphasizing the consistency between AI's internal culture and its public statements: "An internal strategy to facilitate a movement-wide understanding of gender-based violence and its root causes and human rights consequences is inevitable if we are to guarantee this long-term commitment." ${ }^{86}$ It became evident that "without exposing itself to the gender lens, Amnesty could have no hope of political authority with the women's movement." ${ }^{87}$ At this last preparatory consultation meeting, the participants decided to make "change ourselves to change the world" 88 the slogan of the internal campaign, and labeled the public campaign "Stop Violence Against Women." 89

\subsubsection{The SVAW campaign Machinery}

AI established new organizational entities, some of which were at the IS, to ensure the smooth running of the campaign. Making use of the name one of my interviewees mentioned, I label these bodies the SVAW campaign Machinery. This section describes the role and the functioning of the Machinery in detail. As the left side of figure 11 highlights, it was made up of the Campaign Team and the Gender Unit at the IS. The creation of these two new units required substantial financial resources, as it entailed the creation of new posts. It is therefore not astonishing that these entities were key to the running of the campaign.

Further, the Campaign Steering Committee and the SVAW network also formed part of the SVAW campaign Machinery. These were decentralized entities composed of IS and section staff, namely the section's campaign coordinators, who were specifically appointed for the preparation and the

Humanitarian Accountability Project International), Nira Yuval Davis (Prof. in Cender, Sexualities and Ethic Studies at University of East London).

Khan: Letter from the secretary general Irene Khan to sections, 16.09.2003; Amnesty International, International Secretariat: VAW Campaign progress update 28 July 2003 , 28.07.2003.

86 Amnesty International, International Secretariat: The VAW campaign An Agenda for Cender Equity The proposed framework for the "internal strategy", 01.07.2003, p.1.

87 Hopgood 2006, p.153.

88 Khan: Letter form Irene Khan to sections, 01.04.2004.

89 Hopgood 2006, p.237. 
implementation of the campaign at the sectional level. In the present section, I provide details on the Campaign Team and the Gender Unit. I then highlight how their embeddedness in the headquarters and their lack of clear responsibilities and power hampered the implementation of the campaign. In doing so, I also show that the female activists and officials who had initiated AI's work on VAW in the 1990s lost their influence on the organization's work on issues of VAW because of the top-down nature of the campaign. This loss of influence can in turn be seen as one of the reasons why the SVAW campaign did not succeed in making women's rights part of AI's DNA. Later, I focus on the decentralized entities in the SVAW campaign Machinery - the SVAW network and the Campaign Steering Committee. ${ }^{90}$ I provide further details on how AI organized the campaign's implementation at the national level in the upcoming sections on the Swiss and the German sections (section 8.2).

Figure 11: The SVAW campaign Machinery

\section{Centralized at the IS}

Campaign Team Gender Unit

\section{Decentralized}

Campaign Steering SVAWnetwork Committee

Source: own

The Campaign Team was responsible for promoting the movement's campaign and coordinating the campaign. ${ }^{91}$ It was in charge of drafting the campaign strategies, heading the communication about the campaign, and providing the regional research teams at the IS with advice and support throughout the duration of the entire campaign. ${ }^{92}$ The team thus had to closely col-

90 While many archival documents contained information about the Campaign Team and relatively many interviewees mentioned the Campaign Team and the Gender Unit, information on the SVAW network and on the Campaign Steering Committee was scarce. Consequently, the following paragraphs on the Campaign Team and the Cender Unit dig deeper than the passages on the Campaign Steering Committee and the SVAW network. This difference may be interpreted as reflecting the pivotal role the Campaign Team and the Gender Unit played in the implementation of the SVAW campaign, in contrast to the two decentralized entities.

91 Wallace and Baños Smith 2010b.

92 Wallace and Baños Smith 2010b, p.140. 
laborate with and "was reliant on the research teams, who wrote the majority of the research reports. ${ }^{\prime 93}$ Embedded in the IS campaign's department, the team was initially lead by the former IWN coordinator and was composed of "many of the early "gender pioneers" from within the IS." "The members of the first Campaign Team were mainly female officials formally organized in the IWN. Thus, in contrast to the members of the second Campaign Team who coordinated the campaign from 2006 onwards, the members of the first team were senior IS staff possessing consolidated knowledge and expertise in women's rights issues. Indeed, many of them had previously lobbied the organization to increase its work on women's rights.

The campaign reviewer highlighted that all primary team members left in the beginning of the second phase of the campaign, and a new team composed of less experienced and less senior staff was nominated for campaign coordinator. ${ }^{95}$ The latter was led by Widney Brown (formerly responsible for women's issues at HRW and Senior Director of the International Law and Policy department at the IS). At the end of the campaign, the Campaign Team was dissolved and most of its members left AI, with others being integrated into other IS departments. While it was not clear how the work on issues of VAW was to be continued in the aftermath of the SVAW campaign, some of the Campaign Team's work was handed over to the newly created Gender, Sexuality, and Identity Program, which replaced the Gender Unit at the end of the campaign. ${ }^{96}$

Established in 2003, the Gender Unit can be traced back to an initiative of AIUSA ${ }^{97}$ and to the lobbying of the IWN. In fact, as an interviewee explains: "The Gender Unit itself was a product of campaigning by the movement and the women's network within AI."98 Mainly composed of two people, the Gender Unit "[was] situated in different institutional locations" ${ }^{99}$ before being attached to the policy and evaluation program. It was in charge of developing the SVAW campaign and providing policy advice both for it and for AI's work on women and human rights in general. It was also initially responsible for

\footnotetext{
93 Wallace and Baños Smith 2010b, p.140.

94 Wallace and Baños Smith 2010b, p.140.

95 Ganzfried: Interview with A.Z., 26.06.2012.

96 Wallace and Baños Smith 2010b, p.144.

97 Amnesty International, International Secretariat: Report and Decisions of the 24th International Council of Amnesty International, 21.08.1999, p.16.

98 Ganzfried: Interview with A.W., 25.06.2012, p.1.

99 Miller 2006, p.26.
} 
the GAP before handing this responsibility over to the deputy SG. ${ }^{100}$ Thus, the members of the Gender Unit collaborated "with colleagues [from the policy and evaluation program] on all policy issues connected with gender"101 and commented on SVAW reports. ${ }^{102}$

Further, an informant explained that the Gender Unit "was responsible for all the reports. Every report on SVAW went through [their] desk. And most of the sections' reports they invaded [the Gender Unit]. [...] So [the Gender Unit] worked with [the researchers] before, through the report, and worked with them after the report." 103 Because the IS team working on the legal standards of human rights was not sufficiently trained to frame the violations of women's rights within the appropriate legal principles, and because AI did not dispose of its proper policy defining the position of the movement regarding specific women's rights violations at this moment in time, the Gender Unit also had to provide the relevant international policy frameworks on women's rights for the IS research teams. For example, as one of my interviewees reported, AI did not have a position on the issue of "underage sex" or "child marriage," which made it difficult to do research and produce reports on these issues. ${ }^{104}$

Thus, the Gender Unit was responsible for many issues that had significantly changed over time, from "mainstreaming across all AI, strateg[y] for SVAW campaign, [and directing the] short period leading the Campaign, to

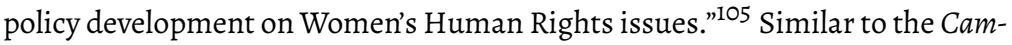
paign Team, the Gender Unit relied on collaboration with the legal teams and the research teams at the IS. The Gender Unit also dissolved at the end of the SVAW campaign and was replaced with the Gender, Identity and Sexuality Program. As I highlight later, AI suspended the head of the Gender Unit after she criticized the organization for taking on the defense of the extrajudicial detainee Moazzam Begg, who was known as a supporter of the Taliban. The

100 Amnesty International, International Secretariat: VAW Campaign progress update 28 July 2003, 28.07.2003, p.6; Wallace and Baños Smith 2010b. Amnesty International: Report of the meeting on: regional campaigning on SVAW wooc research projects in Europe, decembre 2005, p.16.

Amnesty International: Report of the meeting on: regional campaigning on SVAW wooc research projects in Europe, decembre 2005, p.16.

Ganzfried: Interview with A.W., 25.06.2012.

Ganzfried: Interview with A.W., 25.06.2012.

Miller 2006, p.26. 
former head of the Gender Unit argued that AI was risking its reputation on human rights with this association with Moazzam Begg. ${ }^{106}$

The Campaign Team's and the Gender Unit's institutional embeddedness into the IS and their lack of clear responsibility and power prevented the campaign from being effectively implemented. An interviewee described the functioning of the IS as: "It is like 300 organizations are all doing tiny ineffective things."107 Wallace and Baños (2010) stress the "lack of coordination around global campaigning" and "the strongly 'siloed' ways of working in the IS," which were exemplified by "different departments and teams focused on different women's rights issues, some under SVAW and some not, and there was no coherent picture of who was driving campaigning on what issue."108

Moreover, the SVAW campaign was also perceived within the IS as work extraneous to the rest of the headquarters' work. An interviewee explained the difficulty of mainstreaming a gender perspective into the IS's work with the fact that AI's work on VAW "was very much contained as 'that was in that campaign and the rest of our work is entirely separate."'109 Situated in the campaign department's policy and evaluation programs, respectively, the Campaign Team and the Gender Unit were detached from the research program and the legal program, where researchers undertook research that nurtured the campaign and the legal bases of Al's work on human rights were elaborated. Thus, the Campaign Team had to work horizontally with other departments across the IS, ${ }^{110}$ and the Gender Unit had to collaborate closely with the legal teams.

Often, informal contacts compensated for the absence of formalized collaboration between the Campaign Team and other departments. Eventually, they were pivotal for the achievements of the campaign objectives. The campaign review (2010) highlights that: "The relationships fostered [across the departments] appear to have depended on individual initiatives rather than being formalized in any way."111

While there had been good and frequent dialogues between the Campaign Team and other departments (most notably the regional and policy teams),

\footnotetext{
106 Daily Mail Reporter 2010.

107 Ganzfried: Interview with A.Z., 26.06.2012.

108 Wallace and Baños Smith 2010b, p.140.

109 Ganzfried: Interview with A.Z., 26.06.2012.

110 Miller 2006, p.27.

111 Wallace and Baños Smith 2010b, p.146.
} 
and the collaboration between the Campaign Team and the Gender Unit was rather positive, ${ }^{112}$ these entities' lack of clear responsibilities and authority hampered the implementation of the campaign. Indeed, there had been "a confusion over the role of the SVAW team as compared with the Gender Unit" ${ }^{\text {"113 }}$ and over the two entities' roles and responsibilities, as well as over how both of them were linked to the IS's other functions. ${ }^{114}$ The campaign review points out that "both [for example] commented on all documents relating to women's rights." ${ }^{115}$

However, the lack of power seems to have been particularly problematic for the work of the Campaign Team and the Gender Unit. An interviewee explains: "The SVAW team had the responsibility for [the coordination of the campaign] but they had no power, no power to make anything happen."116 Another interviewee refers to the Campaign Team's difficulties from the position of a team member: "So you are left saying 'I am going to lead this campaign but I have no research to lead it with."'117 The team's dependence upon the research teams and the fact that "the team had little authority over the organization's research agenda"118 made campaign coordination difficult.

Similar to the Campaign Team, the members of the Gender Unit also lacked authority and power. An interviewee reports that, "the Gender Unit [...] just cannot go to someone and say you need to change your research a little, do this and that so it deals with women's rights."119 Instead, "the research teams had to do some things on women's rights. But it was pretty much up to them what they did, how they did and when they did and where they did it."120 The Gender Unit's lack of accountability and authority entailed that collaboration was voluntary, which made its work even more difficult. An interviewee explains: "sometimes [the research teams] just did what they like and didn't tell us. [...] If they were good, they came to us to plan [the reports]. If they weren't so good, they just went off on a mission and sent it to us later." ${ }^{\text {212 }}$ The first ex-

112 Wallace and Baños Smith 2010b, p.141.

113 Wallace and Baños Smith 2010b, p.145.

114 Miller 2006.

115 Wallace and Baños Smith 2010b, p.145.

116 Ganzfried: Interview with A.Z., 26.06.2012.

117 Ganzfried: Interview with A.Z., 26.06.2012.

118 Wallace and Baños Smith 2010b, p.140.

119 Canzfried: Interview with A.Z., 26.06.2012.

120 Ganzfried: Interview with A.Z., 26.06.2012.

121 Ganzfried: Interview with A.W., 25.06.2012. 
ternal evaluation of the campaign revealed that the absence of responsibilities and authority also was a problem for the implementation of the internal campaign. In fact, according to Miller (2006), one of the reasons why AI failed to realize the internal campaign objectives was "the lack of strong signals from senior management on the implementation of the GAP,"122 and the fact that no one had the ultimate authority and responsibility to implement it. ${ }^{123}$

In summary, the Campaign Team's and the Gender Unit's detachment from the research program and the legal program, which were both key for AI's overall work because they lay the factual and legal basis for all activities and actions of the organization, and their lack of clear responsibilities and power hampered the work of these centralized entities of the SVAW campaign Machinery and, consequently, the implementation of the campaign. Furthermore, it is worth assuming that the composition of the staff of the Campaign Team and the Gender Unit influenced the implementation of the campaign in qualitative as well as quantitative terms. According to some IS staff members, the fact that the Campaign Team was composed of some very strong people during the first campaign phase hampered the collaboration with other IS teams. ${ }^{124}$ At the same time, the first team greatly contributed to the success of the campaign: "the team's commitment, knowledge and expertise added value to the campaign" and "played an essential role in supporting [sections] to produce campaign strategies."125 Consequently, the composition of the first Campaign Team somehow compensated for the team's detachment from the research program and the absence of clear responsibility and authority.

However, as the following extract from the campaign review shows, the problematic embeddedness of the team and its lack of authority and support played an important role in the first campaign team's decision to leave. The staff of the Campaign Team left at the end of the first campaign phase because they "were exhausted and felt they did not have the authority or resources to fulfill their responsibilities well, and they were not sufficiently supported to implement a major complex global campaign." ${ }^{.126}$ As I have already mentioned, they were replaced by less senior staff that an interviewee qualified

\footnotetext{
122 Miller 2006, p.26.

123 Miller 2006, p.26.

124 Wallace and Baños Smith 2010b, p.141.

125 Wallace and Baños Smith 2010b, p.141.

126 Wallace and Baños Smith 2010b, p.141.
} 
in the following way: "They just weren't senior enough. Not even vaguely senior." ${ }^{127}$ According to her, because the Campaign Team was junior, they lacked the authority and respect necessary to continue effective coordination. ${ }^{128}$ As far as the Gender Unit is concerned, the team's temporary understaffing and its under-qualified replacement hampered the Unit's effectiveness. In an interviewee's words: “They didn't replace her. [Instead] they gave somebody the brief [...] along with all their other work [...] who had no idea of women's rights." ${ }^{129}$

The preceding paragraphs have illustrated the pivotal role the Campaign Team and the Gender Unit played in the running of the SVAW campaign and have highlighted how their problematic embeddedness in the IS and the absence of clear responsibility and authority made their work difficult. Before concluding this section, I briefly describe the role of the SVAW network and the Campaign Steering Committee in the campaign's implementation.

The SVAW network was set up to facilitate the circulation of information from the IS to sections, thereby enhancing the capacity of the movement to campaign on VAW. ${ }^{130}$ It was thus mostly composed of the Campaign Team and the Gender Unit as well as of the sections' SVAW campaign coordinators. In fact, according to one interviewee, the SVAW network was basically "the contact person in each section and structure [the Campaign Team] would send stuff to."131 The campaign evaluation highlighted that, because the sections involved in the SVAW campaign were not required to provide feedback on their work to the Campaign Team, the sharing of information about the campaign was often "done in an ad hoc way, often through the SVAW network."132 While one interviewee saw the SVAW network as an extension of the IWN, explaining that:

"the SVAW network was an attempt to expand the IWN. With the [possibility] that men could join meetings as well, sections could join as well and that it

\footnotetext{
127 Ganzfried: Interview with A.Z., 26.06.2012.

128 Ganzfried: Interview with A.Z., 26.06.2012.

129 Ganzfried: Interview with A.W., 25.06.2012.

130 Amnesty International: Al and a new international women's rights network, November 2009.

131 Ganzfried: Interview with A.Z., 26.06.2012.

132 Wallace and Baños Smith 2010, p.146.
} 
would rally individuals and sections who could not find a feminist orientation as their comfort zone but would be willing to support VAW issues,"133

another interviewee suggested that the setting up of a network for the implementation of the SVAW campaign contributed to the dissolution of the IWN. According to her "the SVAW network was set up and money was put in to that [...]. So, it became a rival of [the IWN]." ${ }^{134}$ Nevertheless, given the lack of data on the SVAW network and the absence of any terms of references, it is worth assuming that it played a minor role in the running of the campaign.

However, at the end of the campaign, the sections' campaign coordinators took advantage of the network in order to pressure the organization into continuing its work on women's rights. ${ }^{135}$ In fact, as pointed out by one of my interviewees, many section campaign coordinators "[...] were in danger of losing their jobs because the SVAW campaign was closing. So, there were women who [...] when the SVAW campaign ended, were looking unemployment in the face." ${ }^{136}$ The same informant pointed out that they:

"protested and [...] they said that 'look, you know we need to have resources to do further work on women's human rights.' [...] They weren't just fighting for their jobs, they were fighting on the principled issue of 'can't just say SVAW is gone, ok, we will do other work."'137

While a part of the Campaign Team's and the Gender Unit's former staff continued working at the IS in a different function, it is not possible to say with certainty what happened to the campaign coordinators within sections. The function of the campaign coordinator of the Swiss section was transformed into a permanent position. It is worth assuming that other sections did the same for their campaign coordinators. However, the lack of information prevents us from making this conclusion with certainty. Similar to what happened to the Campaign Team and the Gender Unit, the SVAW network as such disappeared at the end of the SVAW campaign. However, the former members of the SVAW network at the IS and in different sections formed a new network called the International Women's Human Rights Network in 2011. It sought to "mobilize and strategize on women's human rights at a time when

\footnotetext{
133 Ganzfried: Interview with A.O., 23.01.2015.

134 Ganzfried: Interview with A.W., 25.06.2012.

135 Ganzfried: Interview with A.W., 25.06.2012.

136 Ganzfried: Interview with A.W., 25.06.2012.

137 Ganzfried: Interview with A.W., 25.06.2012.
} 
many are concerned that the gains that have been made in women's rights within AI may be lost." ${ }^{138}$

Similar to the situations described above, I also found very scarce data on the Campaign Steering Committee. None of my interviewees mentioned it when they talked about the SVAW campaign. It is thus worth assuming that it only played a marginal role in the overall running of the campaign. The little information that I did find had to do with its composition and general objectives. The Campaign Steering Committee was composed of senior section representatives, such as the Swiss section's secretary general, and of IS staff. It was meant to monitor and supervise the campaign, to develop lessons for future theme campaigns and "to improve communications and exploit more effectively the expertise and experience in the movement."139 Further, the committee was meant to enhance the commitment of the section directors and contribute to the endorsement of the campaign, particularly of the internal campaign.

Summing up, the organization's leadership initiated the majority of the ICM decisions concerning AI's work on VAW, and pushed AI's work on VAW from the top down with the SVAW campaign. The IWN, which had been initiated by female activists and which had been used as a strategy to make AI increase its work on women's rights throughout the 1990s, was dissolved in 2002. Many of the female officials were part of the feminist caucus at the IS and members of the IWN were included in the preparation and, particularly, in the implementation of the campaign as members of the SVAW campaign Machinery. However, the problematic embeddedness of the Campaign Team and the Gender Unit into the IS and their lack of clear responsibilities and power made it difficult for the women's rights advocates at the IS to effectively implement the campaign. Further, at the end of the first campaign phase, many of the "gender pioneers" at the IS left AI. Others quit at the very end of the campaign in 2010. Thus, it is worth assuming that with the SVAW campaign implemented from the top down, the female activists and officials who initiated AI's work on VAW in the 1990s lost their influence on the organization's work on issues of VAW. This loss of influence can therefore be seen as one of the reasons why AI did not succeed in making women's rights part of its DNA through the SVAW campaign.

138 Amnesty International: Al and a new international women's rights network, November 2009, p.1.

139 Khan 2003, p.9. 


\subsubsection{Resistance against Al's work on VAW}

This section emphasizes AI members' and sections' reaction to and participation in the SVAW campaign and specifically focuses on the debates accompanying the adoption of the ICM decisions on sexual and reproductive rights and abortion. In doing this, I highlight the activists' and officials' resistance to the SVAW campaign and to the adoption of a policy on abortion. Section 8.1.4 begins by examining the opposition to the campaign and shows that three principal factors motivated it. First, some of Al's members and officials opposed the SVAW campaign because they primarily perceived it as a flagship for the change that the adoption of the mission brought about. Second, other criticisms related to the structure and the setting of the campaign, rather than to its content. Third, some opposition related to the content of the campaign itself. Later, I highlight the critiques and the resistance to the adoption of the policy on abortion. This opposition can more clearly be identified as opposition to the issue of abortion and less to AI's overall policy change.

\subsubsection{Resistance against the SVAW campaign}

The 2001 ICM heralded many fundamental changes related to the content of AI's work and to its working methods. By adopting the mission, AI increasingly focused on economic, social, and cultural rights. The organization gave its concentration on individual cases up and opened out to thematic campaigning. At the same time, it increasingly engaged in collaborations with other organizations and abandoned the WOOC rule.

As its first long-term global thematic campaign, AI used the SVAW campaign as a flagship to test these transformations. The campaign thus served to probe the new way of thematic campaigning and to gain experience in giving sections the chance to conduct research on their own country. Evidence shows that part of the staff opposed the campaign because it embodied a departure to a new way of working on human rights and, consequently, a break with the past. An interviewee explained the opposition to the campaign with its "flagship role" in establishing a new way of working under the mission. The same person explained that the fact that the campaign "was used to drive many other things [...], made the campaign very unpopular for a lot of people."140 Kelleher and Bhattacharjya (2013) accurately explain that: 
"the opposition to this [the SVAW campaign] also was not necessarily a misogynistic response at the time, [but] more to the broadened mandate, the feeling that $\mathrm{Al}$ was entering waters it did not have enough expertise in, and that the reasons for doing such work were not clear [...]." ${ }^{n 14}$

Relatedly, the collaboration with external specialists on women's rights, inevitable when AI started dealing with a new thematic issue, posed problems to the IS staff. An interviewee explained that "there was a general kind of resistance to work with anyone else." ${ }^{142}$ In fact, as mentioned before, collaboration with external women's rights specialists was an integral part of the various campaign preparation meetings. Because VAW was a new issue, most IS staff had little or no experience in addressing it in their work, and campaign IS staff was required to collaborate with and learn from women's rights specialists external to AI during the Stop Violence against Women campaign. In his 2006 book Keepers of the flame, Hopgood explained the internal opposition against the SVAW campaign with the incompatibility between AI's original focus and the complexity of VAW. He argued that:

"Violence against women is complex; violence against women takes many forms, has many justifications and excuses, and is politically fraught locally and contentious globally. What would a simple illustrative case be? [...] But Amnesty aims to speak for women everywhere in the name of universal human rights. What case can it choose that truly reflects the core intuition, the very spirit, of universal rights? The founders, [...], had found one: the prisoner of conscience. That Amnesty identified with humanity as a whole-genderless, colorless, without sexuality-had been its virtue."143

Thus, according to him, there was an antagonism between AI's original focus and the complexity of VAW, which explains the challenge that the SVAW campaign presented to the organization and the internal opposition it evoked because, as he explained, "Amnesty [could not] continue to be what it has been as a result." 144

As highlighted previously, the SVAW campaign was implemented in two phases with distinct thematic focuses. Evidence indicates that the modification of the thematic emphasis between the first and the second part was

141 Kelleher and Bhattacharjya 2013, p.5.

142 Ganzfried: Interview with A.Z., 26.06.2012.

143 Hopgood 2006, p.154-155.

144 Hopgood 2006, p.154-155. 
subject to critiques from staff and activists. In fact, officials and activists criticized abandoning the focus on "VAW in armed conflicts" and "Domestic violence" at the end of the first phase. According to them, this change prevented the organization from continuing to build expertise and networks around these issues. As a result, many staff and activists simply ignored the campaign's new direction and carried on doing what they had been doing during the first phase of the campaign, because they did not understand the changes. ${ }^{145}$

For another interviewee, in the second phase "the campaign lost in international coherence [because] beside the girls-action [...], no strong campaigning line was visible." ${ }^{146}$ Further, as mentioned before, the last two years of the SVAW campaign coincided with the preparation of AI's second global thematic campaign Demand Dignity, which was launched at the beginning of 2009. Relatedly, as the evaluation of the SVAW campaign pointed out, "there was never a clear exit strategy for the campaign or for ending the work with partners." ${ }^{147}$ Thus, while not necessarily provoking opposition, the change of the thematic focus away from a unique emphasis on VAW toward becoming an instrument for achieving AI's growth agenda during the second phase, the absence of a clear exit strategy, and the related parallel launch of the Demand Dignity campaign made the SVAW unpopular among staff and activists.

While it is difficult to grasp the IS's opposition to the SVAW campaign in its entirety, the data allow us to locate the resistance and identify the main reasons behind it. Evidence indicates that opposition came from certain groups of researchers at the IS. One interviewee explained that as "traditional researchers, many of them, did not want to look at women's rights. Did not, would not." ${ }^{148}$ Another interviewee highlighted: "a certain research group [...] just didn't take it seriously. They were not interested. They didn't really think that women's rights were an issue in the Middle East for example." ${ }^{149}$ Some researchers refused to integrate a gender perspective into their reports, saying that "[they] d[id]n't have the capacity," 150 whereas others were "only open to incorporate a gender analysis if Gita [the head of the

\footnotetext{
145 Wallace and Baños Smith 2010b, p.139.

146 Amnesty International: Evaluation Kampagnenprojekte 2008, 16.01.2009, p.3.

147 Wallace and Baños Smith 2010b, p.179.

148 Ganzfried: Interview with A.W., 25.06.2012.

149 Ganzfried: Interview with A.Z., 26.06.2012.

150 Ganzfried: Interview with A.O., 23.01.2015.
} 
Gender Unit] would go with them on a mission. And back after the mission, Gita would write the section on gender."151

During the campaign, there were regular conflicts between the Gender Unit and the legal program, which could also be interpreted as a form of opposition to the SVAW campaign coming from some legal staff members. An interviewee explained: "[the Gender Unit was] constantly on battle with our own legal program because they hadn't got a clue about the legal standards related to women's human rights." ${ }^{152}$ The conflict between the Gender Unit and AI's legal and policy experts became manifest in the elaboration of Al's policy on abortion. The Gender Unit submitted a document on the absolute denial of abortion in Nicaragua to the UN Committee Against Torture, considering this denial a form of torture. An informant explains that "several of AI's legal and policy experts were furious" 153 with it, as the submission was a public document and did not reflect the state of AI's position on the issue at that time. However, as the following statement of the same interviewee demonstrates, the legal program's critique of applying black letter laws, such as the UN Convention against Torture, to issues of women's rights reflects a disregard of women's rights issues compared to the traditional human rights issues that AI had focused on before. According to this informant:

"if [the Gender Unit was] trying to use the issue of torture for women's rights it was treated as if [they were] using an inflationary language. [...] this is too precious to be applied to issues of women. It has to be applied to serious things like male political prisoners and so on."154

How can this content-related opposition against the SVAW campaign be accounted for? While it is difficult to definitively establish the reason behind this opposition, evidence indicates that it had to do with the patriarchal mentalities of some of the IS staff. Bhattacharjya identified "patriarchal mindsets" ${ }^{155}$ behind the internal opposition and contestation of the SVAW campaign. Kelleher and Bhattacharjya further explained that many women within AI perceived the functioning of AI to be "deeply patriarchal." ${ }^{156}$ Comparing AI

151 Ganzfried: Interview with A.O., 23.01.2015.

152 Ganzfried: Interview with A.W., 25.06.2012.

153 Ganzfried: Correction of citations A.W., 22.08.2018.

154 Ganzfried: Interview with A.W., 25.06.2012.

155 Bhattacharjya 2013, p.5.

156 Kelleher and Bhattacharjya 2013, p.10. 
to a secular church, defining AI as "basically a church," 157 another interviewee provides a similar explanation for the organization's struggles with the incorporation of women's rights into its overall work. He stated: "And you know how well the church deals with women's rights, very, very badly. Because they think women's rights are not really important enough and it is not fundamental to what it is about. It is about some deeper thing." 158

Thus, while part of the resistances to the SVAW campaign had to do with its flagship role and the campaign's structure and setting, another part of the resistance (observed at least among the IS staff) was clearly linked to the content of the campaign. An explanation for this seems to be the presence of patriarchal mentalities among IS staff members. Or, given that the church as an institution deeply embodies a patriarchal culture more than any other organization, Al's resemblance to a church may also explain the internal resistance. The correlation between AI's resemblance to a church and the opposition to the SVAW campaign also becomes evident within sections. As I show in section 8.2.2, the German section's closeness to the church explains its virulent opposition to the campaign and to the adoption of an abortion policy at least to a certain extent.

\subsubsection{Resistance against the adoption of a policy on abortion}

By focusing on the ICM decisions directly concerning AI's work on VAW, the present section illustrates that "the debate on reproductive rights [...] was one of the most challenging periods for Amnesty [...]." 159 and that abortion was a highly controversial issue. In fact, as figure 12 illustrates, among the decisions directly concerning AI's work on VAW, only the decisions on sexual and reproductive rights that included the issue of abortion provoked debates at their respective ICMs (highlighted in the left column of figure 12). ${ }^{160}$

The first signs of disagreement about the extent to which AI should work on the issue of sexual and reproductive rights, including abortion, became

157 Ganzfried: Interview with B.R., 25.06.2012.

158 Ganzfried: Interview with B.R., 25.06.2012.

159 Ganzfried: Interview with A.O., 23.01.2015.

160 As the report from the 2005 ICM shows, debates heralded the adoption of decision 2 of the 2005 ICM. But, these discussions did not focus on Al's work on women in conflict, but concerned other aspects of the resolution not related to women's rights. For this reason, I classified decision 2 of the 2005 ICM among those not triggering debates. 
Figure 12: ICM decisions and related debates, 2002-2009

Decisions triggering debates among section delegates at the ICM

\begin{tabular}{|c|c|c|}
\hline & Yes & $\begin{aligned} \text { No } \\
\end{aligned}$ \\
\hline 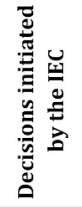 & $\begin{array}{l}\text { Decision } 32005 \text { ICM Sexual and } \\
\text { Reproductive Rights } \\
\text { Decision } 32007 \text { ICM Sexual and } \\
\text { Reproductive Rights }\end{array}$ & $\begin{array}{l}\text { Decision } 12003 \text { ICM Globalizing Justice! } \\
\text { Decision } 22005 \text { ICM The Protection of human rigths } \\
\text { through conflict prevention, intervention and } \\
\text { condemnation of force } \\
\text { Decision } 4 \text { ICM } 2009 \text { Commitment to long-term work on } \\
\text { behalf of individuals at risk, including prisoners of } \\
\text { conscience }\end{array}$ \\
\hline
\end{tabular}

Source: my own, based on the $2003,2005,2007$, and 2009 ICMs reports

evident in 2003. At the 2003 ICM, several South American sections (AI Argentina, AI Mexico, and AI Peru) initiated the discussion by emphasizing the importance of addressing sexual and reproductive rights when working on violence against women. AI Peru noted that this issue was particularly relevant in their region, where women were often denied the right of access to family planning. ${ }^{161}$ At the same time, concerned about AI's credibility with respect to the global SVAW campaign, the Irish section ${ }^{162}$ also called AI to further engage with the subject of abortion. ${ }^{163}$ Others, such as the Italian and the Indian sections, were more reluctant. The 2003 ICM report reflects that "the Italian section stated that they were not ready to enter into the area of abortion but were open to debate on the issue." ${ }^{164}$ The Indian section expressed concerns about how to campaign on the issue of abortion and suggested promoting the decriminalization of abortion but not the right to abortion. ${ }^{165}$ As I mentioned at the beginning of chapter 8 , the IEC launched a movement-wide consultation process with the aim of developing a common position in the aftermath of these initial discussions. Based on the results of the consultation,

161 Amnesty International, International Secretariat: Report and Decisions of the 26th International Council of Amnesty International, 2003, p.154.

162 Later, the same section proved to be more critical towards the adoption of an abortion policy.

163 Amnesty International, International Secretariat: Report and Decisions of the 26th International Council of Amnesty International, 2003, p.153.

164 Amnesty International, International Secretariat: Report and Decisions of the 26th International Council of Amnesty International, 2003, p.154.

165 Amnesty International, International Secretariat: Report and Decisions of the 26th International Council of Amnesty International, 2003, p.154. 
the IEC proposed its first enabling resolution to the 2005 ICM (illustrated in figure 13).

Figure 13: Origin of the two decisions on sexual and reproductive rights

\begin{tabular}{cccc}
\hline \multicolumn{4}{c}{ Resolutions preceding the ICM decisions on sexual and reproductive rights } \\
\hline ICM & Resolution & submitted by (author) & Resulting decision \\
\hline 2005 & HRS D & IEC & accepted in Decision 3 \\
\hline 2007 & HRS A & IEC & accepted as Decision 3 \\
\hline 2007 & HRS B & Peru & accepted as Decision 3 \\
\hline 2007 & HRS C & Italy and Sweden & accepted as Decision 3 \\
\hline 2007 & HRS D & Germany & accepted as Decision 3 \\
\hline
\end{tabular}

Source: my own, based on the 2005 and 2007 ICM reports

The report of the 2005 ICM reveals the sensitivity of the issue: "The Chair [reminded] the Working Party that this topic was very sensitive and urged a respectful debate."166 The discussion of the enabling resolution at the 2005 ICM illustrates the diverging viewpoints, which mostly crystallized on the issue of abortion. In fact, many sections feared that adopting a position on abortion at this moment would result in the drop-out of many AI members. While the delegates agreed that "the IEC [would] develop a policy showing AI's commitment to defending and promoting sexual and reproductive rights within its mission," 167 section representatives disagreed about abortion. While a majority (28 sections) called for further movement-wide consultations before developing a definite position, 19 sections favored the principle of legal, safe and accessible abortions for all women (this position was also espoused by the IEC), another 16 sections chose a position in line with the international legal consensus (i.e. where abortion was legal, it should be safe and where it was illegal, it should be decriminalized), and a minority of five sections favored a position stipulating that AI should only address a woman's right to abortion in instances of sexual assault, rape, and incest. ${ }^{168}$ Further, the sections disagreed on the process of reaching a consensus on this issue.

166 Amnesty International, International Secretariat: Report and Decisions of the 27th International Council of Amnesty International, 14th-20th August 2005, p.74.

167 Amnesty International, International Secretariat: Report and Decisions of the 27th International Council of Amnesty International, 2006, p.69.

168 Amnesty International, International Secretariat: Report and Decisions of the 27th International Council of Amnesty International, 2006, p.67. 
While half of the sections were in favor of adopting a position at the 2005 ICM, the other half wanted additional consultations, arguing that a decision was premature. ${ }^{169}$ Therefore, they opposed the IEC's enabling resolution and wanted to postpone the adoption of a definite position until the 2007 ICM. The divergence around decision 3 of the 2005 ICM thus concerned both the decision-making process and the content of AI's position on abortion. Consequently, the issue was postponed until the 2007 ICM, giving sections additional time for discussion.

However, as the submission of three section resolutions and one enabling resolution to the 2007 ICM (illustrated in Figure 13) shows, two years later, sections still disagreed on AI's future work on sexual and reproductive rights and abortion. AI Germany formulated the most critical position, suggesting that "AI will keep its neutral position on whether or not abortion should be a right of the woman." ${ }^{170}$ As one of the German delegates highlighted at the 2007 ICM, "It was very clear that the German section was perceived pretty much as trouble-makers in this matter"171 by the rest of the movement. The German resolution revealed a conservative understanding of a woman's right to end or not end her pregnancy, which juxtaposed fetal rights with maternal rights, stating:

"the possibility of fetal rights [...] is contentious and has medical, legal, and ethical facets. Experience with decades of discussions around this issue have shown that individuals, societies, and states cannot come to an agreement in the potentially tragic conflict woman-fetus." ${ }^{172}$

The German section explained its reticence to take a position on abortion with its members' belief in the importance of the question of whether "a fetus has a right to life."173

169 Amnesty International, International Secretariat: Report and Decisions of the 27th International Council of Amnesty International, 2006, p.73.

Amnesty International, International Secretariat: 28th International Council Meeting Circular 42 Resolution and Statute Amendment Pack, July 2007, p.12.

171 Ganzfried: Interview by Skype with A.C., 26.04.2015: "Es war aber ganz klar, dass man uns, die deutsche Sektion wahrgenommen hat als ziemliche Störenfriede in dieser Angelegenheit.".

172 Amnesty International, International Secretariat: 28th International Council Meeting Circular 42 Resolution and Statute Amendment Pack, July 2007, p.13.

173 Amnesty International, International Secretariat: 28th International Council Meeting Circular 42 Resolution and Statute Amendment Pack, July 2007, p.13. 
In its resolution, the Swedish section adopted the position most contrasting with the German position. This stance, also shared by the IS, ${ }^{174}$ asked for an evaluation of the current policy on abortion as to whether it fitted AI's future work on the right to health, a main issue within the upcoming Demand Dignity campaign. It also raised the possibility of addressing the global problem of "maternal deaths, [which] are due to unsafe abortions." 175 In its resolution, AI Peru (Figure 13) proposed "a policy on access to quality services for the management of complications arising from abortion,"176 arguing that such a policy did not mean that AI agreed with abortion or with the decriminalization of abortion. Instead, it would guarantee the right of access to health care that every person should enjoy.

At the same time, in its enabling resolution, the IEC demanded the adoption of the policy on selected aspects of abortion (decriminalization of abortion; access to quality services for the management of complications arising from abortion; legal, safe, and accessible abortion in cases of rape, sexual assault, incest, and risks to a woman's life). After some discussion in the working party at the ICM, the delegates finally reached a compromise, and the final resolution (HRS A) was accepted by a large majority to become decision 3. Nevertheless, a small minority (seven votes, which included the Irish, the Venezuelan, and some African sections) still firmly disagreed with the adoption of any policy on abortion. ${ }^{177}$ Even though it shared this disagreement, the German section finally grudgingly accepted decision $3 .{ }^{178}$

In sum, AI took more than six years to find a common position on the issue of abortion. The length of the decision-making process reflects the important opposition of some of AI's members and staff to the adoption of an AI policy on abortion. While the analysis of the ICM reports allows us to understand the decision-making process, the reports do not allow us to identify each section's position. We are, however, able to recognize some regional tendencies thanks to personal interviews. According to one of my interviewees, many Latin American country sections were in favor of adopting a position on

\footnotetext{
174 Ganzfried: Correction of citations A.C., 30.07.2018.

175 Amnesty International, International Secretariat: 28th International Council Meeting Circular 42 Resolution and Statute Amendment Pack, July 2007, p.9.

176 Amnesty International, International Secretariat: 28th International Council Meeting Circular 42 Resolution and Statute Amendment Pack, July 2007, p.8.

177 Amnesty International: 28th international Council Meeting, 2007.

178 Ganzfried: Interview by phone with A.Y., 09.01.2015.
} 
abortion. She explained that "Interestingly the sections in Latin America had no problem with putting abortion [on the agenda]." ${ }^{n 179}$ Similarly, the Nordic sections, such as the Swedish, the Norwegian, and the Danish sections, favored a position in favor of the decriminalization of abortion. In contrast, as I have already illustrated, the German section opposed any policy-making on the issue for many years. Further, African sections seem to have been rather critical of the adoption of the policy.

One of the reasons why some sections strongly opposed the adoption of any position on abortion was their fear of losing members. Speaking on behalf of the critical sections, an interviewee explained: "If we do this, the members are going to go. [...]. They were scared, who is going to give the money?"180 There were cases of long-term activists leaving their sections and the organization when AI adopted its policy on the restricted aspects of abortion. In fact, because of AI's nature of a membership organization based on democratic principles that gave members the opportunity to define the organization's working focus, the attitude of a section's membership towards the issue was paramount for the section's position on AI's policy on abortion. It seems that the traditionally conservative membership, manifest, among other things, in the section's closeness to the Church, explained its opposition to the adoption of an abortion policy, at least in the case of the German section.

In fact, according to an informant, the members of the German section were rather conservative and close to the Church: "It just shows you the type of people and how the organization grew because in the North, interestingly enough, because it all started with Church and going with little groups in the Church here in this country in Germany or whatever." 181 In contrast, the same interviewee explains, Latin American AI sections were generally in favor of adopting an abortion policy because of their progressive membership:

"you can think 'Latin America is very Catholic.' But the people in Latin America who would become members of Al belong to a kind of elite, the middle classes. [...] University students, they are the ones who are becoming members, not the conservative people. [...] The Latin American sections are new ones; the members are university people [...]."182 
My data thus points to a relationship between a section's church-related membership and its willingness to integrate issues of VAW into its work. As I highlight later, this relation is also reflected in the case studies on the German and the Swiss sections.

Summing up, activists and officials put up real resistance to the SVAW campaign and to the adoption of a policy on abortion. In the case of the SVAW campaign, staff and activists also opposed the campaign for reasons other than its content. In the case of the discussion on the ICM decisions on sexual and reproductive rights, the resistance was clearly related to the issue of abortion itself. I therefore argue that the content-related opposition against the SVAW campaign and against the adoption of a policy on abortion were an important reason for AI's failure to integrate VAW into its work through the SVAW campaign.

So far, the analysis at the international level indicates that it is worth assuming that AI did not succeed in integrating VAW into its work through the SVAW campaign for two main reasons. First, female activists and officials who initiated AI's work on VAW in the 1990s lost their influence on the organization's VAW work. Second, activists' and officials' resistances to the SVAW campaign and to the adoption of an abortion policy was too strong to be neglectedAs I demonstrate in the following pages, there were considerable differences in the extent to which AI succeeded in integrating the issue of VAW into its work at the national level, in the section's reactions to the participation in the SVAW campaign, and in the opposition to the adoption of an abortion policy. I examine all of these issues in my case studies on the Swiss and the German sections.

\subsection{The national levels}

My focus on the national level allows me to examine the considerable differences in the extent to which the Swiss and the German sections managed to integrate the issue of VAW into their work in the 2000s. While the Swiss section was more successful in making VAW part of its overall work, the German section hailed limited achievements. Chapter 8.2 provides a detailed picture of the content and the structures supporting the sections' work in the frame of the SVAW campaign. It identifies five criteria that allow me to capture each section's success in integrating VAW into its work. The criteria emerged from the data and have to do with the adoption of the overall campaign by the sec- 
tion; the professionalization of the work on issues of VAW; the leadership's commitment to the SVAW campaign; the influence of a section's women's group or network on the section's work on issues of VAW; and lastly, the section's resistance to the SVAW campaign and the adoption of the abortion policy. In the chapters on the Swiss and the German sections, I demonstrate the extent to which the two sections met these criteria. In conclusion, the present chapter tries to explain the success of the Swiss section and the difficulties of the German section in making VAW part of their overall work by coming back to the central differences between the two sections. I argue that the German section members' relative closeness to the Church and their comparatively powerful position help explain the difference between the two sections.

\subsubsection{The Swiss section}

The present section demonstrates that even though the review of the overall SVAW campaign showed that AI did not succeed in making VAW part of its overall work, this general finding has to be nuanced. The Swiss AI section succeeded in doing so at least partially through the SVAW campaign. The section starts by providing a detailed picture of the Swiss section's campaign and illustrating where the section put the latter's thematic focus. It also details the activities realized within the frame of the campaign. It quickly becomes evident that the Swiss section adopted the thematic focus of the overall campaign and launched an internal as well as an external campaign. Section 8.2.1 then highlights the section leadership's commitment to the SVAW campaign and demonstrates the continued importance of the section's women's network for the work on violence against women. The section shows that despite the top-down implementation of the campaign and the professionalization of the work on VAW at the Swiss section, the female activists and officials of the women's network remained important in defining the section's work on the issue. Then, I focus on the section's participation in and reaction to the SVAW campaign, as well as on the internal discussions regarding the elaboration of the abortion policy. I demonstrate that resistance to the issue of VAW from activists and officials was isolated at the Swiss section. At the same time, the section shows that even though most of the groups participated in the public SVAW campaign, their involvement was more pragmatic than enthusiastic, and that work on VAW remained overwhelmingly confined to the members of the women's network. 


\subsubsection{Merging the international campaign strategy with the section's priorities}

In line with the overall campaign strategy, the Swiss section labeled the campaign Stoppt Gewalt Gegen Frauen, launched an internal campaign and implemented the public campaign in two phases. In contrast to the general campaign, the Swiss section launched the internal campaign and the public campaign simultaneously in 2004. It developed its own Gender Action Plan containing section-specific objectives on how to become a gender-sensitive organization, where gender aspects become a transversal theme in all campaigns and activities and where members engage with the principle that "women's rights are human rights." ${ }^{183}$ According to the section's management, the Gender Action Plan had to help in "making the organization internally coherent with its public discourse.,184 My interviews revealed that one of the key messages the Swiss section wanted to convey to its members through the Gender Action Plan was that the SVAW campaign should be perceived primarily as a human rights campaign, rather than as a feminist endeavor. Thus, the section's management thought it was pivotal to "[pay] attention to the fact that men were also bearers, bearers of the message"185 and to achieve a balanced representation of men and women within all positions at every level of the organization. ${ }^{186} \mathrm{~A}$ long-term official explained: "when there were applications, of course they had to be of equal qualifications, but there was however a specific will to say 'in cases of equal qualifications, we want and we will clearly privilege women's applications for the management board." ${ }^{187}$ In order to enhance the members' gender awareness, the section organized various workshops with external gender specialists. ${ }^{188}$ Evidence shows that these workshops were supposed to make staff and activists reflect on their gender roles

\footnotetext{
183 Jegher: Der Cender Aktionsplan Schweizer Sektion (CAP-Al CH), 18.12.2003.

184 Amnesty International: Plan d'action Cenre de la Section suisse, 17.03.2004, p.2.

185 Ganzfried: Interview with A.]., 09.03.2012: "On a toujours fait attention à ce que les hommes soient aussi porteurs, porteurs de message.".

186 Jegher: Der Gender Aktionsplan Schweizer Sektion (CAP-AI CH), 18.12.2003.

187 Ganzfried: Interview with A.J., 09.03.2012: "Quand il y avait des postulations, bien sûr il fallait une qualité égale au niveau du dossier mais quand même une volonté spécifique qui a été dit 'nous voulons et nous privilégierons en cas de qualité égale, clairement les dossiers femme dans la Ceschäftsleitung.".

188 Jegher: AICH-Kampagnentagung 2005 - durch die Gender-Brille gesehen, 22.10.2005, p.1.
} 
and to sincerely address possible internal resistance to gender issues. ${ }^{189}$ As I emphasize later, the success of these workshops was moderate.

Around the $8^{\text {th }}$ of March 2004, the section also launched the public campaign starting with a media manifesto containing various national personalities' support messages and primarily followed by women's groups' activities. By May 2004, all AI groups had become involved. ${ }^{190}$ The Swiss section implemented the public campaign over the course of six years, from 2004 until the end of 2010. However, just like the overall campaign, the intensity of the campaign was higher during the first phase. ${ }^{191}$ Later, between 2008 and 2009, the SVAW campaign became one of four main global theme campaigns that the section was implementing. ${ }^{192}$ Relatedly, the campaign coordinator explained that the resources for her brief were reduced to about $50 \%$ in 2008 , which by

189 Amnesty International: Plan d'action Genre de la Section suisse, 17.03.2004, p.4.

190 Amnesty International: "Halte à la Violence contre les Femmes" Informations sur la campagne, Janvier 2004; SVAW Projekt Team AICH: Sitzungsprotokoll 12.2.2004, 12.02.2004. Whereas issues related to women's rights or to the SVAW campaign had been discussed at every CA between 2003 and 2006, the same issues disappeared from the CA's agenda or were only marginally mentioned at the 2007, 2008, 2009, and 2010 GAs (Amnesty International: Delegiertenversammlung 2002, 06.04.2002; Amnesty International: Delegiertenversammlung 2003, 12.04.2003; Amnesty International: Delegiertenversammlung AICH 2004, 14.05.2004; Amnesty International: Delegiertenversammlung 2005, 29.05.2005; Amnesty International: Protokoll der Delegiertenversammlung 6.-7. Mai 2006 in Delémont, 07.05.2006; Amnesty International: Delegiertenversammlung 2007, 06.05.2007; Amnesty International: Protokoll der Jahresversammlung 19. und 20. April 2008 Bern, 20.04.2008; Amnesty International: Procès-verbal de l'assemblée générale du 27/28 juin 2009 à Berne, 28.06.2009; Amnesty International; Amnesty International: Protokoll der Generalversammlung 2010 in Fribourg, 25.04.2010). The decline of the activities organized in the frame of the campaign could also be observed at the group level. In fact, screening 44 minutes from meetings of the Al group La côte revealed a declining frequency of the agenda item 'SVAW campaign' or 'women's rights' between 2004 and 2008. While these items were mentioned in $80 \%$ ( 17 out of 20 ) of the minutes of the meetings that took place between 2004 and the end of 2005, the same items only appeared in 54\% (13 out of 24) of minutes of meetings from 2006 until the end of 2008.

192 As reported in the minutes of the $2008 \mathrm{GA}$, in 2008 , beside the SVAW campaign, AICH put emphasis on the Campaign on Dignity, the campaign against the violations of the torture prohibition called Counter Terror with Justice, and the campaign for the respect of human rights at the Olympic Games in Beijing 2008 (Amnesty International 2008, p.11). 
that time was "not sufficient for a more important presence"193 of the SVAW campaign within the section.

The Swiss section broadened the thematic focus of the campaign, concentrating on "Women trafficking" and "Due diligence" in its first phase, ${ }^{194}$ in addition to the themes adopted by the overall campaign ("Domestic violence" and "VAW in armed conflicts"). ${ }^{195}$ In fact, in a consultation, the surveyed national women's rights organization qualified "Women trafficking" and "Due diligence" as important national VAW issues. ${ }^{196}$ Further, similar to the overall campaign, the section mainly emphasized "Violence in intimate relationships" in between the two main campaign phases. ${ }^{197}$

During the second phase, the Swiss section complied with the growth objectives of the overall campaign and defined the growth of its active membership as a means to the organization's effectiveness. ${ }^{198}$ At the same time, the section put a different emphasis on the objective "Human Rights concern" than that proposed by the IS. The section planned to work on the principle of due diligence, to lobby the Swiss government in favor of the ratification of the European convention against human trafficking, to participate in the internal discussion on AI's position on sexual and reproductive rights, and enhance the mainstreaming of women's rights throughout the section. ${ }^{199}$ In 2008 , aside from some smaller actions on the protection of female human rights defenders and on domestic violence, the section essentially focused on

193 Amnesty International: Evaluation Kampagnenprojekte 2008, 16.01.2009, p.3: "ausserdem reichten die deutlich verringerten Ressourcen seitens der Kampagnenleitung (nurmehrca. 50\%) nicht aus für eine stärkere Präsenz.".

194 Jegher: Kampagne Stoppt Gewalt gegen Frauen Mittelfristige Planung per Jan. 05 bis ca. März 06, 23.12.2004; Amnesty International: SVAW - Aktuell vom 7.4.2004 News zur Frauenkampagne Al CH, 07.04.2004; Amnesty International: Kampagnenplanung SVAW AlCH - Strategie- und Aktionsplan updated, July 2004.

195 The Swiss section named this issue "weapon and VAW".

196 In order to identify the campaign's priorities AICH asked more than 30 women's rights organizations and Equality Offices about the occurrence and the nature of genderbased discrimination and VAW in Switzerland. Bourquin: VAW Campaign External Audit, 2003.

197 Amnesty International: VAW in the family Progress update Swiss Section, 28.09.2006.

198 Amnesty International: Operativer Plan 2006-2007 (AICH OP 2) Wachstum und Wirkung unseres Einsatzes für die Menschenrechte, 24.04.2006.

199 Amnesty International: Operativer Plan 2006-2007 (AICH OP 2) Wachstum und Wirkung unseres Einsatzes für die Menschenrechte, 24.04.2006. 
women trafficking in a sub-campaign related to the European football championship, called "Euro 08 against Women Trafficking." 200 According to the campaign coordinator, with the women trafficking campaign, the Swiss section "stressed its own priorities" 201 and "did not take up the 'main' - girls - campaign" ${ }^{202}$ focusing on violence and the right to education, as defined in the overall campaign objective "Human Rights Concerns."

Within the frame of the aforementioned main thematic priorities, the Swiss section carried out numerous advocacy, lobbying and outreach activities. I briefly highlight some of the most important campaign activities realized by the Swiss section in an attempt to shed some light on them. In 2005, various local groups participated in a bicycle tour of the country, initiated by the Bern women's group, with the goal of sensitizing a large public to the issue of domestic violence. ${ }^{203}$ Further, in September 2005 , in what was one of the key moments of the campaign, the section organized an international conference on due diligence in collaboration with other organizations and institutions. ${ }^{204}$ In 2006, various local AI groups participated in the action called "mobile home against domestic violence," which strived to improve the state's interventions against family violence. A tour of the country's rural areas sought to sensitize the public and young men, in particular, to the issue of domestic violence. ${ }^{205}$ Moreover, in collaboration with other organizations, the Swiss section lobbied for the tightening of the Swiss legislation in matters of weapons. ${ }^{206}$ The Swiss section collaborated with the women's movement, just like the campaign's central organs tried to at the international level. ${ }^{207}$ Women NGOs, such as the Marche mondiale des femmes, the NGO-Koordination

200 Amnesty International: Evaluation Kampagnenprojekte 2008, 16.01.2009.

201 Amnesty International: Evaluation Kampagnenprojekte 2008, 16.01.2009, p.3: "Wir setzten mit der Frauenhandels-Kampagne eigene Akzente.".

202 Amnesty International: Evaluation Kampagnenprojekte 2008, 16.01.2009, p.3: "griffen die 'Haupt'-Girls-Kampagne nicht auf..'

203 Amnesty International: Velotour gegen häusliche Gewalt 3./4. September 2005 Ein Aktionsvorschlag der Berner Frauengruppe, 09.03.2005.

204 Amnesty International: Due Diligence: Rolle und Pflichten des Staates in der Bekämpfung von Cewalt gegen Frauen: Standards, Probleme, Perspektiven Internationale Fachtagung zur Kampagne "Stoppt Gewalt gegen Frauen" 21. bis 23. September 2005, 30.03.2005.

205 Amnesty International: VAW in the family Progress update Swiss Section, 28.09.2006.

206 Amnesty International: Notice from Stella Jegher to Caroline Huwiler on the SVAW updates, 06.08.2004.

207 Amnesty International: Kampagne Stop Violence against Women (SVAW) Strategie- und Aktionsplan Schweizer Sektion, 21.01.2004. 
Post Beijing, ${ }^{208}$ the umbrella organization of the Swiss shelters for women, ${ }^{209}$ the Fraueninformationszentrum FIZ, and ${ }^{210}$ the KOFF, ${ }^{211}$ as well as governmental organizations, such as the Federal Office for Gender Equality and the Federal Department of Foreign Affairs, were all among AI's partner institutions during the campaign. ${ }^{212}$

Summing up, the Swiss section implemented the SVAW campaign and adopted the themes of the overall campaign - "VAW in armed conflicts" and "Domestic violence," supplementing them with issues of VAW that were specific to its national context, such as "Women trafficking." The Gender Action Plan and the related workshop were the main components of the internal campaign strategy. ${ }^{213}$ During the second phase, the Swiss section focused on the issues of "Due diligence," "Women trafficking," and the internal discussion of AI's position on sexual and reproductive rights and continued the implementation of the GAP. Thus, the Swiss section successfully merged the section's priorities on issues of VAW with the international campaign strategy.

\subsubsection{The continuing importance of the women's network}

While the preceding section highlighted the content of the Swiss SVAW campaign, this section emphasizes how the section organized the latter's implementation. To do so, I call attention to the leadership's commitment to the campaign and demonstrate the continuing importance of the section's women's network for the work on VAW.

The section's management was committed to and pushed the SVAW campaign forward. The person in charge of the preparation of the campaign wrote: "the Swiss section can count on the clear support of the management" 114 when it faced the challenge of "training and mobilizing the entire

208 Amnesty International: Frauenrechts-Ko-Gruppe Sitzungsprotokoll vom 11. Juni 2007, 11.06.2007.

209 Dachorganisation der Schweizer Frauenhäuser.

210 SVAW Projekt Team AICH: Sitzungsprotokoll 5.8.2004, 05.08.2004, p.2.

211 Amnesty International: Evaluation Kampagnenprojekte 2008, 16.01.2009.

212 Bourquin: Préparation de la VAW - update/listing, 09.09.2003, p.4; Amnesty International: Evaluation Kampagnenprojekte 2008, 16.01.2009.

213 Jegher: Kampagne Stoppt Cewalt gegen Frauen Mittelfristige Planung per]an. 05 bis ca. März 06, 23.12.2004

214 Amnesty International: Campagne interne (objectifstratégique 4 de la VAW), 09.09.2003, p.3: "[L]a section peut s'appuyer sur [...] le soutien clair de la Direction générale de la Section pour les questions droits des femmes, [...].". 
section for [the issue of women's rights]"215 in September 2003. She further declared that: "it seems to be clear that the VAW campaign, and particularly the internal campaign, is part of a process coming from the top to the bottom." ${ }^{216}$ The campaign coordinator explained that the Executive Director (ED) "promoted women's rights within the Swiss section.." ${ }^{217}$ Further archival material suggests that in the beginning of the 2000 s, the ED and the members of the EC were dedicated to intensifying the section's work on women's rights and VAW and to integrating the issue into the section's activities in a sustainable way. In the response to the women's network's postulate to the $2003 \mathrm{GA}$, which called upon the section to take the measures necessary for a sustained integration of women's rights beyond the SVAW campaign, ${ }^{218}$ the management explained that "the EC and the ED [had] the very clear intention to make [women's rights] a permanent issue," 219 and confirmed their commitment to the organization of the internal campaign. ${ }^{220}$

Moreover, the EC was in favor of the creation of the Women's Rights Commission, ${ }^{221}$ which, as I detail later, was an initiative of the women's network and aimed at mainstreaming Al's work on VAW. Evidence also shows that the section's management particularly welcomed the internal campaign. The section's management commented on the overall strategy that: "[they] welcomed in particular the initiative of conducting an internal campaign in parallel with the public campaign that questions [their] own practice regarding women

215 Amnesty International: Campagne interne (objectifstratégique 4 de la VAW), 09.09.2003, p.3.

216 Amnesty International: Campagne interne (objectifstratégique 4 de la VAW), 09.09.2003, p.1: "Il semble clair que la campagne VAW et plus particulièrement la campagne interne, s'intègre dans un processus venant du haut vers le bas.".

217 Ganzfried: Interview with B.Q., 09.09.2011: "Auf Schweizer Ebene förderte Daniel Bolomey die Frauenrechte als Geschäftsleiter.".

218 Amnesty International: Prise de position du CE et du Secrétariat sur le Postulat A adopté par I'AD 2003 à Genève, 22.01.2003; Amnesty International: Protokoll der Vorstandssitzung vom 6. März 2003, 06.03.2003.

219 Amnesty International: Prise de position du CE et du Secrétariat sur le Postulat A adopté par I'AD 2003 à Genève, 22.01.2003, p.2: "I'intention très claire du Comité et du SG est d'en faire une problématique permanente".

220 Amnesty International: Prise de position du CE et du Secrétariat sur le Postulat A adopté par l'AD 2003 à Cenève, 22.01.2003.

221 Amnesty International: Protokoll der Vorstandssitzung vom 23.05.2002, 23.05.2005. 
rights [...]."222 Indeed, the section's leadership stressed the importance of the internal campaign in a letter to the whole section explaining that "the EC made the planning of the campaign and the section's GAP a huge priority."223

Another element that points to the commitment of the section's Executive Director (name of person) was his involvement in the planning of the campaign and its preparation at the international level. He was a member of the international Campaign Steering Committee, contributed to the delegates' mobilization for the campaign at the $2001 \mathrm{ICM},{ }^{224}$ and participated in the movement-wide campaign preparation meeting in Oxford in July 2003 at Irene Khan's request. ${ }^{225}$ On the whole, one can therefore conclude that the Swiss section's management was greatly committed to intensifying its work on VAW and advocated for the effective implementation of the SVAW campaign. At the same time, as the following section demonstrates, female activists and officials continued to play an important role in the section's work on issues of VAW, especially in further institutionalizing the work on VAW within the section.

As chapter 7.2.1 explained, female activists in the Swiss section formed a national women's network at the beginning of 2000 . In 2001, the women's network was composed of four local women's groups (Lausanne, Bern, Geneva, and Zurich) and a Kogruppe and handled the section's work on women's rights and VAW. As we can see, the network remained a driving force behind the section's work on VAW during the SVAW campaign. ${ }^{226}$ Figure 14 provides an overview of the entities involved in the section's work on VAW in the 2000 s. Besides the various women's groups (on the right side), some of which disappeared prior to the SVAW campaign, the campaign coordinator and the

222 Amnesty International: Campagne sur la violence envers les femmes Projet de stratégie 2004-2006, 2004, p.1: "Nous saluons tout particulièrement l'initiative de mener-parallèlement à la campagne public - une campagne interne qui interroge notre propre pratique en matière des droits des femmes, [...].".

223 Amnesty International: Plan d'action Genre de la Section suisse, 17.03.2004, p.2: "Le comité exécutif a accordé une grande priorité dans la planification à cette campagne et au Plan d'action sur le genre.".

224 Amnesty International: Prise de position du CE et du Secrétariat sur le Postulat A adopté par I'AD 2003 à Genève, 22.01.2003.

225 Amnesty International, International Secretariat: Violence Against Women Campaign Report on the International Strategy Consultation Meeting 18-20 July 2003 Oxford, UK, 05.08.2003.

226 The women's network meetings took place in 2002, 2003, 2005, 2007, 2008, 2009. 
Project Team guaranteed the implementation of the campaign between 2003 and 2010. All entities but the SVAW Project Team (on the left side) were part of the women's network.

Figure 14: Entities involved in the Swiss section's work on VAW in the 2000 s

\begin{tabular}{cc}
\multicolumn{2}{c}{ Women's network } \\
Kogruppe & Women's group Zurich \\
$(1999-2002)$ & $($ since 1998) \\
Women's Rights Commission & Women's group Bern \\
$(2002-2004)$ & (since 1998) \\
SVAW campaign coordinator & Women's group Lausanne \\
(since 2003) & (since 1998) \\
Ko-Gruppe Women's Rights & Women's group Geneva \\
(since 2006) & (since 2000)
\end{tabular}

Source: my own

Evidence shows that the women's network, initially composed of four local groups and the Kogruppe, originally pursued two main objectives: first, it sought to attain a broad commitment to and engagement in the work on VAW within the section. Second, the network wanted to professionalize the section's work on VAW. To realize the first objective, the members of the women's network founded the so-called Women's Rights Commission ${ }^{227}$. The professionalization of the section's work on VAW was achieved with the appointment of the SVAW campaign coordinator. In 2006, realizing that their role in the section's work on VAW was weakening, the members of the women's network reinitiated a coordination group (the Ko-Gruppe Women's Rights) that sought to bring the local women's groups back into play. By focusing first on the Women's Rights Commission, then on the SVAW campaign coordinator, and third on the Ko-Gruppe Women's Rights, the following paragraphs provide a detailed picture of the principal actors involved in the section's work on VAW from 2002 until 2010. They demonstrate that the members of the women's network influenced the section's work on VAW, despite the top-down implementation of the SVAW campaign and the related professionalization of the work on violence against women. 
The establishment of the Women's Rights Commission can be seen as an attempt to mainstream women's rights across the section's work initiated by the women's network. Following the dissolution of the Kogruppe 228 at its first national meeting in February 2002, members of the women's network came up with the idea of creating a commission able to better represent their concerns at the sectional level. ${ }^{229}$ The network members argued that the activities undertaken by the women's groups were not sufficient for "the integration of the issue of women's rights into the global work of AI."230 After the presentation of their idea of a women's rights commission, the EC recognized the new structural entity in May $2002 .^{231}$

Aside from its overall goal of "a better integration of women's rights,"232 the commission was meant to sensitize AI members and the public to women's rights, to link AI's work on women's rights to the national and international women's rights movement, to support other AI groups in their work on women's rights, and to promote awareness of and the respect for women's rights. ${ }^{233}$ As defined in its mandate, "the commission [was] composed of women and men who wish[ed] to engage with AI for women's rights" 234 and of a representative from each the secretariat, the EC, and each local women's group. 235

However, evidence reveals that the interest in the commission remained overwhelmingly limited to those female activists and officials already engaged in the section's work on women's rights. In fact, at the beginning of one of the meetings, the members of the commission claimed: "we all know each other! [We regret] that nobody new had joined."236 My findings indicate that the commission disappeared with the launch of the SVAW campaign ${ }^{237}$ because,

\footnotetext{
228 Details on this group can be found in chapter 7.2.1.

229 Morstein: Presentation of the Women's rights commission, 2002.

230 Amnesty International: Jahresbericht der Frauenrechtskommission (FRK), 2003, p.3.

231 Morstein: Presentation of the Women's rights commission, 2002.

232 Amnesty International: Jahresbericht der Frauenrechtskommission (FRK), 2003, p.3.

233 Amnesty International: Jahresbericht der Frauenrechtskommission (FRK), 2003.

234 Morstein: Presentation of the Women's rights commission, 2002, p.2.

235 Morstein: Presentation of the Women's rights commission, 2002.

236 Amnesty International: Protokoll der Frauenrechtskommission, 09.11.2002, p.1.

237 In fact, I could not find any minutes of the commission's meetings after April 2004 (Amnesty International: Protokoll Sitzung Frauenrechtskommission vom 3. April 2004 , 13.04.2004).
} 
as an official involved in the preparation of the campaign observed: "part of [the commission's] mandate [...] is covered by the campaign on VAW today." 238

As I show in the upcoming paragraph, the newly appointed campaign coordinator and the SVAW Project Team took over most of the commission's responsibilities. ${ }^{239}$ The Women's Rights Commission thus only existed for two years, and even though supposed to attract activists and officials beyond the circle of women's rights advocates, it overwhelmingly brought together the people already involved in the section's work on women's rights. Thus, the women's network's objective of ensuring a broad commitment to and engagement in women's rights within the section by installing a Women's Rights Commission was only partially achieved. In contrast, as the next paragraph illustrates, the network's objective of professionalizing the Secretariat's work on women's rights proved to be more fruitful.

Even though various officials had worked on issues of women's rights before, the professionalization of this work only became substantial with the appointment of the SVAW campaign coordinator in 2003. As mentioned in chapter 7.2.1, without having defined terms of reference, a campaigner had been "unofficially responsible for women's rights" 240 in addition to her other briefs at the section's regional office in Lausanne since the beginning of the 2000 s. $^{241}$ The person responsible for lobbying and the staff member responsible for Animation and Education at the secretariat in Bern were later assigned to participate in the preparation of the SVAW campaign. They were both charged with doing this in addition to their other briefs for the period between January and November 2003, again without a related job description. The section's management finally appointed a SVAW campaign coordinator in December 2003. With this appointment, the section's leadership sought to "provid[e] the best conditions for the realization of the internal as well as the external campaign and to guarantee the long-term integration of this issue in the Swiss section." 242

238 Bourquin: Préparation de la VAW-update/listing, 09.09.2003, p.3.

239 Amnesty International: Procès-verbal de la réunion du 8 février 2003, 08.02.2003.

240 Amnesty International: Internal Audit Campaign on violence against women, November 2002, p.1.

241 Bourquin: Journée nationale du réseau femmes de la Section Suisse, 02.02.2002; Ganzfried: Conversation with C.D., 10.02.2017.

242 Amnesty International: Prise de position du CE et du Secrétariat sur le Postulat A adopté par l'AD 2003 à Genève, 22.01.2003, p.2: "afin de nous donner les meilleures conditions pour 
Evidence indicates that the campaign coordinator was important for the success of the SVAW campaign at the Swiss section. Her friends in arms qualified her as an "an important voice within the section" 243 who "had always been on the cutting edge" 244 and who "always tried to pick up [women's rights issues]." 245 According to one of her colleagues, the campaign coordinator was "[their] flagship that helped [them] a lot in [their] internal reflections" ${ }^{246}$ and "had been extremely well connected to a lot of women's organizations which helped her pus[h for] the development [of mainstreaming women's rights issues within the section]." ${ }^{247}$ Further, as a long-term official explained, the appointment of the campaign coordinator also improved the standing of the women's groups within the section: "[these women's groups] did certainly improve with the appointment of [the campaign coordinator] and there really was this integration with this networking. This was extremely important."248

Evidence indicates that the creation of the position of campaign coordinator of the SVAW campaign was the result of months-long women's network lobbying. It began with the network's intention to submit a respective motion to the section's GA at the beginning of 2002 . In fact, at its first national meeting in February 2002, the network members decided to write "a motion for a remunerated position within the Swiss section for women's rights issues [...]." ${ }^{249}$ They would submit the latter to the following $\mathrm{GA}^{250}$ if the section's management had not agreed with their proposition prior to that. The archival documents reveal that the network finally dispensed with it, as the management approved the allocation of additional resources to the engagement of a

réaliser la campagne interne au sein de la Section suisse, ainsi que la campagne publique et intégrer à long terme cette problématique dans la Section suisse.".

243 Ganzfried: Interview with B.K., 16.05.2013.

244 Ganzfried: Interview with A.P., 24.06.2013.

245 Ganzfried: Interview with A.P., 24.06.2013.

246 Ganzfried: Interview with A.J., 09.03.2012: "notre cheval de bataille nous a beaucoup aidé dans notre réflexion interne.".

247 Ganzfried: Interview with A.J., 09.03.2012: "Stella était une personne quiétait extrêmement bien resautée avec beaucoup d'organisations féminines. Ce qui fait qu'elle a pu vraiment pousser en fait le développement.".

248 Ganzfried: Interview with A.J., 09.03.2012: "Elles ont certainement gagné dès le moment où il y a eu l'engagement de Stella et il y a eu vraiment cette intégration avec cette Vernetzung ; c'est ça qui est extrêmement importants." .

249 Bourquin: Journée nationale du réseau femmes de la Section Suisse, 02.02.2002, p.5.

250 By submitting motions or postulates to the GA, the groups can shape the section's agenda. 
SVAW campaign coordinator. Instead, the network submitted a postulate to the $2003 \mathrm{GA}$, asking the EC and the ED to pursue the allocation of the necessary financial and personnel resources allowing women's rights issues to become a central and transversal theme in the section's overall work beyond the SVAW campaign. ${ }^{251}$ The postulate was unanimously accepted at the $2003 \mathrm{GA}$. It can be considered the basis of the sustainable professionalization of the Swiss section's work on VAW.

In addition to the nomination of the campaign coordinator, the section's management also installed a SVAW Project Team, composed of the campaign coordinator, the ED, and representatives from different departments, ${ }^{252}$ as "an interdepartmental structure that discusses the strategies of the [SVAW campaign] and their implementation" ${ }^{253}$. As a steering board, it assisted in defining and implementing the campaign's strategic options and facilitated the dissemination of the decisions to all staff members. ${ }^{254}$ Except for the campaign coordinator, the project team members were not part of the women's network.

With the establishment of the position of campaign coordinator and the decision to allocate the necessary financial and personnel resources for the section's work on VAW beyond the SVAW campaign, the section professionalized its work on women's rights and violence against women and created the basis for a sustained institutionalization. In contrast to the international level, where female activists and officials at the IS lost their influence on the organization's work on VAW over the course of the SVAW campaign, the Swiss section allowed its women's network to remain important in the definition of the section's work on these topics.

In fact, at the end of the first campaign phase, fearing that said professionalization would weaken women's groups's importance, a group of female activists around the campaign coordinator complained of the lack of coordination in the women's groups' activities (except for those taking place in the frame of the SVAW campaign). They also disliked that "each group pursue its

251 Amnesty International: Delegiertenversammlung 2003, 12.04.2003.

252 Amnesty International: Campagne contre les Violences envers les femmes (VAW) Séance du 8 mai 2003, 08.05.2003.

253 Amnesty International: Campagne contre les violences envers les femmes Groupe de projet séance du 2 septembre 2003, 02.09.2003, p.1.

254 Bourquin: Préparation de la VAW-update/listing, 09.09.2003, p.1. 
own issues and sets its own priorities." 255 They formulated the need to let women's groups assume the leading role in the sustainable incorporation of women's rights into the Swiss section, "independently of the coming [...] activities in the frame of the SVAW campaign,"256 and formed a new Ko-Gruppe Women's Rights in 2006. From then on, this Ko-Gruppe (coordinated by the campaign coordinator) organized the women's network's annual meetings ${ }^{257}$ and served as a vessel for the planning and coordination of the section's activities related to women's rights in general and of the SVAW campaign activities in particular.

The meeting minutes of the Ko-Gruppe Women's Rights show that it coordinated the women's groups' activities throughout the second campaign phase, organized the annual network meetings, and played a pivotal role in further institutionalizing the section's work on women's rights. In fact, the group discussed the question of "continu[ing] with the women's rights work in the section" 258 beyond the SVAW campaign and elaborated the "Swiss Strategy Women's Rights and Gender Mainstreaming," 259 a document meant to ensure the sustainable and broad integration of women's rights into the section's activities after 2010. The formation of the Ko-Gruppe Women's Rights thus allowed the reintegration of the women's groups into the agenda-setting process of the section's work on women's rights. It indicates that female activists and officials continued to influence the section's work on issues of VAW, even in the frame of the SVAW campaign.

Summing up, the previous sesction has illustrated the Swiss section leadership's commitment to the SVAW campaign. Meanwhile, the preceding paragraphs have highlighted the remaining importance of the section's women's network for the work on violence against women. It has further demonstrated that the Swiss section succeeded in professionalizing its work on VAW over

255 Amnesty International: Ko-Gruppe Frauenrechte Vorschlag für eine Neuorganisation und Umfrage zum Frauenrechts-Netzwerk, End of 2005, p.1: "Jede Gruppe verfolgt mehr oder weniger ihre eigenen Themen und setzt ihre eigenen Schwerpunkte.".

256 Amnesty International: Ko-Gruppe Frauenrechte Vorschlag für eine Neuorganisation und Umfrage zum Frauenrechts-Netzwerk, End of 2005.

257 Amnesty International: Frauenrechts-Ko-Cruppe Sitzungsprotokoll vom 3. April 2007, 03.04.2007; Amnesty International: Ko-Gruppe Frauenrechte AICH: Protokoll Sitzung vom 3.3.2009, 03.03.2009.

258 Amnesty International: Protokoll Frauenrechts-Kogruppe, 14.12.2009, p.1.

259 Amnesty International: Ko_gruppe Frauenrechte Protokoll Sitzung vom 22. September 2010, 22.09.2010, p.1. 
the course of the SVAW campaign and managed to build a sustainable approach to it. The section has shown that even though the SVAW campaign was implemented from the top to the bottom, female activists and officials continued to successfully influence the section's work on VAW by reorganizing their network.

\subsubsection{Women's rights - confined to a story by women acting for women}

This section focuses on the Swiss section's participation in and reaction to the SVAW campaign as well as on the internal discussions about the elaboration of the abortion policy. I demonstrate that opposition to the SVAW campaign and to the adoption of a policy on abortion was isolated at the Swiss section. The section further shows that even though the Swiss activists participated massively in the SVAW campaign, their involvement was more pragmatic and less driven by an enthusiasm for the campaign. The work on VAW remained mainly promoted by the members of the women's network. My interviewees' answers to the question "AI is engaging in many different rights, what rights are you engaging in?" also indicate that rather than mainstreamed among all members, VAW continued to be an issue mainly embraced and pushed by the members of the women's network. In fact, while a majority of the interviewed activists mentioned rights which are part of the Covenant on Civil and Political rights and two out of nineteen referred to economic, social, and cultural rights; no interviewed activist cited women's rights or issues of VAW as being in the center of his or her engagement at AI. This indicates that despite its management's commitment and its women's network's initiatives, the Swiss section did not succeed in making the issue of VAW part of its DNA. In fact, as I show hereafter, the conclusion of an internal evaluation of the Swiss section's capacity to engage in a women's rights campaign revealed that "women's rights remain[ed] confined to a story by women acting for women" ${ }^{260}$ at the end of the SVAW campaign.

Given the different roles that activists and officials play in the implementation of the SVAW campaign, the following paragraphs present these groups' participation and their reactions separately, beginning with the activists.

As part of the Gender Action Plan, activists were supposed to participate in workshops that sought to sensitize members to the issue of women's rights.

260 Amnesty International: Campagne interne (objectif stratégique 4 de la VAW), 09.09.2003, p.3. 
Evidence shows that despite the objective of reaching all members, only $20 \%$ of the Swiss AI groups - about a hundred activists, a majority of whom were women - participated in the workshops. ${ }^{261}$ Thus, an internal evaluation revealed that the "sensitization to gender issues of all activists of the Swiss section had not been realized via these workshops." ${ }^{262}$ Evidence suggests various reasons for the limited success of these training courses. First, the secretariat allocated insufficient resources for their implementation. According to an internal evaluation, workshops lacked timely and financial resources within the secretariat. ${ }^{263}$ Second, activists were not interested or did not have time. ${ }^{264}$ Another activist explained: "as a grassroots member who is working [...] then we are going to the workshops and then we cannot implement [what we learnt at the workshop] because we already used the time we can devote to AI." ${ }^{265}$ In another case, an activist declared: "I just do not have the time to participate in any workshop. [...] Besides, I do not think I need any more input on these topics." ${ }^{266}$ And third was the somewhat obligatory nature of the workshops. According to the workshop animator and campaign coordinator, "the contradiction between the 'quasi obligatory' nature of the animation proposed to the groups and the personal attachment necessary to accept to enter the relevant exercises" ${ }^{267}$ made activists abstain from participating. The workshop leader further explained that because the members overwhelmingly perceived

261 Amnesty International: Gender Action Plan: Auswertung mit Bettina Kurz und Philippe Beck, 01.06.2005.

262 Amnesty International: Evaluation des ateliers genre de la Section suisse, 06.10.2005, p.1: "La sensibilisation aux questions de gendre de l'ensemble des militant-e-s de la Section n'a pas été réalisé via ces ateliers genre.".

263 Amnesty International: Evaluation des ateliers genre de la Section suisse, 06.10.2005.

264 Amnesty International: Evaluation des ateliers genre de la Section suisse, 06.10.2005.

265 Ganzfried: Interview with A.U., 10.10.2012: "dass wir als Basismitglieder eben die schon arbeiten, nicht noch Zeit haben, also dann gehen wir in den Workshop und dann können wir es nicht umsetzen, weil wir nämlich die Zeit die wir für Al zur Verfügung haben schon gebraucht haben.".

266 Ganzfried: Interview with B.M., 12.10.2012: "ich habe schlicht keine Zeit um noch Workshops zumachen. keine chance und ob es die anderen gemacht haben vermutlich auch nicht also bei uns geht es allen ähnlich. insofern un dich habe auch nicht das gefühl ich müsste da noch gross input haben also das kommt noch dazu.".

267 C.: Email from C.A. to Stella Jegher concerning the gender workshops at AICH, 03.06.2004, p.1: "dans la contradiction entre le caractère 'quasi obligatoire' de l'animation proposée aux groups, et la nécessité d'une adhésion personnelle pour accepter d'entrer dans des exercices pertinents à ce sujet.". 
the Gender Action Plan, and therefore also the training courses, as an imposition by the IS, the plan severely challenged the groups' essential aspiration to engage anonymously, ${ }^{268}$ therefore hampering the workshops' success. According to the campaign coordinator, the workshops' failure had to do with the groups themselves, which "were not ready for such a project," ${ }^{269}$ and with those responsible for the preparation of the project, who "overlooked" 270 the membership's needs and opinions.

In contrast, the activists' participation in the public SVAW campaign activities was comparatively good. In fact, in addition to the women's groups, all sorts of groups actively took part in the campaign activities during its first two years. ${ }^{271}$ After the launch of the campaign in 2004, the campaign coordinator expressed her satisfaction in an internal memo: "the groups' participation was great, stands and actions in almost twenty cities!"272 In April 2005, she explained that "practically all active groups participated in the SVAW campaign." 273 However, in an interview, she qualified that "[the SVAW campaign] was positively received by the groups, but without provoking frenetic activism." ${ }^{274}$ In fact, as the interviews with activists also indicate, the groups' participation in the SVAW campaign was rather pragmatic. Referring to the campaign action "mobile home against domestic violence," an activist explained:

"Well, when a big campaign is coming from the secretariat and it is taking place in Berne, then they [the secretariat] most often rely on the resources of the Bernese groups [...], they [the Bernese groups] participate, that is evi-

C.: Email from C.A. to Stella Jegher concerning the gender workshops at AICH, 03.06.2004. Amnesty International: Gender Action Plan: Auswertung mit Bettina Kurz und Philippe Beck, 01.06.2005, p.1.

Amnesty International: Gender Action Plan: Auswertung mit Bettina Kurz und Philippe Beck, 01.06.2005, p.1.

7 Amnesty International: SVAW - Auswertung der Kampagne, 14.02.2005; Jegher: Motion 5a, Assemblée des délégué-e-s 2004 à Bienne, 26.04.2005; Jegher: Memo about the launch of the SVAW-campaign at the Swiss section, 2004; Amnesty International: Notice from Stella Jegher to Caroline Huwiler on the SVAW updates, 06.08.2004.

Jegher: Memo about the launch of the SVAW-campaign at the Swiss section, 2004, p.1.

Jegher: Motion 5a, Assemblée des délégué-e-s 2004 à Bienne, 26.04.2005, p.2.

Ganzfried: Interview with A.I., 26.09.2012: "je dirais que c'était positivement reçu par les groupes mais sans provoquer un activisme frénetique.". 
dent, if a campaign has been plonked in front of us, then we do not have to produce something just like that." ${ }^{275}$

Alluding to the same campaign action, another long-term activist described his group's participation as follows: "We integrated it into the annual actions [...]. But it has not been a permanent topic for our group." 276

While the activists generally welcomed the public SVAW campaign, evidence points to isolated cases of poor understanding related the campaign's focus and other cases of opposition to participation in the campaign due to its focus on domestic violence. In fact, some activists had problems with the practical implementation of the campaign because of the novelty of its issue. According to an interviewee, "there was a real interrogation about our capacity to act on violence against women." 277 As he explained, activists asked: "do I have to go to my neighbor who is beating his wife to tell him to stop?"'278 Additionally, activists from one particular professional AI group opposed a thematic campaign on VAW. An official explained: "extreme tensions occurred in the [former] medical group. Because it was about domestic violence and some men cancelled their membership in consequence." ${ }^{279}$ These members complained that the SVAW campaign was a feminist campaign, which ignored the universal principle of human rights. In a letter sent to the secretariat, an activist of the medical group disapproved of the focus on domestic violence stating: "Saying that women are victims of violence everywhere on the globe just because they are women is not true."280

275 Ganzfried: Interview with A.U., 10.10.2012: "also, wenn vom Sekretariat eine grosse Kampagne kommt und die in Bern ist, dann greifen sie meistens aufdie Ressourcen der Berner Cruppen zurück. [...] Die machen damit, das ist eigentlich klar. Wenn uns schon eine Kampagne vor die Nase gestellt wird, dann müssen wir nicht selber etwas aus dem Ärmel schütteln.".

276 Ganzfried: Interview with B. L., 24.06.2013: "wir haben es mehr integriert in die Jahresaktionen [...] Aber es ist nicht ein Dauerthema gewesen für unsere Cruppe.."

277 Ganzfried: Interview with A.I., 26.09.2012: "Il y avait une vraie interrogation concernant notre capacité d'agir par rapport à la violence à l'égard des femmes?".

278 Ganzfried: Interview with A.I., 26.09.2012: "Est-ce que je dois aller chez mon voisin qui bat sa femme pour lui dire d'arrêter?".

279 Ganzfried: Interview with A.K., 01.07.2013: "In den Medizinergruppen hat es EXTREME Spannungen gegeben. Weil da ist es natürlich wirklich auch um häusliche Gewalt gegangen und da hat es auch Kündigungen gegeben von gewissen Männern.".

280 C.: Letter addressed to Stella Jegher, 02.06.2004, p.1: "Dire que les femmes sont victimes de violence partout dans le monde du seul fait qu'elles sont des femmes n'est pas vrai.". 
The officials' reactions to the internal and to the public SVAW campaigns were quite different. In an e-mail, an official declared "personally regret[ting] the resources allocated to the GAP workshops for the groups."281 For another official, the campaign helped her focus more on women in her domain of work: "the fact that women's rights issues became transversal led to the prioritizing of women cases in the asylum domain, as well. ${ }^{282}$ According to another, the campaign affected his own work little. ${ }^{283}$ One official explained that "as everybody, [he] was supposed to put a women's rights component into [his] work, which sometimes became absurd,"284 and criticized the mainstreaming approach inherent to the campaign saying:

"[...] I am doing my annual planning for example, the parliamentary lobbying, and I am doing this depending on what? Depending on what I know, more or less, what will happen in the Parliament during the year. And then [the campaign coordinator] tells me 'ah and there is no women's action in there?', and I am telling her 'of course not, wait it is not me who is fixing the program of the Parliament'. [...] here I have certain resistance."285

Thus, evidence suggests that some officials seemed to find integrating VAWrelated issues into their work rather problematic. In fact, according to the same interviewee, there was no problem with the campaign itself, "as long as it remained in the domain of the campaign and the associated actions [...] it was not a problem for anybody, not me in any case." ${ }^{286}$ For another staff

281 C.: Email from W.G. to Stella Jegher concerning the gender workshops, 08.07.2004, p.3: "je regrette à titre personnel les ressources dévolues aux ateliers GAP auprès des groupes.".

282 Ganzfried: Interview with A.K., 01.07.2013: "also dass einfach die Frauenthemen ein Querschnittthema geworden ist, oder, hat dazu geführt dass wir einfach auch im Asylbereich sicher auch noch Frauendossiers Priorität eingeräumt haben.".

283 Ganzfried: Interview with A.H., 31.05.2013.

284 Ganzfried: Interview with A.A., 31.05.2013: "j'étais tenu comme tout le monde...des fois même jusqu'à l'absurde, de chaque fois mettre une composant Women's rights dans mon boulot.".

285 Ganzfried: Interview with A.A., 31.05.2013: "[...] je fais mon planning de l'année par exemple pour le lobbying parlementaire et puis je le fais en fonction de quoi? En fonction de ce que je sais, à peu près, qui va se passer au Parlement dans l'année. Et puis Stella me dit 'ah et alors il n'y a pas d'action femme là-dedans?', je lui dis 'non mais attends, ce n'est pas moi qui fixe le programme du Parlement.' [...], c'est là que moi j'ai quelques résistances.".

286 Ganzfried: Interview with A.A., 31.05.2013: "il n'y a pas eu de problème. Sur la campagne ellemême, tant que c'était dans le domaine de la campagne et des actions liées à la campagne [...] ça ne posait de problème à personne, en tout cas pas à moi.". 
member, the large spectrum of the topics covered by the campaign was problematic. He stated: "for a long time, we thought it was difficult to define what exactly we pick up because it was just somehow large and undefined [...]."287 An official emphasized the difficulties of working with the themes that the campaign proposed when it came to fundraising. He explained: "as long as you could work with violent pictures, such as acid attacks, it worked. But if afterwards you wanted to combine it with domestic violence in Switzerland, then it became increasingly difficult." ${ }^{288}$

Summing up, the Swiss section's activists generally welcomed the SVAW campaign and participated in most of the campaign activities, at least during the latter's first two years. Although most of the groups took part in the public campaign, evidence indicates that this participation was mostly pragmatic and not necessarily driven by the activists' enthusiasm for the campaign's thematic focus. Meanwhile, evidence suggests that parts of the staff did not oppose the implementation of the SVAW campaign but did show a certain reluctance to the focus of the campaign and sometimes had difficulties integrating issues of VAW into their respective fields of work. However, the SVAW campaign did not provoke activists' resistance, except in the case of a single group. The organization's work on VAW remained overwhelmingly in the hands of the women's network. Meanwhile, activists' and staff members' reaction to and participation in the SVAW campaign confirmed that the conclusion of a 2003 internal evaluation that "women's rights remained confined to a story by women for women," ${ }^{289}$ persisted after the end of the SVAW campaign.

Even though the Swiss section supported the elaboration of an abortion policy at the international level, the minutes of the 2005 and 2006 GA meetings suggest that internal debates on the topic took place at the Swiss section as well. In fact, at the $2005 \mathrm{GA}$, representatives from the EC, the International Commission, and the ED discussed the issue of sexual and reproductive rights

287 Ganzfried: Interview with A.F., 05.06.2013: "lange haben wir es schwierig gefunden, was nehmen wirjetzt genau aufund so, weil einfach [...] Irgend wo war es so breit und so undefiniert $[\ldots] "$.

288 Ganzfried: Interview with A.H., 31.05.2013: "solange du mit heftigen Bildern, eben wie die Säure-Attacken arbeiten konntest, hat es funktioniert. Sobald du es dann nachher kombinieren wolltest mit häuslicher Gewalt in der Schweiz, dann ist es schon schwieriger geworden.".

289 Amnesty International: Campagne interne (objectifstratégique 4 de la VAW), 09.09.2003, p.3. 
in one of the thematic forums. ${ }^{290}$ The participants there agreed to support the option that called upon the IEC to elaborate a policy on the non-controversial issues of abortion. Activists and officials seemed to have been more divided when they had to decide upon the content of the respective policy a year later. At the $2006 \mathrm{GA}$, following the IEC proposition, the EC offered the section the chance to position itself on the three aspects of abortion. ${ }^{291}$ At the same time, a local group submitted a motion refusing to take any position. ${ }^{292}$ During the vote in plenary, the participants very clearly rejected the local group's proposition with 98 against 27 votes and adopted the EC position with 87 against 17 votes. $^{293}$

The minutes of the 2006 meeting of the GA show the activists' disagreement on the issue of abortion. The local group officially explained its position with the fear that $\mathrm{AI}$ would lose its focus and become increasingly fragmented "by focusing on 'sexual and reproductive' rights, beside the newly defined strategy of working on economic, social, and cultural rights. ${ }^{294}$ Further, the local group explained that: "The members of the group [xy] consider that the right to life begins at the moment of conception; we do thus not understand how AI could argue in favor of abortion. Abortion has to be considered as infanticide." 295

The controversial nature of abortion also became evident when some of the long-term activists dropped out. One of my interviewees revealed that those who left AI when the organization adopted its policy on abortion, were

290 Amnesty International: Delegiertenversammlung 2005, 29.05.2005, p.10.

291 Decriminalization of abortion; access to quality services for management of complications arising from abortion; and access to legal, safe, and accessible abortion in the case of an unwanted pregnancy (Amnesty International: Postulat A Position der Schweizer Sektion zu Abtreibung, Delegiertenversammlung 2006, 07.05.2006).

292 Amnesty International: Motion 9 Stellungnahme der Sektion zum Thema Abtreibung Delegiertenversammlung 2006, 07.05.2006.

293 Amnesty International: Protokoll der Delegierteversammlung 2006 in Delémont, 07.05.2006.

294 Amnesty International: Motion 9 Stellungnahme der Sektion zum Thema Abtreibung Delegiertenversammlung 2006, 07.05.2006, p.1.

295 Amnesty International: Protokoll der Delegierteversammlung 2006 in Delémont, 07.05.2006, p.14: "Die Mitglieder der Regionalgruppe [xy] sind der Ansicht, dass das Leben bereits mit der Empfängnis beginnt; demnach verstehen wir nicht, wie Al sich zugunsten der Abtreibung aussprechen kann. Abtreibung muss als das gesehen werde, was es ist: Kindsmord.". 
people from religious communities. The official explained: "we were confronted with resistance even at the level of the Swiss section. We had people from religious communities who had been very engaged for many years, who left AI because they could not identify any more with [this new agenda]."296 Other activists did not leave AI or "resist the work on reproductive rights but" preferred "not to engage in this matter."297

Thus, at the Swiss section, opposition against the adoption of an abortion policy existed but was rather isolated. Evidence suggests that, resistance also mainly came from conservative church-related activists or groups, similar to what was observed at the international level.

Consequently, the Swiss section's success in integrating VAW into its overall work can be summarized as follows. First, the Swiss section successfully merged the section's priorities on the issues of VAW with the international campaign strategy. The section adopted the thematic focus of the general campaign and emphasized domestic violence as a national human rights concern for the first time. At the same time, the section conducted an internal campaign to sensitize its members and staff to gender equality. Second, the section professionalized its work on VAW in the long term by creating the position of a campaign coordinator within the secretariat and ensuring its funding beyond the SVAW campaign. Third, the section's leadership seems to have committed to the SVAW campaign. Fourth, the Swiss section's women's network continued to influence the section's work on VAW, even in the frame of the SVAW campaign being implemented from the top down. Fifth, while officials harbored certain skepticism towards the campaign, the SVAW campaign did not generally provoke Swiss activists' and officials' resistance. Further, opposition against the adoption of an abortion policy was isolated at the Swiss section.

296 Ganzfried: Interview with A.J., 09.03.2012: "On a eu droit à des résistances même au niveau de la section suisse d'Al. On avait des gens qui était des communautées réligieuses très engagées depuis des années qui ont quitté Al parce qu'ils n'arrivaient plus à se retrouver dans [cette nouvelle agenda].".

297 Ganzfried: Interview with B.K., 16.05.2013: "Nein, zu diesen reproduktiven Rechten nicht Widerstand aber so im Sinn von "ch möchte mich lieber nicht zu dem engagieren". 


\subsubsection{The German section}

The present chapter shows how the German section implemented the SVAW campaign and demonstrates that the section did not succeed in integrating issues of VAW into the section's overall work through the SVAW campaign. First, the chapter focuses on the thematic content of the German section's SVAW campaign named Look \& Act: Preventing violence against women. ${ }^{298}$ It shows that this campaign strongly emphasized AI's traditional women's rights issues, such as female human rights defenders and FGM, and did not address the general campaign's central concern - "domestic violence" as a national human rights issue. Then I demonstrate that the MaF played a pivotal role in the implementation of the Look $\mathcal{E}$ Act: Preventing Violence against Women campaign, and it no longer tried to influence decision-making at the national or the international level. Meanwhile, the personnel resources allocated to the work on VAW at the secretariat continued to be relatively low. Finally, I emphasize the membership's particularly critical stance towards the campaign, and highlights the existence of important resistance to it and significant opposition to the adoption of a policy on abortion.

\subsubsection{Look \& Act: Preventing Violence against Women}

Diverging from the overall campaign, the German section labeled the SVAW campaign Look \& Act: Preventing Violence against Women. The German section organized an internal and a public campaign, implementing the SVAW campaign as a priority campaign between 2004 and 2005 . Evidence shows that the German section did not implement the second campaign strategy. Instead, issues of VAW were discussed as "one of the main AI issues in the 'regular' country and thematic work," country groups continued with campaign activities after $2005 .{ }^{300}$ Based on the internal gender audit carried out in 2002 , the section formulated an internal campaign objective meant to "ancho[r] equal opportunities at all levels

\footnotetext{
298 Hinsehen \& Handeln: Gewalt gegen Frauen verhindern.

299 Amnesty International Sektion Bundesrepublik Deutschland: Ausformulierte Auswertung SVAW - Campaign, no date, p.1.

300 When talking about the contents and the activities of the campaign, I thus mainly concentrate on the period between 2004 and 2006. I was not able to access archival material on the groups' activities, as these documents are overwhelmingly kept by the different groups themselves.
} 
of AI." ${ }^{301}$ According to a former member of the EC, the internal campaign was implemented mainly before the public campaign. The women's group organized workshops about the SVAW campaign and specifically on the issue of sexual and reproductive rights as part of the former. ${ }^{302}$

The German section's public campaign focused on "VAW in armed conflicts" and "domestic violence," yet placed special emphasis on traditional human rights issues, such as "the support of women human rights defenders," and primarily addressed family violence if it occurred in other countries. ${ }^{303}$ A member of the MaF emphasized the importance of focusing on women human rights defenders at the German section: "How difficult it may be for women, there are always [...] courageous women who are engaging against violations of human rights in their country [...] and to support them, that is of big importance to AI [...]." 304 The section mainly focused on cases of VAW in other countries, such as murders of women in Ciudad Juarez, Mexico, women trafficking and forced prostitution in Kosovo, family violence in Turkey or the consequence of local tribe courts in Pakistan. ${ }^{305}$ Thus, even in the frame of the SVAW campaign, the German section continued to emphasize issues of VAW, which had already been the focus of the organization in the 1990s.

This traditional focus was also reflected in groups' activities. As written in the ai intern, the journal for the German section's members, several groups organized expositions in 2005 . The latter aimed at "giving visitors an understanding of the reality of fleeing, scared, abused and disfigured women from almost all continents and [pointed] to the urgency of the omnipresent violence especially against women." ${ }^{306}$ An interviewee explained the continuing

301 Amnesty International Sektion Bundesrepublik Deutschland: Zwischenbilanz der Kampagne "HINSEHEN \& HANDELN: Cewalt gegen Frauen verhindern", 02.11.2005, p.1: "Cleichberechtigung auf allen Ebenen innerhalb von amnesty verankern.".

302 Ganzfried: Interview by Skype with A.C., 26.04.2015.

303 Amnesty International Sektion Bundesrepublik Deutschland: Zwischenbilanz der Kampagne "HINSEHEN \& HANDELN: Cewalt gegen Frauen verhindern", 02.11.2005.

304 Ganzfried: Interview by phone with A.Y., 09.01.2015: "wie schlimmes auch immer für Frauen stehen möge, es gibt immer [...] mutige Frauen, und beherzte Frauen, die sich einsetzen gegen die Menschrechtsverletzungen in ihrem Land [...] und die zu unterstützen, das ist ein grosses Anliegen von Al [...].".

305 Amnesty International Sektion Bundesrepublik Deutschland: Zwischenbilanz der Kampagne "HINSEHEN \& HANDELN: Cewalt gegen Frauen verhindern", 02.11.2005.

306 Amnesty International Sektion Bundesrepublik Deutschland: ai intern Rundbrief für Mitglieder der deutschen Sektion von amnesty international, September 2006, p.10: "Besuchern die Realität von fliehenden, verängstigten, misshandelten und entstellten Frauen von 
importance that the traditional approach to VAW held for the German section: "The closer it comes to our country, the more difficult it becomes. [The German section] did not actually work on Germany."307

As far as concrete activities were concerned, except for the MaF, local and country groups participated in the campaign and often organized their VAW actions on the occasion of the international women's day or the " 16 days against VAW."308 After 2005, women's rights continued to be mainly thematized within the frame of the section's work on refugee and asylum issues. For example, the section lobbied government institutions to grant refugee status to women facing FGM in their home lands and participated in a campaign against forced prostitution in Germany. It also called attention to the problem of sexual abuse and exploitation of au-pair girls and women. ${ }^{309}$

In contrast, AI members expressed their support for engaging against other forms of violence against women, particularly female genital mutilation. The minutes of the meetings of various general assemblies show that $\mathrm{AI}$ members repeatedly called upon the section to increase its work on FGM. In 2007, the GA called on the EC to examine how to strengthen the work on FGM in consultation with the IS. ${ }^{310}$ In 2008 , the GA asked the EC to demand that AI increase its work on FGM. ${ }^{311}$ The section's participation in a national network on FGM a year later testifies to the importance of this specific women's rights issue for the German section. ${ }^{312}$ An interviewee explained the emphasis on FGM as follows: "[FGM] is a cruel human rights violations that happens

fast allen Erdteilen näher zu bringen und auf die Dringlichkeit der allgegenwärtigen Cewalt besonders gegen Frauen hinzuweisen.".

307 Ganzfried: Interview with A.C., 14.04.2015: "Also je näher es unserem Land / unserer Gesellschaft kommt, desto schwieriger wird es auch. Also zu Deutschland [hat die Deutsche Section] eigentlich nicht gearbeitet."

308 Amnesty International Sektion Bundesrepublik Deutschland: Grobe Auswertung des Fragebogens zu der Kampagne Hinsehen \& Handeln, ca. 2006.

309 Amnesty International, International Secretariat: Feedback and updates from sections and structures on their SVAW related work carried out at national level, July 2008, p.4-5.

310 Amnesty International Sektion Bundesrepublik Deutschland: Beschlüsse der 42. Jahresversammlung 2007 in München, 2007.

311 Amnesty International Sektion Bundesrepublik Deutschland: Beschlüsse der 43. Jahresversammlung 2008 in Hamburg, 2008.

312 Amnesty International Sektion Bundesrepublik Deutschland: Amnesty Intern Zeitschrift für Mitglieder von Amnesty International, March 2009. 
far away." 313 The interviewee continued stating: "In fact, it would have certainly been most comfortable for AI if the issue of women's rights had been reduced to FGM. Because this is ok. The German section has always been engaged in this issue and this has always been important for them. But beyond, it is clearly more difficult." 314

The previous paragraph has shown that even within the frame of the SVAW campaign, the German section continued to mainly emphasize AI's traditional issues of VAW, such as women human rights defenders, FGM, and cases of VAW in other countries. Yet, it only marginally addressed the problem of domestic violence in Germany.

\subsubsection{The MaF - a group of voluntary experts}

As chapter 7.2.2 explained, the women's rights group MaF pushed the section's work on women's rights throughout the 1990s and was also responsible for many of the strides that were made in this issue area. In the same decade, without having specific terms of reference, the official responsible for refugee and asylum issues integrated VAW into her daily work. Thus, no staff member was uniquely responsible for women's rights issues when the organization decided to center its first global thematic campaign on VAW. The present section demonstrates that this distribution of roles with respect to the work on VAW barely changed with the preparation and the implementation of the SVAW campaign. ${ }^{315}$ After the dissolution of the first MaF at the end of the 1990s, a new women's rights group, which was also called MaF, was founded at the beginning of the 2000s. While this group continued carrying out the majority of the work on women's rights issues, the human resources allocated to work on VAW, and specifically to the implementation of the SVAW campaign, at the secretariat continued to be limited.

313 Canzfried: Interview with B.T., 15.04.2015: "Das ist eine grausame Menschenrechtsverletzung und weit weg."

314 Ganzfried: Interview with B.T., 15.04.2015: "Also für Amnesty Deutschland wäre es sicherlich am angenehmsten gewesen, wenn das Thema Frauenrechte aufdas Thema Cenitalverstümmlung reduziert worden wäre. Weil das ist völlig d'accord, ja? Also da hat die deutsche Sektion sich immer dafür stark gemacht und das war ihnen auch immer wichtig, aber darüber hinaus ist es deutlich schwieriger.".

315 In contrast to the Swiss section, for which I found abundant archival material, archival documents on the existing organizational structures responsible for the work on VAW at the German section were scarce. The following findings are thus mainly based on interview testimonies. 
Evidence shows that the SVAW campaign was prepared by a steering group, composed of "relevant Section staff and one member of the women's group," 316 and implemented by the MaF and two staff members. In fact, just like in the 1990s, the MaF shared the thematic responsibility for the campaign with an official who was based in the Countries and Asylum department. ${ }^{317}$ The latter was only able to spend 3 and, later, 9 hours per week on VAW issues. $^{318}$ Additionally, a campaigner who was already working on other campaigns assumed the coordination and the communication of SVAW. ${ }^{319}$ However, this campaigner was only available during the initiative's first two years. From 2006 onward, the MaF and some country groups were the only ones who continued the campaign activities. ${ }^{320}$

The MaF's continued importance for the section's work on VAW also becomes evident when we consider the section's contact with the media on the SVAW campaign. An interviewee explained: "if [the media requests] concerned women's issues, then they were usually passed on to [the MaF], [...], the [expert on women's rights at the secretariat] did not give any interviews." ${ }^{321}$ It is thus not surprising that officials considered the members of the MaF "voluntary experts," ${ }^{322}$ rather than simple activists. As the following statement reveals, MaF members viewed their group as pivotal for the section's work on VAW during the SVAW campaign as well: "well, one may say that my group

316 Stop VAW campaign team: STOP VAW Campaign Progress update 4, 12.2003, p.2.

317 Afrika Referentin in der Abteilung Länder und Asyl. Amnesty International Sektion Bundesrepublik Deutschland: ai intern Rundbrieffür Mitglieder der deutschen Sektion von amnesty international, April 2007.

318 Ganzfried: Interview by phone with A.Y., 09.01.2015; Ganzfried: Interview with B.T., 15.04.2015.

319 The campaigner explained her job as follows: "Well we [were] also doing centralized measures, promotion, events or so [...]. Our jobs actually [consisted] in enabling the members to do effective local campaigning, providing them with good material, good arguments, Q\&A's, all this kind of stuff, you know. Because we only have a limited range." Or, as explained by a women's group member, the officials "produced the material; material means leaflets, postcards, flyers, buttons, eventually and posters and so on, [...].".

320 Ganzfried: Interview by phone with A.Y., 09.01.2015: "Ab 2006 haben wir es dann allein gemacht mit den entsprechenden Länder-Ko-Gruppen und da haben wir noch ganz viel gemacht und manche Länder-Ko-Gruppen haben auch das allein gemacht [...].".

321 Ganzfried: Interview by phone with A.Y., 09.01.2015: "Wenn es Frauenthemen sind, werden die meisten an uns weitergeleitet, also so gut wie immer. Also [die Expertin im Sekretariat] hat überhaupt keine Interviews gegeben." Ganzfried: Interview with B.T., 15.04.2015. 
was an important push factor for the whole women's work. [...] If we had not been here, I do not know, [...]. We are quite essential to the section's work on the issue of women. That is a fact." ${ }^{23}$ The MaF thus continued to play a pivotal role in the section's work on VAW throughout the 2000 , also because the overall organization of the German section meant that the thematic groups remained important for the section's thematic work.

However, in contrast to the 1990s, when the MaF pushed the organization to increase its work on VAW and women's rights both internally and at the international level, the German women's group no longer remained a relevant internal actor in the 2000 s. For example, the MaF did not try to influence decision-making at the national or the international level any more. This distinguishes the MaF from its Swiss counterpart, which successfully pushed for professionalizing the work on VAW by submitting its demand to the GA (the demand was accepted). Thus, it is worth assuming that the female activists and officials who pushed the work on VAW in the 1990s lost their influence in defining the section's work on VAW in the 2000s.

At the same time, evidence also shows the ED's commitment to women's rights issues in general and to the SVAW campaign in particular. Several interviewees referred to Barbara Lochbihler as particularly committed to and very progressive towards women's rights. ${ }^{324}$ One interviewee explained that the section's participation in the SVAW campaign and especially the favorable allocation of resources at the secretariat happened thanks to Barbara Lochbihler, who considered AI's engagement against VAW a part of the larger

323 Ganzfried: Interview by phone with A.Y., 09.01.2015: "Also man kann schon sagen, dass meine Gruppe ein wesentlicher Push-faktor ist für die ganze Frauenarbeit. [...] wenn wir nicht da wären, wüsste ich nicht, [...]. Wir sind schon sehr wesentlich für die Arbeit zum Thema Frauen der Sektion, das ist klar.".

324 Ganzfried: Interview by phone with A.Y., 09.01.2015; Ganzfried: Interview with A.C., 14.04.2015; Ganzfried: Interview with B.T., 15.04.2015; Ganzfried: Interview by phone with A.Q., 27.02.2015. 
work on human rights. ${ }^{325}$ In contrast, as I demonstrate later, the EC was less convinced by the SVAW campaign.

\subsubsection{Highly controversial issues - domestic violence and abortion}

By focusing on the participation in and the reactions to the SVAW campaign and on the internal discussions surrounding the elaboration of AI's abortion policy, the present section sheds light on the important and widespread opposition to the work on issues of VAW at the German section. In contrast to what we observed at the international level, where the opposition to the SVAW campaign was motivated by a general criticism of the adoption of the mission or where resistance related to the structure and the setting of the campaign, the German section mainly resisted the campaign's content. However, this does not mean that the section did not oppose the campaign for other reasons, as well.

My findings do not allow me to discuss how many of the local AI groups effectively participated in Look \&Act: Preventing Violence against Women. Nevertheless, evidence shows that approximately two thirds of the German AI groups signed up for the campaign, ${ }^{326}$ although only a few local groups continued to take part in campaign activities during the second phase. A September 2005 evaluation of the campaign reveals that "experienced group spoke persons report[ed] back that it [would] be extremely difficult to motivate members for the campaign any longer." 327 At the same time, the German section's membership had to be convinced to work on issues of VAW as portrayed in the SVAW campaign. An interviewee explains that members argued that women's

325 Ganzfried: Interview with B.T., 15.04.2015: "Unsere damalige Ceneralsekretärin Barbara Lochbihler, [...] der war das Thema eben auch sehr wichtig. [...] Insofern hat das natürlich [...] schon auch immer dazu geführt, dass sich die Sektion da jetzt auch nicht so völlig [...] da raushalten konnten zum Thema. [...] ich denke das [...] dass Barbara damals das als wichtigen Aspekt der Menschenrechtsarbeit eben auch gesehen hat, das [...] hat eben auch dazu beigetragen, [...] dass hauptamtlich zumindest irgendwie immer mal ein paar Ressourcen dafür zur Verfügung gestellt wurden, ja so und dass das nicht nur rein ehrenamtlich wirklich bearbeitet wird.".

326 Amnesty International Sektion Bundesrepublik Deutschland: Protokoll der 40. Jahresversammlung 2005 in Leipzig, 2005, p.1: "Innerhalb der deutschen Sektion haben sich erfreulicherweise über 400 Gruppen für die Kampagne angemeldet.".

327 "Erfahrene GruppensprecherInnen melden zurück, dass es enorm schwierig wird, Mitglieder weiterhin für die Kampagne zu motivieren." Hartmetz: Hinsehen \& Handeln: Gewalt gegen Frauen verhindern, 02.09.2005, p.1. 
(rights) organizations were better placed to defend the rights of women and that "AI should better engage for the individual political prisoner." ${ }^{328}$ According to an official, for AI members "issues such as women's rights still feel somehow strange"329 and "had to actually find acceptance first." 330 The following statement further reveals that parts of the section did not take the issue of VAW and the work of the MaF seriously. In fact, an interviewee at one of the GAs reported that "[the women activists] had been portrayed as the lilac dungarees who somehow wanted AI to change and would likely make it disappear." 331

Moreover, some of the opposition to the SVAW campaign was radical. In fact, compared to the Swiss section, where opposition essentially came from one particular group, deep-seated resistance was prevalent among part of the membership of the German section. As the following excerpt from a letter from a member indicates, the opposition was based on the members' belief that domestic violence is not an issue of human rights: "[women victims of domestic violence] do not need the protection of a human rights organization, insofar as it is actually about private conflicts between free and adult human beings in a liberal, open society. Here AI is absolutely out of place [...]." ${ }^{332}$ Numerous protest letters reveal the members' harsh criticism of the SVAW campaign, accusing it of being partial, discriminatory or even racist towards men. The authors of these letters complained that the SVAW campaign discriminated against men and violated the universality of human rights. ${ }^{333}$ According to the writers, the campaign was ideologically biased and "an in-

328 Ganzfried: Interview with B.T., 15.04.2015: "Amnesty soll sich dann halt lieber für den einzelnen politischen Gefangenen einsetzen,".

329 Ganzfried: Interview with B.T., 15.04.2015: "so Themen wie Frauenrechte ist irgendwie, ja, es ist ihnen irgendwie immer noch fremd.".

330 Ganzfried: Interview by phone with A.Y., 09.01.2015: "das Thema Frauen überhaupt erst mal Akzeptanz finden müssen.".

331 Ganzfried:Interview by phone with A.Q., 27.02.2015: "wirirgendwie ein bisschen so als die, als die lila Latzhosen hingestellt worden sind, die jetzt irgendwie Amnesty so verändern wollen, dass es die Organisation wahrscheinlich bald nicht mehr gibt.".

332 C.: Protest letter to the German Al section, 14.04.2004, p.2: "[Frauen, Opfer von häuslicher Gewalt] benötigen aber nicht den Schutz einer Menschenrechtsorganisation, soweit es sich nämlich um private Konflikte von freien, erwachsenen Menschen in einer liberalen, offenen Cesellschaft handelt. Hier ist Al absolut Fehl am Platz [...]".

333 C.: Protest letter to the Cerman Al section, 26.05.2006; C.: Protest letter to the Cerman section, 19.04.2004; C.: Protest letter to the German Al section, 06.06.2004. 
strument of the gender war raging in Germany."334 Another author saw AI adopting "a feminist gender racism"335 and called upon the organization not to let itself be abused by the "ongoing feminist 'differentiating campaign."336

In their letters, the members often questioned the gendered prevalence of domestic violence asserting that in contrast to what the campaign communicated, domestic violence concerned men as much as women, if not more. ${ }^{337}$ In an open protest letter, the authors warned AI of a potential loss of members as a result of the "ideologically motivated" 338 campaign, which discriminated against men. The author polemically asked: "Are children and men less worthy of protection from violence?" 339 As the following statement reveals, some opponents must have also resigned from the organization as a consequence of the SVAW campaign: "You will understand, that I do not want to support an organization that criminalizes me because of my sex." 340

In addition to the members' criticism of the work on VAW, my findings also indicate that parts of the section's leadership were skeptical of the SVAW campaign. In fact, a former EC member explained: "We had resistance to, for example, the gender audit in the EC itself. I did not think it was good then, [...] especially because there were many women in the EC at that time." ${ }^{341}$ Pointing

334 C.: Protest letter to the German Al section, 29.03.2004, p.1; C.: Protest letter to the German AI section, 26.05.2006; Gemeinnütziger Bundesverein: Open protest letter to the German AI section, 06.05.2004; C.: Protest letter to the German section, 19.04.2004; C.: Protest letter to the German Al section, 14.04.2004.

335 C.S.: Protest letter to the German Al section, 15.03.2004, p.1: "feministischer Ceschlechterrassismus".

336 C.S.: Protest letter to the German Al section, 15.03.2004, p.1: "laufenden, feministischen 'Differenzierungskampagne".

337 C.S.: Protest letter to the German Al section, 29.03.2004; C.: Protest Letter to the German Al section, 11.05.2004; C.: Protest letter to the German Al section, 17.05.2004; C.S.: Protest letter to the German Al section, 15.03.2004.

338 Gemeinnütziger Bundesverein: Open protest letter to the German Al section, 06.05.2004, p.2: "ideologisch motiviert".

339 Gemeinnütziger Bundesverein: Open protest letter to the German Al section, 06.05.2004, p.3: "Sind Kinder und Männer es weniger wert, vor Gewalt geschützt zu werden?".

340 C.: Protest letter to the German Al section, 17.05.2004, p.2: "Sie werden verstehen, dass ich keine Organisation unterstützen möchte, die mich aufgrund meines Geschlechts kriminalisiert.".

341 Ganzfried: Interview by Skype with A.G., 26.04.2015: "Wir haben im Vorstand selber zum Beispiel den gender audit auch Widerstand gehabt, fand ich damals nicht so gut, [...] zumal in unserem Vorstand damals ziemlich viel Frauen waren. Wo ist denn das Problem?". 
to the appropriate representation of women in different positions all over the section, the interviewee stated: "insofar, the necessity [of conducting a gender audit] was not really seen." 342

Thus, generally speaking, the German section's membership was rather critical of the SVAW campaign and parts of the membership, mainly men, clearly opposed the campaign. Furthermore, there also was criticism of and resistance to the campaign from within the EC.

As mentioned in section 8.1.4, the German section was one of the few sections that firmly opposed the adoption of a policy on abortion and advocated for the status quo of a neutral position at the 2005 and the 2007 ICMs. Given that a section's official position at the ICM is generally preceded by a decision of the section's GA and that members ultimately exercise their decisionmaking power via their vote at the annual GAs, we can assume that the German section's position at the ICM reflected the opinion of a majority of the German AI members.

As the following paragraph reveals, the decisions of the German section's GAs on the adoption of the abortion policy reflects the restrictive opinion of the majority of the membership. It also demonstrates the importance that the section attached to maintaining a neutral position on abortion. In fact, at the 2006 GA, the members called "the Executive Committee, the ICM delegation, and the delegates of the German section to the Chairs Forum in June 2006 to pledge for the preservation of neutrality with regards to the right to abortion at all levels of the international organization." 343 A year later, at the 2007 GA, the members agreed on the contents of the section's resolution to the ICM ${ }^{344}$ and called the EC to anticipate the modification of the neutral position on abortion. The members called on the EC "to communicate as soon as possible the expectation of the members who do not share the new position," 345 and to express its opinion, "if AI members can not only have their own personal

342 Ganzfried: Interview by Skype with A.G., 26.04.2015: "insofern war die Notwendigkeit nicht so ganz gesehen worden.".

343 Amnesty International Sektion Bundesrepublik Deutschland: Beschlüsse der 41. Jahresversammlung 2006 in Berlin, 2006: "die ICM-Delegation und die Delegierten der Deutschen Sektion für das Chairs Forum im Juni 2006 auf, sich in allen Ebenen der internationalen Organisation für die Wahrung der Neutralität zur Frage des Rechts auf Abtreibung einzusetzen.".

344 Resolution HRS D.

345 Amnesty International Sektion Bundesrepublik Deutschland: Beschlüsse der 42. Jahresversammlung 2007 in München, 2007, p.6: "baldmöglichst eine Aussage darüber zu tr- 
opinion, but if they may express and declare it or if this will be considered as an attitude damaging for the association." ${ }^{346}$

After the adoption of the policy on selected aspects of abortion, the German section critically observed the rigorous application of the policy and its potential future modification. In fact, the $2008 \mathrm{GA}$ called on the EC and all other thematic bodies of the German section to "defend a restrictive position on abortion [...]. Further, the EC should, if need be, actively involve itself and specifically pledge for the respect of the highest possible transparency and democratic processes in case of any modification of the actual position." ${ }^{347}$ As explained by one of my interviewees, after the adoption of the AI policy on selected aspects of abortion, members continued to monitor the implementation of the policy as well as any potential future modifications: "quite a few members of our section pay attention very thoroughly that all petitions and announcements" ${ }^{348}$ respect the decision agreed upon at the 2007 ICM.

Similar to the international level, the members and staff at the German section subjected Al's abortion policy to substantial discussions. As the following testimony shows, the policy continued to be a subject of controversy until recently. An activist explained: "There is a really delicate issue in our section. [Abortion] is still triggering very, very huge resistance, even today."349 Referring to the discussion in the 2000s, an activist stated that some of her

effen und intern zu kommunizieren, wie die Erwartung an Mitglieder ist, die die neue Position nicht teilen.".

346 Amnesty International Sektion Bundesrepublik Deutschland: Beschlüsse der 42. Jahresversammlung 2007 in München, 2007, p.6: "Insbesondere wird er sich dazu äußern, ob ai-Mitglieder nicht nur ihre eigene abweichende persönliche Meinung haben können, sondern sie auch in ai-Zusammenhängen benennen und bekennen dürfen oder ob dies als vereinsschädliches Verhalten gewertet wird.".

347 Amnesty International Sektion Bundesrepublik Deutschland: Beschlüsse der 43. Jahresversammlung 2008 in Hamburg, 2008, p.4: "sich für eine restriktive, nur auf schwere Menschenrechtsverletzungen bezogene, und menschenrechtskonforme Position zum Schwangerschaftsabbruch, einzusetzen, sich gegebenenfalls aktiv einzubringen, und insbesondere aufdie Beachtung größtmöglicher Transparenz und demokratischer Prozesse bei jeglicher Änderung der derzeitigen Position zu drängen.."

348 Canzfried: Interview by phone with A.Y., 09.01.2015: "Es gibt in unserer Sektion etliche, also Mitglieder die das GANZ streng daraufachten, dass äh bei allen Verlautbarungen und Petitionen und was, das nicht anders rüberkommt.".

349 Ganzfried: Interview by phone with A.Y., 09.01.2015: "Es gibt ein ganz heikles Thema bei uns auch in der Sektion. Aus unserer Sektion gab es halt sehr sehr grosse Widerstände auch heute noch [dem Theam abortion gegenüber].". 
colleagues refused to work on the issue of abortion. According to her, the internal resistance was harsh and opponents predicted a "horror vision" 350 of a section that would fall apart if the organization decided to take a position on abortion.

The extent of the opposition becomes visible in an internal non-representative survey of German section activists, realized in 2006. The study showed that almost $74 \%$ of the activists either partially or entirely opposed an AI engagement on the issue of abortion. ${ }^{351}$ Numerous letters to the editors of the membership magazine ai intern ${ }^{352}$ show the vivacity and the content of the controversy. An activist explained his resistance thus: "I can already hardly bear that AI is engaging with a lot of energy against the Death Penalty and remaining silent on the issue of abortion. If AI ought to engage for the right to abortion.... I want to work for human rights and not against them!!!"353 Another AI member published his support for the adoption of an abortion policy by expressing his incomprehension of denying health services to women suffering from complications after an abortion stating: "all, dangerous criminals as well - the comparison is already hardly acceptable in my point of view have the right to access to medical treatment, if needed. A human rights organization should take this for granted." 354 Thus, abortion was and continued to be a highly controversial issue for the German AI section until recently. Resistance to AI adopting a position on abortion was widespread and very strong.

Consequently, the German section's success in integrating VAW into its work can be summarized as follows. First, in contrast to the overall cam-

350 Ganzfried: Interview by phone with A.Y., 09.01.2015: "Eine Horrorvision".

351 Amnesty International Sektion Bundesrepublik Deutschland: ai intern Rundbrief für Mitglieder der deutschen Sektion von amnesty international, June 2006, p.1.

352 Published between June 2006 and November 2007.

353 Amnesty International Sektion Bundesrepublik Deutschland: ai intern Rundbrief für Mitglieder der deutschen Sektion von amnesty international, June 2006, p.7: "Es ist für mich schon jetzt sehr schwer zu ertragen, dass sich Al mit viel Energie für die Abschaffung der Todesstrafe einsetzt, aber beim Thema Abtreibung schweigt. Falls sich Al für ein Recht auf Abtreibung einsetzen sollte, .... Ich möchte für die Menschenrechte arbeiten, und nicht dagegen!!!".

354 Amnesty International Sektion Bundesrepublik Deutschland: ai intern Rundbrief für Mitglieder der deutschen Sektion von amnesty international, September 2006, p.12: "Alle, auch Schwerverbrecher - der Vergleich ist hier meiner Auffassung nach bereits kaum akzeptabel - haben das Recht auf eine medizinische Versorgung, falls dies erforderlich ist. Für eine Menschenrechtsorganisation sollte dies selbstverständlich sein.". 
paign and to the Swiss section, the German section's Look $\&$ Act: Preventing Violence against Women essentially focused on AI's traditional women's rights issues, such as women human rights defenders and FGM. It did not address the campaign's central concern, namely "domestic violence" as a national human rights issue. Second, the German section's internal structures working on issues of VAW remained largely the same as in the 1990s. The human resources allocated to the work on women's rights at the secretariat never exceeded nine working hours a week, just like in the 1990s. Thus, in contrast to the Swiss section, there was no professionalization of the section's work on VAW. Third, we lack information on the German section's leadership's commitment to the SVAW campaign. Fourth, the data indicate that the influence of the MaF on the section's work on VAW in the 2000 s was less important than it had been in the previous decade. In fact, while the MaF continued to operate as the section's expert group on all issues related to VAW, it no longer tried to influence decision-making on the matter at the national or international level. Furthermore, the 1990s saw MaF disappeared and a new women's rights group, also called MaF, was founded at the beginning of the 2000 s. Fifth, there was strong and widespread resistance to the SVAW campaign even among the EC members. It was primarily related to the content of the campaign and not to its flagship role or its structure. At the same time, there was important opposition to the adoption of a policy on abortion from the membership.

\subsubsection{Comparison between the Swiss and the German Al sections}

Let me briefly recapitulate the findings from the two case studies on the basis of the five criteria measuring a section's success in integrating VAW into its work.

Figure 15 provides a comparison of the success of the Swiss and the German sections in integrating VAW into their work in the 2000 s on the basis of five criteria. Besides the leadership's commitment to the SVAW campaign (criteria 3), information for which is missing in the German case, the other criteria indicate that the Swiss section was more successful in integrating VAW into its work. In contrast to the German section, which continued to focus primarily on Al's traditional women's rights issues and did not address "domestic violence," the Swiss section adopted the thematic focus of the overall campaign and did emphasize "domestic violence" as a national human rights concern. Third, the Swiss section professionalized its work on VAW over the 
Figure 15: Comparison between the Swiss and the German AI sections of their success in integrating VAW into their section's work

\begin{tabular}{|c|c|c|}
\hline $\begin{array}{l}\text { Criteria success of integrating VAW } \\
\text { into the section's work }\end{array}$ & Swiss AI section & German AI section \\
\hline Adoption of the overall campaign (1) & $\begin{array}{l}\text { Adopted the thematic focus of the } \\
\text { general campaign and emphasized } \\
\text { "domestic violence" as a national } \\
\text { human rights concern for the first } \\
\text { time. }\end{array}$ & $\begin{array}{l}\text { Essentially focused on } \mathrm{Al}^{\prime} \mathrm{s} \\
\text { traditional women's rights issues } \\
\text { and did not address "domestic } \\
\text { violence" as a national human rights } \\
\text { issue. }\end{array}$ \\
\hline $\begin{array}{l}\text { Professionalization of the work } \\
\text { on issues of VAW (2) }\end{array}$ & $\begin{array}{l}\text { Created the position of campaign } \\
\text { coordinator; ensured its funding } \\
\text { beyond the SVAW campaign. }\end{array}$ & $\begin{array}{l}\text { No professionalization of the } \\
\text { section's work on VAW. }\end{array}$ \\
\hline $\begin{array}{l}\text { Commitment of the leadership } \\
\text { to the SVAW campaign ( } 3 \text { ) }\end{array}$ & $\begin{array}{l}\text { The section's leadership was } \\
\text { committed to the SVAW campaign. }\end{array}$ & - \\
\hline $\begin{array}{l}\text { Influence of the section's women's } \\
\text { network or group } \\
\text { (changes vis-a-vis the 1990s) (4) }\end{array}$ & $\begin{array}{l}\text { The women's network continued to } \\
\text { influence the section's work on } \\
\text { VAW in the frame of the SVAW } \\
\text { campaign implemented top-down. }\end{array}$ & Less important \\
\hline $\begin{array}{l}\text { Resistance to the SVAW campaign and } \\
\text { the adoption of the abortion policy (5) }\end{array}$ & $\begin{array}{l}\text { Certain skepticism towards the } \\
\text { campaign among officials, but the } \\
\text { SVAW campaign did not meet with } \\
\text { activists' and officials' resistance } \\
\text { against the SVAW campaign. } \\
\text { Opposition against the adoption of } \\
\text { an abortion policy was isolated. }\end{array}$ & $\begin{array}{l}\text { Important opposition against the } \\
\text { adoption of a policy on abortion. }\end{array}$ \\
\hline
\end{tabular}

Source: My own

course of the SVAW campaign. In contrast, just like in the 1990s, the personnel resources allocated to the thematic work on women's rights at the German secretariat never exceeded nine working hours per week. Fourth, while the Swiss section's women's network successfully pushed for further professionalizing its work on VAW through a sustainable approach to work on women's rights, the MaF was important for the implementation of the campaign but no longer tried to influence decision-making at the national or at the international level. Fifth, in contrast to the Swiss section, the German section witnessed strong and widespread resistance to the campaign Look \& Act: Preventing Violence against Women and harsh opposition to the adoption of a policy on abortion. These differences demonstrate that the Swiss section was more successful than the German section in integrating the issue of VAW into its work.

In order to account for this difference, it is worth looking at the central dissimilarities between the sections. Chapter 6.3.2 highlighted substantial differences in four domains: the power structure between the secretariat (professional structure) and the groups (activists). The latter have a relatively pow- 
erful position in the German section due to their role in the thematic work and their ability to participate in the decision-making both at the national and at the local level. In contrast, the Swiss professional structure seems to be more powerful than its membership, as thematic work is centralized and professionalized at the Secretariat. This particularity can serve as an explanation as to why the Swiss section professionalized its work on issues of VAW over the course of the SVAW campaign, while the German section continued to allocate only limited human resources to the work on women's rights. This conclusion also suggests that the "professionalization of the work on issues of VAW" criterion is not that useful when assessing a section's success in integrating VAW into its work. On the other hand, the relatively powerful position of the German section's membership may be one explanation for the resistance to the SVAW campaign and to the adoption of an abortion policy at the German section. It is worth assuming that German activists' comparatively huge opportunities to participate in the section's decision-making processes gave the policy opponents significantly more weight. Nevertheless, more member power does not necessarily translate into more resistance to these kinds of activities or policies. Instead, the reason for the resistance must be sought in the members' attitudes. The lack of data prevents us from knowing or measuring members' attitudes. However, there is some evidence that the German section's members are comparatively more conservative and traditionally closer to the Church. Further, in Germany, the Protestant Church (Evangelische Kirche in Deutschland) and the Catholic Church have had a long tradition of collaborating in the promotion of a common position on sexual and reproductive rights and abortion. Despite harboring differing views on abortion law, they have stood together for protecting life. ${ }^{355}$ Consequently, it is worth assuming that the German section's closeness to the Church explains its comparatively huge opposition to the campaign and its failure in integrating issues of VAW into its overall work. At the same time, the differences between the Swiss and the German sections might also come down to the fact that the share of women in the Swiss EC was higher than in the German EC over the whole period. While it is impossible to demonstrate a clear correlation, given the previous research on the relationship between the absence of women in leadership positions within organizations and the gender bias in the mainstreaming understanding of human rights, it is worth assuming that a link did exist. 
Sixth, it is also possible that the difference between the Swiss and the German sections had to do with the relationship between the section and the headquarters. In fact, the data indicate that the Swiss section was open to mandate changes and a rather assimilated member of the overall AI network. This is in contrast to its neighbor, which has been described as rather critical to mandate changes and whose relationship with the IS has been characterized as periodically conflictual. Thus, the Germans' refusal to address "domestic violence" as a national human rights issues, while continuing to work on traditional women's rights issues, such as female human rights defenders and FGM, under the SVAW campaign, can be interpreted more as a sign of a generally critical stance to propositions coming from the headquarters than as a sign of refusal to work on issues of women's rights.

Ultimately, it is difficult to definitively conclude why the Swiss section was more successful than the German section in integrating issues of VAW into its work through the SVAW campaign. A definite answer certainly needs a database of interviews with a greater number of activists and officials. Furthermore, taking the respective national political and legislative contexts into account would provide a deeper - and better - understanding of this difference. In the Swiss case, the successful process of designing and passing a law that made domestic violence a crime persecuted ex officio ${ }^{356}$ in the Swiss Parliament between 1996 and 2003 - which also contributed to sensitizing the Swiss public in general - certainly could have helped the campaign to unlaesh. However, a similar legislative process took place in Germany during the same period. In fact, the Federal Government adopted the first Action Plan to combat violence against women in 1999. The Protection against Violence Act (Gewaltschutzgesetz) was an essential component of this plan and came into effect in 2002, bringing the issue of domestic violence out of its niche and making it claim its place in the legal-political and juridical discussion. ${ }^{357}$ Thus, a legislation process that mirrored the international debate on the recognition of VAW as a violation of human rights, and which could be used to explain the difference between the two sections, took place in both countries. Nevertheless, the present study does not define if and how these

356 Frauen Macht Geschichte. Frauenpolitik und Gleichstellung in der Schweiz 2001-2017. Bern 2017. Herausgeberin: Eidgenössische Kommission für Frauenfragen EKF.

357 Berliner Initiative gegen Cewalt an Frauen BIC e.V. 10 Jahre Cewaltschutzgesetz, 1. Auflage 2012. 
national legal and political developments affected public opinion and influenced the implementation of AI's campaign in Switzerland and Germany. Indeed, more research and a broader focus are needed to better understand these relationships.

Given AI's basic nature of a membership organization based on democratic principles, which gives members the possibility to define the organization's working focus, the attitude of a section's membership towards the SVAW campaign or the adoption of an abortion policy is paramount to the section's actions. In turn, this suggests that the German section's generally rather conservative membership, visible in its relative closeness to the Church, combined with activists' comparatively huge opportunities to participate in the section's decision-making processes to further amplify opposition to the SVAW campaign and contribute to the section's failure to integrate issues of VAW into its overall work.

\subsection{Intermediate conclusions}

Before continuing with the discussion of the empirical findings, it is worth summing up the insights into the post-mandate period that this chapter has provided. In the 2000s, AI adopted a first policy on sexual and reproductive rights and abortion, framing these rights as civil and political rights as well as economic, social, and cultural rights. In so doing, it recognized them as essential "to the realization of every individual's human rights." ${ }^{358}$ Additionally, the organization made the principle of gender equality part of its policy at the end of the 2000s. Chapter 8 has illustrated how the content of AI's work on VAW evolved with the launch of the SVAW campaign, when the organization emphasized the issue of domestic violence for the first time and engaged in a comprehensive internal change. With the latter, AI members and staff embraced the campaign's underlining principle of gender equality and integrated the principle of "Women's Rights are Human Rights" into their work and activism.

Further, my focus on the origin of the relevant ICM decisions and on the implementation of the SVAW campaign has revealed a top-down process of

358 Amnesty International, International Secretariat: Statement Summarizing Al's current policy on Sexual and Reproductive Rights, 12.10.2006, p.2. 
integrating VAW into AI's work in the post-mandate period. The organization's leadership initiated the majority of the relevant ICM decisions and established a campaign machinery at the IS for the effective implementation of the SVAW campaign.

Nevertheless, AI did not succeed in integrating VAW into its work. The analysis of the role of the women's rights activists and officials and the reaction to the SVAW campaign and the adoption of an abortion policy indicates that this failure has two principal reasons. First, with the SVAW campaign being implemented from the top down, the female activists and officials who had initiated AI's work on VAW in the 1990s lost their influence on the organization's work on the topic. Second, activists and officials at the international and the national levels opposed the SVAW campaign and members resisted the adoption of a policy on abortion.

However, the focus on the national level has showed that there were considerable differences in the extent to which the Swiss and the German sections managed to integrate the issue of VAW into their work in the 2000 s. Whereas the Swiss section at least partially succeeded in integrating the issue of VAW into its work, the German section did not do so. I argue that the German section members' relative closeness to the Church and their comparatively powerful position help explain this difference between the two sections. 


\section{Discussion and outlook}

This final chapter starts by recapitulating my main findings and discussing them with a view to the existing literature on the integration of women's rights into AI's work. Following the two-part structure of the empirical analysis, chapter 9.1 highlights the book's new insights into the mandate period and the post-mandate period separately. In section 9.2, I draw some broader implications and offer recommendations on how other human rights NGOs can best integrate women's rights into their work. By relating the results of the analysis back to the literature on norm diffusion and dynamics, section 9.3 discusses the new theoretical insights. It specifically highlights the study's contribution to the understanding of the ways comparatively powerless actors within a transnational network are able to cause a new norm to emerge, and elucidates the study's contribution to better comprehending the causes of incomplete norm diffusion. Section 9.4 then concludes with an outlook focusing on AI's internal developments with respect to women's rights in the years after the SVAW campaign until today.

\subsection{Summary and new insights}

This section starts by recalling the study's general objective and discusses the book's main insights into the mandate and the post-mandate period separately (section 9.1.1 and 9.1.2).

The present study intended to shed light on the reasons why AI chose VAW in the private sphere as the theme of its first global long-term thematic campaign, despite a historically grown gender-biased vision of human rights. AI largely informed the dominant understanding of human rights in the second half of the $20^{\text {th }}$ century as individuals' rights to be protected from state despotism. It treated women's rights only marginally and mainly as violations 
occurring in the public sphere. I therefore identified the organization's decision to focus its first global thematic campaign on the issue of VAW in the private sphere as a surprising development. Thus, the books has sought to answer the following questions: 1) Why did AI decide to focus its first global thematic campaign on the issue of VAW and, especially, on forms of violence in the private sphere?

As the condemnation of VAW in the public sphere preceded AI's interest in VAW in the private sphere and as these approaches interrelate, it was pivotal to clarify why and how AI dealt with issues of VAW during the mandate and in the post-mandate period. The study thus also intended to answer the following research questions: 2) Why has AI integrated VAW into its activities? 3) How has AI integrated VAW into its activities? How has AI's human rights policy changed and how was this transformation assimilated and integrated by AI's officials and activists? Relatedly, the book explored two sub-questions: What was the role of female activists and officials in the integration process? and Has there been any resistance from activists and/or from officials and, if so, what kind of resistance?

The study explored in detail how VAW developed from an ephemeral concern reflected in the adoption of cases of female prisoners of conscience, initiated at the end of the 1980 s by female activists at the local level, to the central issue of AI's first global long-term campaign under the mission at the beginning of the 2000 s. Female activists and officials substantially contributed to the integration of VAW into AI's work and to the decision to launch a first global long-term campaign on the issues of VAW in the private sphere in a bottom-up process. They did so in a beneficial international political environment marked by the fourth WCW in Beijing and using strategies of parallel networking and analogous framing. Nevertheless, AI wasn't successful in making VAW an integral part of its work through the SVAW campaign. Long-standing women's rights activists and officials lost their influence on AI's work on VAW and some activists and officials strongly resisted the campaign and, relatedly, the adoption of AI's first policy on abortion. These factors are key in explaining AI's failure to transform women's rights into part of its DNA through the SVAW campaign. 


\subsubsection{New insights into the mandate period}

Female activists played a central role in initiating AI's work on women's rights at the end of the 1980s and in the subsequent bottom-up process of integrating VAW into AI's activities, which culminated in the SVAW campaign at the beginning of the 2000s. Al's growing interest in issues of VAW and, relatedly, the decision to make VAW the topic of AI's first long-term thematic campaign under the mission must mainly be seen as the result of the feminist strategies of parallel networking and analogous framing. These strategies were successful because the first was adapted to the overall structure and functioning of AI, while the second conformed to the organization's overall human rights policy. Because analogous framing did not challenge the organization's traditional understanding of human rights, which, at this time, essentially focused on civil and political rights, members or officials did not resist it.

While these feminist strategies are key to understanding developments at the international level, female activists and officials in different sections organized in accordance with the structure of their sections' voluntary members into local, regional, or thematic groups or networks in the 1990s. The subsequent professionalization of each section's work on VAW also followed the overall organization of the section's thematic work. While in the German section, the MaF pursued a strategy that sought to influence decision-making at the international level, female activists in the Swiss section first organized into four local groups and formed a national women's network in 2000, which focused primarily on their section's work. While the Swiss section started to professionalize its work on women's rights in the late 1990s, in the German section issues of violations of women's rights remained in the MaF's hands. Women activists and officials thus appear to have played a key role in the initiation of AI's work on VAW and its subsequent increase in the 1990 .

However, this does not mean that male activists and officials did not contribute to the integration process. While the data clearly indicate that it was predominantly women who had agency in this change process, we cannot conclude that men were not involved, as well. Both female and male ICM section delegates decided upon the adoption of resolutions. Therefore, it is worth assuming that men must at least have supported the issue from the moment the demand for more work on issues of women's rights became integrated into AI's policy at the 1989 ICM. Further, as the examples of the former SG Pierre Sané and the former ED of the Swiss section Daniel Bolomey show, men also played a positive role. Using a feminist research approach that fo- 
cuses primarily on comparatively powerless actors, I have paid less attention to comparatively powerful actors, most of whom were men during this period. It is plausible that the study has somehow underestimated the contribution of men (particularly male officials) to the change process. In fact, as demonstrated by Kelleher and Bhattacharjya, Pierre Sané was committed to women's rights and took a leading role in enunciating AI's increasing interest in women's rights issues. ${ }^{1}$

Aside from the positive stance of the $S G$, it is possible that the increase in the proportion of women in the organization's leadership positions may also have contributed to making AI consider issues of VAW more seriously. Nevertheless, while these numbers indicate a relationship, they do not suffice to fully clarify the transformation process, as they tell us nothing about the agency of the women behind it.

We know that external factors influenced AI's interest in women's rights issues as well. For example, human rights violations' changing pattern amplified at the end of the bipolar world order. It made AI rethink its state-focused mandate and contributed to making AI consider violations of women's human rights during the 1990 s more seriously. ${ }^{2}$ More important, the growing international awareness of gender equality (initiated during the UN Decade for Women 1975-1985), which was reflected in the WCWs, did not leave AI unaffected. Relatedly, the international women's rights movement - or the Transnational Feminist Networks, ${ }^{3}$ as Moghadam calls them - challenged AI and other human rights organizations to expand their mandate to violations of human rights in the private sphere. ${ }^{4}$ In particular, the 1995 WCW in Beijing provided those within AI who wanted the organization to increase its work on VAW with an important momentum, and it can therefore be interpreted as a window of opportunity facilitating the integration process within AI.

In light of the internal and external factors that must have positively impacted AI's work on VAW in the 1990s, the results of the present study, with their emphasis on female activists' and officials' strategies, may at first glance seem too reductionist. It is therefore important to acknowledge the results in light of the book's specific focus and approach. In fact, the emphasis on AI's

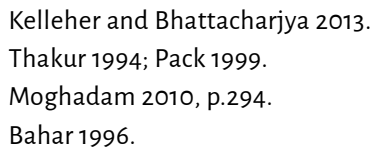


inner life and the focus on women as competent actors within the organization, which follows from the theoretical paradigm of feminist constructivism, entail that the study has not concentrated on the role of more powerful actors and of potential external factors. Thus, we can assume that Pierre Sanés positive stance, the increase in the proportion of women in AI's leadership, and the favorable global political climate must have contributed to making AI increase its work on VAW as well. Nevertheless, the following reflections attribute AI's increasing interest in women's rights issues to feminist strategizing. In fact, events such as the WCW in Beijing, can only open windows of opportunities for actors exploiting them to their advantage.

In that sense, it is worth assuming that without women's appropriate strategizing within AI, AI would probably have integrated issues of VAW into its work as a result of an international bandwagon effect. Yet, the process of integration would probably have taken a different path and VAW in the private sphere would not necessarily have become the central theme of AI's first global long-term campaign under the mission. Consequently, although I have not demonstrated the interplay of all of the factors that eventually contributed to making AI increase its work on VAW during the 1990s, I have clearly demonstrated the existence of two feminist strategies - parallel networking and analogous framing - and their significance for the process of change.

\subsubsection{New insights into the post-mandate period}

The 2001 decision to launch the first thematic long-term campaign under the mission on the issue of VAW in the private sphere marked the end of the bottom-up process and the beginning of a top-down approach to the integration of VAW issues into AI's work. In fact, between 2002 and 2010, the organization's leadership initiated the majority of the ICM decisions concerning the work on violence against women. It also established campaign-machinery at the IS for the effective implementation of the organization's first global thematic long-term campaign. In contrast to the activities related to VAW in the 1990s, the SVAW campaign sought to change the organization from within by enhancing its members' and officials' awareness of gender equality. AI considered its staff's and activists' commitment to gender equality pivotal for AI's public credibility. The SVAW campaign was embedded in the major change of policy and working methods. It naturally followed from the adoption of the mission and combined an internal and an external aspect. It therefore was a highly ambitious and challenging endeavor. 
It is thus not surprising that the campaign's flagship role and its structure and setting provoked the opposition of some members and officials. The Review of the SVAW Campaign ${ }^{5}$ highlights that these elements certainly hampered the implementation of the campaign. However, my findings suggest that two other elements are key to explaining why AI did not succeed in making women's rights part of its DNA through the SVAW campaign. First, were the activists' and officials' content-related resistance to the SVAW campaign at the international and the national levels and the members' opposition to the adoption of a policy on abortion. Second, with the top-down campaign, female activists and officials who initiated and pushed the work on VAW in the 1990s lost their influence on the organization's work in this area.

My national-level analysis demonstrates that the Swiss section succeeded in integrating the issue of VAW into its work at least partially. Meanwhile, the German section did not succeed in integrating issues of VAW into its overall work through the SVAW campaign. This difference can be explained with the general differences between the two sections. The facts that there had always been more women in the Swiss section's EC and that the Swiss section had generally been more open to mandate modifications than its neighbor help account for this. Nevertheless, Al's grassroots democratic structure, which gives members the right to have a say, suggests that the reason for the difference is most likely to be found in the membership. An important indication of the conservative attitude of the German section's members is their relative closeness to the church. Data indicate that the German section's members are generally closer to the church than their colleagues at the Swiss section. However, this is a very general observation, and in order to better understand the members' attitudes, this connection should be further explored with more interview data. Moreover, German members have comparatively more power than their Swiss counterparts, which must have amplified the opposition to the SVAW campaign and to the adoption of the abortion policy. Furthermore, to reach a definite conclusion on the differences between the two sections, it would be worthwhile to take into account the societal contexts and, especially, the legislation processes related to VAW that took place in Switzerland and in Germany during the same period.

The analysis of the data on the German section reveals that, while the German section is representative of other big Western AI sections members- and funding-wise, it differs from the rest of the AI sections because of its special 
history. For a long time, the section developed in parallel with the international movement, on its own and without a model of how to organize its work. This implies that the internal generalizability of my findings is somehow limited. Because these two characteristics distinguish the German section not only from the Swiss section, but also from many other AI sections, and because other Western AI sections must therefore more closely resemble the Swiss section in terms of membership and structure, it is worth assuming that the extent to which other sections succeeded in integrating VAW into their overall work is similar to that observed at the Swiss section. To verify this assumption, it would be interesting to more closely explore how other European AI sections dealt with the issue of VAW in the frame of the SVAW campaign.

The study provides an internal explanation for Al's failure to make women's rights part of its DNA through the SVAW campaign by highlighting the content-related resistance to the latter and the opposition to the adoption of an abortion policy and by demonstrating the female activists' and officials' loss of influence on AI's work on issues of VAW in the frame of the top-down campaign. We should assess these findings keeping in mind that the feminist constructivist theoretical paradigm underpinning the book entails focusing on AI's inner life and on the role of female activists and officials. However, in order to understand AI's difficulties in making women's rights part of its DNA through the SVAW campaign, it is worth contextualizing the findings within the global climate on women's rights in the 2000s. With the 1993 UN Human Rights Conference in Vienna, the 1994 International Conference on Population and Development in Cairo, and the 1995 WCW in Beijing, the 1990 s had witnessed major progress in the area of women's rights and the international context for advancing the issue within AI was beneficial.

The global situation was different in the 2000s. A backlash against women's rights achievements took place in the post-Beijing period and especially in the aftermath of September 11, 2001. ${ }^{6}$ Fundamentalist forces, including the Vatican, US Christian right organizations, and several African and Middle Eastern states, such as Egypt, Iran, Pakistan, Libya, and Sudan, had already organized around the UN conferences in the 1990 s to counter the developments in women's rights, particularly with respect to sexual and reproductive rights. However, with a global climate changing away from 
multilateralism towards a US unilateralism and a "disregard for international norms," these fundamentalist forces really gained momentum in the beginning of the 2000s. ${ }^{7}$ For example, at a meeting of the UNCHR in 2003 , the Vatican and the Organization of the Islamic Conference (OIC) countries strongly opposed a resolution calling governments to recognize discrimination based on sexual orientation as a violation of human rights. ${ }^{8}$ At the same time, "the global consensus that VAW is a violation of human rights was also called into question" at a meeting of the CSW. Aware of the rise of these anti-feminist forces, and in fear of losing the achievements gained since Beijing, the CSW deliberately decided not to call for a fifth WCW. ${ }^{10}$

This particular global climate must therefore be considered another element explaining AI's failure to make women's rights part of its DNA, as it strengthened the traditionalist voices within AI. Thus, similar to what I discussed in relation to the mandate period, it is important to take into account the global political climate in order to fully understand the developments in AI's work on VAW in the 2000s. Consequently, even though my analysis has downplayed these external factors and was not able to highlight the interaction of the internal and external elements, all of which must have played a role in AI's failure to make women's rights part of its DNA, I have nonetheless demonstrated the existence of content-related opposition to the SVAW campaign and to the adoption of the abortion policy, as well as its harming influence on AI's ability to integrate VAW into its work. Furthermore, I have also highlighted the loss of influence of those women activists and officials who pushed for the increase in AI's work in the 1990s in the frame of the topdown SVAW campaign and its potentially negative influence on AI's ability to make women's rights part of its DNA.

In consideration of the above, the study has largely answered the underlying research questions. Research question 3 is the only exception. In fact, I could not fully answer the research question How has this transformation been assimilated and integrated by AI's officials and activists? The fact that AI did not succeed in making women's rights part of its DNA through the SVAW campaign suggests that AI's officials and activists did not fully assimilate and integrate the transformation from a human rights approach centered

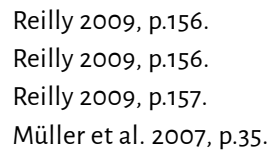


on violations of human rights in the public sphere to an approach considering abuses of human rights in the private domain. While I could demonstrate that women's rights issues were not paramount for the activists interviewed at the Swiss section, I was not able to describe in more detail exactly how activists and officials effectively assimilated and integrated issues of VAW. One of the reasons for this shortcoming is the limited number of interviews at the German section and at the IS. In order to fully answer this question, more interviews with activists and officials at the German section as well as with IS staff would have been necessary.

\subsection{Implications for other human rights NGOs}

I defined $\mathrm{AI}$ as a transnational network because of its structure with a central headquarters and a broad grassroots membership organized in country sections. However, as far as AI's work is concerned, the relevant literature and the media commonly refer to $\mathrm{AI}$ as a human rights NGO. ${ }^{11}$ It is thus worth it to present the implications of the study for other human rights NGOs rather than for transnational networks, as this term refers first and foremost to the structure of a given organization and not to the focus of the organization's work. In fact, the findings offer several general recommendations on how to successfully integrate issues of women's rights into everyday work that are potentially useful for human rights NGOs.

Nevertheless, when we look at the following recommendations and think about applying them to other organization, we have to bear in mind that the findings are based on AI - an institution characterized by a networked organizational structure. Given that AI's approach to integrating issues of VAW was different before and after the adoption of the mission in 2001, my findings allow me to make recommendations on how human rights NGOs can successfully integrate issues of women's rights into their work in two situations: Either when an organization intends to integrate issues of women's rights into its public activities (such as campaigns or reports) or when an NGO chooses a gender-mainstreaming approach, implying an internal change process as well. In the first case, a favorable global climate and a window of opportunity 
are important but not sufficient. While the commitment of an organization's leadership matters, the presence of women pursuing strategies for pushing their claims forward that are adequate to the organization is key. These strategies can be parallel networking or analogous framing.

However, the successful use of these strategies is subject to certain conditions. The strategy of parallel networking seems to be effective when the organization is structured as a network composed of a powerful central node and a large grassroots movement, when the internal decision-making process is based on democratic principles, and when a certain number of individuals, disseminated more or less equally across the basic network, become members of the parallel network. Further, the strategy of analogous framing seems to depend on the topics the NGO works on.

The case of AI showed the effectiveness of women's networking beyond the formal organizational units. When they frame their concerns in a way that is oriented towards this fundamental policy rather than in contradiction to it, women are likely to influence their organization's agenda. In a democratically organized network, where the members are involved in the decisionmaking process, such as AI, linking up with other like-minded individuals beyond the formal organizational units allows women to purposefully and efficiently influence the decision-making processes. However, given the myriad of very different organizations, other feminist strategies are conceivable as well. Further, a certain proportion of women in leadership positions seems to be important, too. This seems to be a necessary, but not a sufficient condition for successful integration.

In the second situation, when the issue of women's rights is embraced by the organization's management and promoted from the top, it is important to keep in mind that if a bottom-up process preceds the top-down approach, those who first initiated the issue and pushed it from the bottom be adequately involved in the ongoing process of integration. This means that the organization is able, if possible, to build upon preexisting (informal) organizational structures instead of (only) establishing new ones. If the organization decides to create new entities, it is pivotal to provide them with sufficient financial and personal resources and to embed them in the preexisting organizational structure, clearly defining their responsibilities and ensuring internal accountability. The management's commitment is important but not sufficient in this case either. 


\subsection{The study's theoretical contribution}

This section relates the results of the analysis back to the relevant literature on norm diffusion and dynamics. It starts with a discussion of the new theoretical insights into the ways comparatively powerless actors within a transnational network are able to cause a new norm to emerge. The section then elucidates the study's contribution to a better understanding of the causes of limited norm diffusion.

\subsubsection{Ways that comparatively powerless actors can influence norm emergence}

Female activists and officials successfully used the strategies of parallel networking and analogous framing to make AI increase its work on VAW in the 1990s. The employment of these strategies was one of the factors that led AI to choose the issue of VAW in the private sphere as the topic of its first global long-term campaign, the SVAW campaign. The use of these strategies can thus be considered to have played a pivotal role in causing a new norm to emerge within AI: recognizing VAW as a human rights violation, whether it occurs in the private or in the public sphere and whoever the perpetrator. Since the integration of VAW into AI's work followed a bottom-up process and female activists and officials who were not part of AI's leadership spurred AI to work on VAW, I consider these women comparatively powerless actors. My results thus show that by using the strategies of parallel networking and analogous framing, comparatively weak actors in a transnational network are able to cause a new norm to emerge.

As such, my findings relativize the headquarters' essential role as the principal norm entrepreneur within AI as well as the IS's influence on AI's policy and thematic orientation that have both been highlighted by different authors. ${ }^{12}$ Furthermore, my study confirms Hertel's (2006) findings on the influence of comparatively powerless activists on norm dynamics. ${ }^{13}$ In her study Unexpected Power Conflict and Change among Transnational Activists, she has pointed to various ways in which comparatively powerless activists can alter the content of a transnational campaign. By differentiating between the 
senders framing the campaign from the North and the receivers of the campaign in the South, Hertel (2006) demonstrates that local activists at the receiving side of a transnational campaign could alter its content by employing two mechanisms: Blocking or Backdoor-moves. Powerless members of a normative community are thus able to change the content of a norm and influence its dissemination.

However, Hertel's study does not demonstrate if and how comparatively weak actors may affect norm emergence. My study's theoretical contribution departs from this point, as my research identifies the strategies of parallel networking and analogous framing, which comparatively powerless members of a transnational network can employ in order to influence their network's agenda and, consequently, norm emergence.

Nevertheless, the results of my study also suggest that the effectiveness of these strategies is linked to specific conditions. The strategy of parallel networking depends on three conditions. The first is the transnational network's overall structure; second - it's functioning; and third - the number and distribution of the people involved in the parallel network. A transnational network composed of a powerful central node and a large grassroots movement has been fruitful for comparatively powerless actors' use of the strategy of parallel networking. Parallel networking can be a successful strategy for weak actors within a transnational network if the network's decision-making process follows democratic rules.

Lastly, the strategy of parallel networking also needs a certain number of individuals to become network members and to be distributed more or less equally throughout the actual transnational network. Otherwise, they are less able to influence decision-making. In fact, a certain number of female activists and officials were present at various sections as well as at the IS. They were thus more or less broadly disseminated within AI. This enhanced the likelihood of constructing an effective intersectional network as it allowed them to reach out to the whole AI network and build majorities for their demands at the ICMs.

In contrast, the strategy of analogous framing seems to mostly depend on the transnational network's policy framework or, said differently, on the topics on which the basic network is focused. In order for this strategy to be effective, it must therefore conform to the themes of the basic network. In fact, because analogous framing did not challenge AI's traditional understanding of human rights, which, at the time, focused on civil and political rights, it did not result in major resistance from members and officials, and it was there- 
fore successful. Consequently, my study's theoretical contribution to norm emergence comes down to the insight that norm entrepreneurs are not the only actors key to the emergence of new norms; comparatively powerless actors can create a new norm, as well. By using the strategies of parallel networking and analogous framing, comparatively powerless activists within a transnational network can influence the network's agenda and cause a new norm to emerge within the network under certain conditions. The deployment of these strategies, however, seems to depend on the network's structure, functioning, the number and distribution of those using the strategy of parallel networking, and on the network's overall policy framework.

\subsubsection{Reasons for limited norm diffusion}

I have provided evidence for two main arguments why AI failed to make women's rights a part of its DNA. Translating these findings into the terminology of norm diffusion allows me to highlight two reasons why the norm did not diffuse further within AI. First are activists' and officials' content-related resistance to the SVAW campaign and their opposition to the adoption of an abortion policy. Second is the loss of influence that female activists and officials who initiated and pushed the work on VAW in the 1990s went through as far as the organization's work on VAW in the frame of the top-down campaign is concerned. These outcomes confirm Wiener's (2007) and Müller and Wunderlich's (2013) findings about the importance of contestation for understanding norm compliance or non-compliance and norm diffusion. ${ }^{14}$ Wiener (2007) demonstrated that the likelihood of norm contestation increases when a norm is transposed into a different context. In fact, when a norm is implanted into a new environment, its meaning becomes contested as differently socialized actors interpret it. ${ }^{15}$ This process took place within AI with the norm that recognizes VAW as a violation of human rights. In my two case studies, the members' closeness to the church attested to their different socialization. Contestation was more important in the German section, where the membership was generally closer to the church, than in the Swiss section. That resistance against women's rights is widespread among church-related groups is not new. The Catholic Church is widely known for its conservative 
and patriarchal values, having always opposed women's sexual and reproductive rights. ${ }^{16}$ The Vatican was particularly active in restricting these rights in the 2000 s.

Norm diffusion is also described as a permanent process of negotiation, throughout which norm entrepreneurs have to continually work to further consolidate the norms and to defend them against norm challengers. ${ }^{17}$ If norm entrepreneurs fail to defend a norm, we observe norm regression. In the case of AI and VAW, I have shown that comparatively weak actors - female activists and officials - were the primary drivers of norm diffusion. However, the book has not provided information about whether these women's rights advocates defended the norm from internal norm challengers. The fact that members' participation in sections' decision-making processes may hinder the integration of VAW into AI's overall work indicates that norms interpreters' influence within a normative framework, as well as socialization, matters for norm contestation. In fact, my results about the consequences of members' participation in decision-making processes suggest that when the latter offer extensive power to norm interpreters, norm contestation is more effective and the likelihood of norms' continued diffusion decreases. Consequently, two main factors account for norm decay in a transnational network. First, are differently socialized actors who contest the norm; second is the norm contesters' power in terms of their access to decision-making processes.

To sum up my contribution to the understanding of norm diffusion: In addition to norm entrepreneurs, comparatively powerless actors within a transnational network are also able to cause a new norm to emerge by using the strategies of parallel networking and analogous framing. Second, beside the norm interpreters' socialization or norm entrepreneurs' capacity to defend their norm against norm challengers, the latter's power to access decisionmaking processes matters for norm degeneration.

\subsection{Outlook}

The present study has deliberately focused on the period between 1989, when AI first started to work on women's rights, and 2010, marking the end of

\footnotetext{
16 Strahm 2017.

17 Müller and Wunderlich 2013.
} 
Al's first global long-term thematic campaign focusing on VAW in the private sphere. I have shown that AI's work on issues of VAW evolved tremendously within this period, even though the organization did not succeed in making women's rights part of its DNA through the SVAW campaign. Broadening the time frame, it becomes evident that AI has not stopped working on issues of VAW after the end of the SVAW campaign. In fact, the Demand Dignity campaign, the integration of the principle of a balanced representation of men and women within the organization, and the anchoring of gender mainstreaming in the 2010-2016 strategic plan all indicate that women's rights issues have remained relevant after the closing of the SVAW campaign. Moreover, AI underwent important changes with regards to its internal structure in the 2010s. The following paragraph briefly highlights the most important developments concerning AI's structure and functioning as well as its work on issues of VAW since 2010.

AI's "Moving Closer to the Ground" initiative, launched in the early 2010s, sought to create a bottom-up approach of human rights work that would enable the organization to work closely with local human rights organizations and to respond more quickly to human rights violations. ${ }^{18}$ It must be considered the most important transformation in the functioning of the NGO. This structural shift entailed the delocalization of the regional programs from the headquarters to key regional hubs, such as Dakar, Johannesburg, Hong Kong, and Mexico ${ }^{19}$ It has modified and continues to alter the power relations among sections, as new sections were founded in the Global South and already existing Southern sections grew.

This modification is also likely to have altered the direction of the movement's work on issues of VAW over the past years. Although AI has not launched an endeavor comparable to the SVAW campaign as far as length and resources are concerned, the organization has continued its activities in the domain of VAW and women's rights since 2010. Relatedly, its policy and its internal structure in these domains have continued to evolve since 2010. Activity-wise, AI has integrated VAW into the Demand Dignity campaign (its second thematic campaign under the mission), which was launched at the end of 2009 and focused on maternal mortality, forced eviction, discrim- 
ination, and exclusion. ${ }^{20}$ From 2014 to 2015 , in reaction to the backlash against sexual and reproductive rights, AI organized the My Body My Rights campaign, seeking to promote people's rights to decide upon their bodies and a life free of coercion. ${ }^{21}$ Today, Al's website shows a wide range of topics in which the organization is engaged, including sexual and reproductive rights. ${ }^{22}$ Thus, sexual and reproductive rights have become a central topic of Al's work on women's rights over the past several years.

At the same time, as the examples of the Swiss and the German sections show, women's groups have continued to take action on issues such as FGM, trafficking, domestic violence, women human rights defenders, and forced marriage. ${ }^{23}$ Concerning policy developments on women's rights, gender mainstreaming became of one of the central objectives of AI's ISP 2010$2016^{24}$ as a consequence of the integration of the principle of gender equality in the nominations for IEC members and other international elected positions at the 2009 ICM. ${ }^{25}$

In addition, it is worth mentioning the recently adopted new policy on abortion calling for a decriminalization of abortion, which replaced the 2007 policy on the issue. Indeed, on July 9, 2018, the Deputy Europe Director at AI announced on Twitter: "Excited to announce @amnesty global movement has decided to trust women - we are fully pro-choice organization. ${ }^{26}$ He was referring to AI's new abortion policy that guarantees "access to safe and legal abortion in a broad way that fully respects the rights of all women, girls, and people who can get pregnant" ${ }^{\prime 2}$ adopted at the ICM in Warsaw in July 2018.

AI has also continued to pursue its commitment to human rights violations against women with the establishment of the Gender, Sexuality, and Identity Program at the IS in 2010. The organization has made gender one of the categories to consider when analyzing human rights abuses and how

20 Amnesty International: Al's global Campaign for Human Dignity: a strategy to end human rights abuses that keep people poor, 2008.

21 Amnesty International.

22 Amnesty International.

23 Amnesty International Sektion Bundesrepublik Deutschland; Amnesty International.

24 Amnesty International: Amnesty International's Integrated Strategic Plan 2010 to 2016, 2010.

Amnesty International, International Secretariat: 29th International Council Meeting Circular 46 ICM Decisions 2009, 16.08.2009.

26 Van Gulik 2018.

27 Amnesty International, International Secretariat. 
best to face them. As one of my interviewees explained, the restructuring of the Gender Unit into the Gender, Sexuality, and Identity Program also occurred because of the recommendations resulting from the SVAW campaign. The latter advised that AI not limit its gender or women's rights work only to a campaign but apply gender lenses to various aspects of its work. ${ }^{28}$ Whereas AI slightly increased the human resources devoted to its work on women's rights issues by creating the Gender, Sexuality, and Identity Program, these resources were not sufficient to actually ensure that intersectionality is taken into consideration in each of AI's projects. ${ }^{29}$

The foundation of the International Women's Human Rights Network (IWHRN) in 2011 can be considered another recent, important structural change with respect to AI's work on VAW. In fact, by creating this network, former section SVAW campaign coordinators reconstituted the IWN. Their goals were to strengthen AI's work on women's rights and gender equality at all stages and to support and follow up on the process of gender mainstreaming formalized in the ISP 2010-2016 through the organization. ${ }^{30} \mathrm{At}$ the national level, one can observe a continuity in the structural entities responsible for the work on violence against women within the Swiss and the German sections. In fact, a permanent position at the secretariat of the Swiss section has been responsible for women's rights issues since the SVAW campaign. The national women's network, composed of a coordination group linking the women's groups (Geneva, Zürich and Bern) to the secretariat and to the IS, has continued to coordinate the section's work on women's rights. In the German section, the work on women's rights violations has continued to be primarily in the hands of the thematic expert group MaF.

At the same time, women's rights issues have continued to challenge the organization from within. The head of the Gender Unit's departure from the IS, ${ }^{31}$ can be mentioned as one example of such internal challenges. ${ }^{32}$ Later, the adoption of an official position in favor of decriminalizing prostitution in

\footnotetext{
28 Ganzfried: Interview with B.C., 24.06.2012.

29 Ganzfried: Interview with B.C., 24.06.2012.

30 C.: Al International Women's Human Rights Network, 2011.

31 The departure followed a public dispute with Al's senior management in 2011 for publicly endorsing a survivor of torture at Guantanamo Bay who was also supposedly linked to violent fundamentalist groups.

32 Kelleher and Bhattacharjya 2013.
} 
May 2016 apparently led to important internal debates, provoking the withdrawal of many long-term activists and causing huge opposition from other organizations in the field of women's rights, human rights, and trafficking. ${ }^{33}$ As the example of one of my informants who left AI shows, the newly adopted pro-choice position on abortion must have also provoked internal discussion and withdrawals. In fact, the informant explained that she was very happy to have left AI before this policy change, as she could no longer identify with this new direction.

This outline of the developments that have taken place since 2010 shows that the internal structures responsible for women's rights issues, which were established during the 1990s and the 2000s, have remained beyond the SVAW campaign and that AI has continued working on VAW, among other issues the organization is focusing on. Since the SVAW campaign, AI has mainly addressed VAW by framing it as an issue of sexual and reproductive rights. This emphasis reflects a growing awareness of the gendered nature of human rights and a willingness to consider violations of human rights equally, whether occurring in the private or the public sphere and whoever the violator.

However, if sexual and reproductive rights are addressed as the rights of every individual regardless of their identity, then this focus bears the risk of ignoring the gendered power relations that put women in a subordinated position in most societies. Further, the adoption of the pro-choice position on abortion could be interpreted as a significant advancement for the progressive feminist voices within $\mathrm{AI}$, as such a policy change would not have raised a majority of the ICM delegates ten years before. It can thus be assumed that focusing on the 2010s would have given a more positive picture of AI's work on women's rights. Given AI's democratic decision-making process, it is worth assuming that this development is also the result of a change in the membership, not only due to the organization's age but also as a consequence of the AI's "Moving Closer to the Ground" initiative that has only recently come to an end. In fact, a younger, more global and diverse generation of activists has joined the movement over the past decade and is therefore unaware of AI's former limited mandate. Instead, they have identified with a broader understanding of human rights. Such activists have increasingly shaped the organization and its thematic directions, and it is they who must have made policy changes, such as the one on abortion, possible. 
On account of these structural modifications and the continuing emergence of new human rights challenges, AI's work will continue to evolve in the future. What this means in terms of AI's work against VAW and the respect of women's rights remains to be seen. As the recently adopted pro-choice position on abortion demonstrates, however, it is likely that AI will continue to evolve in a progressive direction, addressing human rights violations equally wherever they occur and whoever the perpetrator is. At the same time, due to the empowerment of local activists, the decentralization process could also lead to an increase in internal debates on the positions that AI should take on particular women's rights issues. These hypothetical considerations lead to the question of whether and how the recent internal change process has affected AI's work on VAW. Are there new or different feminist demands articulated due to the decentralization of the organization? Does the "Moving Closer to the Ground" facilitate feminist strategizing, or does it hamper feminist demands?

In conclusion, I would like to highlight a few points about the study's significance and contributions to our knowledge of AI's work on women's rights and beyond. By closely following AI's work in the field of VAW over a period of 20 years, the book has shed light on a little-known part of the work of the one of the most important human rights organization worldwide. By giving a voice to AI's female activists and officials, whose actions have often remained unnoticed by the overall organization and by the public, I have made them visible as important internal actors and showed that female activists and officials were key to leading Al's growing interest in women's rights issues and to the decision to launch the organization's first global thematic long-term campaign on the issues of VAW in the private sphere.

Additionally, the study has provided a comprehensive picture of the functioning of two of the most important AI sections in terms of members and funding, thereby making a major contribution to the documentation of AI Switzerland and AI Germany, as well as to their work on VAW. In this endeavor, I have consulted and analyzed a wide range of largely unknown, firsthand archive material. In addition, the book has facilitated the further development of knowledge on norm dynamic, as it has provided evidence that both comparatively powerless actors and norm entrepreneurs can cause a new norm to emerge under certain conditions.

Moreover, my findings indicate that in addition to norm interpreters' socialization and norm entrepreneurs' capability to defend their norm from norm challengers, norm challengers' ability to access the decision-making 
process helps explain why a norm ceases to diffuse. The constructivist and feminist theoretical paradigm underpinning my work, my qualitative case study approach, and the use of GT research techniques were essential for gaining new insights into why and how AI integrated women's rights into its work between the late 1980 s and 2010 and contributed greatly to the development of new theoretical insights. Consequently, diversifying the focus away from the mainstream approach of cross-national research towards the micro level, placing individuals in the center, is worthwhile for the production of knowledge in the area of norm dynamics. Further, analyzing processes of norm diffusion with gender lenses can be fruitful, as this allows for the discovery of power relations informing these processes that are invisible at first glance. 


\section{Appendix}

\section{Appendix 1:}

Coordinators of the Intersectional Women's Network IWN

1991-1995: Susanne Roach, AIUSA

July-September 1995: Susanne Reichinger, AI Germany

1995- 2002: Edna Aquino, International Secretariat

\section{Appendix 2: Additional graphs and figures}

Graph 6: Evolution of AI sections, 1964-2011

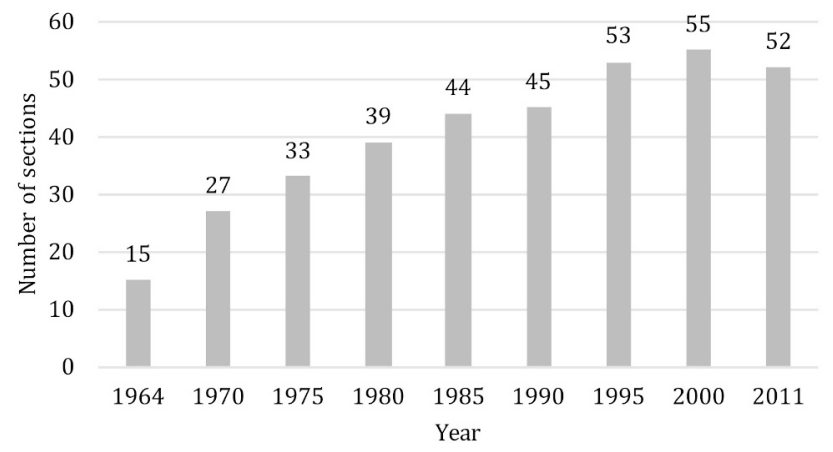

Source: http://www.amnesty-chronik.de/ 
Graph 7: AICH's evolution in terms of number of groups, 1970-2011

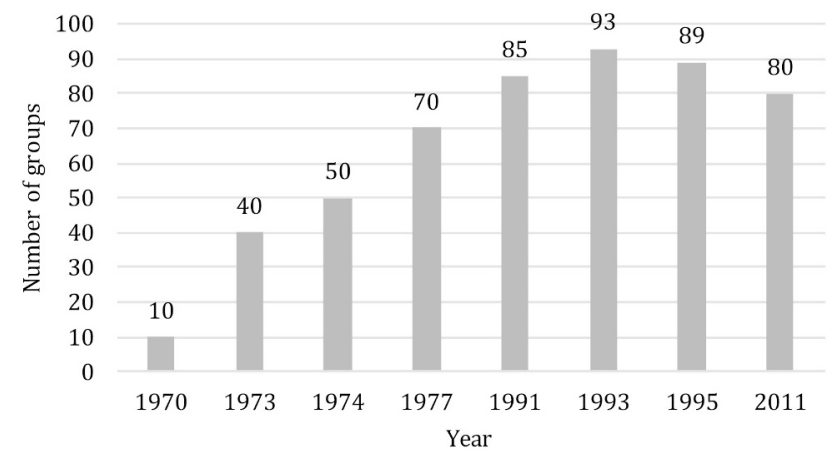

Source: Amnesty International Schweiz, 1991; Amnesty International Schweiz, 1995; Amnesty International, 11/8/2011, Steffen, 26/8/1997" "Amnesty International: Die Gründng von Amnesty International in der Schweiz, April 2001.

Graph 8: AI Germany's evolution in terms of number of groups, 1964-2009

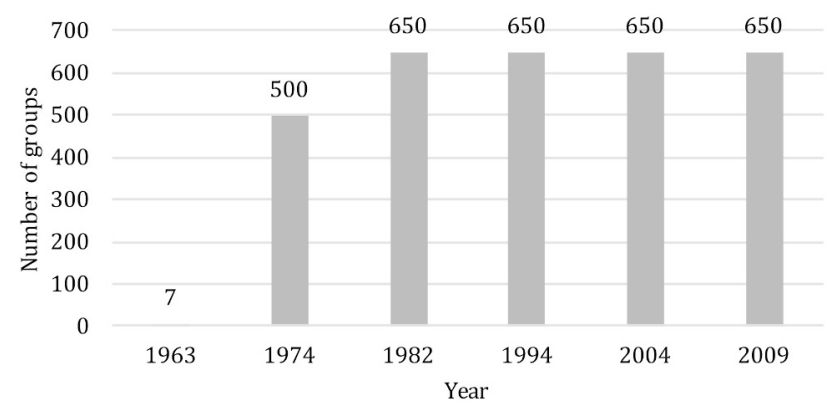

Source: Deile et al. 2015

The "Chronik der Deutschen Sektion von Amnesty International" provides figures only for the years presented in the table. Groups include local groups, thematic and country groups called Ko-gruppen. 
Figure 16: Origins of the resolutions preceding an ICM decision directly concerning AI's work on VAW

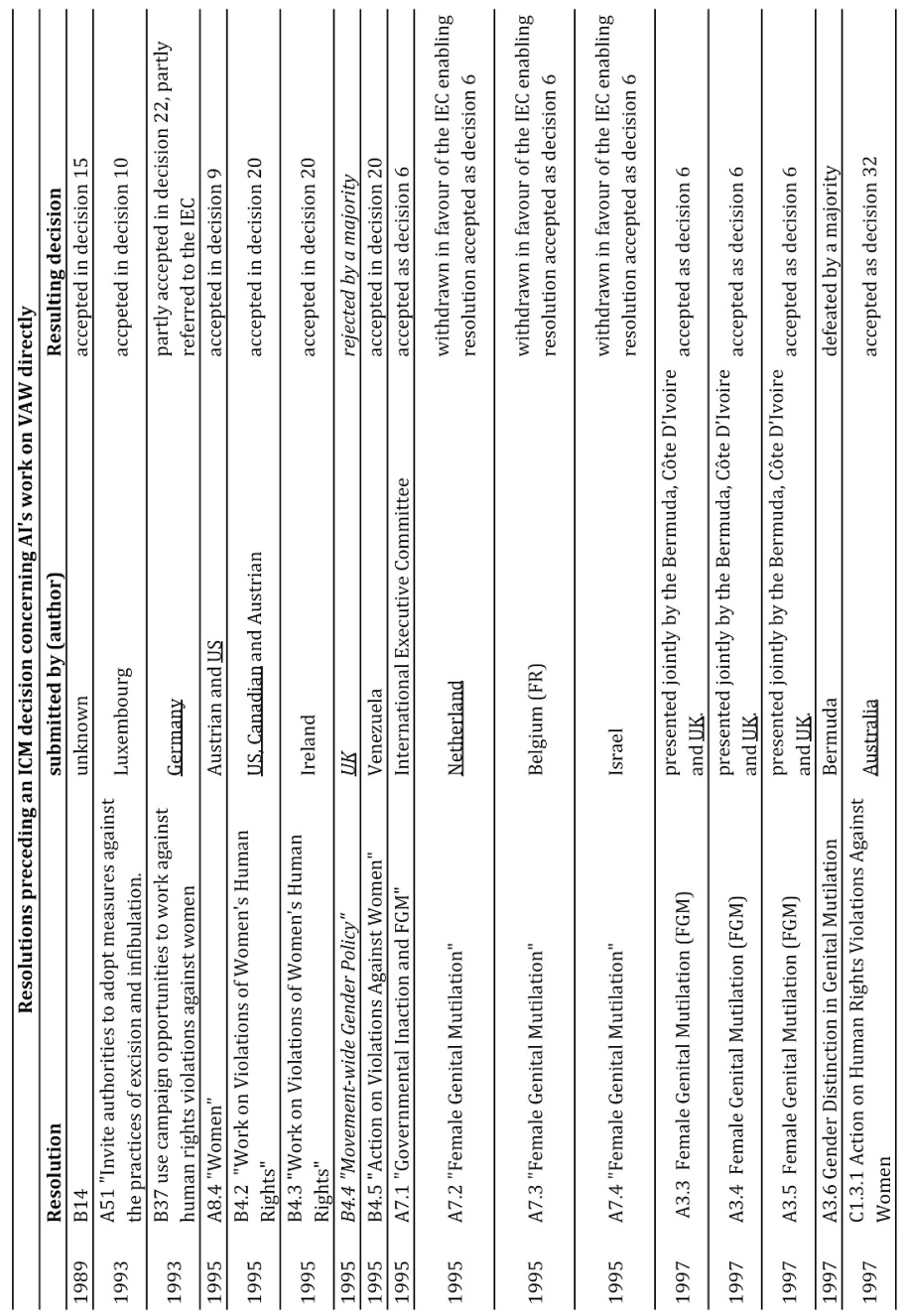

Source: ICM reports 


\section{Appendix 3: Al's statute, mandate, and mission}

Prior to 2001, AI oriented its work towards the fulfillment of its mandate, defined in its statute as amended by the 1995 ICM:

The object of AMNESTY INTERNATIONAL is to contribute to the observance throughout the world of human rights as set out in the Universal Declaration of Human Rights. In pursuance of this object, and recognizing the obligation on each person to extent to others rights and freedoms equal to his or her own, AMNESTY INTERNATIONAL adopts as its mandate:

To promote awareness of and adherence to the Universal Declaration of Human Rights and other internationally recognized human rights instruments, the values enshrined in them, and the indivisibility and interdependence of all human rights and freedoms; To oppose grave violations of the rights of every person freely to hold and to express his or her convictions and to be free from discrimination and of the right of every person to physical and mental integrity, and, in particular, to oppose by all appropriate means irrespective of political considerations:

a. The imprisonment, detention or other physical restrictions imposed on any person by reason of his or her political, religious or other conscientiously held beliefs or by reason of his or her ethnic origin, sex, color, language, national or social origin, economic status, birth or other status, provided that he or she has not used or advocated violence (hereinafter referred to as 'prisoners of conscience'; AMNESTY INTERNATIONAL shall work towards the release of and shall provide assistance to prisoners of conscience);

b. The detention of any political prisoner without fair trial within a reasonable time or any trial procedures relating to such prisoners that do not conform to internationally recognized norms;

c. The death penalty, and the torture or other cruel, inhuman or degrading treatment or punishment of prisoners or other detained or restricted persons, whether or not the persons affected have used or advocated violence;

d. The extrajudicial execution of persons whether or not imprisoned, detained or restricted, and "disappearances", whether or not the persons affected have used or advocated violence. ${ }^{1}$ 
After 2001, AI realized its activities according to the mission:

1. Amnesty International's vision is of a world in which every person enjoys all of the human rights enshrined in the Universal Declaration of $\mathrm{Hu}$ man Rights and other international human rights standards. In pursuit of this vision, Amnesty International's mission is to undertake research and action focused on preventing and ending grave abuses of the rights to physical and mental integrity, freedom of conscience and expression, and freedom from discrimination, within the context of its work to promote all human rights. ${ }^{2}$

Amnesty International: Statute of Amnesty International as amended by the 22nd International Council, meeting in Ljubljana, Slovenia, 12-20 August 1995, 1995.

2 Amnesty International, International Secretariat 2001. 



\section{Sources and Literature}

\section{Sources}

\section{Amnesty International archive}

AIDAN Search, AI's electronic archive, with access restricted to AI members only, https://intranet.amnesty.org/wiki/display/Portal/Home ${ }^{1}$

ACT 77 - Outreach: Women

IOR 41 - UN: Sessions and meetings

ORG 50 - International Council Meeting (ICM): General

ORG 51 - ICM: Agenda/Working papers/Resolutions (Biennial)

ORG 52 - ICM: Records of (ICM) Decisions/Reports (Biennial)

ORG 53 - ICM: Implementation of Decisions

ORG 70 - International Executive Committee (IEC): General

ORG 72 - IEC Meetings: Reports

ORG 80 - International Consultation: General

ORG 81 - International Meetings

POL 20 - Statute

POL 21 - Mandate

POL 38 - Women

POL 50 - AI Planning

POL 51 - Action Planning Bulletin

1 Amnesty International, International Secretariat: Update to the Amnesty International Index (revised), 27.09.2011. 


\section{Archive of the Swiss section of Amnesty International, Bern}

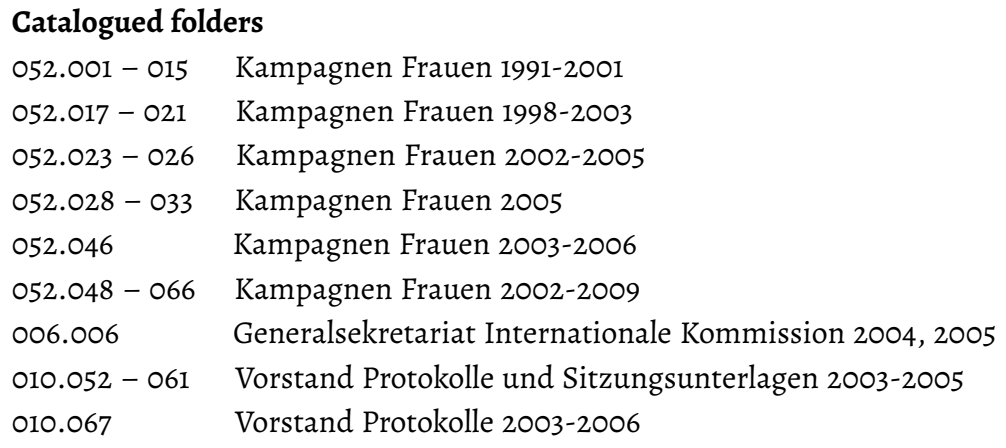

\section{Not catalogued physical folders}

\begin{tabular}{|c|c|}
\hline AI.A.001-008 - 040 & Delegiertenversammlung 1986-2001 \\
\hline AI.A.002-019 - 032 & Vorstand Unterlagen 1990-2002 \\
\hline AI.A.003-001 & Geschäftsleitung 1991 \\
\hline AI.A.003-002 & Internationale Kommission 1993-1995 \\
\hline \multicolumn{2}{|l|}{ AI.A.003-003 } \\
\hline \multicolumn{2}{|l|}{ AI.A.003-004 } \\
\hline \multicolumn{2}{|l|}{ AI.A.003-005 } \\
\hline AI.C.012-088 & Groupe AU femmes Chêne-bourg \\
\hline D.001-045 & SVAW - Aktionen 2008-2009 \\
\hline D.001-122 & Diverse Korrespondenz Stella Jegher 2004-2011 \\
\hline D.001-124 & SVAW Frauenhandel Followup 2008-2009 \\
\hline D.001-131 & Kampagne Frauenhandel 2006-2009 \\
\hline D.001-132 & SVAW Tagungs-/Weiterbildungsunterlagen Sje 2005- \\
\hline \multicolumn{2}{|l|}{2015} \\
\hline D.001-133 & SVAW Abschluss 2008-2010 \\
\hline
\end{tabular}

\section{Not catalogued electronic folders}

Minutes of meetings Delegiertenversammlungen 2002, 2003, 2004, 2006, 2007

Minutes of meetings General Assemblies 2008, 2009, 2010

Minutes of meetings Ko-Gruppe Women's Rights 2006-2011 
Archive of the German section of Amnesty International, Berlin

Online Chronik von AI www.amnesty-chronik.de

Not catalogued physical documents 1979-2006

Ai intern 1981-1995

JV Ordner 1979-1982

JV Ordner 1988

JV Ordner 1989

JV Ordner 1992

Menschenrechtskonferenz Wien 1993

Peking 1995

SVAW Kampagne

Not catalogued electronic documents 2001-2006

Ai intern 2006-2010

Jahresversammlungen 2000-2009

SVAW Kampagne

\section{Private archives}

Bernadette Chevalier, Geneva

Doris Gerber Pluss, Nyon 


\section{Archival Material}

Amnesty International: 1991 ICM Decisions.

Amnesty International (August 1991): Report of the Intersectional Meeting on Women and Human Rights.

Amnesty International (August 1991): Statute of Amnesty International.

Amnesty International (1995): Statute of Amnesty International as amended by the 22nd International Council, meeting in Ljubljana, Slovenia, 12-20 August 1995.

Amnesty International (2001): Report and decisions of the 25th International Council of Amnesty International.

Amnesty International (decembre 2005): Report of the meeting on: regional campaigning on SVAW wooc research projects in Europe.

Amnesty International (2007): 28th international Council Meeting.

Amnesty International (2008): AI's global Campaign for Human Dignity: a strategy to end human rights abuses that keep people poor.

Amnesty International (2010): Amnesty International's Integrated Strategic Plan 2010 to 2016.

Amnesty International; International Secretariat (December 1995): Evaluation Campaign 1995.

Amnesty International; Stuttard, Anna (04.11.1994): Bonn Meeting - Summary of minutes.

Amnesty International; Svorad, Lea (09.1994): Bericht über die Tagung in Bonn.

Amnesty International, Canadian Section (27.04.1993): Letter to the IS concerning AI's work on women's rights.

Amnesty International, Österreichische Sektion (1993): Minutes of the meeting "AI and Women's Human Rights" at the UN World Conference on Human Rights in Vienna.

Amnesty International, Österreichische Sektion (07.07.1993): Letter from the Austrian Section to the ICM Delegation 1993 and to the German section.

Amnesty International, Österreichische Sektion (October 1994): Internationale Tagung über die ai-Kampagne für die Menschenrechte von Frauen, Bonn, 16.-18. September 1994.

Amnesty International, Schweizer Sektion.

Amnesty International, Schweizer Sektion (Juni 1983): Aufbau eines Solidaritätsnetzes in der Deutschschweiz Frauen helfen politisch verfolgten Frauen. AICH, AIC.012-088. In: Schweizer Sektion Amnesty International (Hg.): Amnesty Magazin.

Amnesty International, Schweizer Sektion (1991): Frauenkampagne 1991. 
Amnesty International, Schweizer Sektion (08.03.1992): Frauenkampagne 1992 Aktionsanleitung.

Amnesty International, Schweizer Sektion (1993): ICM 1993: Resolutionen B.

Amnesty International, Schweizer Sektion (09.02.1993): Schlussbericht zur Reorganisation der Berufs- und Zielgruppen.

Amnesty International, Schweizer Sektion (30.04.1994): Delegiertenversammlung 1994 Postulat F Vorbereitung der Weltfrauenkonferenz in Peking 1995.

Amnesty International, Schweizer Sektion (03.11.1994): Protokoll der Sitzung vom 3.11.1994 im AI-Sekretariat, Bern Themen: Peking, Frauenkampagne, Stärkung der Frauengruppen.

Amnesty International, Schweizer Sektion (15.12.1994): Protokoll der Sitzung vom 15. Dezember 1994 zur Vorbereitung der Frauenkampagne und Peking.

Amnesty International, Schweizer Sektion (15.12.1994): Sitzung in Zürich vom 15. Dezember 1994 zur Vorbereitung der Frauenkampagne und Peking.

Amnesty International, Schweizer Sektion (25.02.1995): Formation continue Campagne Femmes engagée - femmes en danger.

Amnesty International, Schweizer Sektion (27.04.1997): Delegiertenversammlung 1997.

Amnesty International, Schweizer Sektion (21.09.1999): Reconnaissance d'un groupe Amnesty en formation.

Amnesty International, Schweizer Sektion (20.10.1999): Protokoll der Sitzung Aufbauprojekt Kogruppe Frauen.

Amnesty International, Schweizer Sektion (07.12.1999): Einladung zum Frauennetzwerktreffen.

Amnesty International, Schweizer Sektion (March 2000): Einladung zum Frauennetzwerktreffen 19. April 2000.

Amnesty International, Schweizer Sektion (April 2001): Die Gründng von Amnesty International in der Schweiz.

Amnesty International, Schweizer Sektion (06.04.2002): Delegiertenversammlung 2002.

Amnesty International, Schweizer Sektion (November 2002): Internal Audit Campaign on violence against women.

Amnesty International, Schweizer Sektion (09.11.2002): Protokoll der Frauenrechtskommission.

Amnesty International, Schweizer Sektion (2003): Jahresbericht der Frauenrechtskommission (FRK).

Amnesty International, Schweizer Sektion (22.01.2003): Prise de position $d u C E$ et du Secrétariat sur le Postulat A adopté par l'AD 2003 à Genève. 
Amnesty International, Schweizer Sektion (08.02.2003): Procès-verbal de la réunion du 8 février 2003.

Amnesty International, Schweizer Sektion (06.03.2003): Protokoll der Vorstandssitzung vom 6. März 2003.

Amnesty International, Schweizer Sektion (12.04.2003): Delegiertenversammlung 2003.

Amnesty International, Schweizer Sektion (08.05.2003): Campagne contre les Violences envers les femmes (VAW) Séance du 8 mai 2003.

Amnesty International, Schweizer Sektion (02.09.2003): Campagne contre les violences envers les femmes Groupe de projet séance du 2 septembre 2003.

Amnesty International, Schweizer Sektion (09.09.2003): Campagne interne (objectif stratégique 4 de la VAW).

Amnesty International, Schweizer Sektion (2004): Campagne sur la violence envers les femmes Projet de stratégie 2004-2006.

Amnesty International, Schweizer Sektion (Janvier 2004): "Halte à la Violence contre les Femmes" Informations sur la campagne.

Amnesty International, Schweizer Sektion (21.01.2004): Kampagne Stop Violence against Women (SVAW) Strategie- und Aktionsplan Schweizer Sektion.

Amnesty International, Schweizer Sektion (17.03.2004): Plan d'action Genre de la Section suisse.

Amnesty International, Schweizer Sektion (07.04.2004): SVAW - Aktuell vom 7.4.2004 News zur Frauenkampagne AI CH.

Amnesty International, Schweizer Sektion (13.04.2004): Protokoll Sitzung Frauenrechtskommission vom 3. April 2004.

Amnesty International, Schweizer Sektion (14.05.2004): Delegiertenversammlung AICH 2004.

Amnesty International, Schweizer Sektion (July 2004): Kampagnenplanung SVAW AICH - Strategie- und Aktionsplan updated.

Amnesty International, Schweizer Sektion (06.08.2004): Notice from Stella Jegher to Caroline Huwiler on the SVAW updates.

Amnesty International, Schweizer Sektion (End of 2005): Ko-Gruppe Frauenrechte Vorschlag für eine Neuorganisation und Umfrage zum FrauenrechtsNetzwerk.

Amnesty International, Schweizer Sektion (14.02.2005): SVAW - Auswertung der Kampagne.

Amnesty International, Schweizer Sektion (09.03.2005): Velotour gegen häusliche Gewalt 3./4. September 2005 Ein Aktionsvorschlag der Berner Frauengruppe. 
Amnesty International, Schweizer Sektion (30.03.2005): Due Diligence: Rolle und Pflichten des Staates in der Bekämpfung von Gewalt gegen Frauen: Standards, Probleme, Perspektiven Internationale Fachtagung zur Kampagne "Stoppt Gewalt gegen Frauen" 21. bis 23. September 2005.

Amnesty International, Schweizer Sektion (23.05.2005): Protokoll der Vorstandssitzung vom 23.05.2002.

Amnesty International, Schweizer Sektion (29.05.2005): Delegiertenversammlung 2005.

Amnesty International, Schweizer Sektion (01.06.2005): Gender Action Plan: Auswertung mit Bettina Kurz und Philippe Beck.

Amnesty International, Schweizer Sektion (06.10.2005): Evaluation des ateliers genre de la Section suisse.

Amnesty International, Schweizer Sektion (24.04.2006): Operativer Plan 20062007 (AICH OP 2) Wachstum und Wirkung unseres Einsatzes für die Menschenrechte.

Amnesty International, Schweizer Sektion (07.05.2006): Motion 9 Stellungnahme der Sektion zum Thema Abtreibung Delegiertenversammlung 2006.

Amnesty International, Schweizer Sektion (07.05.2006): Postulat A Position der Schweizer Sektion zu Abtreibung, Delegiertenversammlung 2006.

Amnesty International, Schweizer Sektion (07.05.2006): Protokoll der Delegiertenversammlung 6.-7. Mai 2006 in Delémont.

Amnesty International, Schweizer Sektion (07.05.2006): Protokoll der Delegierteversammlung 2006 in Delémont.

Amnesty International, Schweizer Sektion (28.09.2006): VAW in the family Progress update Swiss Section.

Amnesty International, Schweizer Sektion (03.04.2007): Frauenrechts-KoGruppe Sitzungsprotokoll vom 3. April 2007.

Amnesty International, Schweizer Sektion (06.05.2007): Delegiertenversammlung 2007.

Amnesty International, Schweizer Sektion (11.06.2007): Frauenrechts-KoGruppe Sitzungsprotokoll vom 11. Juni 2007.

Amnesty International, Schweizer Sektion (20.04.2008): Protokoll der Jahresversammlung 19. und 20. April 2008 Bern.

Amnesty International, Schweizer Sektion (16.01.2009): Evaluation Kampagnenprojekte 2008.

Amnesty International, Schweizer Sektion (03.03.2009): Ko-Gruppe Frauenrechte AICH: Protokoll Sitzung vom 3.3.2009. 
Amnesty International, Schweizer Sektion (28.06.2009): Procès-verbal de l'assemblée générale du 27/28 juin 2009 à Berne.

Amnesty International, Schweizer Sektion (14.12.2009): Protokoll FrauenrechtsKo-Gruppe.

Amnesty International, Schweizer Sektion (2010): Stellenentwicklung im Sekretariat.

Amnesty International, Schweizer Sektion (25.04.2010): Protokoll der Generalversammlung 2010 in Fribourg.

Amnesty International, Schweizer Sektion (22.09.2010): Ko gruppe Frauenrechte Protokoll Sitzung vom 22. September 2010.

Amnesty International, Schweizer Sektion; Frauennetzwerk (01.02.2000): Protokoll des Frauennetzwerktreffens vom 21.1.2000.

Amnesty International, Schweizer Sektion; Frauennetzwerk (20.06.2000): Protokoll des Frauennetzwerktreffens vom 20. Juni 2000.

Amnesty International, Schweizer Sektion; Internationale Kommission (28.09.1995): Procès-verbal de la séance du 28 septembre 1995.

Amnesty International, U. K. (November 2009): AI and a new international women's rights network.

Amnesty International, U.S.A. (10.05.1993): Letter from the Chair of the Board of Directors of AIUSA to the Chair of the IEC.

Amnesty International, U.S.A. (18.11.1993): Fax from the IWN to the IEC and SG.

Amnesty International, U.S.A. (10.06.1994): Amnesty International USA 1994 Annual General Meeting.

Amnesty International, U.S.A. (1995): Amnesty International Intersectional Women's Network Member List.

Amnesty International Sektion Bundesrepublik Deutschland (no date): Ausformulierte Auswertung SVAW - Campaign.

Amnesty International Sektion Bundesrepublik Deutschland (Juni 1986): Artikel im ai info 6/86.

Amnesty International Sektion Bundesrepublik Deutschland (März 1987): Artikel im ai-info 3/1987.

Amnesty International Sektion Bundesrepublik Deutschland (April 1988): Artikel im ai-info 4/1988.

Amnesty International Sektion Bundesrepublik Deutschland (24.05.1988): Protokoll der 23. Jahresversammlung vom 21.5. bis 23.5.1988 in Wuppertal.

Amnesty International Sektion Bundesrepublik Deutschland (März 1989): Mehrere Artikel im ai-intern 3/1989 zum Thema "Frauen und Menschenrechte". 
Amnesty International Sektion Bundesrepublik Deutschland (15.05.1989): Protokoll der Jahresversammlung 1989 Oldenburg 13. bis 15. Mai 1989.

Amnesty International Sektion Bundesrepublik Deutschland (19.03.1992): Antrag an die Jahresversammlung 1992 der AK-Menschenrechtsverletzungen an Frauen.

Amnesty International Sektion Bundesrepublik Deutschland (1994): Letter from Frauke Marohn from the MAF-Sektions-AK.

Amnesty International Sektion Bundesrepublik Deutschland (32.3.1994): Aufriss des MAF-Sektions-AK's zu einer internationalen ai-Kampagne gegen Menschenrechtsverletzungen an Frauen 1995.

Amnesty International Sektion Bundesrepublik Deutschland (24.06.1994): Letter from the Sektions-Arbeitskreis Menschenrechtsverletzungen to the Executive Committee.

Amnesty International Sektion Bundesrepublik Deutschland (13.05.1995): Protokoll Lobbygespräch im Auswärtigen Amt am 22.3.1995.

Amnesty International Sektion Bundesrepublik Deutschland (2005): Protokoll der 40. Jahresversammlung 2005 in Leipzig.

Amnesty International Sektion Bundesrepublik Deutschland (02.11.2005): Zwischenbilanz der Kampagne "HINSEHEN \& HANDELN: Gewalt gegen Frauen verhindern".

Amnesty International Sektion Bundesrepublik Deutschland (2006): Beschlüsse der 41. Jahresversammlung 2006 in Berlin.

Amnesty International Sektion Bundesrepublik Deutschland (ca 2006): Grobe Auswertung des Fragebogens zu der Kampagne Hinsehen 8 Handeln.

Amnesty International Sektion Bundesrepublik Deutschland (June 2006): ai intern Rundbrieffür Mitglieder der deutschen Sektion von amnesty international.

Amnesty International Sektion Bundesrepublik Deutschland (September 2006): ai intern Rundbrief für Mitglieder der deutschen Sektion von amnesty international.

Amnesty International Sektion Bundesrepublik Deutschland (November 2006): ai-intern.

Amnesty International Sektion Bundesrepublik Deutschland (2007): Beschlüsse der 42. Jahresversammlung 2007 in München.

Amnesty International Sektion Bundesrepublik Deutschland (April 2007): ai intern Rundbrieffür Mitglieder der deutschen Sektion von amnesty international.

Amnesty International Sektion Bundesrepublik Deutschland (2008): Beschlüsse der 43. Jahresversammlung 2008 in Hamburg. 
Amnesty International Sektion Bundesrepublik Deutschland (March 2009): Amnesty Intern Zeitschrift für Mitglieder von Amnesty International.

Amnesty International International, Executive Committee (17.10.1995): IEC Information Bulletin No. 12.

Amnesty International, International Executive Committee (January 1998): IEC Information Bulletin No. 21.

Amnesty International, International Executive Committee (April 1998a): IEC Information Bulletin No. 23.

Amnesty International, International Executive Committee (April 1998b): IEC Information Bulletin No. 23.

Amnesty International, International Executive Committee (April 1999): IEC Information Bulletin No. 27.

Amnesty International, International Executive Committee (July 2001): IEC Information Bulletin 37.

Amnesty International, International Executive Committee (02.03.2004): IEC Information Bulletin 48.

Amnesty International, International Secretariat (1989): Decision No 15 ICM 1989, 30.10.2013.

Amnesty International, International Secretariat (19.08.1989): Report and Decisions of the 19th International Council of Amnesty International 19-27 August 1989, Dublin, Ireland.

Amnesty International, International Secretariat (1990): Women's action 1991.

Amnesty International, International Secretariat (August 1991): Report of the Intersectional Meeting on Women and Human Rights.

Amnesty International, International Secretariat (December 1991): International Women's Day Action 1992.

Amnesty International, International Secretariat (1993): 21th International Council Meeting Report and Decisions, Resolutions referred to the IEC.

Amnesty International, International Secretariat (30.06.1993): Strategic directions: 1995-1998 A discussion paper.

Amnesty International, International Secretariat (30.09.1993): The Decisions of the 1993 ICM.

Amnesty International, International Secretariat (26.07.1994): Report of the meeting of the IEC 15-18 April 1994.

Amnesty International, International Secretariat (16.11.1994): Minutes of the fifth meeting of the standing committee on the mandate (SCM).

Amnesty International, International Secretariat (25.11.1994): AI's Presence in Beijing (Internal). 
Amnesty International, International Secretariat (1995): 22nd International Council Meeting.

Amnesty International, International Secretariat (01.03.1995): Letter from the Project Coordinator WCW.

Amnesty International, International Secretariat (03.03.1995): International Council 1995 Circular XII.

Amnesty International, International Secretariat (07.03.1995): Campaign on women and human rights - theme leaflets.

Amnesty International, International Secretariat (14.07.1995): Report of the Standing Committee on Mandate to the 1995 ICM.

Amnesty International, International Secretariat (01.09.1995): The Decisions of the 1995 ICM.

Amnesty International, International Secretariat (October 1995): Report of the Fourth UN World Conference on Women Beijing, China 4-15 September.

Amnesty International, International Secretariat (December 1995): Inside the mandate.

Amnesty International, International Secretariat (March 1996): "Beyond Beijing - the struggle continues" Follow-up activities on the Platform for Action.

Amnesty International, International Secretariat (27.09.1996): International Secretariat Operational Plan 1996-97, 15.11.2013.

Amnesty International, International Secretariat (October 1996): Evaluation of Theme Campaign - Women and Human Rights.

Amnesty International, International Secretariat (1997): 23rd International Council Meeting Report and Decisions.

Amnesty International, International Secretariat (1998): Why are we still waiting The struggle for women's human rights.

Amnesty International, International Secretariat (January 1998): Women's Human Rights and the UDHR 5oth Anniversary Campaign.

Amnesty International, International Secretariat (05.01.1998): The Decision of the 1997 ICM.

Amnesty International, International Secretariat (November 1998): Letter from Habiba Hasan (IEC member with brief on Women 8 gender) giving an update on the Gender Audit and Intersectional Women's Network.

Amnesty International, International Secretariat (January 1999): Gender Sensitive Research Methodology Guidelines.

Amnesty International, International Secretariat (06.07.1999): Strengthening Research and Action on Human Rights Violations against Women Formulating an Implementation Strategy for the LAP (1996-2000). 
Amnesty International, International Secretariat (21.08.1999): Report and Decisions of the 24th International Council of Amnesty International.

Amnesty International, International Secretariat (September 1999): 24th Internatinal Council 1999.

Amnesty International, International Secretariat (11.10.1999): Making A Reality of Women's Rights: Bringing into force the Optional Protocol to the Women's Convention.

Amnesty International, International Secretariat (2000): Take A Step To Stamp Out Torture.

Amnesty International, International Secretariat (July 2000): Final Implementation Report of the Ljubljana Action Plan, 1996-2000.

Amnesty International, International Secretariat (August 2000): Mandate Review 1997-2001: Non-State Actors, 15.11.2013.

Amnesty International, International Secretariat (November 2000): Inside the mandate - issue 9.

Amnesty International, International Secretariat (2001): Broken bodies, shattered minds Torture and ill-treatment of women.

Amnesty International, International Secretariat (2001): Report and Decisions of the 25th International Council of Amnesty International.

Amnesty International, International Secretariat (May 2001): 25th International Council Meeting Circular 23 All Human Rights for All: An Integrated Approach to Action, Mandate and Organization.

Amnesty International, International Secretariat (May 2001): Information pack for Intersectional Women's Network.

Amnesty International, International Secretariat (July 2001): Female Genital Mutilation: An evaluation of the work of AI in four West African countries.

Amnesty International, International Secretariat (October 2001): 2002 Intersectional Women's Network (IWN) Meeting.

Amnesty International, International Secretariat (November 2001): Action Planning Bulletin November 2001.

Amnesty International, International Secretariat (2002): AI Intersectional Women's Network Survey 2001 - Brief Overview of Results.

Amnesty International, International Secretariat (02.04.2002): Key milestones of AI's work on women's human rights.

Amnesty International, International Secretariat (12.05.2002): IS Staff Forum on Violence Aganist Women Campaign 9 May 2002.

Amnesty International, International Secretariat (23.10.2002): Courrier électronique hebdomadaire 40/02 à l'attention des coordonnatuers Campagnes. 
Amnesty International, International Secretariat (14.11.2002): Report of the Violence Aganist Women Campaign Consultation Forum.

Amnesty International, International Secretariat (2003): Report and Decisions of the 26th International Council of Amnesty International.

Amnesty International, International Secretariat (01.07.2003): The VAW campaign An Agenda for Gender Equity The proposed framework for the "internal strategy".

Amnesty International, International Secretariat (28.07.2003): VAW Campaign progress update 28 July 2003.

Amnesty International, International Secretariat (August 2003): Campaign against VAW.

Amnesty International, International Secretariat (05.08.2003): Violence Against Women Campaign Report on the International Strategy Consultation Meeting 1820 July 2003 Oxford, UK.

Amnesty International, International Secretariat (September 2003): Stop VAW Campaign internal strategy.

Amnesty International, International Secretariat (2004): Report and Decisions of the 25th International Council of Amnesty International.

Amnesty International, International Secretariat (19.02.2004): Women and their role in the Amnesty International movement.

Amnesty International, International Secretariat (July 2004): Stop Violence Against Women 2004-2010 Campaign projects for 2004-2006.

Amnesty International, International Secretariat (14th-20th August 2005): Report and Decisions of the 27th International Council of Amnesty International.

Amnesty International, International Secretariat (21.12.2005): SVAW Campaign 2006-2010 Draft Strategy for Consultation.

Amnesty International, International Secretariat (2006): Report and Decisions of the 27th International Council of Amnesty International.

Amnesty International, International Secretariat (02.01.2006): Phase IV - VAW in the family action circular: "VAW in intimate relationships".

Amnesty International, International Secretariat (12.10.2006): Statement Summarizing AI's current policy on Sexual and Reproductive Rights.

Amnesty International, International Secretariat (20.04.2007): Amnesty International policy on selected aspects of abortion.

Amnesty International, International Secretariat (July 2007): 28th International Council Meeting Circular 42 Resolution and Statute Amendment Pack. 
Amnesty International, International Secretariat (July 2008): Feedback and updates from sections and structures on their SVAW related work carried out at national level.

Amnesty International, International Secretariat (16.08.2009): 29th International Council Meeting Circular 46 ICM Decisions 2009.

Amnesty International, International Secretariat (27.09.2011): Update to the Amnesty International Index (revised).

Amnesty International, International Secretariat; Amnesty International, International Secretariat (May 1997): 1997 Meeting of the Intersectional Women's Network (IWN).

Bourquin, Véronique (02.02.2002): Journée nationale du réseau femmes de la Section Suisse.

Bourquin, Véronique (2003): VAW Campaign External Audit.

Bourquin, Véronique (09.09.2003): Préparation de la VAW - update/listing.

C., A. (03.06.2004): Email from C.A. to Stella Jegher concerning the gender workshops at AICH.

C., B. (23.11.1994): Persönliche Stellungnahme zur Mandatserweiterung "State inaction".

C., C. (08.07.2004): Email from W.G. to Stella Jegher concerning the gender workshops.

C., F. (06.06.2004): Protest letter to the German AI section.

C., G. (14.04.2004): Protest letter to the German AI section.

C., H. (17.05.2004): Protest letter to the German AI section.

C., I.; C., J. (April 2002): IWN meeting.

C., K. (11.05.2004): Protest Letter to the German AI section.

C., L. (29.03.2004): Protest letter to the German AI section.

C., M. (26.05.2006): Protest letter to the German AI section.

C., N. (17.06.1994): Letter to the IWN members.

C., N. (10.03.1995): Letter to the IWN members.

C., P. (2011): AI International Women's Human Rights Network.

C., Q. (19.04.2004): Protest letter to the German section.

C., R. (02.06.2004): Letter addressed to Stella Jegher.

C., S. (15.03.2004): Protest letter to the German AI section.

Chevalier, Bernadette (26.04.2001): Mémo chronologique de la création de la section suisse 1964-1975.

Frauengruppe Bern (25.11.1999): Protokoll der Monatssitzung November der Frauengruppe Bern.

Frauennetzwerk (ca. 2000): Le réseau femmes se présente. 
Frey, Regina (August 2002): Gender Audit bei ai Deutschland - die Ergebnisse.

Gemeinnütziger Bundesverein (06.05.2004): Open protest letter to the German AI section.

Groupe AI femmes - Lausanne (30.10.1999): Procès-verbal de la réunion du groupe Amnesty Femmes - Lausanne: 25 Octobre 1999.

Groupe femmes Chêne-bourg (03.12.1987): Procès-verbal du 3 décembre 1987.

Groupe femmes Chêne-bourg (07.04.1988): Procès-verbal du 7 avril 1988.

Groupe femmes Chêne-bourg (14.03.1989): Leaflet on the women's group Chênebourg.

Gruber, Andrea; Frauenkommission Sektion der Bundesrepublik Deutschland (05.10.1994): Letter from the Women's group of AI Germany to the AI German section.

Hartmetz, Annette (02.09.2005): Hinsehen 8 Handeln: Gewalt gegen Frauen verhindern.

Jegher, Stella (18.12.2003): Der Gender Aktionsplan Schweizer Sektion (GAP-AI CH). Jegher, Stella (2004): Memo about the launch of the SVAW - campaign at the Swiss section.

Jegher, Stella (23.12.2004): Kampagne Stoppt Gewalt gegen Frauen Mittelfristige Planung per Jan. 05 bis ca. März 06.

Jegher, Stella (26.04.2005): Motion 5a, Assemblée des délégué-e-s 2004 à Bienne.

Jegher, Stella (22.10.2005): AICH-Kampagnentagung 2005 - durch die Gender-Brille gesehen.

Khan, Irene (16.09.2003): Letter from the Secretary General Irene Khan to sections.

Khan, Irene (01.04.2004): Letter form Irene Khan to sections.

Leiterin Zielgruppe Frauen (05.12.1994): Stellungnahme zur Frage der Mandatserweiterung betreffend "Governmental inaction".

Morstein, Sandra (2002): Presentation of the Women's rights commission.

Reichinger, Susanne; Sektionsarbeitskreis Menschenrechtsverletzungen an

Frauen (30.11.1993): Die Weltmenschrechtskonferenz in Wien - eine Bilanz aus frauenspezifischer Sicht.

Stop VAW Campaign Team (12.2003): STOP VAW Campaign Progress update 4.

SVAW Projekt Team AICH (12.02.2004): Sitzungsprotokoll 12.2.2004.

SVAW Projekt Team AICH (05.08.2004): Sitzungsprotokoll 5.8.2004.

SVAW Team (IS) (October 2006): SVAW campaign strategy: "Make rights real!". 


\section{Interview Material}

Ganzfried (12.08.2011): Conversation with C.D. Bern. Ganzfried (09.09.2011): Interview with B.Q. Bern. Ganzfried (09.03.2012): Interview with A.J. Bern. Ganzfried (04.04.2012): Interview mit B.F. Schaffhausen. Ganzfried (12.04.2012): Interview with A.B. Geneva. Ganzfried (24.06.2012): Interview with B.C. London. Ganzfried (25.06.2012): Interview with A.W. London. Ganzfried (25.06.2012): Interview with A.X. London. Ganzfried (25.06.2012): Interview with B.R. London. Ganzfried (26.06.2012): Interview with A.Z. London. Ganzfried (12.09.2012): Interview by skype with A.T. Bern. Ganzfried (26.09.2012): Interview with A.I. Bern. Ganzfried (10.10.2012): Interview with A.U. Ostermundigen. Ganzfried (12.10.2012): Interview with B.M. Bern. Ganzfried (15.05.2013): Interview with A.S. Delémont. Ganzfried (16.05.2013): Interview with B.K. Bern. Ganzfried (31.05.2013): Interview with A.A. Bern. Ganzfried (31.05.2013): Interview with A.H. Bern. Ganzfried (03.06.2013): Interview with A.N. Delémont. Ganzfried (05.06.2013): Interview by phone with B.G. Ganzfried (05.06.2013): Interview with A.F. Bern. Ganzfried (06.06.2013): Interview with A.D. Nyon. Ganzfried (06.06.2013): Interview with A.L. Nyon. Ganzfried (06.06.2013): Interview with B.N. Nyon. Ganzfried (07.06.2013): Interview by phone with B.V. Bern. Ganzfried (07.06.2013): Interview with B.I. Yverdon. Ganzfried (14.06.2013): Interview with A.E. Geneva. Ganzfried (24.06.2013): Interview with A.P. Bern. Ganzfried (24.06.2013): Interview with B.L. Basel. Ganzfried (01.07.2013): Interview with A.K. Bern. Ganzfried (18.12.2014): Interview by skype with B.H. Ganzfried (09.01.2015): Interview by phone with A.Y. Bern. Ganzfried (23.01.2015): Interview with A.O. Bern. Ganzfried (13.02.2015): Interview by phone with B.U. Bern. Ganzfried (27.02.2015): Interview by phone with A.Q. Bern. Ganzfried (06.03.2015): Interview by phone with B.E. Bern. 
Ganzfried (14.04.2015): Interview with A.C. Berlin. Ganzfried (15.04.2015): Interview with B.T. Berlin.

Ganzfried (26.04.2015): Interview by skype with A.G. Bern.

Ganzfried (10.02.2017): Conversation with C.D. Bern.

Ganzfried (30.07.2018): Correction of citations A.G.

Ganzfried (22.08.2018): Correction of citation A.W.

Ganzfried (22.08.2018): Correction of citations A.W.

Ganzfried (24.08.2018): Correction of citations A.W.

\section{Internet Documents}

Amnesty International: My Body My Rights. https://www.amnesty.org/en/getinvolved/my-body-my-rights/, 20.07.2018.

Amnesty International: What is an International Council Meeting (ICM)? http:// www.amnesty.org.au/about/comments/32375, 24.04.2014.

Amnesty International: What we do. https://www.amnesty.org/en/what-we-d o/, 20.07.2018.

Amnesty International, Schweizer Sektion: Frauenrechtsgruppen Schweizer Sektion. https:/www.amnesty.ch/de/mitmachen/gruppen/frauenrechtsgrup pen, 20.07.2018.

Amnesty International Sektion Bundesrepublik Deutschland: Amnesty in Zahlen. www.amnesty.de/amnesty-zahlen.de, 26.04.2013.

Amnesty International Sektion Bundesrepublik Deutschland: Satzung von Amnesty International. www.amnesty.de/satzung-von-amnesty-international.de, 26.04.2013.

Amnesty International Sektion Bundesrepublik Deutschland: Themengruppe Menschenrechtsverletzungen an Frauen. http://www.amnesty-frauen.de/Ma in/UnsereGruppe, 20.07.2018.

Amnesty International, International Secretariat: Amnesty International movement adopts new policy positions on abortion and drug control. https://www.a mnesty.org/en/latest/news/2018/07/amnesty-international-adopts-abort ion-and-drug-control-stance/, 31.07.2018.

Clos, Rainer (2009): Wir brauchen eine gemeinsame Anstrengung. Wegweisendes evangelisch-katholisches Dokument zum Schutz des Lebens vor 20 Jahren erschienen. Evangelische Kirche in Deutschland. https://www.ekd.de/news_ 2009_11_28_2_gott_ist_ein_freund_des_lebens.htm, 01.02.2019. 
Cohen, D.; Crabtree, B. (2006): Qualitative Research Guidelines Project. http://w ww.qualres.org/HomeLinc-3684.html, 14.06.2017.

Deile, Volkmar; Dinkelbach, Gudula; Franck, Peter; Kessler, Stefan; Probst, Larissa; Titze, Benjamin (2015): Chronik der Deutschen Sektion von Amnesty International. Berlin. http://www.amnesty-chronik.de/doku.php?id=vorw ort, 03.02.2018.

Friese, Susanne (2011): Using ATLAS.ti for Analyzing the Financial Crisis Data. Hg. v. Forum: Qualitative Social Research, 14.12.2017.

Kirchen Arbeitskreis (AK) München und Oberbayern: Amnesty International Kirchen AK München und Oberbayern. http://www.amnesty-muenchen-rel igion.de/, 23.08.2018.

Shetty, Salil (2015): Moving Amnesty closer to the ground is necessary, not simple. https://www.opendemocracy.net/openglobalrights/salil-shetty/movi ng-amnesty-closer-to-ground-is-necessary-not-simple, 13.08.2018.

Sidhu, Gretchen; Chatterjee, Patralekha (1995): Human rights: Amnesty takes a limited stand. Women's Feature Service. New Dehli, India. https://gro ups.google.com/forum/\#!topic/misc.activism.progressive/PES1wjxc21I, 15.04.2016.

Strahm, Doris (2017): Frauenrechte als Prüfstein: Menschenrechte aus feministischtheologischer Sicht. Studientag des Täuferischen Forums für Frieden und Gerechtigkeit. Biel. http://friedenundgerechtigkeit.ch/wp-content/uploa ds/2017/12/4StrahmTextDi.pdf, 24.11.2018.

UN Women: Commission of the Status of Women. www.unwomen.org/en/csw, 04.05.2016.

UN Women: Defining Violence against Women and Girls. http://www.endvawno w.org/en/articles/295-defining-violence-against-women-and-girls.html, 10.07.2017.

UN Women (1995): The United Nations Fourth World Conference on Women. www.un.org/womenwatch/daw/beijing/platform/violence, 04.05.2016.

UNHCR (1993): Vienna Declaration and Programme of Action. Adopted by the World Conference on Human Rights in Vienna on 25 June 1993, 21.03.2012.

United Nations (1986): Report of the World Conference to Review and Appraise the Achievements of the United Nations Decade for Women: Equality, Development and Peace. New York. http://www.un.org/womenwatch/confer/nfls/Nairobi19 85report.txt, 05.07.2017.

Van Gulik, Gauri: Announcement of new policy on abortion. https://twitter.com/g aurivangulik, 31.07.2018. 
Wikipedia, the free encyclopedia: Child Labor Deterrence Act. https://en.wikipe dia.org/wiki/Child_Labor_Deterrence_Act, 30.07.2017.

\section{Literature}

Acharya, Amitav (2004): How Ideas Spread: Who's Norms Matter? Norm Localization and Institutional Change in Asian Regionalism. In: International Organization 58 (2), p. 239-275.

Adler, Emanuel (2012): Constructivism in International Relations. Sources, Contributions, and Debates. In: Walter Carlsnaes, Thomas Risse und Beth and Simmons (Hg.): Handbook of International Relations. Thousand Oaks: Sage Publications, p. 112-144.

Amnesty International Sektion Bundesrepublik Deutschland (1991): Frauen im Blickpunkt. Zwischen Auflehnung und politischer Verfolgung. 2., überarb. Bonn: Amnesty International, Sekt. der Bundesrepublik Deutschland.

Amnesty International, Sektion Bundesrepublik Deutschland (1995): Frauen in Aktion - Frauen in Gefahr. Weltweite Kampagne gegen Menschenrechtsverletzungen an Frauen. Bonn: Amnesty International, Sektion der Bundesrepublik Deutschland.

Baehr, Peter (1994): Amnesty international and its self-imposed limited mandate. In: Netherlands quarterly of human rights 12, p. 5-22.

Baer, Susanne (1994): Feministische Perspektiven zu Recht und Menschenrechte. In: Olympe, p. 74-81.

Bahar, Saba (1996): Human Rights Are Women's Rights: Amnesty International and the Family. In: Hypatia 11 (1), p. 105-134.

Benninger-Budel, Carin (Hg.) (2008): Due diligence and its application to protect women from violence. Leiden, Boston: Martinus Nijhoff Publishers.

Benninger-Budel, Carin; Lacroix, Anne-Laurence (1999): Violence contre les femmes. Un rapport. Genève: Organisation Mondiale Contre la Torture.

Berliner Initiative gegen Gewalt an Frauen BIG e.V. 10 Jahre Gewaltschutzgesetz, 1. Auflage 2012.

Besset, Jean-Paul (1991): Amnesty International, la conspiration de l'espoir. Trente ans au service des droits de l'homme. Paris: Edition du Félin.

Bhattacharjya, Manjima (2013): A Tale of Two Movements: How women's rights became human rights. Hg. v. Bridge Cutting Edge Programme. 
Binion, Gayle (2006): Human Rights: A feminist perspective. In: Bert B. Lockwood (Hg.): Women's Rights. A Human Rights Quarterly Reader. Baltimore: The Johns Hopkins University Press, p. 70-84.

Birks, Melanie; Mills, Jane (2011): Grounded Theory. A Practical Guide. London: Sage Publications.

Brown Thomson, Karen (2002): Women's Rights Are Human Rights. In: Sanjeev Khagram, James V. Riker und Kathryn Sikkink (Hg.): Restructuring World Politics. Transnational Social Movements, Networks, and Norms. Minneapolis: University of Minnesota Press, p. 96-122.

Bryant, A.; Charmaz, K. (Hg.) (2007): The Sage handbook of grounded theory. London: Sage.

Buchanan, Tom (2002): 'The Truth Will Set You Free': The Making of Amnesty International. In: Journal of Contemporary History 37 (4), p. 575-597.

Bunch, Charlotte (1990): Women's Rights as Human Rights: Towards a ReVision of Human Rights. In: Human Rights Quarterly 12 (4), p. 486-498.

Bunch, Charlotte (1995): Transforming Human Rights from a Feminist Perspective. In: Julie Peters und Andrea Wolper (Hg.): Women's Rights, Human Rights: International Feminist Perspectives. New York: Routledge, p. 11-17.

Bunch, Charlotte (1997): International Human Rights: Challenges Posed by Women. In: Niamh Reilly (Hg.): Women's Rights as Human Rights: Local and Global Perspectives. Strategies and Analyses from the ICCL Working Conference on Women's Rights as Human Rights (Dublin, March 1997). Dublin, March, p. 7-9.

Bunch, Charlotte (2001): International Networking for Women's Human Rights. In: Michael Edwards und John Gaventa (Hg.): Global citizen action. Colorado: Lynne Riener Publishers, p. 373-384.

Bunch, Charlotte (2006): Women's Rights as Human Rights: Toward a ReVision of Human Rights. In: Bert B. Lockwood (Hg.): Women's Rights. A Human Rights Quarterly Reader. Baltimore: The Johns Hopkins University Press.

Bunch, Charlotte; Fried, Susana T. (1996): Beijing ‘95: Moving Women’s Human Rights from Margin to Center. In: Signs 22 (1), p. 200-204.

Bunch, Charlotte; Hinojosa, Claudia; Reilly, Niamh (Hg.) (2000): Les voix des femmes et les droits de l'homme. New Brunswick: Rutger University, Center for Women's global leadership. 
Butler, Tom; O'Reilly, Philip (2010): Recovering the Ontological Foundations of the Grounded Theory Method. In: International Conference on Information Systems (75).

Byrnes, Andrew (1988): Women, Feminism and International Human Rights Law - Methodological Myopia, Fundamental Flaws or meaningful Marginalisation?: Some current issues. In: Australian Year Book of International Law, p. 205-240.

Calás, Marta B.; Smircich, Linda (2009): Feminist Perspectives on Gender in Organizational Research: What is and is Yet to be. In: David Buchanan und Alan Bryman (Hg.): The SAGE Handbook of organizational research methods. London: Sage Publications, p. 246-269.

Callamard, Agnès (2000): "Droits de l'homme" ou "Droits humains"? In: Charlotte Bunch, Claudia Hinojosa und Niamh Reilly (Hg.): Les voix des femmes et les droits de l'homme. New Brunswick: Rutger University, Center for Women's global leadership, p. 23-30.

Carpenter, R. Charli (2011): Vetting the Advocacy Agenda: Network Centrality and the Paradox of Weapons Norms. In: International Organization 65 (1), p. 69-102.

Charlesworth, Hilary (1994): What are "Women's International Human Rights”. In: Rebecca J. Cook (Hg.): Human Rights for Women. National and international Perspectives. Philadelphia: University of Pennsylvania Press.

Charlesworth, Hilary (1995): Human rights as men's rights. In: Julie Peters und Andrea Wolper (Hg.): Women's Rights, Human Rights: International Feminist Perspectives. New York: Routledge, p. 104.

Charlesworth, Hillary; Chinkin, Christine (1993): The gender of jus cogens. In: Human Rights Quarterly 15 (1), p. 63-76.

Charmaz, Kathy (1995): Grounded theory. In: J. Smith, R. Harre und L. Langehove (Hg.): Rethinking methods in psychology. London: Sage, p. 27-65.

Chinkin, Christine (1999): A critique of the public/private dimension. In: European journal of international law 10 (2), p. 387-395.

Clark, Ann Marie; Friedman, Elisabeth J.; Hochstetler Kathryn (1998): The Sovereign Limits of Global Civil Society: A Comparison of NGO Participation in UN World Conferences on the Environment, Human Rights, and Women. In: World Politics 51 (1), p. 1-35.

Clark, Ann Marie; McCann, James A. (1991): Enforcing International Standards of Justice. Amnesty International's Constructive Conflict Expansion. In: Peace \& Change 16 (4), p. 379-399. 
Clark, Anne Marie (2001): Diplomacy of Conscience: Amnesty International and Changing Human Rights Norms. Princeton: Princeton University Press.

Clarke, Adele (2005): Situational analysis: Grounded Theory after the postmodern turn. Thousand Oaks: Sage.

Clifford, Bob (2002): Globalization and the Social Construction of Human Rights Campaign. In: Alison Brysk (Hg.): Globalization and Human Rights. Berkley Los Angeles London: University of California Press, p. 133147.

Clifford, Bob (2005): Rights on the Rise: International Mobilization for New Human Rights. American Political Science Association Annual Conference. Washington D.C., September 2005.

Coomaraswamy, Radhika (1997): Reinventing International Law: Women's Rights as Human Rights in the International Community. In: Commonwealth Law Bulletin 23 (3-4), p. 1249-1262.

Daily Mail Reporter (2010): Amnesty chief suspended after attacking group's links to 'Britain's most famous Taliban supporter'. In: Daily Mail 2010, 09.02.2010.

Davis, Kathy (2013): Workshop: Academic Writing in Gender Studies. Graduate School Gender Studies, University of Bern. Interdsiciplinary Center for Gender Studies, University of Bern. Bern, 23.10.2013.

Dolgopol, Ustinia (1994): Comfort women: An unfinished ordeal: report of a mission. Hg. v. International Commission of Jurists.

Ehrenreich Brooks, Rosa (2002): Feminist justice, at home and abroad: feminism and international law: An Opportunity for Transformation. In: Yale Journal of Law and Feminism 14 (345), p. 350.

Ennals, Martin (1982): Amnesty International and Human Rights. In: Peter Willetts (Hg.): Pressure Groups in the Global System. The Transnational Relations of Issue-Oriented Non-Governmental Organizations. New York: St. Martin's Press.

Finnemore, Martha (1996): National Interests in International Society. Ithaca, NY: Cornell University Press.

Finnemore, Martha; Sikkink, Kathryn (1998): International Norm Dynamics and Political Change. In: International Organization 52 (4), p. 887-917.

Fraser, Arvonne S. (1999): Becoming Human: The Origins and Development of Women's Human Rights. In: Human Rights Quarterly 21 (4), p. 853-906. 
Frauen Macht Geschichte. Frauenpolitik und Gleichstellung in der Schweiz 2001-2017. Bern 2017. Herausgeberin: Eidgenössische Kommission für Frauenfragen EKF.

Freitas, Raquel (2004): UNHCR's decision making on internally displaced persons. In: Bob Reinalda und Bertjan Verbeck (Hg.): Decision Making within International Organizations. London: Routledge, p. 123-136.

Fried, Susana T. (1994): The Indivisibility of Women's Human Rights: A Continuing Dialogue. Report of the (1994) women's global leadership Institute. $\mathrm{Hg}$. v. Center for Women's global leadership. Center for Women's global leadership. New Brunswick.

Friedman, Elisabeth (1995): Women's Human Rights. The Emergence of a Movement. In: Julie Peters und Andrea Wolper (Hg.): Women's Rights, Human Rights: International Feminist Perspectives. New York: Routledge, p. 18-35.

Friedman, Elisabeth (2003): Gendering the Agenda: The Impact of the Transnational Women's Rights Movement at the Conferences of the 1990 s. In: Women's Studies International Forum 26 (4), p. 313-331.

Gallagher, Anne (1997): Ending the Marginalization: Strategies for Incorporating Women into the United Nations Human Rights System. In: Human Rights Quarterly 19 (2), p. 283-333.

Geist, Darren (2016): 5 Reasons to Be Wary of Amnesty's Prostitution Policy. Move could increase sex trafficking and reduce quality of life for prostitutes. In: RollingStone, 01.06.2016.

Glaser, Barney G.; Strauss, Anselm L. (1967): The Discovery of Grounded Theory: Strategies for Qualitative Research. New York: Adeline.

Goldfarb, Sally F. (2000): Violence Against Women and the Persistence of Privacy. In: Ohio State Law Journal 61 (1), p. 1-87.

Hausammann, Christina (2002): Menschenrechte - Impulse für die Gleichstellung von Frau und Mann in der Schweiz. Basel: Helbing \& Lichtenhahn.

Hertel, Shareen (2006): Unexpected Power. Conflict and Change among Transnational Activists. Ithaca, N.Y: Cornell University Press.

Hoffmann, Matthew J. (2003): Entrepreneurs and Norm Dynamics: An AgentBased Model of the Norm Life Cycle. University of Delaware. Newark.

Hoffmann, Matthew J. (2010): Norms and Social Constructivism in International Relations. In: Robert Allen Denemark und Renée MarlinBennett (Hg.): The International Studies Encyclopedia. Malden, MA: Wiley-Blackwell, p. 5410-5426. 
Hopgood, Stephen (2006): Keepers of the Flame: Understanding Amnesty International. New York: Cornell University Press.

Hosken, Fran (1981): Toward a Definition of Women's Human Rights. In: Human Rights Quarterly 3 (2), p. 1-10.

Hughes, Melanie M.; Krook, Mona Lena; Paxton, Pamela (2015): Transnational Women's Activism and the Global Diffusion of Gender Quotas. In: International Studies Quarterly 59 (2), p. 357-372.

Human Rights Watch (1992): Double Jeopardy Police Abuse of Women in Pakistan.

Human Rights Watch (1994a): Trafficking of Burmese Women and Girls into Brothels in Thailand.

Human Rights Watch (1994b): Second Class Citizens: Discrimination Against Women Under Botswana's Citizenship Act. New York, Washington.

Jegher, Stella (2011): Integriertes Kommunikationsmanagement in NPOs. am Praxisbeispiel Amnesty International Schweiz. Fachhochschule Nordwestschweiz, Olten. Hochschule für Soziale Arbeit Hochschule für Wirtschaft.

Joachim, Jutta (1999): Shaping the Human Rights Agenda: The Case of Violence aganist Women. In: Mary K. Meyer und Elisabeth Prügl (Hg.): Gender Politics in Global Governance. New York: Rowman \& Littlefield Publishers, Inc., p. 142-159.

Johnstone, Ian (2007): The Secretary-General as Norm Entrepreneur. In: Simon Chesterman (Hg.): Secretary or General? The UN Secretary-General in World Politics. Cambridge u.a.: Cambridge Univ. Press, p. 123-138.

Johnstone, Rachel (2006): Feminist Influences on the United Nations Human Rights Treaty Bodies. In: Human Rights Quarterly 28 (1), p. 148-185.

Kaplan, Temma (2001): Women's Rights as Human Rights: Grassroots Women Redefine Citizenship in a Global Context. In: Patricia Grimshaw, Katie Holmes und Marilyn Lake (Hg.): Women's Rights and Human Rights International Historical Perspectives. New York: Palgrave Macmillan.

Katzenstein, Peter J. (1996): The Culture of National Security: Norms and Identity in Public Life. New York: Columbia University Press.

Keck, Margaret E.; Sikkink, Kathryn (1998): Activists Beyond Borders. Advocacy Networks in International Politics. Ithaca, N.Y: Cornell University Press.

Kelleher, David; Bhattacharjya, Manjima (2013): The Amnesty International Journey: Women and Human Rights. Hg. v. Bridge. 
Kelly, Liz (2005): Inside Outsiders. In: International Feminist Journal of Politics 7 (4), p. 471-495.

Khagram, Sanjeev; Riker, James V.; Sikkink, Kathryn (2002): From Santiago to Seattle: Transnational Advocacy Groups Restructuring World Politics. In: Sanjeev Khagram, James V. Riker und Kathryn Sikkink (Hg.): Restructuring World Politics. Transnational Social Movements, Networks, and Norms. Minneapolis: University of Minnesota Press, p. 3-23.

Khan, Irene (2003): 26th International Council Meeting Circular 31. Secretary General's Report to the 2003 ICM.

Krook, Mona Lena; True, Jacqui (2012): Rethinking the life cycles of international norms. The United Nations and the global promotion of gender equality. In: European Journal of International Relations 18 (1), p. 103-127.

Kurkowska-Budzan, Marta; Zamorski, Krystof (Hg.) (Hg.) (2009): Oral History: The challenge of dialogue. Amsterdam: John Benjamins Publishing Company.

Lake, David A.; Wong, Wendy (2009): The Politics of Networks: Interests, Power, and Human Rights Norms. In: Miles Kahler (Hg.): Networked politics: agency, power, and governance. Ithaca: Cornell University Press.

Lamnek, Siegfried; Krell, Claudia (2016): Qualitative Sozialforschung. 6., überarbeitete Auflage. Weinheim und Basel: Beltz.

Lasco, Chanté (2002): Virginity Testing in Turkey: A Violation of Women's Human Rights. In: Human Rights Brief 9 (3).

Locher, Birgit; Prügl, Elisabeth (2001): Feminism and Constructivism: Worlds Apart or Sharing the Middle Ground? In: International Studies Quarterly 45 (1), p. 11-129.

Maggs-Rapport, Frances (2000): Combining methodological approaches in research: Ethnography and interpretative phenomenology. In: Journal of Advanced Nursing 31, p. 219-225.

March, James G.; Olsen, Johan P. (1989): Rediscovering Institutions. The Organizational Basis of Politics. New York: The Free Press, A Division of Macmillan, Inc.

Maxwell, Joseph A. (2002): Understanding and Validity in Qualitative Research. In: Hubermann, A. Michael and Miles, Matthew B. (Eds) (Hg.): The Qualitative Research Companion. Thousand Oaks: Sage, p. 37-64.

Michel, Claudia (2009): Rechte fordern. Schweizer Frauenorganisationen zwischen Feminismus und Menschenrechten 1990-2005. Bern: eFeFVerlag. 
Miller, Carol (2006): External Evaluation of Amnesty International's Stop Violence Against Women Campaign.

Moghadam, Valentine M. (2000): Transnational Feminist Networks: Collective Action in an Era of Globalization. In: International Sociology 15 (1), p. 5785.

Moghadam, Valentine M. (2010): Transnational Activism. In: Shepherd, Laura, J. (Hg.): Gender Matters in Global Politics: A Feminist Introduction to International Relations. London \& New York: Routledge, p. 292-306.

Müller, Harald; Wunderlich, Carmen (Hg.) (2013): Norm Dynamics in Multilateral Arms Control. Interests, Conflicts, and Justice. Athens: University of Georgia Press.

Müller, Johannes; Kiefer, Mattias; Braunmühl, Claudia von (2007): Frauen

- Gewinnerinnen oder Verliererinnen der Globalisierung? Neue Herausforderungen für eine Gender-gerechte Weltordnung. Stuttgart: W. Kohlhammer.

Mutua, Makau (2001): Human Rights International NGOs. A Critical Evaluation. In: Claude Emerson Welch (Hg.): NGOs and Human Rights. Promise and Performance. Philadelphia: University of Pennsylvania Press, p. 151163.

Noy, Chaim (2008): Sampling Knowledge: The Hermeneutics of Snowball Sampling in Qualitative Research. In: International Journal of Social Research Methodology 11 (4), p. 327-344.

O'Hare, Ursula A. (1999): Realizing Human Rights for Women. In: Human Rights Quarterly 21 (2), p. 364-402.

Pack, Peter (1999): Amnesty International: An evolving Mandate in a changing word. In: A. Hegarty und S. Leonard (Hg.): A Human Rights: An Agenda for the 21st Century. London, Sydney: Cavendish Publishing Limited, p. 233-246.

Parisi, Laura (2000): Reclaiming Spaces of Resistance. Women's Human Rights and Global Restructuring. In: Marianne H. Marchand und Anne Sisson Runyan (Hg.): Gender and Global Restructuring. Sightings, Sites and Resistances. London, New York: Routledge.

Payne, Rodger A. (2001): Persuasion, Frames and Norm Construction. In: European Journal of International Relations 7 (1), p. 37-61.

Power, Jonathan (2001): Like Water on Stone. The Story of Amnesty International. London: The Penguin Press.

Price, Richard M. (1997): The chemical weapons taboo. Ithaca: Cornell Univ. Press. 
Quataert, Jean H. (2006): The Gendering of Human Rights in the International Systems of Law in the Twentieth Century. Washington: American Historical Association.

Reilly, Niamh (2007): Linking local and global feminist advocacy: Framing women's rights as human rights in the Republic of Ireland. In: Women's Studies International Forum (30), p. 114-133.

Reilly, Niamh (2009): Women's Human Rights. Cambridge, UK, Malden, Mass: Polity Press.

Reinharz, Shulamit (1992): Feminist Methods in Social Research. Oxford: Oxford University Press.

Risse, Thomas; Ropp, Stephen; Sikkink, Kathryn (1999): The Power of Human Rights: International Norms and Domestic Change. Cambridge: Cambridge University Press.

Ritchie, Donald A. (2003): Doing Oral History. A Practical Guide. Oxford.

Ritchie, Donald A. (Ed.) (Hg.) (2011): The Oxford Handbook of Oral History. Oxford.

Roach, Suzanne (1994): Input in the thematic panel at the 1994 Women's Global Leadership Institute: Setting a women's human rights framework. In: Center for Women's global leadership (Hg.): The Indivisibility of Women's Human Rights: A Continuing Dialogue. Report of the (1994) women's global leadership Institute. Center for Women's global leadership. New Brunswick, p. 9-12.

Romany, Celina (1995): State Responsability Goes Private: A Feminist Critique of the Public/Private Distinction in International Human Rights Law. In: Julie Peters und Andrea Wolper (Hg.): Women's Rights, Human Rights: International Feminist Perspectives. New York: Routledge, p. 85-111.

Ron, James; Ramos, Howard; Rodgers, Kathleen (2005): Transnational Information Politics: NGO Human Rights Reporting, 1986-2000. In: Int Studies Q 49 (3), p. 557-588.

Roth, Kenneth (1994): Domestic Violence as an International Human Rights Issue. In: Rebecca J. Cook (Hg.): Human Rights for Women. National and international Perspectives. Philadelphia: University of Pennsylvania Press, p. 326-339.

Rubin, Herbert J.; Rubin, Irene S. (2005): Qualitative Interviewing: The Art of Hearing Data. 2nd edition. Thousand Oaks: Sage Publications.

Sandholtz, Wayne (2007): Prohibiting Plunder: How Norms Change. New York NY: Oxford University Press. 
Schmidt-Häuer, Julia (1998): Feministische Herausforderungen an das herkömmliche Menschenrechtsparadigma. In: Uta Ruppert (Hg.): Lokal Bewegen - global verhandeln. Internationale Politik und Geschlecht. Frankfurt am Mein, New York: Campus Verlag.

Schmitz, Hans Peter (2010): Transnational Human Rights Networks: Significance and Challenges. In: Robert A. Denmark (Hg.): International Studies Encyclopedia: Wiley-Blackwell (Volume XI), p. 7189-7208.

Scoble, Harry M.; Wiseberg, Laurie S. (1974): Human Rights and Amnesty International. In: Annals of the American Academy of Political and Social Science (413), p. 11-26.

Scott, Joan W. (1994): Gender: Eine nützliche Kategorie der historischen Analyse. In: Nancy Kaiser (Hg.): Selbst bewusst. Frauen in den USA. 1. Aufl. Leipzig: Reclam, p. 27-75.

Snow, David A.; Burke Rochford e., JR; Worden, Steven K.; Benford, Robert D. (1986): Frame Alignment Processes, Micromobilization, and Movement Participation. In: American Sociological Review 51, p. 464-481.

Sperling, Valerie; Marx Ferree, Myra; Risman, Barbara (2001): Constructing Global Feminism: Transnational Advocacy Networks and Russians Women's Activism. In: Globalization and Gender 26 (4), p. 1155-1186.

Steiner, Henry J. (1991): Diverse Partners: Non-Governmental Organizations in the Human Rights Movement: The report of a Retreat of Human Rights Activists. Cambridge: Harvard Law School Human rights program and Human rights internet.

Steinke, Ines (2000): Gütekriterien qualitativer Forschung. In: Uwe Flick, Ernst von Kardorff und Ines Steinke (Hg.): Qualitative Forschung. Ein Handbuch. Reinbek bei Hamburg: Rowohlt Taschenbuch Verlag GmbH, p. 319-334.

Strauss, Anselm L.; Corbin, Juliet M. (1990): Basic of Qualtitative Research. Grounded Theory Procedures and Techniques. Newbury Park: CA.: Sage.

Strauss, Anselm L.; Corbin, Juliet M. (1998): Basics of qualitative research: Techniques and procedures for developing grounded theory. 2nd ed. Thousand Oaks: Sage.

Sullivan, Donna (1995): The public/privat Distinction in International Human Rights Law. In: Julie Peters und Andrea Wolper (Hg.): Women's Rights, Human Rights: International Feminist Perspectives. New York: Routledge, p. 126-134. 
Tarrow, Sidney (1999): International Insitutions and Contentious Politics: Does Internationalization Make Agents Freer - or Weaker? American Sociological Association Annual Meeting. Chicago Illinois, 06.08.1999.

Thakur, Ramesh (1994): Human Rights: Amnesty International and the United Nations. In: Journal of Peace Research 31 (2), p. 143-160.

True, Jacqui; Mintrom, Michael (2001): Transnational Networks and Policy Diffusion: The Case of Gender Mainstreaming. In: International Studies Quarterly 45 (1), p. 27-57.

UN General Assembly (1993): Article 2. In: UN (Hg.): Declaration on the Elimination of Violence against Women. A/RES/48/104.

United Nations Human Rights Office of the High Commissioner (2014): Women's Rights are Human Rights. New York and Geneva.

Wallace, Tina; Baños Smith, Helen (2010a): A Synthesis of the learning from the Stop Violence Against Women campaign 2004-10. Amnesty International Publication 2010.

Wallace, Tina; Baños Smith, Helen (2010b): Review of the SVAW Campaign. Amnesty International Publication 2010. London.

Wapner, Paul (1995): Politics Beyond the State: Environmental Activism and World Civic Politics. In: World Politics 47 (3), p. 311-340.

Watson, Elizabeth (1997): Amnesty International and Women's Human Rights: An Organisational Dilemma. In: Australian Journal of Human Rights (19).

Welch, Claude Emerson (2001): Amnesty International and Human Rights Watch. A comparison. In: Claude Emerson Welch (Hg.): NGOs and $\mathrm{Hu}-$ man Rights. Promise and Performance. Philadelphia: University of Pennsylvania Press, p. 85-118.

West, Lois A. (1999): The United Nations Women's Conferences and Feminist Politics. In: Mary K. Meyer und Elisabeth Prügl (Hg.): Gender Politics in Global Governance. New York: Rowman \& Littlefield Publishers, Inc., p. 177-194.

Wiener, Antje (2007): Contested Meanings of Norms: A Research Framework. In: Comparative European Politics 5, p. 1-17.

Wight, Colin (1999): 'They Shoot Dead Horses Don't They? Locating Agency in the Agent-Structure Problematique'. In: European Journal of International Relations 5 (1).

Winston, Morton E. (2001): Accessing the Effectiveness of International $\mathrm{Hu}-$ man Rights NGOs. Amnesty International. In: Claude Emerson Welch (Hg.): NGOs and Human Rights. Promise and Performance. Philadelphia: University of Pennsylvania Press, p. 25-54. 
Women in the Law Project (1994): No Justice, No Peace: Accountability for Rape and Gender-Based Violence in the Former Yugoslavia. In: Hastings Women's Law Journal 5 (1), p. 91-127.

Wunderlich, Carmen (2013): Theoretical Approaches in Norm Dynamics. In: Harald Müller und Carmen Wunderlich (Hg.): Norm Dynamics in Multilateral Arms Control. Interests, Conflicts, and Justice. Athens: University of Georgia Press, p. 20-47.

Yuval-Davis, Nira (2006): Human/Women's Rights and Feminist Transversal Politics. In: Myra Marx Ferree und Aili Mari Tripp (Hg.): Global Feminism. Transnational Women's Activism, Organizing, and Human Rights. New York and London: New York University Press, p. 275-295. 


\section{List of abbreviations}

\begin{tabular}{|l|l|}
\hline AI & Amnesty International \\
\hline AICH & The Swiss Al section \\
\hline AIUSA & The US Al section \\
\hline CEDAW & $\begin{array}{l}\text { Convention for the Elimination of All Forms of Discrimination Against } \\
\text { Women }\end{array}$ \\
\hline CSW & Commission of the Status of Women \\
\hline EC & Executive Committee \\
\hline ED & Executive Director \\
\hline FCM & Female Cenital Mutilation \\
\hline CA & Ceneral Assembly \\
\hline CAP & Cender Action Plan \\
\hline HRW & Human Rights Watch \\
\hline IC & International Council \\
\hline ICM & International Council Meeting \\
\hline IEC & International Executive Committee \\
\hline ICOs & Intergovernmental Organizations \\
\hline ILO & International Labor Organization \\
\hline IR & International Relations \\
\hline IS & International Secretariat \\
\hline ISP & Integrated Strategic Plan \\
\hline IWHRN & International Women's Human Rights Network \\
\hline IWN & Intersectional Women's Network \\
\hline
\end{tabular}




\section{List of abbreviations (continued)}

\begin{tabular}{|l|l|}
\hline LAP & Ljubljana Action Plan \\
\hline MaF & Menschenrechtsverletzungen an Frauen \\
\hline NATO & North Atlantic Treaty Organization \\
\hline NCOs & Non-Covernmental Organizations \\
\hline OIC & Organization of the Islamic Conference \\
\hline SCM & Standing Committee on the Mandate \\
\hline SC & Secretary Ceneral \\
\hline SVAW & Stop Violence Against Women \\
\hline TANs & Transnational Advocacy Networks \\
\hline UDHR & Universal Declaration of Human Rights \\
\hline UNCHR & United Nation Commission on Human Rights \\
\hline UNIFEM & UN Development Fund for Women \\
\hline VAW & Violence Against Women \\
\hline WCW & World Conference on Women \\
\hline WOOC & Work-On-Own-Country \\
\hline WWII & World War II \\
\hline
\end{tabular}




\section{Social Sciences}

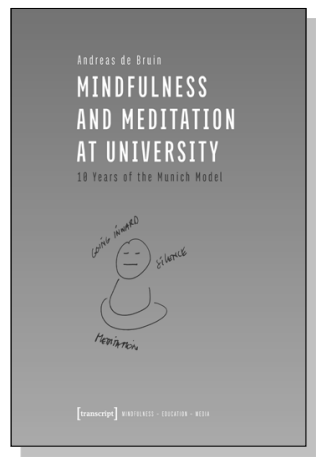

kollektiv orangotango+ (ed.)

\section{This Is Not an Atlas}

A Global Collection of Counter-Cartographies

2018, 352 p., hardcover, col. ill.

$34,99 €$ (DE), 978-3-8376-4519-4

E-Book: free available, ISBN 978-3-8394-4519-8

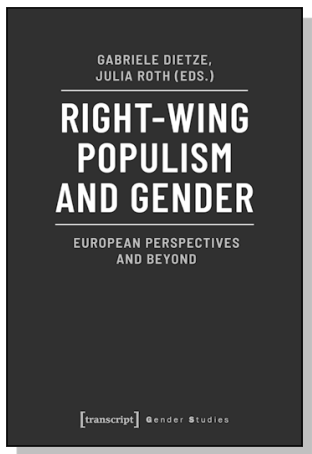

Gabriele Dietze, Julia Roth (eds.)

Right-Wing Populism and Gender

European Perspectives and Beyond

April 2020, 286 p., pb., ill.

35,00€ (DE), 978-3-8376-4980-2

E-Book: 34,99 € (DE), ISBN 978-3-8394-4980-6

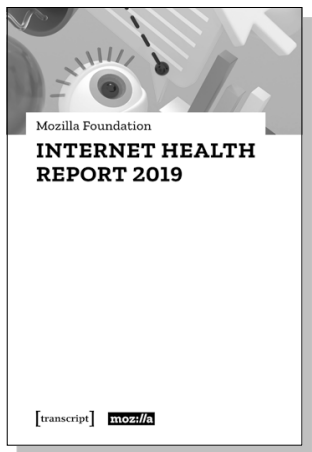

Mozilla Foundation

Internet Health Report 2019

2019, 118 p., pb., ill.

$19,99 €$ (DE), 978-3-8376-4946-8

E-Book: free available, ISBN 978-3-8394-4946-2

All print, e-book and open access versions of the titles in our list are available in our online shop www.transcript-publishing.com 


\section{Social Sciences}

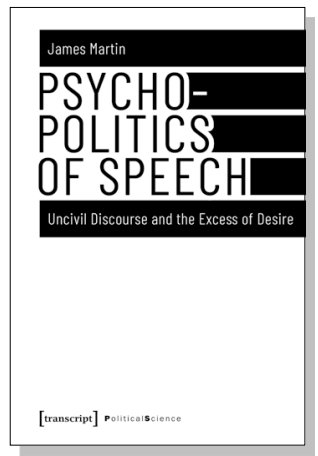

James Martin

\section{Psychopolitics of Speech}

Uncivil Discourse and the Excess of Desire

2019, 186 p., hardcover

79,99€ (DE), 978-3-8376-3919-3

E-Book:

PDF: 79,99 € (DE), ISBN 978-3-8394-3919-7

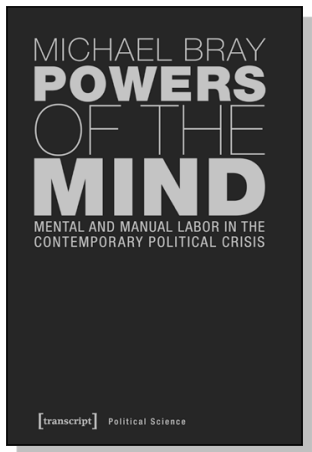

Michael Bray

\section{Powers of the Mind}

Mental and Manual Labor

in the Contemporary Political Crisis

2019, 208 p., hardcover

99,99€ (DE), 978-3-8376-4147-9

E-Book:

PDF: 99,99 € (DE), ISBN 978-3-8394-4147-3

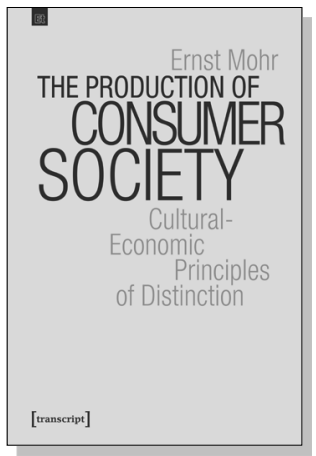

\section{Ernst Mohr}

The Production of Consumer Society

Cultural-Economic Principles of Distinction

April 2021, 340 p., pb., ill.

39,00€ (DE), 978-3-8376-5703-6

E-Book: available as free open access publication

PDF: ISBN 978-3-8394-5703-0 